INSTITUTO DE PESQUISAS ENERGÉTICAS E NUCLEARES

Autarquia associada à Universidade de São Paulo

\title{
PREPARO, CARACTERIZAÇÃO E USO DE UM MATERIAL DE REFERÊNCIA PARA ENSAIOS DE PROFICIÊNCIA PARA DETERMINAÇÃO DE METAIS EM TECIDO DE PEIXE
}

IN NATURA

LUCIANA VIEIRA DE SANTANA

Dissertação apresentada como parte dos requisitos para obtenção do Grau de Mestre em Ciências na Área de Tecnologia Nuclear Materiais.

Orientador:

Prof. Dr. Jorge Eduardo de Souza Sarkis

São Paulo 
Dedicatória

Dedico este a todos os que colaboraram de forma direta ou indireta para sua execução em especial à minha família, ao Dr. Jorge Eduardo de Souza Sarkis pela paciência e orientação, aos colegas do LCQ e as amigas Mônica Marcelino da Costa e Thaynã Farias Pasqual pelo apoio. 
Agradecimentos

Gostaria de agradecer a todos que deram sua valiosa contribuição para execução deste trabalho. Em especial, ao Conselho Nacional de Desenvolvimento Científico e Tecnológico, ao Instituto de pesquisas Energéticas e Nucleares, ao Conselho Nacional de Desenvolvimento Científico e Tecnológico e à Pró-reitoria de Pósgraduação da Universidade de São Paulo pelo auxílio financeiro ao projeto;

A parceria com o os responsáveis pelos seguintes Laboratórios Nacionais Agropecuários do Ministério da Agricultura Pecuária e Abastecimento: Dra . Maria de Fátima Pinhel, Lanagro-SP; Dr. Nilson Cesar, Lanagro-MG; Drª . Maria de Fátima Ventura, Lanagro-PE; Dr. Antonio Nascimento, Lanagro-PA; Drª. Adriane Cruvinel, Lanagro-GO; Drâ. Maria Aparecida Espírito Santo, Lanagro-RS. Ao Dr. Silvio Mario Filho responsável pelo Laboratório de Química Analítica do Instituto de Tecnologia de Pernambuco. Ao Dr. Marcelo Oliveira Lima do Laboratório de Meio Ambiente do Instituto Evandro Chagas. Ao Dr. Paulo Tiglea do Laboratório de Contaminantes Inorgânicos do Instituto Adolfo Lutz. A Dra . Déborah Inês Teixeira Fávaro do Laboratório de análise por ativação neutrônica do Centro do Reator de Pesquisas (CRPQ/IPEN), pela colaboração e participação no programa piloto de ensaio de proficiência para metais em peixe;

À Drª . Maria Eugenia Azevedo Vargas, responsável técnica pelo laboratório de controle de qualidade e segurança alimentar (LACQSA) do Lanagro MG, pela colaboração nos contatos iniciais com a rede de laboatótios Lanagro.

Ao Dr. Jorge Eduardo de Souza Sarkis, pelo apoio, sugestões e confiança em meu trabalho;

À Engenheira Elizabeth S. R. Somessari do Centro de Tecnologia das Radiações do IPEN - CNEN/SP pela presteza e disponibilidade de Tempo para irradiação das amostras;

Ao Dr. Marcos Roberto Lopes do Nascimento do Laboratóio de Poços de Caldas -LAPOC - CNEN/MG pela colaboração na determinação dos elementos 
presentes nas amostras e ao Dr. Cassio H. de Abreu Junior do Centro de Energia Nuclear na Agricultura-CENA/USP.

Aos colegas e amigos do Laboratório de Caracterização Química, em especial àqueles que doaram horas valiosas de seu tempo na colaboração deste estudo (Dr. João Cristiano Ulrich,Talita Carol de Oliveira, Msc. Marcos Hortellani, Msc. Isabella Leal Bordon, Drª Gláucia Bueno Benedetti, Drª . Juliana Souza Azevedo, Rafael Pestana, Rafael Marin, Msc. Maria Cristina Tessari, Mariana Lima e Nathalia Pereira);

A todos que participaram direta e indiretamente na confecção deste trabalho. 
Oração de Agradecimento a Santa Rita

É com o coração profundamente comovido e perturbado que hoje venho a vós, ó gloriosa e poderosa Santa Rita. Na hora do perigo, no momento em que estava ameaçada a minha felicidade e a dos que me são caros, a vós roguei com a alma aflita e cheia de apreensão. A vós supliquei, a vós que todos chamam de Santa dos Impossíveis, Advogada nos Casos Desesperados, Refúgio na Última Hora... Não foi iludida a minha confiança em vós.

Agora volto a vós, não mais com as lágrimas do sofrimento nos olhos, mas com alegria e serenidade no coração, para vos ofertar meu infinito reconhecimento. Esta alegria, esta serenidade, a vós eu devo, cara Santa, a vós que intercedestes em meu favor junto a Deus, apesar da minha indignidade, e me alcançastes a graça desejada.

Quisera poder melhor exprimir-vos o profundo sentimento de gratidão que enche meu coração, ó Santa milagrosa, ó consoladora dos aflitos, mas a própria emoção causada pela felicidade de ter obtido esta graça paralisa minhas expressões e somente sei murmurar: graças vos dou, muitas graças, mil graças, Santa Rita. 


\title{
PREPARO, CARACTERIZAÇÃO E USO DE UM MATERIAL DE REFERÊNCIA PARA ENSAIOS DE PROFICIÊNCIA PARA DETERMINAÇÃO DE METAIS EM TECIDO DE PEIXES
}

\author{
IN NATURA \\ Luciana Vieira de Santana
}

\author{
RESUMO
}

Os ensaios de proficiências são amplamente utilizados para avaliar a capacidade analítica de laboratórios e também como parte dos processos de acreditação. Por esta razão, são importantes ferramentas para o controle dos resultados analíticos obtidos nos laboratórios que atuam diretamente com as empresas exportadoras de pescado. No Brasil não há provedores de ensaios de proficiência para metais potencialmente tóxicos em pescado. Neste trabalho serão descritos todos os passos utilizados para a produção de materiais de referência a serem utilizados em um estudo piloto de ensaios de proficiência para $\mathrm{As}, \mathrm{Cd}, \mathrm{Pb}$ e $\mathrm{Hg}$ em tecido de peixe in natura, seguindo as recomendações do Guia ISO 35. O esquema de preparação consistiu na seleção de indivíduos, limpeza, trituração, homogeneização e fortificação com $\mathrm{As}$, $\mathrm{Cd}$ e $\mathrm{Pb}$ em dois níveis de concentração. A preparação resultou em 164 sachês de $10 \mathrm{~g}$ cada. A fim de avaliar o efeito da irradiação gama na conservação das amostras 52 sachês foram irradiados com uma fonte gamacell de cobalto $60\left({ }^{60} \mathrm{Co}\right)(10,00 \pm 1,05 \mathrm{KGy})$ e 52 não irradiadas, ambos selecionados aleatóriamente foram separados para os estudos de homogeneidade e estabilidade. $O$ restante 60 sachês foram utilizados no ensaio de proficiência. Os resultados demonstraram que ambos os materiais foram homogêneos e apresentaram boa estabilidade (durante um período de 45 dias). No entanto, o material irradiado, apresentou uma melhor integridade foi um passo era crucial para assegurar a preservação da integridade, para a degradação biológica, quando armazenado em temperatura ambiente. Por esta razão, eles foram usados para o programa piloto de ensaios de proficiência. Dez laboratórios 
participaram do estudo piloto de ensaios de proficiência e os resultados foram avaliados por meio dos seguintes testes: z-score, a confiança elipse e erro normalizado. Este trabalho demonstra a capacidade do laboratório para a produção de materiais de referência, bem como para organizar e realizar testes de proficiência.

Palavras-chave: Ensaios de proficiência, elipse de confiança, a irradiação de alimentos, material de referência 


\title{
PREPARATION, CHARACTERIZATION AND USE OF A REFERENCE MATERIAL TO PROFICIENCY TESTING FOR DETERMINATION OF METALS IN FISH TISSUE IN NATURA
}

\section{Luciana Vieira de Santana}

\begin{abstract}
The proficiency tests are widely used to evaluate the analytical capacity of laboratories and also as part of the accreditation process. For this reason, are important tools for the control of the quality of the analytical results obtained in the laboratories that work directly with seafood companies. In Brazil there are no providers of proficiency testing for metals potentially toxics in fish tissues. In this work will be described all steps used for the production of reference materials to be used in a proficiency testing pilot study for $\mathrm{As}, \mathrm{Cd}, \mathrm{Pb}$ and $\mathrm{Hg}$ in fish tissue following the recommendations of the ISO Guide 35. He preparation scheme consisted in selecting the individuals, cleaning, grinding, homogenization and fortification with $\mathrm{As}, \mathrm{Cd}$ and $\mathrm{Pb}$ in two concentration levels. The preparation resulted in 164 sachets of $10 \mathrm{~g}$ each. In order to evaluate the effect of gamma irradiation in the samples conservation 52 sachets were irradiated with ${ }^{60} \mathrm{Co}(10.00$ $\pm 1.05 \mathrm{kGy}$ ) in a gamma cell. This material with others non irradiated 52 sachets were used for the homogeneity and stability studies. The remaining 60 were used for the proficiency testing. The results demonstrated that both materials were homogeneous and presented good stability (during a period of 45 days). However, the irradiated material present better integrity, concerning biological degradation, when stored in ambient temperature. For this reason they were used to the proficiency testing pilot program. Ten laboratories participated in the proficiency testing pilot study and the results were evaluated using the following tests: $z$ score, confidence ellipse and En numbers. This work demonstrates the capability of the laboratory to produce reference materials as well as to organize and conduct proficiency testing.
\end{abstract}

Keywords: Proficiency testing, confidence ellipse, food irradiation, reference material. 


\section{SUMÁRIO}

1. INTRODUÇÃO

1.1 A importância da atividade pesqueira para a economia brasileira

1.2 Materiais de referência para ensaios de proficiência

1.3 A importância da utilização de materiais de referência 29

1.4 Objetivos 32

1.5 Relevância 33

\section{FUNDAMENTOS TEÓRICOS}

2.1 Produção de materiais de referência

2.1.1 Planejamento 34

2.1.2 Produção do material de referência 34

2.1.2.1 Seleção da matéria prima 35

2.1.2.2 Preparação 35

2.1.2.3 Importância das propriedades de interesse $\mathrm{Hg}$, As, Cd e Pb 35

2.1.2.4 Fortificação de amostras 36

2.1.2.5 Embalagens 37

2.2 Estudo de homogeneidade 39

2.3 Estudo de estabilidade 40

2.4 Métodos analíticos empregados na determinação de elementos 43 metálicos em amostras biológicas

2.4.1 Espectrofotometria de absorção atômica (AAS)

2.4.2 Espectrometria de massas com fonte de plasma induzidamente 46 acoplada (ICP-MS)

2.5 Tratamento dos dados

2.6 Caraterização de um material de referência

2.6.1 Cálculo das incertezas

2.7 Incerteza associada ao valor certificado

2.8 Ensaios de proficiência 55

2.8.1 Protocolos utilizados neste trabalho para o cálculo estatístico do 56 ensaio de proficiência 
3.4 Descontaminação do material volumétrico

3.5 Etapas de produção do material 65

3.5.1 Planejamento 66

3.5.2 Implementação da produção do material de referência 68

3.5.2.1 Seleção do pescado 68

3.5.2.2 Propriedades de interesse para os mensurandos $\mathrm{Hg}, \mathrm{As}$, $\mathrm{Cd}$ e $\mathrm{Pb} \quad 69$

3.5.2.3 Produção do material de referência 72

3.5.2.4 Preparação das soluções de fortificação 73

3.5.2.4.1 Solução padrão de mercúrio $\quad 73$

3.5.2.4.2 Solução padrão de cádmio $\quad 74$

3.5.2.4.3 Solução padrão de chumbo $\quad 74$

3.5.2.4.4 Solução padrão de arsênio $\quad 74$

3.5.2.5 Preparação das amostras fortificadas $\quad 75$

3.5.2.6 Processo de esterilização com radiação gama 80

3.6 Métodos analíticos empregados nos estudos de homogeneidade, 83 estabilidade e caracterização do material

3.6.1 Geração de vapor frio acoplado à espectrofotometria de absorção atômica com injeção em fluxo para análise de mercúrio total (FIA-CVAAS)

3.6.2 Geração de vapor de hidretos pela técnica de espectrofotometria de absorção atômica com injeção em fluxo para análise de arsênio total (FIA-HG-AAS)

3.6.3 Espectrometria de massas com fonte de plasma induzidamente 85 acoplado para determinação de cádmio e chumbo (ICP-MS)

3.7 Processo de digestão das amostras 86

3.8 Estudo de homogeneidade $\quad 88$

3.9 Estudo de estabilidade $\quad 89$

3.10 Caracterização dos elementos de interesse 89

3.10.1 Cálculo da incerteza para análise pela técnica de AAS 90

3.10.2 Cálculo da incerteza para análise pela técnica de ICP-MS 98

4. RESULTADOS E DISCUSSÕES 105

4.1 Resultados do teste para fortificação do material de referência 105

4.2 Resultados de homogeneidade obtidos na etapa de pré envase $\quad 106$ 
4.3 Resultados obtidos para o estudo de homogeneidade para o 107 elemento mercúrio após a irradiação

4.3.1 Estudo da massa mínima para mercúrio total

4.3.2 Resultados obtidos para o estudo de homogeneidade para 0 elemento arsênio

4.3.3 Estudo da massa mínima para arsênio total

4.4 Resultados obtidos para o estudo de estabilidade em curto prazo

4.4.1 Estudo de estabilidade em curto prazo para o elemento mercúrio

4.4.2 Representação gráfica dos resultados do estudo de estabilidade em curto prazo para o elemento mercúrio

4.4.3 Estudo de estabilidade em curto prazo para o elemento arsênio

4.4.4 Representação gráfica dos resultados do estudo de estabilidade em curto prazo

4.5 Estimativa das incertezas

4.5.1 Incerteza de caracterização

4.5.2 Incerteza para homogeneidade

4.5.3 Incerteza para estabilidade

4.5.4 Incerteza associada ao valor de referência

4.6 Resultados do programa piloto de ensaio de proficiência

4.6.1 Valor designado

4.6.2 Resultados dos testes de desempenho

4.6.2.1 Índice z-score

4.6.2.2 Erro normalizado

4.6.2.3 Elipse de confiança

4.6.2.4 Capacidade analítica (CA) e viabilidade analítica (VA)

4.7 Acompanhamento da estabilidade do material de referência durante o ensaio piloto de proficiência

4.8 Avaliação do ensaio de proficiência realizada pelos laboratórios participantes

5. CONCLUSÕES

APÊNDICE A- Resultados obtidos no teste piloto para o preparo do material de referência de pescado in natura APÊNDICE B- Cálculo da incerteza analítica 
APÊNDICE C- Ensaios para validação do método de determinação de arsênio

APÊNDICE D- Teste para fortificação de tecido de peixe

APÊNDICE E- Rastreabilidade do programa piloto de ensaio de

proficiência

6. REFERÊNCIAS BIBLIOGRÁFICAS 
TABELA 1- Provedores e programas de ensaio de proficiência no mundo

TABELA 2- Tabela de análise de variância para regressão linear

TABELA 3- Dose para irradiação de alimentos

TABELA 4- Resultados médios da recuperação dos elementos 105 adicionados a amostras de tecido muscular de peixe em menor concentração

TABELA 5- Resultados médios da recuperação dos elementos 105 adicionados a amostras de tecido muscular de peixe em maior concentração

TABELA 6- Concentração média, variância, desvio padrão, DPR e 106 resultados da ANOVA, calculados na determinação de $\mathrm{Hg}, \mathrm{As}, \mathrm{Cd}$ e Pb, em $\mu \mathrm{g} \mathrm{g}^{-1}$, nas amostras de menor concentração, pré-envase (base úmida)

TABELA 7- Concentração média, variância, desvio padrão, DPR e 107 resultados da ANOVA, calculados na determinação d Hg, As, Cd e Pb, em $\mu \mathrm{g} \mathrm{g}^{-1}$, nas amostras de maior concentração, pré-envase (base úmida)

TABELA 8- Média \pm DP, variância, DPR, resultados da ANOVA, obtidos 108 na determinação de mercúrio total em $\mu \mathrm{g} \mathrm{g}^{-1}$ por FIA-CV-AAS, na amostra de menor concentração (base úmida) para o estudo de homogeneidade

TABELA 9 - Média \pm DP, variância, DPR, resultados da ANOVA, obtidos 109 na determinação de mercúrio total em $\mu \mathrm{g} \mathrm{g}^{-1}$ por FIA-CV-AAS, na amostra de maior concentração (base úmida) para o estudo de homogeneidade

TABELA 10- Média \pm DP, variância, DPR, resultados da ANOVA, obtidos 112 na determinação de arsênio total em $\mu \mathrm{g} \mathrm{g}{ }^{-1}$ por FIA-HG-AAS, na amostra de menor concentração (base úmida) para o estudo de homogeneidade 
TABELA 11 - Média \pm DP, variância, DPR, resultados da ANOVA, obtidos na determinação de arsênio total em $\mu \mathrm{g} \mathrm{g}^{-1}$ por FIA-HG-AAS, na amostra de maior concentração (base úmida) para o estudo de homogeneidade

TABELA 12- Valores médios obtidos na determinação de mercúrio total 116 em $\mu \mathrm{g} \mathrm{g}^{-1}$ por FIA-CV-AAS, na amostra de menor concentração irradiada (base úmida), por 0-45 dias

TABELA 13- Valores médios obtidos na determinação de mercúrio total 116 em $\mu \mathrm{g} \mathrm{g}^{-1}$ por FIA-CV-AAS, na amostra de menor concentração não irradiada (base úmida), por 0-45 dias

TABELA 14- Valores médios obtidos na determinação de mercúrio total em $\mu \mathrm{g} \mathrm{g}^{-1}$ por FIA-CV-AAS, na amostra de maior concentração irradiada (base úmida), por 0-45 dias

TABELA 15- Valores médios obtidos na determinação de mercúrio total 117 em $\mu \mathrm{g} \mathrm{g}^{-1}$ por FIA-CV-AAS, na amostra de maior concentração não irradiada (base úmida), por 0-45 dias

TABELA 16- Valores médios obtidos na determinação de arsênio total 124 em $\mu \mathrm{g} \mathrm{g}^{-1}$ por FIA-HG-AAS, na amostra de menor concentração irradiada (base úmida), por 0-45 dias

TABELA 17- Valores médios obtidos na determinação de arsênio total 125 em $\mu \mathrm{g} \mathrm{g}^{-1}$ por FIA-HG-AAS, na amostra de menor concentração não irradiada (base úmida) , 0-45 dias

TABELA 18- Valores médios obtidos na determinação de arsênio total em $\mu \mathrm{g} \mathrm{g}^{-1}$ por FIA-HG-AAS, na amostra de maior concentração irradiada (base úmida) , 0-45 dias

TABELA 19- Valores médios obtidos na determinação de arsênio total 126 em $\mu g g^{-1}$ por FIA-HG-AAS, na amostra de maior concentração não irradiada (base úmida), 0-45 dias

TABELA 20- Estimativa da incerteza expandida e incerteza de 132 caracterização para THg e TAs nas amostras irradiadas, para ambas as concentração

TABELA 21- Estimativa da incerteza expandida e incerteza de 132 caracterização para $\mathrm{THg}$ e TAs nas amostras não irradiadas, para ambas as concentração 
TABELA 22- Estimativas da incerteza padrão de homogeneidade para os resultados obtidos por FIA-AAS

TABELA 23- Estimativa da incerteza padrão de estabilidade para os 135 resultados obtidos por FIA-AAS

TABELA 24- Estimativas da incerteza padrão de estabilidade para os 136 resultados obtidos por FIA-AAS

TABELA 25- Estimativa das incertezas padrão combinadas para os 137 elementos THg e TAS

TABELA 26- Estimativa da incerteza associada ao valor referência das 138 amostras de THg e TAs irradiadas de maior e menor concentração

TABELA 27- Estimativa da incerteza associada ao valor de referência 138 das amostras de $\mathrm{THg}$ e TAs não irradiadas de maior e menor concentração

TABELA 28- Valor informativo \pm incerteza associada das amostras de 139 TCd e TPb irradiadas de maior e menor concentração

TABELA 29- Valor informativo \pm incerteza associada das amostras de 139 TCd e TPb não irradiadas de maior e menor concentração

TABELA 30- Informações solicitadas aos laboratórios participantes do 141 ensaio de proficiência

TABELA 31- Técnica analítica utilizada, e limite de detecção (LD) para 143 determinação dos elementos pelos laboratórios

TABELA 32- Resultados reportados, em $\mu \mathrm{g} \mathrm{g}^{-1}$, pelos participantes do 144 programa piloto de ensaio de proficiência (base úmida)

TABELA 33- Estimativa para os valores designados e incerteza de 145

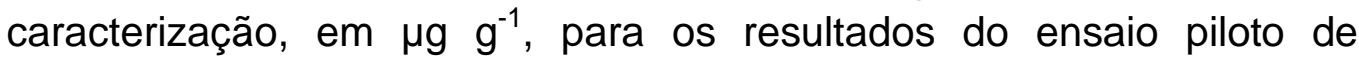
proficiência (base úmida)

TABELA 34- Resultados \pm DP e \% de recuperação, reportados pelos laboratórios participantes para a amostra de $\mathrm{MRC}\left(\mathrm{\mu g} \mathrm{g}^{-1}\right)$

TABELA 35- Valores de z-score obtidos para o MRC pelos laboratórios 150 participantes 
TABELA 36- Valores de z-score obtidos pelos laboratórios participantes para as amostras 1 e 2

TABELA 37- Valores de referência e incerteza associada para o cálculo 153 do erro normalizado dos laboratórios que enviaram suas incertezas

TABELA 38- *Valores dos erros normalizados obtidos pelos participantes 153 para MRC

TABELA 39- *Valores dos erros normalizados obtidos pelos participantes 154 para amostras 1 e 2

TABELA 40- Capacidade analítica (CA) dos laboratórios

TABELA 41- Viabilidade analítica (VA) na determinação dos elementos 162 fortificados nas amostras enviadas aos laboratórios

TABELA 42 - Resultados médios, DP ,em $\mu \mathrm{g} \mathrm{g}^{-1}$, DPR \% e incerteza de 169 medição \%, na determinação de mercúrio total (Traíras $s p$ )

TABELA 43- Média \pm DP, variância, DPR, resultados da ANOVA, obtidos 170 na determinação de mercúrio total, em $\mu \mathrm{g} \mathrm{g}^{-1}$, por FIA-CV-AAS, para o estudo de homogeneidade (base úmida)

TABELA 44- Valores médios obtidos na determinação de mercúrio total em $\mu \mathrm{g} \mathrm{g}^{-1}$ por FIA-CV-AAS, na amostra não irradiada (base úmida), por 0-45 dias

TABELA 45- Valores médios obtidos na determinação de mercúrio total 172 em $\mu \mathrm{g} \mathrm{g}^{-1}$ por FIA-CV-AAS, na amostra irradiada (base úmida), por 0-45 dias

TABELA 46- Fontes de Incerteza padrão e incerteza relativa para a caracterização do $\mathrm{THg}$

TABELA 47- Fontes de Incerteza padrão e incerteza relativa para a caracterização do TAs

TABELA 48- Fontes de Incerteza padrão e incerteza relativa para a caracterização do TCd

TABELA 49- Fontes de Incerteza padrão e incerteza relativa para a 187 caracterização do $\mathrm{TPb}$ 
TABELA 50- Resultados obtidos para validação do TAs

TABELA 51- Concentração média de TAs, em $\mu \mathrm{g} \mathrm{g}^{-1}$, obtidas por HGAAS, para os materiais de referência certificados utilizados neste ensaio

TABELA 52- Resultados de TAs adicionado ao tecido muscular do peixe 191

TABELA 53- Resultados de THg presentes no tecido muscular do peixe 192

TABELA 54- Resultados de TCd adicionados ao tecido muscular do 193 peixe

TABELA 55- Resultados de TPb adicionados ao tecido muscular do 193 peixe

TABELA 56- Laboratórios participantes da $1^{\circ}$ Rodada do EP MP 11/12 
FIGURA 1- Produção nacional de pescado 2003-2009

FIGURA 2- Produção da pesca e aquicultura no Brasil

FIGURA 3- Leiaute do estudo de homogeneidade entre - frascos

FIGURA 4- Leiaute do estudo de homogeneidade dentro do frasco

FIGURA 5- Esquema simplificado de um espectrofotômetro de Absorção Atômica

FIGURA 6- Componentes principais de um espectrômetro de massas

(Ulrich, 2011)

FIGURA 7- Fluxogrma das etapas de produção do material

FIGURA 8- Porto de Itaituba

FIGURA 9- Fluxograma de Preparo do material referência

FIGURA 10a- Peixe sem cabeça e eviscerado

FIGURA 10b- Limpeza do Peixe

FIGURA 10c- Filetagem do peixe

FIGURA 10d- Filé de Tucunaré

FIGURA 10e- Trituração do Filé

FIGURA 10f- Filé triturado em solução de metais

FIGURA 10g- Homogeneização do tecido muscular adicionado de metais

FIGURA 11a- Embalagem plástica de polietileno transparente (PEBD)

FIGURA 11b- Embalagem Trad-Pouch (metalizada em alumínio resvestido internamente com poliéster) 
FIGURA 12c- Pesagem das amostras

FIGURA 12d- Amostra embalada e etiquetada

FIGURA 13- Resultados típicos da irradiação de alimentos

FIGURA 14- Diagrama de causa e efeito para a determinação de THg e

TAs por AAS

FIGURA 15- Diagrama de causa e efeito para a determinação de TCd e 98 TPb por HRICP-MS

FIGURA 16- Desvio padrão relativo obtido na determinação de THg no intervalo de massa estudado

FIGURA 17- Desvio padrão relativo obtido na determinação de TAs no intervalo de massa estudado

FIGURA 18- Resultados da análise de regressão para o estudo de 120 estabilidade para $\mathrm{THg}$ em diferentes temperaturas e períodos de tempo, barra de erro com Desvio Padrão em $\mu \mathrm{g} \mathrm{g}^{-1}$

FIGURA 19- Resultados da análise de regressão para o estudo de estabilidade para $\mathrm{THg}$ em diferentes temperaturas e períodos de tempo, barra de erro com Desvio Padrão em $\mu \mathrm{g} \mathrm{g}^{-1}$

FIGURA 20- Gráficos da Concentração de THg nas amostras de maior concentração x Tempo para cada faixa de temperatura estudada

FIGURA 21- Gráficos da Concentração de THg nas amostras de menor 123 concentração x Tempo para cada faixa de temperatura estudada

FIGURA 22- Resultados da análise de regressão para o estudo de estabilidade para TAs em diferentes temperaturas e períodos de tempo, barra de erro com Desvio Padrão em $\mu \mathrm{g} \mathrm{g}^{-1}$

FIGURA 23- Resultados da análise de regressão para o estudo de estabilidade para TAs em diferentes temperaturas e períodos de tempo, barra de erro com Desvio Padrão em $\mu \mathrm{g} \mathrm{g}^{-1}$ 
FIGURA 24- Gráficos da Concentração de TAs nas amostras de maior concentração $\times$ Tempo para cada faixa de temperatura estudada

FIGURA 25- Gráficos da Concentração de TAs nas amostras de menor 131 concentração $x$ Tempo para cada faixa de temperatura estudada

FIGURA 26- Dispersão dos resultados dos laboratórios participantes 147 para o MRC. A linha cheia representa o valor designado e as linhas tracejadas os limites superior e inferior, $\mathrm{LI}=$ limite inferior e $\mathrm{LS}=$ limite superior $(2 \times$ desvio padrão fornecido pelo certificado do material de referência)

FIGURA 27-Dispersão dos resultados dos laboratórios participantes para 148 os 4 elementos de interesse da amostras (1) a-d maior concentração. A linha cheia representa o valor designado, linha tracejada limite superior e inferior

FIGURA 28- Dispersão dos resultados dos laboratórios participantes para os quatro elementos de interesse. A linha cheia representa o valor designado, linha tracejada limites superior e inferior amostra (2) e-h menor concentração

FIGURA 29a- Gráficos de z-score dos laboratórios participantes para o 150 MRC

FIGURA 29b- Gráficos de z-score dos laboratórios participantes para o 151 MRC

FIGURA 30- Gráficos de z-score dos laboratórios participantes para as 152 amostras 1 e 2.

FIGURA 31- Resultados da elipse de confiança para o MRC, elementos 155 cádmio e chumbo

FIGURA 32- Resultados da elipse de confiança para o MRC elementos 156 mercúrio e arsênio

FIGURA 33- Resultados da elipse de confiança para o elemento 157 mercúrio nas amostras 1 e 2

FIGURA 34- Resultados da elipse de confiança para o elemento arsênio 158 nas amostras 1 e 2 
FIGURA 35- Resultados da elipse de confiança para o elemento chumbo nas amostras 1 e 2

FIGURA 36- Resultados da elipse de confiança para o elemento cádmio 160 nas amostras 1 e 2

FIGURA 37- Gráfico de controle da estabilidade para o ensaio de 163 proficiência, THg e TAs nas amostras 1 e 2, valor da concentração \pm incerteza

FIGURA 38- Gráfico de controle da estabilidade para o ensaio de 164 proficiência, THg e TAs no MRC 1 e 2, valor da concentração \pm incerteza

FIGURA 39- Avaliação do ensaio de proficiência EP/MP 11/12 165

FIGURA 40- Seladora manual 169

FIGURA 41- Sachê de tecido muscular de peixe 169

FIGURA 42- 31 e $54 \mathrm{~N} 23^{\circ} \mathrm{C}$, após 30 dias

FIGURA 43- 81 e $5 \mathrm{~N} 23^{\circ} \mathrm{C}$, após 45 dias

FIGURA 44- Amostras $40^{\circ} \mathrm{C}$, por 30 dias

FIGURA 45- Amostras $60^{\circ} \mathrm{C}$, por 30 dias

FIGURA 46- Concentração de THg em amostras não irradiadas a temperatura de $5^{\circ} \mathrm{C}$ durante o período de 0 a 45 dias

FIGURA 47- Concentração de THg em amostras não irradiadas a temperatura de $23^{\circ} \mathrm{C}$ durante o período de 0 a 45 dias

FIGURA 48- Concentração de THg em amostras irradiadas a 175 temperatura de $5^{\circ} \mathrm{C}$ durante o período de 0 a 45 dias

FIGURA 49- Concentração de THg em amostras irradiadas a temperatura de $23^{\circ} \mathrm{C}$ durante o período de 0 a 45 dias

FIGURA 50- Concentração de THg em amostras não irradiadas a temperatura de $45^{\circ} \mathrm{C}$ durante o período de 0 a 45 dias 
FIGURA 52- Concentração de THg em amostras irradiadas a temperatura de $40^{\circ} \mathrm{C}$ durante o período de 0 a 45 dias

FIGURA 53- Concentração de THg em amostras irradiadas a temperatura de $60^{\circ} \mathrm{C}$ durante o período de 0 a 45 dias

FIGURA 54- Porcentagem de contribuição de incertezas para 182 caracterização do $\mathrm{THg}$

FIGURA 55- Porcentagem de contribuição de incertezas para 183 caracterização do TAs

FIGURA 56- Porcentagem de contribuição de incertezas analítica para 186 $\mathrm{TCd}$

FIGURA 57- Porcentagem de contribuição de incertezas analítica para 187 $\mathrm{TPb}$

FIGURA 58- Gráfico de controle para ensaio de arsênio em MRC para 189 matriz peixe, valor da concentração \pm incerteza

FIGURA 59- Adição de 0,200, 0,320, 0,500, 0,512, 0,819 $\mu \mathrm{g} \mathrm{g}^{-1}$ 190

FIGURA 60- Adição de 1,000, 1,310, 1,500, 2,000, 2,096 $\mu \mathrm{g} \mathrm{g}{ }^{-1}$ 190 


\section{LISTA DE ABREVIATURAS E SIGLAS}

AAS Espectrometria de Absorção Atômica, Atomic Absorption Spectrometry

ABNT Associação Brasileira de Normas Técnicas

ANOVA Análise da Variância

ANVISA Agência Nacional de Vigilância Sanitária

$\mathrm{b}_{0}$ Estimativa para intersecção

$\mathrm{b}_{1}$ Estimador para inclinação

CE Comunidade Europeia

CRPq Centro do Reator de Pesquisas

EURACHEM Rede de organizações Européias que tem como objetivo o estabelecimento de um sistema de rastreabilidade internacional de medições químicas e a promoção de boas práticas da qualidade

F Estatística da distribuição $F$

HG-AAS Absorção Atômica com geração de hidretos

CNPq Conselho Nacional de Pesquisa e Desenvolvimento Cientifico

FIA-CV-AAS Espectrometria de Absorção Atômica com injeção em fluxo e geração de vapor frio, Flow Injection Analysis-Cold Vapor-Atomic Absorption Spectrometry

FIG. Figura

gl Graus de liberdade (para ANOVA)

ICP-MS Espectrometria de Massas com Plasma Indutivamente Acoplado, Inductively Coupled Plasma Mass Spectrometry

IDR Ingestão diária recomendada

INCQS Instituto Nacional de Controle da Qualidade na Saúde

INMETRO Instituto Nacional de Metrologia, Qualidade e Tecnologia

IPEN Instituto de Pesquisas Energéticas e Nucleares

IPT Instituto de Pesquisas Tecnológicas

IRMM Instituto de Medições e Materiais de Referência - Institute for Reference Materials and Measurements

ISO Organização Internacional de Normalização (International Organization for Standardization)

$\mathrm{K}$ kelvin (unidade de temperatura) 
kGy Quilogray, unidade de dose de radiação, em função da energia absorvida pelo produto irradiado

LCQ Laboratório de Caracterização Química

LD Limite de detecção

LQ Limite de quantificação

MAPA Ministério da Agricultura, Pecuária e Abastecimento

MPA Ministério da Pesca e Aquicultura

MQ Média quadrática (na ANOVA)

$M Q_{\text {dentro }}$ Média quadrática dentro dos frascos (na ANOVA)

$M Q_{\text {entre }}$ Média quadrática entre frascos (na ANOVA)

MR Material de Referência

MRC Material de Referência Certificado

NIST Instituto Nacional de Padrões e Tecnologia dos Estados Unidos da América, National Institute for Standards \& Technology

NRCC Conselho Nacional de Pesquisa do Canadá, National Research Council Canada

ORNL Oak Ridge National Laboratory

s(b1) Desvio padrão para o estimador para inclinação

$\mathrm{S}_{\mathrm{bb}}$ Desvio padrão de homogeneidade (heterogeneidade) entre frascos

$\mathrm{s}^{2}$ bb Variância de homogeneidade (heterogeneidade) entre frascos

$\mathrm{s}^{2}$ an Variância analítica (para teste de "homogeneidade suficiente")

$\mathrm{s}^{2}$ bb Variância de homogeneidade (heterogeneidade) entre frascos

$\mathrm{S}^{2}$ sam Estimativa da variância analítica entre frascos

SI Sistema Internacional de Unidades

SQ Soma quadrática (na ANOVA)

t Valor crítico superior da distribuição t de Student

TAB. Tabela

TAs Arsênio total

TCd Cádmio total

THg Mercúrio total

TPb Chumbo total

U Incerteza expandida

VIM Vocabulário Internacional de Metrologia 
$\mu_{\mathrm{bb}}=$ Incerteza padrão devida à homogeneidade (heterogeneidade) entre frascos

$\mu_{\text {car }}$ Incerteza padrão devida à caracterização

um Micrômetro

$\mu_{\mathrm{MRHg} / \mathrm{As} / \mathrm{Cd} / \mathrm{Pb}}$ Incerteza combinada padrão para o mensurando de interesse no MR

$\mu_{\text {sts }}$ Incerteza padrão devida à estabilidade (instabilidade) em curto prazo.

$S_{a n}$ Desvio padrão analítico (para teste de "homogeneidade suficiente")

$s_{p}$ Desvio padrão alvo (ou esperado) (para teste de "homogeneidade suficiente")

$s^{2}$ all Variância permissível entre-amostras (para teste de "homogeneidade suficiente") 


\section{INTRODUÇÃO}

\subsection{A importância da atividade pesqueira para a economia brasileira}

Segundo os dados fornecidos pela Secretária de Comercio Exterior (2012), o Brasil é um país de perfil agroexportador e seus produtos de origem animal e vegetal, industrializados ou in natura, figuram entre os maiores volumes exportados. Em 2012 estes produtos representaram cerca de $40 \%$ da pauta de exportações do país (MAPA, 2012).

Nesse cenário, no período de 2003 e 2009, a produção de pescado se destacou apresentando um crescimento em torno de $25,2 \%$. Somente no ano de 2009, esse crescimento chegou a 5,4 \%, atingindo a marca de 479,398 toneladas (IBAMA, 2010) (FIG. 1 e FIG. 2).

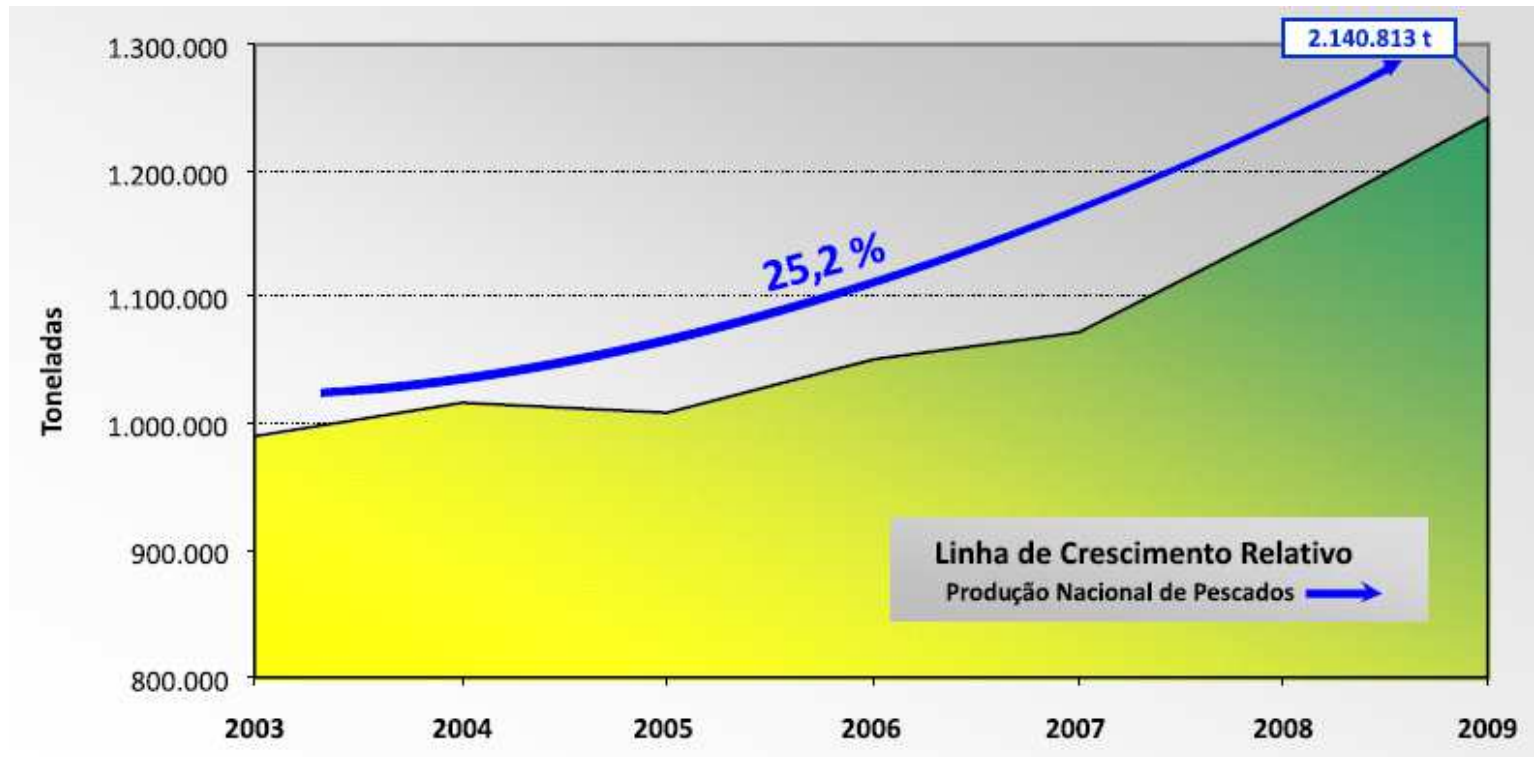

Fonte: Ministério da Pesca e Aquicultura, 2010

FIGURA 1- Produção Nacional de Pescado 2003-2009 


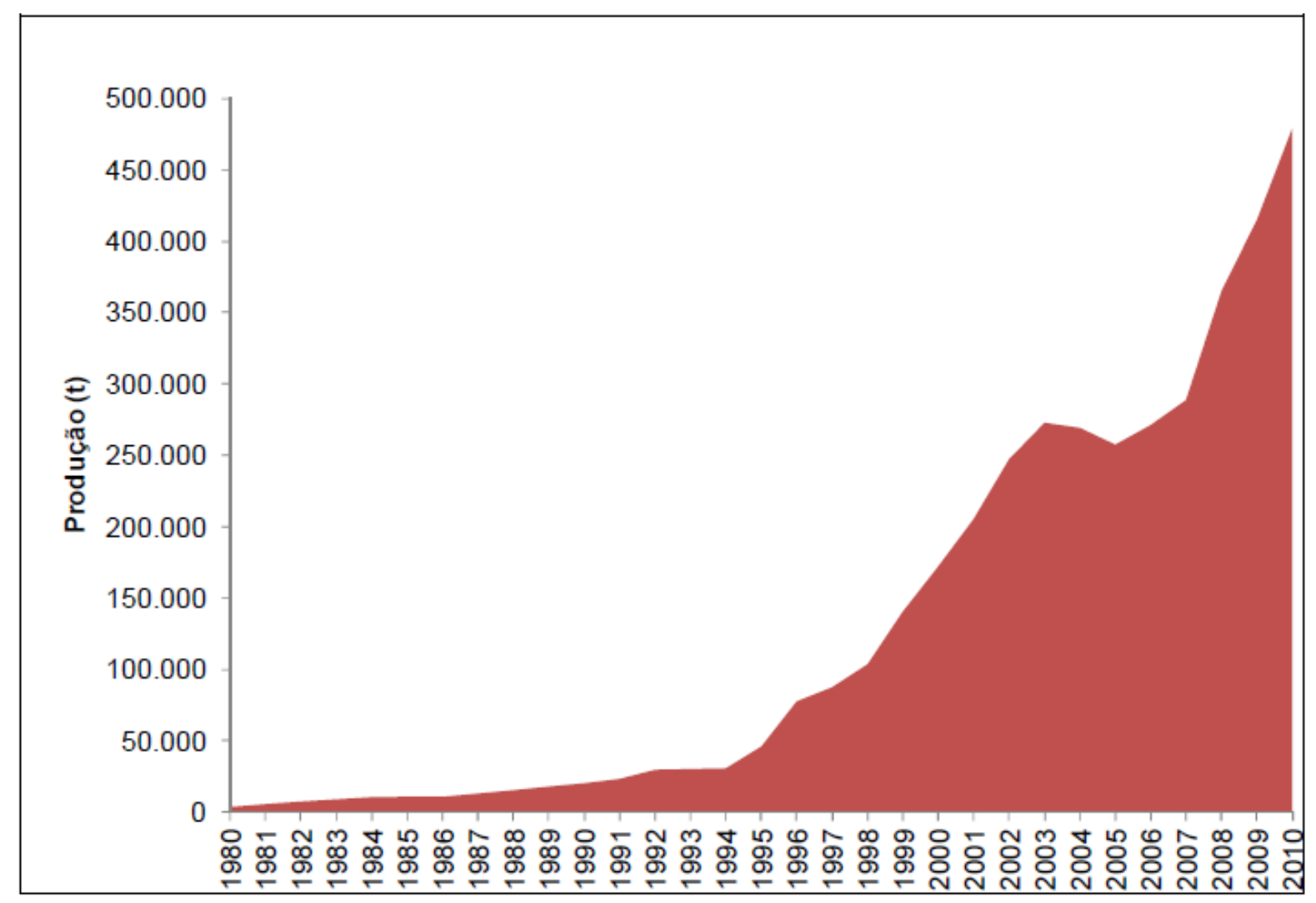

Fonte: Ministério da Pesca e Aqüicultura, 2012

FIGURA 2- Produção da Pesca e Aquicultura no Brasil

De acordo com os dados fornecidos pelo Ministério da Agricultuta, Pecuária e Abastecimento (MAPA) $50 \%$ das exportações de pescados do Brasil no ano de 2012 foram destinadas aos Estados Unidos, França, Espanha, Coréia do Sul, China, MERCOSUL e países do Oriente Médio, movimentando cerca de US\$190 milhões. Contudo, quando comparadas às taxas de exportações de 2011 e 2012 (para os mesmo países), os dados da balança comercial demonstraram uma redução de 4,3 \% no total exportado, sugerindo um possível aumento no consumo interno do pescado (Ministério da Agricultuta Pecuária e Abastecimento, 2012; Ministério da Pesca e Aquicultura, 2012).

Tanto para a exportação, quanto para o consumo interno, a produção de pescado e alimentos em geral, deve obedecer a rígidos padrões sanitários e de qualidade, os quais cobrem aspectos como: a presença de contaminantes inorgânicos e orgânicos, níveis máximos de resíduos, higiene do produto, 
conservação por radiação, etiquetagem e classificação, entre outros, dependendo do produto.

O descumprimento desses itens ou de itens técnicos administrativos pode ocasionar no caso da exportação o embargo do produto, e/ou sua retirada do mercado (Ministério das Relações Exteriores, 2002; MAPA, 2007; Segurança alimentar, 2010).

No Brasil os limites adotados para contaminantes inorgânicos em alimentos constam da portaria ํo 685 de 27 de agosto de 1998 da ANVISA (republicada no Diário Oficial da União de 24 de setembro de 1998), a qual estabelece como limite máximo de tolerância para peixes e produtos da pesca: mercúrio $0,5 \mu \mathrm{g} \mathrm{g}^{-1}$ (exceção para peixes predadores $1,0 \mu \mathrm{g} \mathrm{g}^{-1}$ ), cádmio 1,0 $\mu \mathrm{g} \mathrm{g}^{-1}$, chumbo 2,0 $\mathrm{\mu g} \mathrm{g}^{-1}$ e arsênio 1,0 $\mathrm{g} \mathrm{g} \mathrm{g}^{-1}$ (Kering et al, 2009; ANVISA Portaria ํㅜ685/98).

Para a exportação, a maior parte dos países europeus adota a norma européia (regulamento CE no 1881/2006), a qual admite para pescado valores entre $0,5 \mu \mathrm{g} \mathrm{g}^{-1}$ e $1,0 \mu \mathrm{g} \mathrm{g}^{-1}$ para mercúrio, cádmio $0,05 \mu \mathrm{g} \mathrm{g}^{-1}$, chumbo $0,3 \mu \mathrm{g} \mathrm{g}^{-1}$, não constando valores para arsênio.

Enquanto que em outros países e nos continentes Africano e Asiático adota-se a norma CODEX STAN 193 (1995), (segue os principios básicos do Codex Alimentarius FAO/OMS), estabelecendo limites para mercúrio entre 0,5 $\mu \mathrm{g}$ $\mathrm{g}^{-1}$ e $1,0 \mu \mathrm{g} \mathrm{g}{ }^{-1}$, cádmio $0,02 \mu \mathrm{g} \mathrm{g}^{-1}$ e arsênio $0,05 \mu \mathrm{g} \mathrm{g}^{-1}$.

Esse é um dos aspectos, que faz com que seja necessário aprimorar no país, a modernização de toda infraestrutura produtiva do pescado. Nesse cenário, deve-se incluir a qualificação de laboratórios particulares e órgãos governamentais de controle. Dessa forma a determinação de $\mathrm{Hg}$, $\mathrm{As}, \mathrm{Cd}$ e $\mathrm{Pb}$ em pescados é um item fundamental na cadeia produtiva desses alimentos, exigindo a qualificação de todos os laboratórios, particulares e/ou governamentais envolvidos em todas as etapas deste processo.

Nesse contexto, a participação em ensaios de proficiência, promovido por instituições credenciadas e independentes, é uma das formas mais comuns no processo de avaliação, e acreditação dos laboratórios. 


\subsection{Materiais de referência para ensaio de proficiência}

Ensaios de proficiência são programas de comparações interlaboratoriais de resultados de medição visando fornecer subsídios para avaliação de competências técnicas aos laboratórios participantes (ABNT NBR ISO/IEC 17043: 2011).

A participação em ensaios de proficiência, normalmente, é utilizada pelos organismos de acreditação como ferramenta para avaliação da competência dos laboratórios de ensaio. Deste modo os laboratórios podem também demonstrar a confiabilidade de seus resultados (ABNT NBR ISO/IEC 17043: 2011).

Consequentemente, o processo de acreditação pode ser considerado como o reconhecimento formal por um organismo de acreditação, de que um laboratório, ou um organismo de certificação ou inspeção, atende a requisitos previamente definidos e demonstra ser competente para realizar suas atividades com confiança (ABNT NBR ISO/IEC 17011:2005; INMETRO, 2006).

O processo de acreditação é executado por organismos reconhecidos internacionalmente. No caso do Brasil, o INMETRO (Instituto Nacional de Metrologia, Normalização e Qualidade Industrial) é o órgão responsável pela execução desse processo (ABNT NBR ISO/IEC 17011:2005; ABNT NBR ISO/IEC 17043: 2011).

Nesse contexto, para a realização de um ensaio de proficiência é necessária à utilização de um item de ensaio, que pode ser um material de referência, uma amostra, um produto, um artefato, um equipamento, um padrão ou um conjunto de dados (ABNT NBR ISO/IEC 17043:2011)

Deste modo, pode-se, por exemplo, utilizar os dados provenientes dos ensaios para verificar a competência de um grupo de laboratórios para um tipo específico de análise, desde que a mesma seja organizada em uma sequencia devidamente estruturada (ILAC G13, 2007).

Os resultados de medição de um laboratório dentro de um ensaio interlaboratorial são comparados com aqueles obtidos por um ou mais 
participantes do programa, contudo o provedor deve apresentar um numero significativo de participantes para validar os resultados de consenso (ABNT NBR ISO/IEC 17043:2011).

Assim, os resultados obtidos pelos programas de intercomparação, geralmente, podem ser avaliados adotando-se as sugestões das normas do ISO/IEC 13528 (2005), ABNT NBR ISO/IEC 17043 (2011), e o Protocolo Harmonizado da International Union of Pure and applied Chemistry (IUPAC, 2006). Onde a interpretação destes resultados é realizada por métodos estatísticos convenientes.

Estas normas propõem que para avaliação dos resultados obtidos é necessário atentar a algumas considerações importantes, para minimizar a influência de valores espúrios antes de se obter um valor de consenso para o grupo. Assim deve-se:

- Verificar a diferença entre resultados de ensaios obtidos por um laboratório em particular em relação a um valor de referência aceito (ABNT NBR ISO/IEC 17043:2011; ISO/IEC 13528, 2005).

- Certificar-se que o material de ensaio permanece estável no período de realização dos programa (ABNT NBR ISO/IEC 17043:2011).

- Especificar aos participantes que estes realizem análise das amostras de ensaio com os mesmos procedimentos utilizados em sua rotina (verificar a repetibilidade do método) (ABNT NBR ISO/IEC 17043:2011).

Estes três itens são importantes, pois podem influenciar diretamente nos resultados de um laboratório demostrando a importância de uma avaliação regular de seu desempenho (ABNT NBR ISO/IEC 17043:2011).

Atualmente, estão em andamento 1113 programas interlaboratoriais no mundo. Deste total, 285 abrangem o escopo de análise de alimentos e bebidas, mostrando um interesse mundial pelo controle de qualidade e sanitário dos alimentos. Destes 285 apenas 22 são brasileiros como apresentado na TAB. 1 (Eptis, 2013). 
TABELA 1- Provedores e Programas de Ensaios de Proficiência no Mundo

\begin{tabular}{|c|c|c|c|c|c|c|c|c|}
\hline País & Provedores & Programas & País & Provedores & Programas & País & Provedores & Programas \\
\hline Alemanha & 45 & 232 & Dinamarca & 7 & 29 & \begin{tabular}{|l|} 
Irlanda \\
\end{tabular} & 1 & 1 \\
\hline Argentina & 2 & 24 & E.U.A & 10 & 51 & Itália & 20 & 41 \\
\hline Australia & 2 & 46 & Equador & 1 & 7 & Noruega & 12 & 15 \\
\hline Austria & 19 & 43 & Espanha & 24 & 46 & $\begin{array}{l}\text { Portugal } \\
\text { Reino }\end{array}$ & 4 & 30 \\
\hline Bélgica & 12 & 17 & Finlândia & 4 & 4 & $\begin{array}{l}\text { Unido } \\
\text { Rep. }\end{array}$ & 25 & 72 \\
\hline Bolívia & 1 & 12 & França & 31 & 137 & Tcheca & 4 & 19 \\
\hline Brasil & 22 & 110 & Grêcia & 2 & 2 & Suécia & 6 & 9 \\
\hline Canadá & 4 & 11 & Holanda & 12 & 127 & Suiça & 15 & 19 \\
\hline & $\begin{array}{l}\text { Total de } \\
\text { Provedores }\end{array}$ & & & & I & 285 & & \\
\hline & $\begin{array}{l}\text { Total de } \\
\text { Programas }\end{array}$ & & & & I & 1113 & & \\
\hline
\end{tabular}

Fonte: EPTIS, 2013

No Brasil existem cerca de 110 programas de ensaios de proficiência operados por 22 provedores de ensaios de proficiência segundo o EPTIS (Eptis, 2013).

No que diz respeito ao pescado, existem apenas 4 programas de proficiência para metais em pescado no mundo, 2 sediados na Inglaterra (FAPAS, LGC), 1 sediado na Espanha (INTER2000 Q-Foodstuffs) e 1 sediado na França (ILC 32b-Trace elements in sea products). Destes programas em andamento no periodo de 2012 a 2013 apenas os programas ingleses e o francês apresentam os elementos $\mathrm{As}, \mathrm{Cd}, \mathrm{Pb}$ e $\mathrm{Hg}$ no mesmo ensaio (Eptis, 2013). 


\subsection{A importância da utilização de materiais de referência}

Materiais de referência (MR) são definidos como materiais suficientemente homogêneos e estáveis em relação a uma ou mais propriedades específicas, os quais são preparados para se adequar a uma medição ou exames de propriedades qualitativas (ABNT ISO GUIA 35:2012).

Materiais de referência certificados (MRC) são materiais de referência acompanhados de documentação emitida por uma entidade reconhecida, a qual fornece valores de propriedades especificos com as suas incertezas e rastreabilidades associadas. Estes são largamente utilizados como um dos parâmetros para validação de metodologias analíticas, assim como no controle de qualidade dos ensaios (ABNT ISO GUIA 35:2012).

Existem poucos produtores de materiais de referência, os quais atendem a um número cada vez maior, mas ainda limitado, de tipos de ensaios.

Assim, atualmente no Brasil existem 5 instituições acreditadas junto ao Instituto de Nacional de Metrologia, Qualidade e Tecnologia (INMETRO), como produtores de materiais de referências (Centro Tecnológico Polímeros Senai/CETEPO; Centro de Tecnológia Mineral - CETEM; Digicrom Analítica Ltda.

- EPP; Visomes Comercial Metrológica Ltda.; Laboratório de Referências Metrológicas - LRM/IPT). Dessa forma, a maioria dos materiais necessários é adquirida no exterior, principalmente nos Estados Unidos, Inglaterra, Alemanha e Austrália, entre outros, fazendo com que estes materiais apresentem um alto custo.

Em linhas gerais, a produção de um MR requer um planejamento experimental detalhado, prevendo-se a quantidade adequada de material para seu uso final e de todas as etapas inerentes ao seu desenvolvimento. As quais são: preparo do material; envasamento das amostras, estudos para verificar a homogeneidade do material nos recipientes, avaliação da estabilidade, a qual garantirá sua integridade durante o transporte e estocagem por tempo préestabelecido e a certificação dos valores atribuídos às propriedades de interesse do material preparado (Cardoso et al, 2010). 


\subsection{Objetivos}

-Produzir um material de referencia para ensaios de proficiência para $\mathrm{Hg}, \mathrm{Cd}, \mathrm{Pb}$ e As em pescados in natura;

-Estruturar um programa piloto de ensaios de proficiência para $\mathrm{Hg}, \mathrm{Cd}, \mathrm{Pb}$ e As em pescados in natura.

\subsection{Relevância}

Os laboratórios da área de controle de qualidade de alimentos apresentam uma grande demanda para acreditação de ensaios para determinação de contaminantes inorgânicos e a consequente participação em ensaios de proficiência dessa natureza (Ulrich, 2011).

Nesse contexto, cabe ressaltar que 0 Brasil ainda não possui nenhum provedor de ensaios de proficiência para metais em pescado, contando apenas com 1 provedor para ensaios microbiológicos sediado no Rio Grande do Sul, o que diminui a competitividade comercial do pais (Eptis, 2013).

Por este motivo, propomos neste trabalho a preparação de um material de referência para ensaios de proficiência para $\mathrm{Hg}$, $\mathrm{As}, \mathrm{Cd}$ e $\mathrm{Pb}$ em pescados in natura e a estruturação do primeiro ensaio de proficiência nacional para estes metais em pescado.

Os esforços aqui realizados, tem o intuito de oferecer aos laboratórios nacionais paticulares e/ou governamentais, envolvidos com a atividade pesqueira, um programa de proficiência de baixo custo e fácil adesão, que atenda aos requisitos de acreditação baseados na norma ABNT NBR ISO/IEC 17025 (2005), e deste modo, trazer uma contribuição para a cadeia produtiva do pescado. 


\section{FUNDAMENTOS TEÓRICOS}

\subsection{A PRODUÇÃO DE MATERIAIS DE REFERÊNCIA}

\subsubsection{Planejamento}

As principais etapas de planejamento envolvidas na produção de um material de referencia são: avaliação inicial das necessidades do mercado, estudo de viabilidade, planejamento do transporte e vida útil do material, implementação da produção, preparação e envase, métodos de medição, avaliação da homogeneidade, avaliação da estabilidade, tratamento estatístico dos dados, caracterização e cálculo de incertezas (BAM, 2010; ABNT ISO GUIA 35:2012).

A avaliação inicial consiste em especificar o que será produzido, qual o seu objetivo, a necessidade comercial, a demanda, os benefícios e se existe viabilidade para sua produção. Para este fim é recomendado a aplicação das normas e regulamentos existentes como o BAM RM Guidelines (2010), e as normas da serie ISO/IEC 34 e 35 que tratam das estratégias aplicaveis a produção de materiais de referência e materiais de referência certificados.

O estudo de viabilidade de um projeto visa avaliar questões referentes a protocolos de preparação das amostras, tais como: equipamentos, área física, seleção e aquisição da matéria prima, características de interesse da materia prima, custos de produção, rastreabilidade na produção, programas de qualidade do laboratório, e procedimentos de medição que serão necessárias para a obtenção de um material suficientemente homogêneo e estável, que atenda ao uso pretendido (BAM, 2010; ABNT ISO GUIA 35:2012).

Outros parâmetros a serem considerados antes da etapa de produção são o transporte e o tempo de vida útil. O transporte deve ser avaliado antes do inicio da produção, pois o material produzido deve chegar ao seu destino seguindo normas e regulamentos de transporte existentes. Assim a embalagem e as rotulagens adequadas são requisitos básicos para atender as legislações adotadas pelos países, ou regiões receptoras destes materiais (BAM, 2010; ABNT ISO GUIA 35:2012). 
A vida útil do material é uma variável dependente da natureza da matéria prima selecionada para a produção do material e do tempo de uso. Neste caso devem ser considerados mecanismos que possam afetar a estabilidade e a homogeneidade do material. Logo, devem ser avaliados processos de produção que evitem a deterioração da matéria prima. Desde que não ocasionem efeitos negativos nas características de interesse do material produzido (BAM, 2010; ABNT ISO GUIA 35:2012).

\subsubsection{Produção do material de referência}

\subsubsection{Seleção da matéria prima}

Para que um ensaio possa ser oferecido continuamente, deve-se atentar para a aquisição de matéria prima suficiente para a produção do material, se esta será utilizada in natura ou sofrerá algum processo de industrialização, selecionar o nível das propriedades desejadas, ou em alguns casos pode-se optar pela técnica de mistura e/ou fortificação de amostras com os níveis das propriedades desejadas em quantidade suficientes (BAM, 2010; ABNT ISO GUIA 35:2012).

A quantidade de matéria prima requerida deve ser suficiente para realização dos estudos de homogeneidade, estabilidade, caracterização e medições necessárias para recertificação ao longo do tempo de prateleira, quando se tratar de materiais de referencia certificados, e distribuição do material (BAM, 2010).

\subsubsection{Preparação}

O objetivo a que se destina o material de referência fornecerá as orientações gerais sobre os processos de preparação. Assim é necessário avaliar o tipo de matriz a ser selecionada, já que o intuito é produzir um lote de material que seja o mais semelhante possível às amostras de rotina de um laboratório. 
Nesse sentido é imprescindivel que o material seja homogêneo e estável com os níveis de propriedades adequados ao uso. Desse modo, pode-se optar pela fortificação do material para que estes sejam usados com os métodos de ensaio para controle de qualidade (BAM, 2010; ABNT ISO GUIA 35:2012).

Para tanto, deve ser desenvolvido um conjunto de protocolos com diversas técnicas como moagem, trituração, limpeza, esterilização, mistura de matrizes, fortificação de amostras e tantas outras que melhor se adequem a matriz selecionada (BAM, 2010; ABNT ISO GUIA 35:2012).

\subsubsection{Importância dos Elementos de Interesse As, Cd, $\mathrm{Pb}$ e Hg}

Nos últimos anos, a demanda por materiais de referência certificados e ensaios de proficiencia para alimentos tem crescido. Principalmente materiais cujas propriedades de interesse são: elementos potencialmente tóxicos, como por exemplo, $\mathrm{Hg}$, As, $\mathrm{Cd}$ e $\mathrm{Pb}$, poluentes orgânicos e microorganismos (ensaios de proficiência). Isso se deve ao risco potencial destes elementos ao meio ambiente e à saude humana, por esta razão, são propostos pelas autoridade responsáveis pelo controle sanitário de alimentos, padrões rígidos sobre a presença destes elementos em diferentes produtos para exportação e importação.

Nesse sentido, existe grande interesse e necessidade na produção destes materiais para a implementação de programas de qualidade de laboratórios que desejam atender aos requisitos da norma ABNTNBR ISO/IEC:17025 (2005). 


\subsubsection{Fortificação de Amostras}

A fortificação (spiking) pode ser definida como o acréscimo de uma quantidade conhecida de uma substância simples, composta ou elementos a um material de matriz (ABNT ISO GUIA 35:2012).

O ABNT ISO GUIA 35 (2012), sugere que a fortificação pode ser adequada quando do preparo de material de referência a partir de materiais na forma de um sólido, atentando para o fato da necessidade do material estar suficientemente homogêneo e estável no final da produção.

Fatores como temperatura durante o preparo da amostra, concentração da solução, tempo de imersão, superfície de contato, tipo de tecido muscular do animal selecionado (dorsal, ventral), método de digestão da amostra, forma de adição do metal, $\mathrm{pH}$, entre outras, influenciam diretamente na recuperação final do analito e podem ocasionar diferenças significativas na ligação dos mensurandos naturalmente presentes e aqueles adicionados por fortificação (ABNT ISO GUIA 35:2012; Ribeiro, 2008).

Não foram encontradas bibliografia específicas para a preparação de protocolos de fortificação para o tipo de material a ser produzido neste trabalho. Deste modo, os estudos apresentados a seguir serviram de base para a montagem dos protocolos utilizados na etapa experimental deste trabalho.

Assim, considerando os estudos disponíveis, podem ser adotadas duas estratégias para a fortificação de materiais de matriz peixe, adição do elemento de interesse durante a preparação do material ou adição do elemento de interesse na ração do espécime escolhido como matéria prima, como será descrito a seguir.

Em um estudo realizado por Kalay e Canli (1999), 20 peixes da espécie Tilápia zilli foram expostos a $1 \mathrm{mg} \mathrm{L}^{-1}$ de $\mathrm{Cd}\left(\mathrm{CdCl}_{2} . \mathrm{H}_{2} \mathrm{O}\right)$ e $\mathrm{Pb}\left(\mathrm{Pb}\left(\mathrm{NO}_{3}\right)_{2}\right)$, durante 10 dias. Os individuos apresentaram acumulo significativo de aproximadamente $0,05 \mathrm{mg} \mathrm{g}^{-1}$ dos elementos chumbo e cádmio (em peso vivo) em seus tecidos, ou seja, uma recuperação de $5 \%$. 
Poornima e col. (2007), realizaram um estudo caso/controle expondo peixes a diferentes concentrações de Cloreto de cádmio $\left(\mathrm{CdCl}_{2}\right), 1 \mathrm{mg} \mathrm{L}^{-1}$ a $8 \mathrm{mg}$ $\mathrm{L}^{-1}$ por 96 horas, encontrando ao longo do estudo diferentes concentrações do elemento, respectivamente: $4,13 \mathrm{mg} \mathrm{L}^{-1}, 4,57 \mathrm{mg} \mathrm{L}^{-1}, 4,89 \mathrm{mg} \mathrm{L}^{-1}, 7,28 \mathrm{mg} \mathrm{L}^{-1}$. Evidenciando diferenças significativas na bioacumulação do metal no referido tempo de exposição.

A adição de concentrações letais de arsênio e cromo em aquários também evidenciou o acúmulo destes metais no sangue dos peixes. Uma exposição de 24hs a 28,30 $\mathrm{mg} \mathrm{L}^{-1}$ de arsênio e $61 \mathrm{mg} \mathrm{L}^{-1}$ de cromo, resultaram em 21,1 $\mathrm{mg} \mathrm{L}^{-1}$ de arsênio e 21,6 $\mathrm{mg} \mathrm{L}^{-1}$ de cromo (Vutukuru et al, 2007).

Ishikawa (2007), realizou um estudo expondo Tilápias em baixas concentrações de mercúrio $\left(0,02,0,002,0,0002 \mathrm{mg} \mathrm{L}^{-1} \mathrm{Hg}\right)$ durante 14 dias, contudo não encontrou quantidade de mercúrio significativa nos parâmetros hematológicos dos indivíduos concluindo que quantidade adicionada não foi suficiente para afetar o quadro hematológico da Tilápia.

No caso do enriquecimento de alimentos, a proposta é suprir perdas por processos industriais ou suplementá-los com nutrientes em nível superior ao seu conteúdo normal, no entanto o enriquecimento ou fortificação é permitido desde que em $100 \mathrm{~mL}$ ou $100 \mathrm{~g}$ do produto, pronto para consumo, seja fornecido no mínimo $15 \%$ da IDR de referência, no caso de líquidos, e 30 \% da IDR de referência, no caso de sólidos. (Portaria da ANVISA nํ31, 1998).

Zarbielli e col. (2004), verificaram a recuperação da quantidade de ferro adicionado na preparação de queijo minas frescal, (citrato férrico amoniacal (Merck)) nas concentrações de 150, 200 e $250 \mathrm{mg} \mathrm{L}^{-1}$ de leite, respectivamente). As amostras apresentaram teores de ferro de 55, 57 e $89 \mathrm{mg} \mathrm{L}^{-1}$, com uma recuperação de $30 \%$.

Comparando-se as informações a respeito da adição de metais em diferentes matrizes, observou-se que para o preparo de um material de referência, a adição dos elementos diretamente na matriz apresenta resultados mais satisfatórios (ISO GUIDE 35, 2006; Portaria da ANVISA nํ 31, 1998). 


\subsubsection{Embalagens}

Segundo Moura e Banzato (1997), os requisitos para embalagem de um produto podem seguir o seguinte conceito: pode ser utilizado um elemento ou conjunto de elementos destinados a envolver, conter e proteger produtos durante a sua movimentação, transporte, armazenagem, comercialização e consumo.

A finalidade das embalagens é proteger e conservar os materiais de fácil degradação, mantendo-os sem alterações significativas na sua composição e qualidades sensoriais, bem como protegê-lo de fenômenos que signifiquem redução de sua vida útil. Além de estampar cores atrativas e informações que o tornem um veículo de comunicação entre o produtor, o produto e o consumidor final (Donatti, 2011; BAM, 2010).

Geralmente, as embalagens podem ser confeccionadas em vidro, metal, papel, plástico e/ou multi camadas. Neste caso, as propriedades mais importantes são: serem inertes, recicláveis, transparentes ou opacas quando necessário e permitirem um possível processamento após o envase (Donatti, 2011).

As embalagens metálicas (principalmente aço e alumínio) são destinadas a materiais tratados termicamente, devido à boa resistência a altas pressões e temperaturas e por sua estabilidade mecânica, podendo apresentar barreira a gases e vapor d'água, além de proteger da luz (Donatti, 2011).

No caso de embalagens de papel, os tipos mais comuns podem ser fornecidas na forma de folhas ou caixas que nem sempre estão em contato com o material, uma vez que estas aceitam o formato de multi camadas, costumam serem revestidos com filmes plásticos, metálicos, ceras, etc. São também recicláveis e biodegradáveis (Donatti, 2011).

As embalagens produzidas em plástico, rígidas ou flexíveis, transparentes ou não, podem receber internamente uma camada protetora ao material que evita sua interação com o plástico e promove a proteção contra luz (Donatti, 2011).

Mais recentemente, estão sendo desenvolvidas embalagens antimicrobianas ativas, oferecendo maior proteção aos materiais facilmente 
degradáveis, aumentando assim seu tempo de vida útil. Dentre as substâncias já provadas e aprovadas estão a prata, o etanol, o wasabi e o ácido sórbico (Donatti, 2011).

O envase do material pode ser manual ou mecânico depedendo das condições do laboratório e do tipo de matriz selecionada. A vantagem do processo mecânico são as embaladoras a vacuo que extraem 99 \% do oxigênio contido na embalem, possui como benefício evitar o contato do individuo com a amostra evitando possíveis contaminações (Donatti, 2011).

Assim para armazenar um material em condições adequadas deve-se selecionar o tipo de embalagem, a capacidade de armazenamento adequada da embalagem, as condições de armazenamento como proteção contra luz, temperatura, umidade, e as demais propriedades especificas de cada material (BAM, 2010; ABNT ISO GUIA 35:2012).

\subsection{Estudo de homogeneidade}

O estudo de homogeneidade tem 0 intuito de demonstrar que o lote produzido é suficientemente homogêneo para garantir a qualidade do material, e verificar a variação que pode existir entre os recipientes do lote (ABNT ISO GUIA $35: 2012)$.

O estudo de homogeneidade realizado após o envase geralmente ocorre por meio aleatório, e é realizado em duas etapas: entre os recipientes e dentro do recipiente como está representado nas Figuras 3 e 4 . O estudo entre os recipientes fornecerá a variação da homogeneidade existente entre os mesmos e é computada de acordo com a equação 1(ABNT ISO GUIA 35:2012)

$$
s_{b b}^{2}=s_{A}^{2}=\frac{M Q_{\text {entre }}-M Q_{\text {dentro }}}{n_{0}}
$$


Onde $\mathrm{s}_{\mathrm{bb}}^{2}=$ variância da homogeneidade entre os recipientes; $\mathrm{s}_{\mathrm{A}}^{2}=$ variância da homogeneidade dentro do recipiente; $M Q_{\text {entre }}=$ média quadrática entre as partes; $M Q_{\text {dentro }}=$ média quadrática dentro da parte; $\mathrm{n}_{0}=$ número de replicatas. E assim, para a avaliação da incerteza assume-se que $s^{2}$ bb é idêntica a $u^{2} b$.

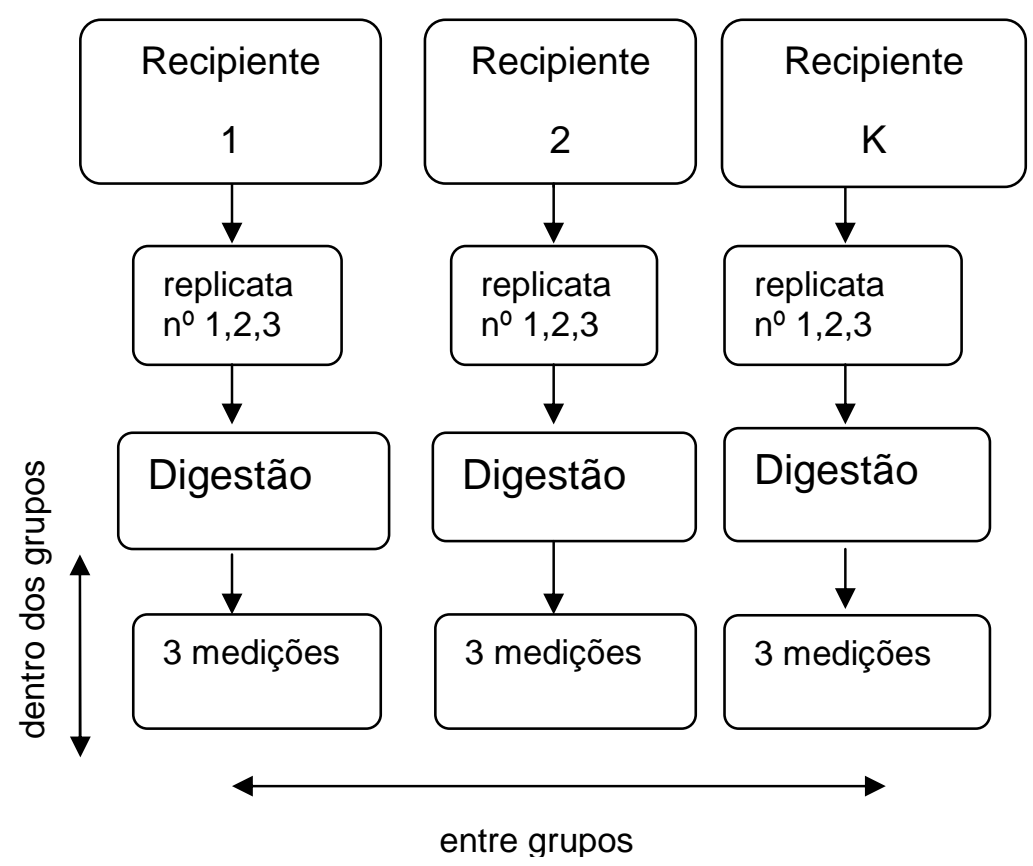

Fonte: ISO GUIDE 35

FIGURA 3- Leiaute do estudo de homogeneidade entre recipientes 


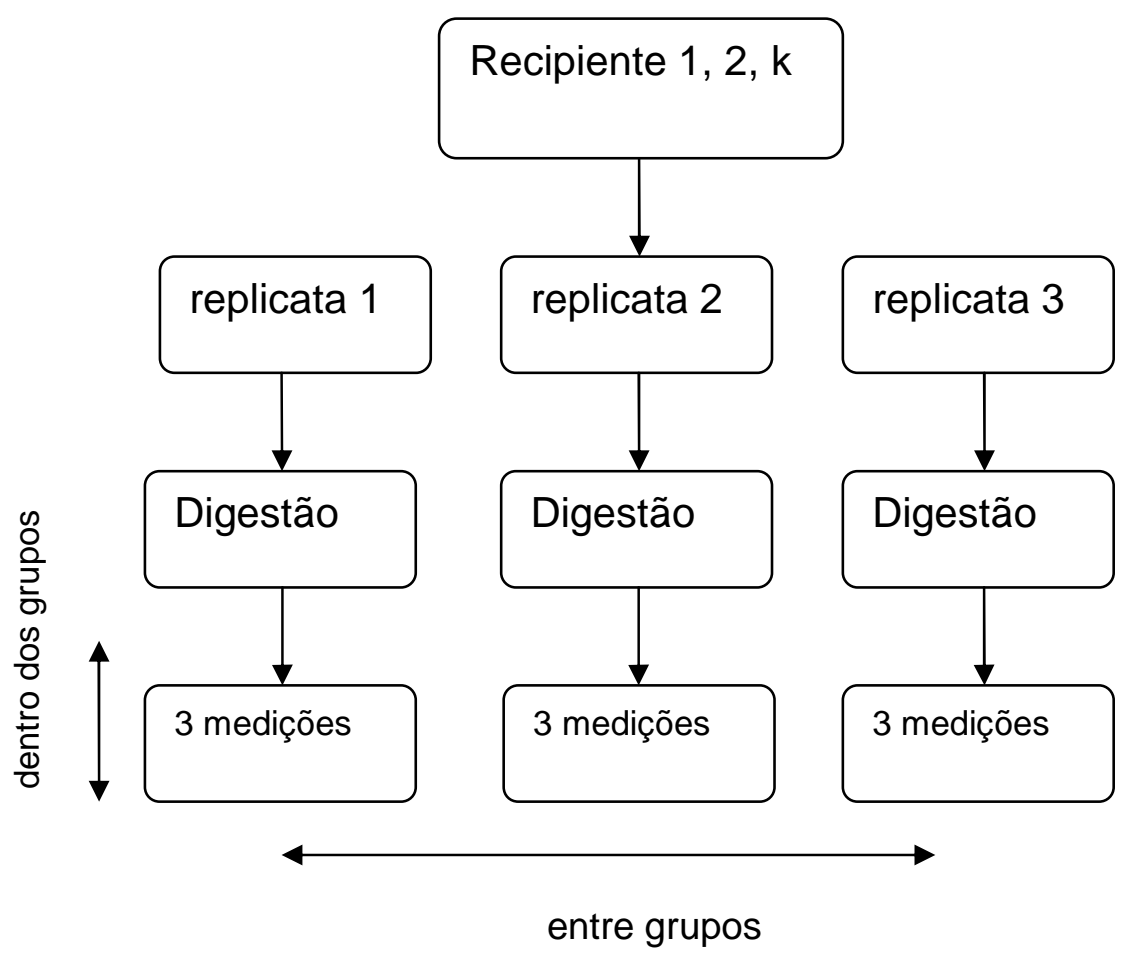

Fonte: ISO GUIDE 35

FIGURA 4- Leiaute do estudo de homogeneidade dentro do recipiente

Em casos em que o método de medição escolhido, apresentar repetibilidade insuficiente ou o material não permitir uma sub amostragem é recomendado utilizar a seguinte equação:

$u_{b b}=\sqrt{\frac{M Q_{\text {dentro }}}{n}} \sqrt[4]{\frac{2}{v_{M Q_{\text {dentro }}}}}$

Onde: $\mathrm{u}_{b b}=$ incerteza da homogeneidade; $M Q_{\text {dentro }}=$ média quadrática dentro dos frascos; $\mathrm{n}=$ número de repetições; $\nu_{\text {MQdentro }}=$ graus de liberdade de $M Q_{\text {dentro. }}$.

A utilização destas fórmulas é dependente dos valores do desvio padrão da homogeneidade $\left(\mathrm{s}_{\mathrm{bb}}\right)$ e do desvio padrão de repetibilidade $\left(\mathrm{s}_{\mathrm{r}}\right)$. Quando $\mathrm{s}_{\mathrm{bb}}$ for menor que $\mathrm{s}_{\mathrm{r}}$, é adequado aplicar a equação (2), pois esta expressão se baseia na amplitude de um intervalo de confiança de $95 \%$, levando em consideração à 
variância de repetibilidade das medições utilizadas no estudo de homogeneidade entre os recipientes (ABNT ISO GUIA 35:2012).

A técnica estatística utilizada para determinar a variabilidade entre os recipientes e dentro do recipiente é a Análise de Variâncias - ANOVA.

\subsection{Estudo de estabilidade}

Baseando-se no BAM (2010) e ABNT ISO GUIA 35 (2012), considera-se que 0 ensaio de estabilidade visa identificar eventuais alterações da propriedade em estudo, em um período de tempo compatível com o uso do material produzido. Esse estudo é feito no material já embalado, lacrado e em condições que simulem seu armazenamento e transporte. Entre os principais fatores estudados estão: a temperatura, umidade, contaminação externa, entre outros.

Para tanto, são avaliadas eventuais alterações temporais no parâmetro em questão. Desta forma, o ensaio de estabilidade é realizado com seleção aleatória de recipientes sob 2 condições distintas (BAM, 2010; ABNT ISO GUIA 35:2012):

1- Condições de armazenamento;

2- Condições de transporte.

1- As condições específicas de armazenamento são avaliadas pelo estudo de estabilidade em longo prazo, geralmente durante um período de tempo de 24 a 36 meses. Recomenda-se selecionar uma faixa de temperatura que atenda as condições de uso do material de tal modo que algum grau de instabilidade que possa ser detectado seja insignificante. O número mínimo de recipientes usados deve estar em torno de 10 a 12 para cada temperatura, com pelo menos 5 a 6 pontos no tempo considerando-se o lote produzido (BAM, 2010; ABNT ISO GUIA 35:2012).

2- O estudo de estabilidade em curto prazo é realizado com objetivo de identificar a existência de alterações, nas propriedades de um material de referência durante o transporte sob condições especificadas. Neste caso são 
utilizadas diferentes faixas de temperatura a fim de estudar o efeito da mesma sobre os níveis de propriedade do material. Desta forma, recomendá-se a seleção de 6 a 10 recipientes, para cada temperatura, por um período de 1 a 2 meses com 3 a 5 pontos no tempo (BAM, 2010; ABNT ISO GUIA 35:2012).

Existem dois esquemas experimentais para a realização do estudo de estabilidade. O modelo clássico e o modelo isócrono.

No caso do modelo clássico os recipientes individuais são deixados ao mesmo tempo sob condições idênticas e avaliados no transcorrer do tempo determinado para cada faixa de temperatura (exemplo 2 recipientes permanecem a $5{ }^{\circ} \mathrm{C}$ por 7 dias e após são analisados). Assim, o ensaio é realizado sob condições de reprodutibilidade o que pode acarretar uma incerteza relativa elevada, pois é considerada a instabilidade do sistema de medição (BAM, 2010; ABNT ISO GUIA 35:2012).

O modelo isócrono de estudo de estabilidade tem sido cada vez mais empregado, pois reduz a dispersão dos pontos no tempo e proporciona uma incerteza relativa menor, já que considera a diferença entre a repetibilidade e a reprodutibilidade do método de medição adotado. Neste modelo os recipientes permanecem nas temperaturas de referência pela ordem de tempo, do maior para o menor e são analisados ao final do período estabelecido (por exemplo, o frasco a $5{ }^{\circ} \mathrm{C}$ é deixado primeiro a 2 meses e após, a 1 mês no final são analisados no mesmo dia) (BAM, 2010; ABNT ISO GUIA 35:2012).

A estimativa da incerteza devida à estabilidade em curto prazo (Usts) e longo prazo (ults) é obtida multiplicando-se o valor do erro padrão $\left(s_{(}\left(b_{1}\right)\right)$ da variável $X$ obtido na análise de regressão linear dos dados de estabilidade para 0 analito testado por um tempo de $t$ (meses), conforme a equação 3 (ABNT ISO GUIA 35:2012):

$$
u_{s t s / t s}=\mathrm{s}(\mathrm{b} 1) \cdot t
$$

Onde: $\mathrm{u}_{\mathrm{sts} / \mathrm{ts}}=$ incerteza para estabilidade; $\mathrm{s}(b 1)=$ desvio padrão de $b 1 ; \mathrm{t}=$ tempo (meses). 


\subsection{Métodos analíticos empregados na determinação de elementos metálicos em amostras biológicas}

Dentre os métodos analíticos atualmente empregados para a análise de metais em amostras biológicas, as mais utilizadas são: a espectrometria de absorção atômica (AAS) com chama, vapor frio, geração de hidretos e forno de gráfite, a espectrometria de massa com plasma indutivamente acoplado (ICPMS), a espectrometria de emissão óptica com plasma indutivamente acoplado (ICPOES), ativação por nêutrons (NAA), a emissão de raios- $X$ induzida por partículas (PIXE) (Giné, 1999; Skoog et al, 2006; Oliveira, 2006; Becker, 2007; Ulrich, 2011).

No escopo deste trabalho empregou-se os métodos de absorção atômica utilizando-se como técnicas de atomização o vapor frio para determinação de $\mathrm{Hg}$, a geração de hidretos para determinação de As e espectrometria de massas com plasma indutivamente acoplado no modo de baixa resolução para a determinação de $\mathrm{Cd}$ e $\mathrm{Pb}$.

\subsubsection{Espectrometria de Absorção Atômica (AAS)}

A Espectrometria de Absorção Atômica (AAS-Atomic Absortion Espectrometry) é uma técnica espectroanalítica para determinação quantitativa de elementos, cujo princípio envolve a medida da absorção da intensidade da radiação eletromagnética proveniente de uma fonte de luz, por átomos livres no estado gasosos (estado fundamental) (Welz \& Sperling, 2005).

Os mensurandos são transformados para o estado de átomos livres em um dispositivo de atomização pelo aumento da energia térmica aptos a absorver radiação de mensurandos específicos. Para esta finalidade, uma lâmpada de catodo oco feita dos mesmos mensurandos a serem investigados é introduzida no caminho do raio do espectrômetro atômico com dispositivo de atomização e um detector. Dependendo da concentração do mensurando na amostra, a intensidade 
de radiação da lâmpada de catodo oco é absorvida pelos átomos formados. Dois fotomultiplicadores medem a intensidade da radiação não atenuada e da radiação após deixar o dispositivo de atomização durante o fornecimento de uma solução de amostra. A concentração do mensurando pode ser calculada à partir da diferença da duas intensidades (Welz \& Sperling, 2005).

A FIG. 5 representa um modelo de esquema simplificado do funcionamento de um espectrofotômetro de absorção atômica.

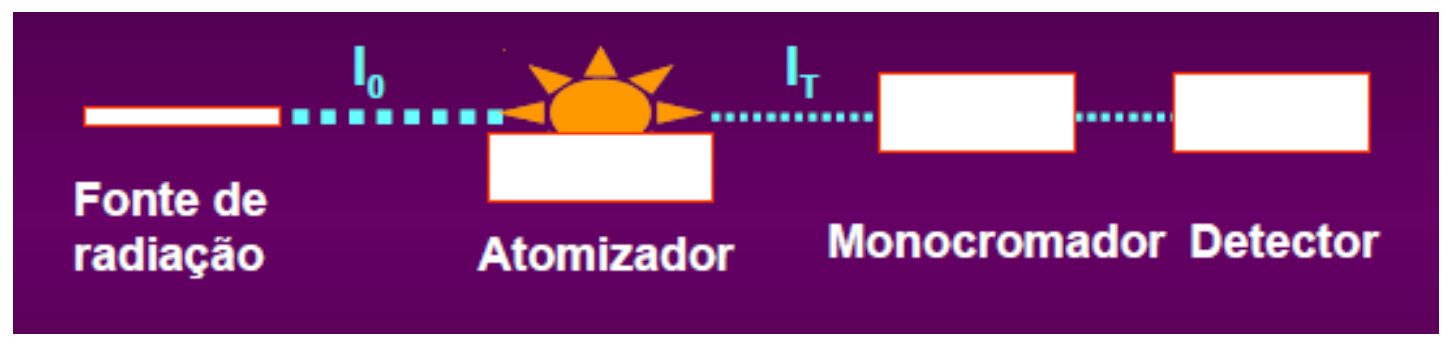

FIGURA 5 - Esquema simplificado de um espectrofotômetro de Absorção Atômica

\subsubsection{Espectrometria de Massas com Fonte de Plasma induzidamente acoplada (ICP-MS)}

$\mathrm{Na}$ espectrometria de massas (ICP-MS), a separação dos isótopos pelo ICP-MS depende da formação de íons positivos monovalentes que são separados em função da razão massa/carga do isótopo.

O equipamento é constituído de 5 partes principais: sistema de introdução de amostras, fonte de ionização, sistema de focalização, analisador de massa e sistema de detecção de íons (Giné, 1999; Oliveira, 2006; Becker, 2007; Ulrich, 2011 ) (FIG. 6). 


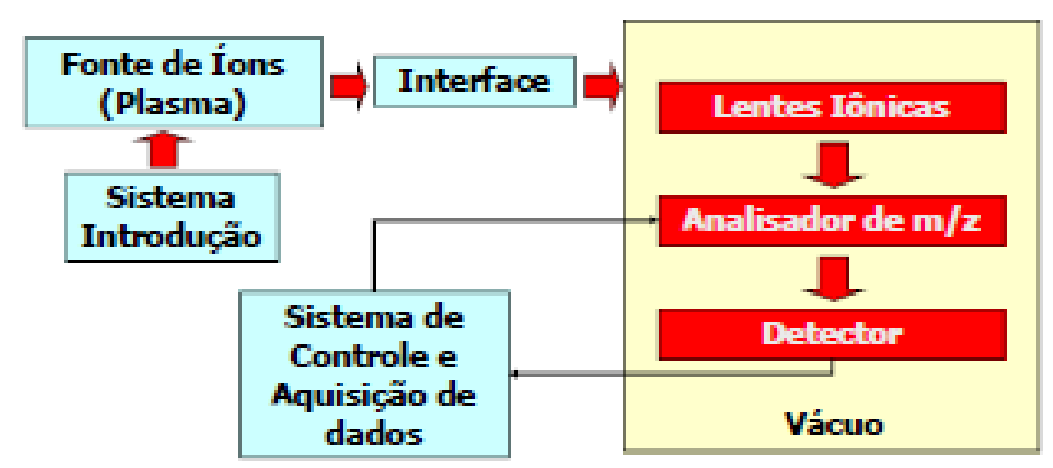

FIGURA 6- Componentes principais de um espectrômetro de massas (Ulrich, 2011)

O ICP é a fonte de íons do sistema e opera à pressão atmosférica. Em uma das extremidades do ICP encontra-se acoplado o sistema de introdução de amostras, que é o meio pelo qual a amostra (na forma sólida, líquida ou gasosa) é transformada em aerossol, antes de ser introduzidas no plasma, onde ocorre o processo de atomização - ionização do material. Ao deixarem a região do plasma, os íons encontram a interface, onde ocorre a transição do sistema à pressão atmosférica ao sistema de alto vácuo. Depois, o feixe atravessa um sistema de lentes de focalização e alcança o sistema analisador que faz a separação dos isótopos em função da razão massa/carga. Assim, ao atingirem os detetores, os íons geram uma corrente elétrica produzindo um sinal cuja intensidade está diretamente relacionada à quantidade de íons introduzida no sistema (Shibuya, 1999).

\subsection{Tratamento dos dados}

Os modelos estatísticos utilizados devem atender aos objetivos do projeto baseando-se na natureza dos dados (distribuição da normalidade - testes probabilísticos, avaliação de dados discrepantes, avaliação da tendência, emprego de testes estatísticos de hipóteses para comprovar a homogeneidade e estabilidade) (ABNT ISO GUIA 35:2012; ABNT NBR ISO/IEC 17043:2011).

A distribuição da normalidade é avaliada por testes estatísticos probabilísticos que verificam se a população de dados apresenta uma distribuição 
normal. Existem vários testes e são realizados em função do $\mathrm{n}$ de amostragem (ISO 5725-2, 2005; ABNT ISO GUIA 35:2012; ABNT NBR ISO/IEC 17043:2011).

Os resultados discrepantes podem ocorrer entre o conjunto de dados e convém que sejam descartados ou, em algumas situações como erros de cálculo, estes podem ser substituídos por dados corrigidos. O ideal é que sejam aplicados pelo menos dois testes estatísticos antes da remoção dos dados. É indicado que os valores discrepantes em variâncias (ordens de magnitude diferentes) só sejam removidos em casos extremos, isto é, quando forem incompatíveis com o conjunto de dados. Normalmente, novas medições adicionais não são aceitáveis, pois as condições em que os dados foram obtidos não são mais as mesmas para todos os resultados (ABNT ISO GUIA 35:2012; ABNT:NBR ISO/IEC 17043:2011; AMC, 1989a e 1989b).

Os resultados obtidos no estudo de homogeneidade podem ser avaliados através da ferramenta estatística ANOVA-análise de variâncias fator único, desde que seja utilizado um método de medição com precisão compatível com a técnica de medição utilizada e se possível com um conjunto de dados que apresente um $n>10$. A população de dados deve apresentar distribuição normal com variâncias da mesma ordem de magnitude. A ANOVA está disponível na maioria dos softwares estatísticos, e neste caso considera-se como homogêneo o material

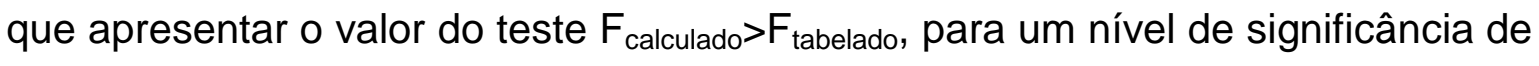
$95 \%$.

Outra abordagem para a avaliação dos resultados do estudo de homogeneidade foi proposta por Fearn \& Thompson (2001), "teste de Homogeneidade suficiente". Neste teste avalia-se um limite de desvio padrão analítico = Gan em relação ao "desvio padrão esperado" para o dado op. Assim a razão de $\sigma_{\text {an }}$ por $\sigma_{p}$ deve ser menor que 0,5 , ou seja, a razão $\sigma_{a n} / \sigma_{p}<0,5$. 0 cálculo do valor crítico para comparação é outro ponto importante a ser considerado. Este valor é calculado a partir da obtenção dos valores da variância permissível entre-recipientes $\left(\sigma^{2}\right.$ all), da variância analítica $\left(S^{2}\right.$ an) e dos fatores $F_{1}$ e $F_{2}$, (obtidos na tabela gerada pela ANOVA) da estimativa da variância entre recipientes $\left(S^{2}\right.$ sam) e do chamado $\mathrm{c}$ (valor crítico calculado para o teste) obtido 
pela multiplicação $F_{1} \times \sigma^{2}$ all e $F_{2} \times S^{2}$ an, em seguida somam-se os resultados, $F_{1}$ e $F_{2}$, os quais são usados para testar "homogeneidade suficiente".

O material será considerado homogêneo se " $\mathrm{S}^{2}$ sam $<\mathrm{C}$ " (o teste de homogeneidade foi aceito e a homogeneidade é comprovada), quando " $\mathrm{S}_{\text {sam }}^{2}>\mathrm{C}$ " o teste de homogeneidade falhou e a homogeneidade não pode ser comprovada (Fearn \& Thompson, 2001).

Para a avaliação dos dados obtidos pelo estudo de estabilidade, a análise de tendências é frequentemente utilizada. Neste caso procura-se verificar a adequação dos dados ao modelo de distribuição linear empregando-se o teste $F$ (van der Veen e Pauwels, 2001; Lisinguer, 2001; ABNT ISO GUIDE 35:2012).

O modelo de distribuição linear é expresso pela seguinte equação:

$\mathrm{Y}=\beta_{0}+\beta_{1} X+\varepsilon$

Onde: $\beta_{0}$ é o coeficiente linear, $\beta_{1} \circ$ coeficiente de regressão, e $\varepsilon$ indica o componente de erro aleatório, $X$ variável independente, indicará o tempo e $Y$ variável dependente, indicará o valor de propriedade do MR.

Desta forma se o material for estável $\beta_{1}$ tenderá para zero. Como são utilizados mais de um recipiente por ponto no tempo e devido à repetição da medição mais de um valor de $Y$ estará disponível para cada $X$, logo é recomendável que estes aspectos sejam incluídos no modelo de estudo, podendo ser utilizado no caso de tendência o resultado médio de todos os recipientes no tempo X (van der Veen e Pauwels, 2001; Lisinguer, 2001; ABNT ISO GUIA 35:2012).

De forma direta estes parâmetros de regressão podem ser calculados a partir das expressões dadas abaixo. No caso do estimador para a inclinação $\left(b_{1}\right)$, as seguintes expressões podem ser utilizadas: 


$$
b_{1}=\frac{\sum_{i=1}^{n}\left(X_{i}-\bar{X}\right)\left(Y_{i}-\bar{Y}\right)}{\sum_{i=1}^{n}\left(X_{i}-\bar{X}\right)^{2}}
$$

A partir da expressão anterior a estimativa para a intersecção será calculada pela equação 6:

$$
b_{0}=\bar{Y}-b_{1} \bar{X}
$$

Dessa forma, a análise de erro, fornecerá as expressões para os cálculos dos desvios padrão em $b_{1}$ e $b_{0}$. Assim o desvio padrão estimado de $b_{1}$ será dado por:

$$
s\left(b_{1}\right)=\frac{s}{\sqrt{\sum_{i=1}^{n}\left(X_{i}-\bar{X}\right)^{2}}}
$$

Onde:

$$
s^{2}=\frac{\sum_{i=1}^{n}\left(Y_{i}-b_{0}-b_{1} X_{i}\right)^{2}}{n-2}
$$

A variância estimada de $b_{0}$ será dada por:

$$
V\left(b_{0}\right)=V\left(\bar{Y}-b_{1} \bar{X}\right)=s^{2}\left[\frac{1}{n}+\frac{\bar{X}^{2}}{\sum_{i=1}^{n}\left(X_{i}-\bar{X}\right)^{2}}\right]=\frac{s^{2} \sum_{i=1}^{n} X_{i}{ }^{2}}{n \sum_{i=1}^{n}\left(X_{i}-\bar{X}\right)^{2}}
$$

Observando-se as equações nota-se que $b_{1}$ e $\bar{Y}$ não estão correlacionados, logo com base no desvio padrão de $b_{1}$ associado a um fator $t$ (test $\mathrm{t}$ ) para $\mathrm{n}-2$ graus de liberdade, testa-se a significancia de $b_{1}$ para a tendência dos dados, através do cálculo do desvio de $b_{1} \mathrm{~s}\left(b_{1}\right)$ (van der Veen e Pauwels, 2001; Lisinguer, 2001; ABNT ISO GUIA 35:2012). 
Outro método empregado para avaliar a significancia de regressão dos dados é através de softwares de cálculo, os quais irão fornecer uma tabela para o test $F$ (ABNT ISO GUIA 35:2012) (TAB. 2).

TABELA 2 - Tabela de análise da variância para regressão linear

\begin{tabular}{lcccc}
\hline Fonte de variação & $\begin{array}{c}\text { Graus de } \\
\text { lberdade }\end{array}$ & $\begin{array}{c}\text { Soma } \\
\text { quadrática } \\
S Q\end{array}$ & $\begin{array}{c}\text { Média } \\
\text { quadrática } \\
M Q\end{array}$ & $F$ \\
\hline $\begin{array}{l}\text { Devido à regressão } \\
\text { Sobre a regressão }\end{array}$ & 1 & $\sum_{i=1}^{n}\left(\hat{Y}_{i}-\bar{Y}\right)^{2}$ & $M Q$ reg & $F=\frac{M Q_{\text {reg }}}{s^{2}}$ \\
(residual) & $n-2$ & $\sum_{i=1}^{n}\left(Y_{i}-\hat{Y}_{i}\right)^{2}$ & $s^{2}=\frac{S Q}{n-2}$ \\
$\begin{array}{l}\text { Total, corrigido para } \bar{Y} \\
\text { médio }\end{array}$ & $n-1$ & $\sum_{i=1}^{n}\left(Y_{i}-\bar{Y}\right)^{2}$ & \\
\hline & Fonte: (ISO GUIDE 35, 2006)
\end{tabular}

A vantagem de se empregar a tabela $F$, ao invés do método utilizando o teste $t$, é que a mesma é gerada pela maioria dos softwares e pode ser estendida a outros modelos de regressão, o que a torna amplamente aplicável (ABNT ISO GUIA 35:2012).

O resultado é considerado significativo, quando o desvio padrão de repetitividade de medição, possivelmente em conjunto com a homogeneidade entre recipientes, for suficientemente pequeno. Assim pode ser demonstrado que, se o desvio padrão de repetibilidade for comparável àquele do estudo de homogeneidade e da caracterização do material (por exemplo, a determinação do valor da propriedade), isto significa que este requisito está sendo atendido no que concerne à repetitividade de medição (ABNT ISO GUIA 35:2012). 
Deste modo, o efeito da heterogeneidade entre os recipientes pode ser reduzido tomando-se múltiplos recipientes em cada ponto no tempo. Essa abordagem pode ser necessária quando o desvio padrão de homogeneidade $s_{b b}$ é igual ou maior que a repetitividade da medição. Se uma tendência for observada, isto significa, geralmente, que o material não poderá ser certificado (ABNT ISO GUIA 35:2012).

Convém que para a certificação de um material seja adotado um critério baseado na incerteza (esperada) associada ao valor da propriedade do material de referência, no tempo (desejado) de prateleira e na tendência durante este período (ABNT ISO GUIA 35:2012).

Se a tendência for significativa durante o tempo (desejado) de prateleira com relação à incerteza associada ao valor da propriedade do $\mathrm{MR}$, o material não poderá ser certificado devido à ausência de estabilidade ou, então, recomenda-se diminuir o tempo de prateleira (ABNT ISO GUIA 35:2012).

\subsection{Caracterização de um material de referência}

Os materiais de referência podem ser caracterizados baseando-se na exatidão de uma medida, com a melhor estimativa possível do "valor verdadeiro". Além disso, a precisão da medida não deve apresentar um desvio maior do que a sua incerteza de medição declarada (ABNT ISO GUIA 35:2012).

São apresentados na ABNT ISO GUIA 34 (2012), algumas abordagens para a caracterização de alguns grupos de MR. A norma sugere a utilização de quatro abordagens básicas para a caracterização, as quais podem ser implementadas de diversas formas por produtores e órgãos de certificação como as que se seguem:

1. Medição por meio de um método (primário) único em um laboratório único;

2. Medição por meio de dois ou mais métodos de referência independentes em um laboratório, ou vários laboratórios; 
3. Medição por meio de uma rede de laboratórios empregando um ou mais métodos com rastreabilidade;

4. Uma abordagem com método específico que fornece apenas os valores de propriedade específicos do método, utilizando uma rede de laboratórios (ABNT ISO GUIA 34, 2012).

Entretanto, estas abordagens não abrangem todas as possibilidades de produção de um MR e o estabelecimento de seus valores de propriedade, incluindo as incertezas associadas. Deste modo, a caracterização também pode ser realizada utilizando-se técnicas cujos resultados de medição possuem robustez e rastreabilidade.

\subsubsection{Cálculo de Incertezas}

A incerteza de medição pode ser interpretada como a "dúvida" em relação à qualidade de um resultado de medição. Segundo o Vocabulário Internacional de Metrologia (VIM) é o "parâmetro não negativo que caracteriza a dispersão dos valores atribuídos a um mensurando, com base nas informações utilizadas" (Ulrich et al., 2003, apud VIM, 2012).

A estimativa da incerteza é geralmente realizada segundo os princípios estabelecidos pelo Guia para a Expressão da Incerteza de Medição ISO-GUM (GUM, 2008). O procedimento é baseado na identificação e quantificação, da influência de cada parâmetro analítico utilizado durante o processo de medição (Ulrich et al., 2003, apud GUM, 2008).

O cálculo é realizado a partir da identificação dos parâmetros intermediários da mensuração e as possíveis dispersões envolvidas nessa medição; combinação das contribuições de cada parâmetro para o cálculo da incerteza padrão combinada; aplicação do fator abrangência, $k$, para o cálculo da incerteza expandida, $U$, até a apresentação dos resultados (Moreira, 2010, apud GUM, 2008). 
Este cálculo pode ser realizado por softwares, planilhas geradas por excel ou guias para cálculo de incertezas (Ulrich, 2011).

\subsection{Incerteza associada ao valor certificado}

O cálculo da incerteza do valor certificado de um material de referência considera a incerteza da homogeneidade, estabilidade a longo e curto prazo e a incerteza da caracterização do lote. Para tanto se recomenda utilizar a incerteza padrão combinada, já que esta leva em consideração todos os fatores que contribuem para a incerteza associada aos valores de propriedade do MRC (ABNT ISO GUIA 35:2012).

Logo a equação 10 expressa a incerteza associada ao valor de propriedade do material de referência:

$U_{\mathrm{MRC}}=k \sqrt{u_{\mathrm{car}}^{2}+u_{\mathrm{bb}}^{2}+u_{\mathrm{lts}}^{2}+u_{\mathrm{sts}}^{2}}$

Onde: $\boldsymbol{k}$ = fator de abrangência baseado em um nível de confiança ideal de 95\%; $\boldsymbol{u}_{\text {car }}=$ incerteza de caracterização do mensurando obtida pela técnica analítica usada; $\boldsymbol{u}_{b \boldsymbol{b}}=$ incerteza padrão da homogeneidade entre frascos; $\boldsymbol{u}_{t / s}=$ incerteza padrão da estabilidade em longo prazo; $\boldsymbol{u}_{\text {sts }}=$ incerteza padrão da estabilidade em curto prazo.

Neste trabalho foi realizado apenas o estudo de estabilidade em curto prazo para o cálculo da incerteza, contudo a estabilidade foi monitorada até o final do ensaio de proficiência. 


\subsection{Ensaios de Proficiência}

Segundo o ILAC-G13:8 (2007), os ensaios de proficiência fazem parte do rol de estudos de comparação interlaboratoriais podendo ser conduzidos para diversos fins, os quais incluem a verificação da eficácia e precisão de métodos de ensaio, verificação do desempenho individual do pessoal de laboratório, determinação das características de um material para um determinado grau de precisão (por exemplo, a preparação de materiais de referência).

De acordo com ILAC-G13:8 (2007); ABNT NBR ISO/IEC 17043, (2011), um item de ensaio de proficiência pode ser uma amostra, um produto, um artefato, um material de referência, um equipamento, um padrão, um conjunto de dados ou outra informação utilizada pelo provedor do ensaio de proficiência.

Os requisitos técnicos e administrativos para organização de ensaios de proficiência são de responsabilidade do laboratório que conduz o programa, o qual deve assegurar que todas as tarefas envolvidas na prestação do mesmo tenham rastreabilidade e confidencialidade, onde de preferência sejam rastreáveis ao SI (ILAC-G13:8, 2007; ABNT NBR ISO/IEC 17043:2011).

É conveniente que o fornecedor do programa apresente todas as informações necessárias para que os participantes selecionem corretamente os programas que sejam apropriados para seu escopo de ensaios cumprindo com os requisitos de interesse para o propósito de acreditação (ABNT NBR ISO/IEC 17043:2011).

Os resultados fornecidos pelos laboratórios participantes de um programa são registrados e analisados por métodos estatísticos válidos que identifiquem a presença de erros e valores discrepantes (outliers) e que estejam de acordo com o propósito do programa, afim de fornecer resultados consistentes (ISO/IEC 13528, 2005; ABNT NBR ISO/IEC 17043:2011; ILAC-G13:08, 2007; ABNT ISO GUIA 35:2012; THOMPSON et al., 2006).

Deste modo, as estatísticas de desempenho devem proporcionar aos participantes de um programa, a compreensão clara e objetiva da qualidade de 
seus resultados em um campo particular ou dentro do conjunto de resultados obtidos dentro do ensaio (ABNT:NBR ABNT NBR ISO/IEC 17043:2011).

\subsubsection{Protocolos utilizados neste trabalho para o cálculo estatístico do ensaio de proficiência}

Neste trabalho, seguiram-se os protocolos estabelecidos pelas normas ISO/IEC 13528 (2005); ABNT: NBR ISO/IEC 17043 (2011); ILAC-G13:08 (2007); ABNT ISO GUIA 35 (2012); e o protocolo harmonizado para ensaios de proficiência IUPAC, THOMSON et al. (2006).

Estes sugerem o uso de técnicas estatísticas robustas, para cálculo da média, desvio-padrão e incerteza para os resultados emitidos pelos participantes de ensaios de proficiência, pois estas minimizam a influência de resultados espúrios.

Desta forma, etapa inicial deste processo, consiste na aplicação de testes para a identificação de valores espúrios (outliers) no conjunto de resultados recebidos. Os testes de Dixon e Grubbs costumam ser os mais utilizados em exercícios interlaboratoriais (AMC, 2001).

O teste de Dixon compara valores individuais obtidos por um operador ou valores médios obtidos por vários operadores, podendo comparar também as diferenças entre dois resultados obtidas por vários operadores. Este teste é um bilateral, ou seja, são testados os valores mínimos e máximos.

Logo, ao se analisar um conjunto de resultados $Z(h), h=1,2, \ldots H$, estes são agrupados em ordem crescente, utilizando o seguinte critério de avaliação para os dados:

Se o total de resultados estiver entre 3 e 7 ,

$$
\text { Dcalc }=\frac{Z(2)-Z(1)}{Z(H)-Z(1)} \quad \text { e } \quad \frac{Z(H)-Z(H-1)}{Z(H)-Z(1)}
$$


Se o total de resultados estiver entre 8 e 12 ,

$$
\text { Dcalc }=\frac{Z(2)-Z(1)}{Z(H-1)-Z(1)} \text { e } \frac{Z(H)-Z(H-1)}{Z(H)-Z(2)}
$$

Se o total de resultados estiver entre 13 e 40 ,

$$
\text { Dcalc }=\underline{Z(3)-Z(1)} \begin{array}{ll}
Z(H-2)-Z(1) & \frac{Z(H)-Z(H-2)}{Z(H)-Z(3)}
\end{array}
$$

Se Dcalc< Dtab 5\%, o valor não é rejeitado.

Se Dtab 1\% > Dcalc > Dtab 5\%, o valor é considerado suspeito.

Se Dcalc > Dtab 1\%, o valor é considerado disperso.

Os valores críticos deste teste estatístico encontram-se tabelados para 95 e $99 \%$ de confiança (ISO 5725, 1994).

O teste de Grubbs também se inicia com a ordenação dos resultados em ordem crescente. Contudo a avaliação os dados é realizada a partir da proposição da hipótese de que o menor valor, x1, ou o maior valor, xn, seja considerado como valor suspeito (outlier). Assim considerando como T o valor testado, este é calculado da seguinte forma:

$$
\mathrm{T}=\frac{\bar{X}-X_{1}}{s} \quad \text { ou } \quad \mathrm{T}=\underline{X}_{\underline{n}}-\overline{\bar{X}}
$$

O risco aceitável de falsa rejeição é de $5 \%$ e os valores comparados com os valores Tabelados.

O cálculo do valor designado e do desvio padrão, podem ser obtidos com a análise robusta através do emprego do algoritmo A (Hubber), ou estatísticas ponderadas como o cálculo da mediana e da MAD (desvio padrão da mediana) (ABNT NBR ISO/IEC 13528:2005; Jeng, 2010; ABNT NBR ISO/IEC 17043:2011).

O algoritmo A (Hubber) é calculado da seguinte forma: após a avaliação e retirada de valores de concentração considerados outliers, os valores são colocados em ordem crescente e procede-se ao cálculo da mediana de $\mathrm{x}_{1}$ (valor 
de concentração reportado pelos laboratórios) $=\left(x^{*}\right)$ e do desvio padrão (s), empregando-se as equações 15 e 16.

$$
\begin{aligned}
& x^{*}=\text { mediana } x_{1} \\
& s=1,483 \times \text { med }\left|x_{1}-x^{*}\right|
\end{aligned}
$$

Onde: med é a mediana; $\mathbf{x}_{1}$ é o valor de concentração reportado pelo laboratório. A partir destes dados é calculado o valor do fator $F 1$ pela equação 17 , para que sejam estimados os valores máximos e mínimos de concentração dos elementos.

$$
F_{1}=1,5 s^{*}
$$

Logo os valores superior e inferior são dados por:

valor superior $=\mathrm{x}^{*}+F_{1}$

valor inferior $=\mathrm{x}^{*}-F_{1}$

Cada valor de concentração fornecido pelos laboratórios é comparado com estes valores e aqueles que se apresentarem acima ou abaixo, são considerados discrepantes (outliers) e são retirados. 20.

Em seguida é calculado o novo desvio padrão robusto $\left(\mathrm{s}^{*}\right)$, pela equação

$$
S^{*}=1,134 \times s
$$

O procedimento de cálculo é aplicado para os resultados de cada um dos elementos de interesse do ensaio, estimando-se assim os valores de média robusta (valor designado) e desvio padrão robusto (Jeng, 2010).

De posse dos valores designados, o desempenho dos laboratórios pode ser realizado pelo Índice $z$, erro normalizado e avaliação dos gráficos de Youden (ABNT NBR ISO/IEC 13528:2005; ABNT NBR ISO/IEC 17043:2011; ILACG13:08, 2007; THOMPSON et al., 2006). 
O Índice z (z-score) é calculado pela equação 21 e interpretado da seguinte maneira (ISO/IEC 13528, 2005; ABNT NBR ISO/IEC 17043:2011; THOMPSON et al., 2006):

$|z| \leq 2-$ Resultados satisfatórios,

$2<|z|<3$ - Resultados questionáveis,

$|z| \geq 3-$ Resultados insatisfatórios.

$z=\frac{\left(X_{l a b}-X_{r e f}\right)}{\sigma}$

Onde: $\mathbf{x}_{\mathrm{lab}}$ é o valor médio do laboratório participante; $\mathbf{x}_{\mathrm{ref}}$ é o valor designado e $\sigma$ é o desvio obtido para o ensaio de proficiência.

A partir destes dados, os laboratórios são capazez de verificar seu desempenho em relação aos valores de consenso e aos valores obtidos pelo grupo de laboratórios participantes (ABNT NBR ISO/IEC 13528: 2005).

O erro normalizado é calculado a partir dos resultados enviados pelos laboratórios acompanhados de suas incertezas expandidas $\left(x_{\text {lab }} \pm U_{\mathrm{lab}}\right)$ e dos resultados de referência do laboratório promotor do ensaio acompanhados de suas incertezas $\left(\mathrm{x}_{\text {ref }} \pm U_{\text {reff }}\right)$. Este teste permite observar a variação existente entre o resultado obtido pelo laboratório, associado a sua incerteza de medição e o valor de consenso obtido pelo programa através da estatística robusta, associada a sua incerteza obtida pela mesma estatística (ISO/IEC 13528, 2005).

O cálculo é realizado de acordo com a equação 22 (ABNT NBR ISO/IEC 13528:2005; ABNT NBR ISO/IEC 17043:2011; ILAC-G13:08, 2007; THOMPSON et al., 2006).

$$
E n=\frac{V_{\text {lab }}-V_{r e f}}{\sqrt{\left(U^{2} \text { lab }+U^{2}{ }_{r e f}\right)}}
$$


Onde: $\mathbf{V}_{\text {lab }}$ é o valor obtido pelo laboratório participante; $\mathbf{V}_{\text {ref }}$ é o valor de designado; $\mathbf{U}_{\text {lab }}$ é a incerteza expandida do laboratório participante; $\mathbf{U}_{\text {ref }}$ é a incerteza expandida do valor designado.

Considera-se satisfatório o resultado do erro normalizado que satisfaz a seguinte condição:

$-1<$ En $<+1$, ou seja $|E n| \leq 1$ - Resultado satisfatório;

En $<-1$ ou En $>+1$ - Resultado não satisfatório.

A técnica da elipse de confiança (Diagrama de Youden) permite que a interpretação dos resultados seja feita por meio da visualização simples e rápida, embora não forneça os parâmetros de repetibilidade e reprodutibilidade. 0 diagrama é feito para cada elemento de interesse baseado na dispersão dos resultados do laboratório. Cada laboratório é representado por um ponto onde a abscissa é a média das medições obtidas para a amostra $A$ e a ordenada é a média das medições obtidas para a amostra B (duplicatas) (Chui, 2004).

O método permite a avaliação das replicas dos resultados obtidos pelo próprio laboratório, frente ao valor de consenso (Chui, 2004).

A elipse é traçada de modo que a probabilidade de um ponto estar situado dentro da elipse ser igual a 100x(1- $\alpha) \%$. Assim, a dispersão dos pontos ao longo do eixo maior está associada aos erros sistemáticos, enquanto que ao longo do eixo menor está associada aos erros aleatórios (Chui, 2004).

Portanto para os pontos dentro da elipse, se a dispersão é uniforme em um angulo de $45^{\circ}$ em relação ao eixo das abscissas, o desempenho do laboratório pode ser considerado adequado. Se a dispersão é uniforme em um eixo maior tendendo à posição vertical ou horizontal não é possível afirmar que o laboratório apresente desempenho satisfatório em virtude da possibilidade da existência de problemas com uma das amostras (Chui, 2004).

Para os pontos fora da elipse, afastados do eixo maior, o erro aleatório é mais significativo podendo ser atribuído à variabilidade do laboratório devido a erros do operador, de leitura, do cálculo da conversão de valores, da transcrição 
de dados entre outros. Pontos externos, próximos ao eixo maior da elipse, indicam erros sistemáticos (Chui, 2004).

A capacidade analítica pode ser definida como a capacidade de um laboratório determinar satisfatoriamente os elementos presentes em uma amostra. Sua determinação é feita baseando-se na porcentagem de elementos analisados por um laboratório, multiplicada pelo percentual de resultados satisfatórios obtidos pelo índice z-score para os elementos analisados (INCQS, 2012).

Viabilidade analítica corresponde à viabilidade de determinação de um elemento pelo conjunto de laboratórios participantes de uma rodada de ensaio de proficiência, esta também é calculada com base nos resultados obtidos pelo índice z-score, considerando cada elemento separadamente (INCQS, 2012).

Tanto o teste de capacidade analítica, quanto o teste de viabilidade analítica consideram em sua avaliação, o desempenho do laboratório em relação a sua tomada de decisão quanto aos procedimentos que são adotados para se chegar ao resultado final da determinação do elemento em questão.

Por tudo isso, a utilização de ensaios de proficiência, num programa de controle de qualidade constitui uma fonte de informação, que permite ao laboratório garantir a eficácia do controle de qualidade implementado internamente. Além de contribuir como referência externa de exatidão dos resultados obtidos e da possibilidade da sua comparação com os fornecidos por outros laboratórios. 


\section{MATERIAL E MÉTODOS}

\subsection{Materiais}

Placa de Petri;

Dessecador com sílica gel;

Frasco com tampa de $30 \mathrm{~mL}$;

Abridor de lata doméstico;

Balões volumétricos de vidro de $100 \mathrm{~mL}$;

Béquer de vidro $100 \mathrm{~mL}$;

Papel manteiga para pesagem das amostras;

Espátula plástica tamanho pequeno;

Proveta de $10 \mathrm{~mL}$;

Pipeta graduada de vidro de $10 \mathrm{~mL}$;

Frasco plástico com capacidade de 100 mL;

Tesoura de aço inoxidável;

Facas de corte de aço inoxidável;

Filme plástico;

Embalagem plástica metalizada tipo de poliéster polietileno para seladora manual TradBorß.

Ponteiras descartáveis de $1 \mathrm{~mL}$;

Micropipetas de $10 \mu \mathrm{L}, 200$ a $1000 \mu \mathrm{L}, 2$ a $10 \mathrm{~mL}$. 


\subsection{Equipamentos}

Espectrômetro de Massas com fonte de plasma induzidamente acoplado Element 2, Finnigam mat ${ }^{\circledR}$, Alemanha;

Espectrometro de absorção atômica; sistema para geração de vapor a frio em injeção em fluxo SpectrAA 220 fast sequential, Varian®, Estados Unidos;

Ciclotron Cyclone 30 da Ion Beam Applications;

Balança analítica AL500C, resolução: 0,001 g, Marte®;

Balança semi-analítica BG2000, resolução: 0,02 g, Gehaka®;

Geladeira 280 L, Brastemp®;

Freezer F26, 280 L, Electrolux®;

Multiprocessador de alimentos walita®;

Misturador de massas (batedeira) Walita $\AA_{\text {; }}$

Separador de fases, de vidro, com esferas de vidro;

Suporte universal com garra;

Célula de absorção de quartzo;

Suporte para a célula de absorção;

Termômetro com escala até $110^{\circ} \mathrm{C}$;

Seladora Manual;

Capela com exaustão;

Chapa de aquecimento. 


\subsection{Reagentes}

Os reagentes utilizados neste trabalho apresentam baixo teor de mercúrio, arsênio, cádmio e chumbo.

Ácido Clorídrico (HCl) Merck (32\% v/v);

Ácido Perclórico $\left(\mathrm{HClO}_{4}\right)$ Merck $(72 \% \mathrm{v} / \mathrm{v})$;

Ácido Nítrico $\left(\mathrm{HNO}_{3}\right)$ Merck (65 \% v/v);

Ácido Sulfúrico $\left(\mathrm{H}_{2} \mathrm{SO}_{4}\right)$ Merck $(98 \% \mathrm{v} / \mathrm{v})$;

Água Milli-Q (Academic, 18,2 M $\Omega-\mathrm{cm}$, Millipore Corporation);

Cilindro de gás Argônio XL45, White Martins® (90 \% teor de pureza);

Óxido Estanoso Sinty 98,7 \% teor de pureza;

Óxido de Mercúrio Jonhson Matthey Chemicals 99,7 \% teor de pureza;

Óxido de Chumbo Jonhson Matthey Chemicals 99,7 \% teor de pureza;

Óxido de Cádmio Jonhson Matthey Chemicals 99,7 \% teor de pureza;

Triióxido de Arsenio Jonhson Matthey Chemicals 99,7 \% teor de pureza;

lodeto de Potássio Sinty 98,7 \% teor de pureza;

Borohidreto de Sódio Merck 98,7 \% teor de pureza;

Hidróxido de Sódio Merck 98 \% teor de pureza;

Ácido L-Áscorbico Merck 98,8 \% teor de pureza;

Permanganato de potássio $\left(\mathrm{KMnO}_{4}\right)$ Merck (90 \% teor de pureza);

Extran MA Alcalino Merck;

Material de Referência - DORM-2 National Research Council of Canadá (NRCC). 


\subsection{Descontaminações do material volumétrico}

Todo material utilizado para a análise laboratorial e amostragem foi deixado imerso em solução de Extran a $10 \%$ por $24 \mathrm{~h}$, em seguida enxaguado com água desmineralizada e colocado em solução de $\mathrm{HNO} 3$ a $10 \%$ por $24 \mathrm{~h}$.

O material utilizado no processo de digestão das amostras foi deixado imerso em solução de extran a $10 \%$ por $24 \mathrm{~h}$. Em seguida foi imerso em solução de $\mathrm{KMnO}_{4}$, enxaguado com água desmineralizada e colocado em solução de HNO3 a $10 \%$ por $24 \mathrm{~h}$. Após foram enxaguados com água desmineralizada e colocados em estufa a $80^{\circ} \mathrm{C}$ para secagem.

\subsection{Etapas de Produção do material}

A produção do material seguiu a sistemática da Organização Internacional para Padronização, ISO, presente nos Guias da série 30 a 35, as recomendações do Guia da BAM para produção de MR e na norma ABNT NBR ISO/IEC 17043 (2011) que trata dos requisitos gerais para ensaios de proficiência, e demais bibliografias especializadas na área de produção de materiais de referência.

De modo a obter um material metrologicamente rastreável aos padrões internacionais, foram consideradas todas as etapas pertinentes desde 0 planejamento, até o desenvolvimento de um novo modelo para ensaios de proficiência, que seja útil para laboratórios acreditados e também para aqueles que desejam iniciar o processo de acreditação.

$\mathrm{Na}$ Figura 7 tem-se uma representação de todas as etapas de planejamento relacionadas à produção do material de referência. 


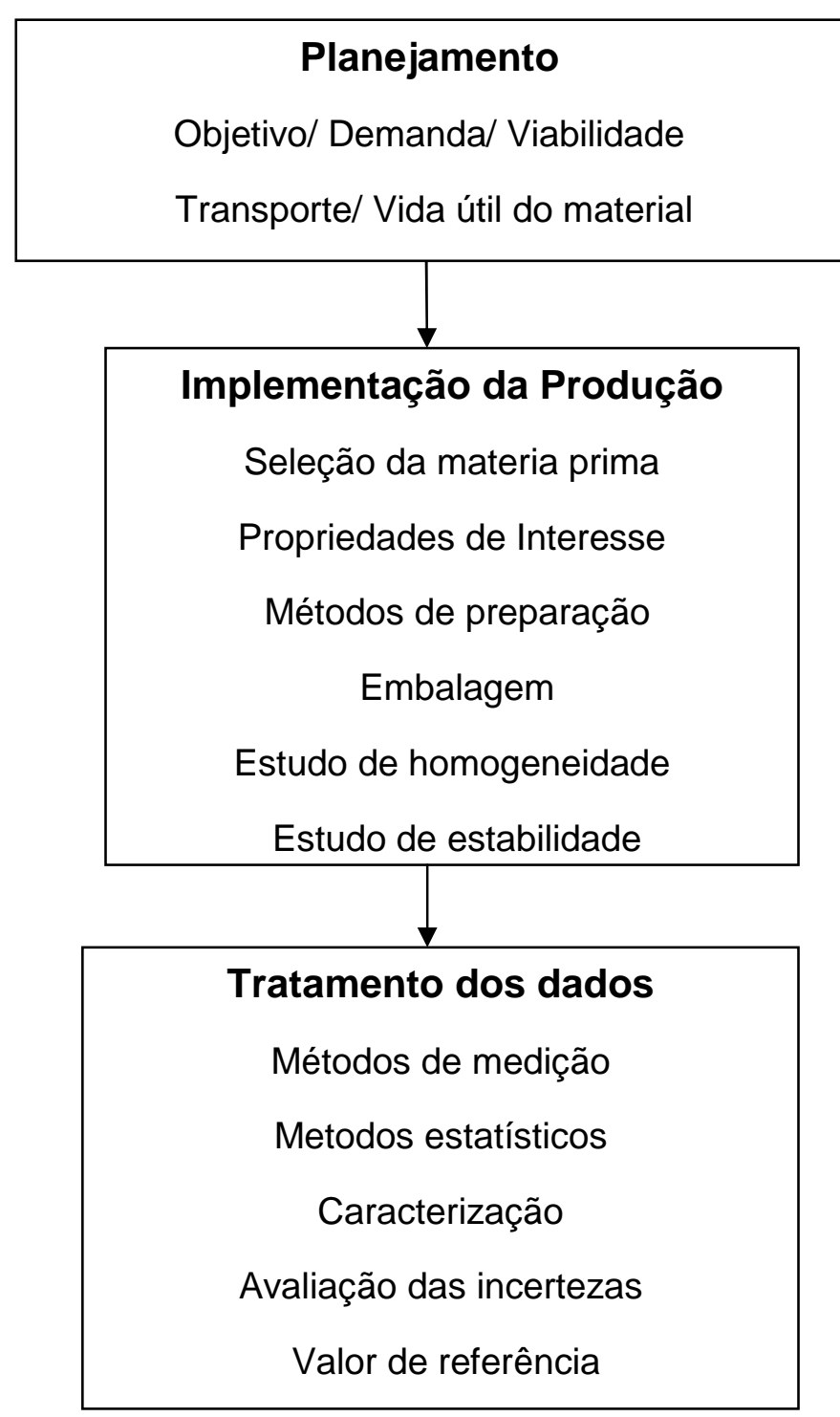

FIGURA 7- Fluxograma das etapas de produção do material

\subsubsection{Planejamento}

O Brasil exporta um volume anual considerável de pescado e não possui nenhum provedor de ensaios de proficiência para metais em pescado, o que torna a demanda pelo produto viável.

Para a matriz peixe o principal fornecedor de material de referência certificado é o Conselho Nacional de Pesquisa do Canadá, NRCC, que além de produzir MRCs para toxinas em mariscos, também produz MRC para elementos traço em músculo e fígado de peixe. 
Os demais produtores, contam com uma gama de matrizes biológicas marinhas para fins de monitoramentos ambientais. Como por exemplo: o Instituto Nacional de Padrões e Tecnologia dos Estados Unidos da América, NIST, o qual produz MRCs para contaminantes orgânicos e elementos traço em organismos marinhos, tais como mexilhões e ostras e o Instituto para Materiais de Referência e Medições, IRMM, da União Européia, que comercializa MRCs para elementos traço em mexilhão (NIST, 2010; NRCC, 1999; IAEA, 2005; Moreira, 2010).

Os MRCs produzidos pela IAEA os quais visam estudos ambientais são certificados para contaminantes orgânicos e espécies de mercúrio em mexilhão. Atualmente a IAEA conta com um projeto para a capacitação de laboratórios da América Latina para o preparo e certificação de MRs de peixe marinho (IAEA, 2005).

Em reuniões com a equipe de técnicos do $L C Q$, foi realizado um levantamento da viabilidade das etapas de produção do material, tais como: avaliar o tipo de matriz; seleção da matriz; modelo de transporte; a vida útil do material após a produção, levando-se em conta dados da literatura fornecida pelos produtores citados anteriormente e procedimentos realizados pelos mesmos. 


\subsubsection{Implementação da Produção do Material de Referência}

\subsubsection{Seleção do pescado}

A seleção da materia prima "pescado in natura" foi iniciada com o levantamento das principais espécies exportadas pelo Brasil, o tipo de pesca e a área de pesca, com o intuito de adquirir espécimes de interesse comercial.

Dessa forma, foram adquiridos 20 espécimes de Tucunaré $s p$ com comprimento na faixa de $34,6 \pm 9,8 \mathrm{~cm}$ e peso na faixa de $895 \pm 204 \mathrm{~g}$, provenientes de mercados da cidade de Itaituba, região Amazônica. O município de Itaituba está situado no interior do estado do Pará, cujo acesso à cidade pode ser feito por via aérea, ou pelas Rodovias BR-163 (Rodovia Cuiabá-Santarém) e BR-230 (Transamazônica) (FIG. 8).

Além do Rio Tapajós. A partir do Porto de Itaituba partem regularmente embarcações de pequeno, médio e grande porte, conectando a cidade aos portos de Santarém, Belém, Manaus e Macapá, uma importante rota de escoamento da produção pesqueira da região.

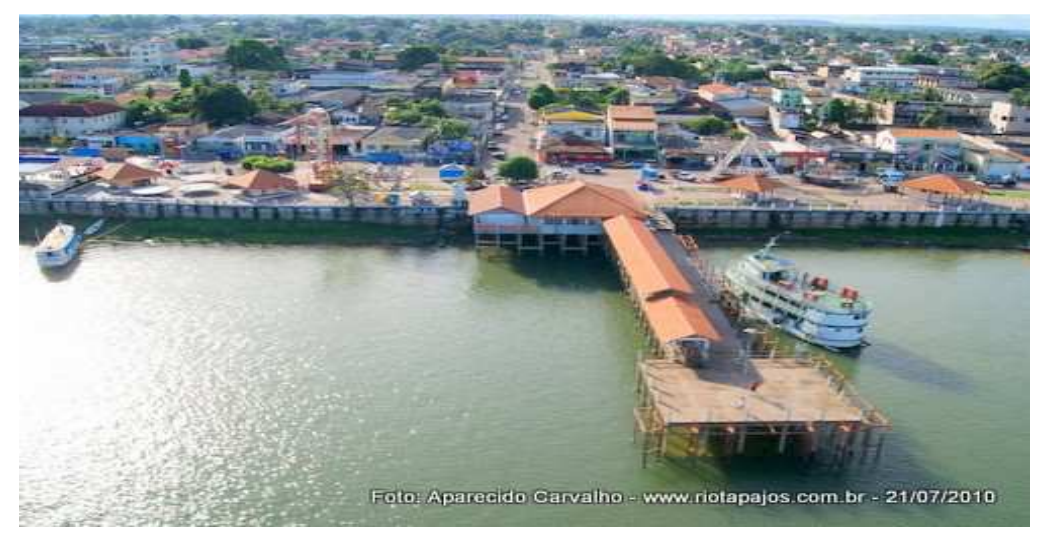

Fonte: WWW.riotapajos.com.br

FIGURA 8- Porto de Itaituba 


\subsubsection{Propriedades de Interesse para os mensurandos $\mathrm{Hg}, \mathrm{As}, \mathrm{Cd} \mathrm{e} \mathrm{Pb}$}

A especie escolhida destaca-se na exportação de pescado e os individuos adquiridos apresentaram baixos teores de $\mathrm{As}, \mathrm{Cd}, \mathrm{Pb}$ e teores $\mathrm{Hg}$ dentro dos limites estipulados pela Anvisa, legislação europeia e Codex stan (Lima, 2005; Ysrael, 2008; Kering, 2009).

Os elementos $\mathrm{Cd}, \mathrm{Hg}$, As e $\mathrm{Pb}$, são considerados como potencialmente tóxicos, pois se acumulam em organismos causando distúrbios aos processos metabólicos dos mesmos (Capar, Mindak, Cheng, 2007).

Por este motivo são monitorados constantemente em alimentos tanto para importação quanto para exportação e são regulamentados em normas e avaliações de exposição em curto e longo prazos, para que seja determinado seu grau de toxicidade para o homem e demais organismos participantes da cadeia alimentar (Capar, Mindak, Cheng, 2007).

Governos em geral e organizações, como a Comunidade Européia, Comissão do Codex Alimentarius, Organização Mundial da Saúde, Organização Mundial do Comércio e Anvisa, estabelecem normas regulamentadoras para controlar os teores desses metais em alimentos para regular o comércio e preservar a saúde das populações (Capar, Mindak, Cheng, 2007).

O cádmio é um metal tóxico, oriundo de atividades humanas (corantes de cimento, fertilizantes fosfatados, etc.) e poluente ambiental que pode acumular-se nos tecidos moles como fígado, placenta, rins, pulmões, cérebro e até ossos. É antagônico de elementos essenciais como ferro e zinco se ligando a sítios de ligação, tais como proteínas de transporte e de armazenamento, metaloenzimas e receptores, podendo provocar como sintomas de intoxicação aguda em seres humanos: náuseas, vômitos, dor abdominal e dificuldade respiratória (Poornima et al, 2008).

A exposição prolongada pode acarretar em doença pulmonar obstrutiva crônica, deficiência renal, fragilidade óssea, anemia, distúrbios de aprendizagem, e doenças cardiovasculares entre outras. Níveis de $5 \mu \mathrm{g} \mathrm{dl}^{-1}$ e acima de $10 \mu \mathrm{g} \mathrm{dl}^{-1}$, 
em creatinina urinária, já são considerados como sugestivos de toxicidade em testes laboratoriais (Poornima et al, 2008).

O mercúrio é considerado como um elemento de alto potencial tóxico, já que além do estado elementar pode se apresentar como os íons $\mathrm{Hg}^{+1} \mathrm{e} \mathrm{Hg}^{+2}$, fomando compostos orgânicos através de reações como a metilação (Martiniano et al, 2008).

A forma metilmercúrio é considerada a mais tóxica e quando presente em ecossistemas aquáticos acarreta a contaminação do pescado, sendo considerada a principal fonte de contaminação para o homem. A contaminação ocorre de modo progressivo através da cadeia trófica e da água, causando efeito neurotóxico em seres humanos (Fonseca et al., 2009).

É proveniente de fontes naturais como o intemperismo, atividades vulcânicas, degaseificação da crosta ou fontes antropogênicas como agricultura, a extração mineral (amalgamação do ouro em garimpos) e atividades industriais, as doses mais baixa podem levar ao longo da exposição a sintomas como: paralisia cerebral, distúrbios mentais, retardamento do desenvolvimento de várias funções psicomotoras, convulsões, cegueira e má formação interna e externa dos ouvidos, na exposição pré-natal. Nas intoxicações agudas principalmente devido à ingestão do metilmercúrio, variando de leve a letal podem ocorrer vômitos, tremores, ataxia (falta de coordenação motora), parestesia (alterações sensoriais), paralisia, cegueira, perda da voz, coma e morte (Fonseca et al., 2009).

Em estados avançados (crônico), afeta principalmente o sistema nervoso central (SNC), levando a parestesia, dificuldade de articular palavras, sensação generalizada de fraqueza, fadiga e incapacidade de concentração, além da perda da visão, audição e morte (Fonseca et al., 2009).

As fontes de arsênio encontradas no ambiente são oriundas de pesticidas, mineração, fundição (ouro, chumbo, cobre e níquel), produção de ferro e aço, combustão de carvão. As lixiviações de minas abandonadas de ouro, de décadas e séculos atrás, continuam sendo fonte significativas de poluição por arsênio nos sistemas aquáticos (Fonseca et al., 2009). 
A toxicidade do arsênio se manifesta na inibição de várias enzimas mitocondriais (desacoplamento da fosforilação oxidativa), causando uma deficiência na respiração celular, pois este é capaz de interagir com grupos sulfídricos de proteínas, enzimas e substituir o fósforo em várias reações bioquímicas (Vutukuru et al., 2007).

O envenenamento por arsênio causa conjuntivite, melanose, despigmentação e queratose (feridas), tumores na bexiga, fígado, pulmões e rins (Fonseca et al., 2009).

A emissão industrial do chumbo proveniente da exploração mineral ou reciclagem de fragmentos de metal, baterias, incineradores, são as principais fontes de poluição ambiental (Tavares, 2010).

Atividades humanas também contribuem para a poluição ambiental, aumentando o risco à saúde humana e de animais, já que podem levar a contaminação por chumbo do ar, poeira, alimentos contaminados (cultivados em solos contaminados), bebidas (contaminação da água de preparo) e tinta (reformas de casas, construções, brinquedos pintados, cosméticos faciais, tinturas de cabelo, impressão colorida, água de tubulações com solda a base de chumbo, entre outros), em se tratando de alimentos e bebidas contaminados estes são a principal fonte de ingestão diária de chumbo (Tavares, 2010).

Deste modo, concentrações de chumbo acima de $25 \mu \mathrm{g} \mathrm{kg}^{-1}$ de peso corpóreo/semana são capazes de comprometer o sistema nervoso, os rins e o sangue. Os sintomas atingem vários órgãos como tecido ósseo e soro (pode provocar lesão renal e desenvolvimento de danos a tireóide), sistema reprodutor masculino e feminino (redução da fertilidade, aumento da probabilidade de abortos espontâneos, teratogênia em animais), sistema cardiovascular (aumento da pressão sanguínea, lesões cardíacas), além de ser carcinogênico (Tavares, 2010). 


\subsubsection{Produção do Material de Referência}

Todas as etapas de produção do material foram realizadas no laboratório LCQ/CQMA, em sala reservada e devidamente higienizada para este fim. O material foi processado dentro de uma capela de fluxo laminar, devidamente limpa e descontaminada, com paramentação adequada (luvas, touca, mascara e propé) (FIG. 9).

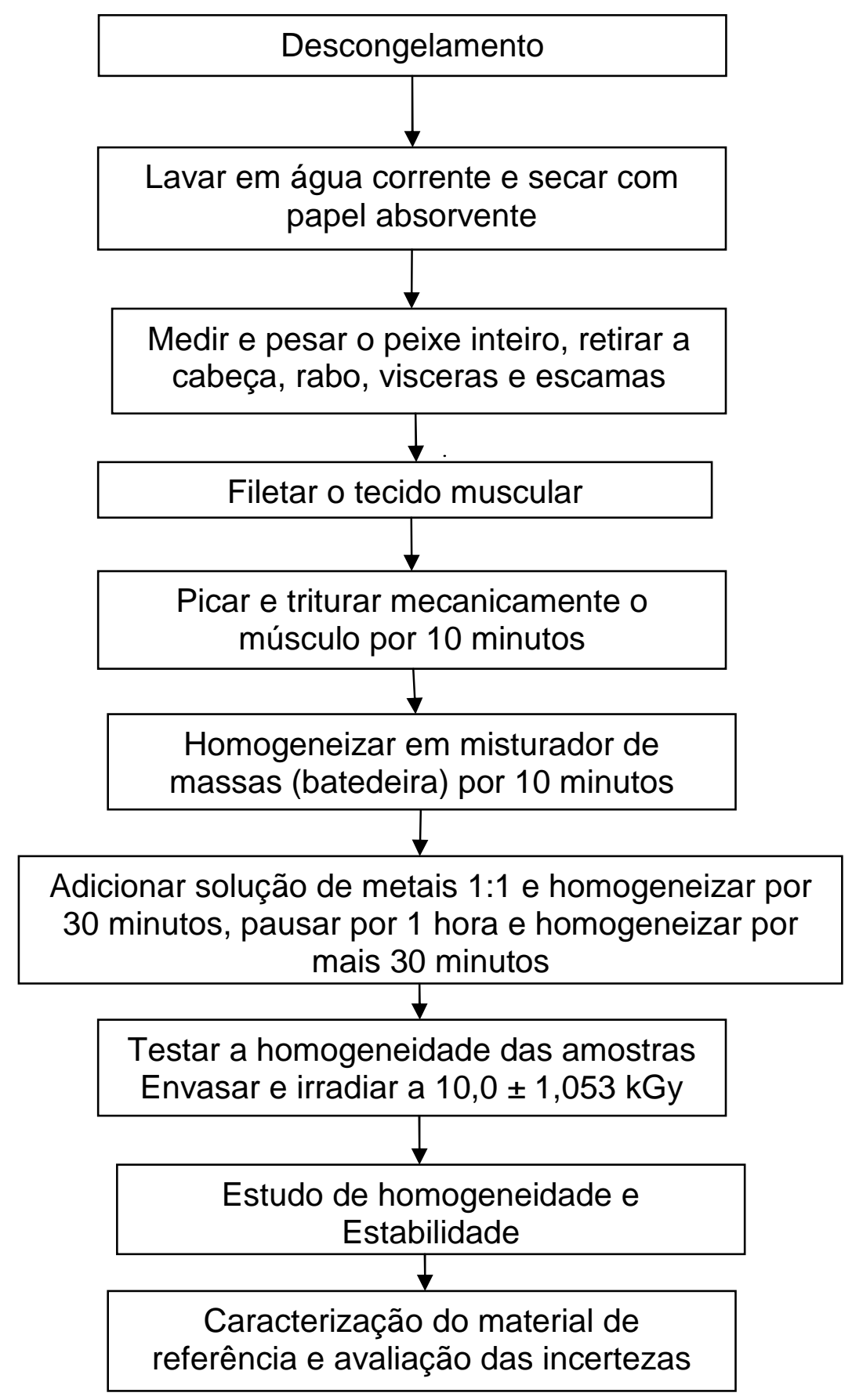

FIGURA 9- Fluxograma de Preparo do material referência 
Os espécimes foram recebidos congelados à $-10^{\circ} \mathrm{C} \pm 1^{\circ} \mathrm{C}$ em embalagem plástica dentro de uma caixa de isopor contendo gelo e devidamente identificada. Em seguida foram lavados em água corrente, colocados em embalagem plástica e levados ao freezer (Frostfree Brastemp com capacidade de $280 \mathrm{~L}$ ) à $-5^{\circ} \mathrm{C} \pm 1$ ${ }^{\circ} \mathrm{C}$ onde permaneceram até as etapas de processamento.

\subsubsection{Preparações das Soluções de Fortificação}

Foi realizado um teste inicial para verificar a melhor faixa de recuperação de cada solução fortificada (Apêndice E).

Após a avaliação dos resultados foram preparadas soluções fortificadas, em 2 níveis de concentração, individuais de arsênio, cádmio e chumbo a partir de seus respectivos óxidos, a fim de proporcionar as amostras teores dos metais semelhantes aos presentes na Anvisa e Legislação Europeia. As soluções foram armazenadas em geladeira a $5 \pm 1^{\circ} \mathrm{C}$ até a utilização não apresentando nenhuma alteração dos elementos.

\subsection{Solução Padrão de Mercúrio}

A solução padrão estoque com 1000,14 $\mu \mathrm{g} \mathrm{mL}^{-1}$ de mercúrio foi preparada diluindo-se óxido de mercúrio em água milli-Q, até $200 \mathrm{~mL}$ e estabilizado com uma solução de dicromato de potássio a $0.1 \%$. A partir desta solução foram preparadas soluções de $0,100 \mu \mathrm{g} \mathrm{g}^{-1}$ para preparação da curva analítica nas concentrações de $0,020,0,050,0,100,0,150,0,200$ e $0,300 \mu g^{-1}$, pois o tecido muscular de peixe já apresentava concentrações naturais de mercúrio na faixa de $0,25 \mu g^{-1}$ e $1,20 \mu g g^{-1}$. 


\subsection{Solução Padrão de Cádmio}

A solução padrão estoque com 1058,94 $\mathrm{gg} \mathrm{mL}^{-1}$ de cádmio foi preparada diluindo-se 0,100 g de óxido de cádmio em ácido nítrico concentrado e avolumado com água milli-Q até $100 \mathrm{~mL}$. A partir desta solução, foram preparados, soluções de $1,0 \mu \mathrm{g} \mathrm{g}^{-1}$ e $1,5 \mu \mathrm{g} \mathrm{g}^{-1}$, para serem utilizadas como solução de fortificação para o tecido do peixe e solução de $0,100 \mu \mathrm{g} \mathrm{g}^{-1}$ para preparação da curva analítica com concentrações de 0,010, 0,025, 0,050,0,075, 0,125 $\mu \mathrm{g} \mathrm{g}^{-1}$.

\subsection{Solução Padrão de Chumbo}

A solução padrão estoque com $899,10 \mu \mathrm{g} \mathrm{mL} \mathrm{m}^{-1}$ de chumbo foi preparada diluindo-se $0,100 \mathrm{~g}$ de óxido de chumbo (II) em ácido nítrico concentrado e avolumado com água milli-Q até $100 \mathrm{~mL}$. Com está soluça foram preparados soluções de $1,5 \mu \mathrm{g} \mathrm{g}^{-1}$ e 2,5 $\mu \mathrm{g} \mathrm{g}^{-1}$, para serem utilizadas como solução de fortificação para o tecido do peixe e solução de $0,100 \mu \mathrm{g} \mathrm{g}^{-1}$ para preparação da curva analítica com concentrações de 0,010, 0,025, 0,050,0,075, 0,125 $\mathrm{ug} \mathrm{g}^{-1}$.

\subsection{Solução Padrão de Arsênio}

A solução padrão estoque com 999,99 $\mu \mathrm{g} \mathrm{mL} \mathrm{m}^{-1}$ de Arsênio foi preparada diluindo-se $0,100 \mathrm{~g}$ de óxido de arsênio (III) em ácido nítrico concentrado e avolumado com água milli-Q até $100 \mathrm{~mL}$. A partir desta solução, foram preparados soluções de, $1,0 \mu \mathrm{g} \mathrm{g}^{-1}$ e $1,5 \mu \mathrm{g} \mathrm{g} \mathrm{g}^{-1}$, para serem utilizadas como solução de fortificação para o tecido do peixe e solução de $0,100 \mu \mathrm{g} \mathrm{g}{ }^{-1}$ para preparação da curva analítica concentrações de 0,020, 0,050, 0,100, 0,150, 0,200 e $0,300 \mu \mathrm{g} \mathrm{g}^{-1}$. 


\subsubsection{Preparação das Amostras fortificadas}

A maior parte dos estudos realizados com adição de metais em amostras é normalmente realizado com soluções de adição que serão analisadas prontamente ou adicionado em espécimes in vivo (contaminação do substrato nutricional de animais ou plantas). Por este motivo a preparação de amostras fortificadas carece de bibliografia especializada. Assim, neste estudo foi tomado como base para o preparo das amostras, trabalhos no âmbito do enriquecimento nutricional de alimentos com metais (micronutrientes) e a adição de metais in vivo para análise de risco toxicológico (Portaria da ANVISA, n³1, 1998; Zarbielli e col, 2004; Vutukuru et al., 2007).

Dessa forma, preparou-se um lote de $1,300 \mathrm{~kg}$ de tecido muscular de peixe adicionando-se uma solução de $1300 \mathrm{~mL}$ dos metais de interesse nas seguintes concentrações: Cd e As $1,5 \mu \mathrm{g} \mathrm{g}^{-1}$ e $\mathrm{Pb} 2,5 \mu \mathrm{g} \mathrm{g}^{-1}$, para que pelo menos $80 \%$ destes mensurandos fossem recuperados no material final o que, corresponderia a concentrações próximas as estipuladas como limite pela Anvisa e Legislação Europeia.

Com o intuito de verificar a resposta dos laboratórios frente a baixas concentrações dos mensurandos pelos laboratórios, foi preparado um segundo lote de $1,100 \mathrm{~kg}$ de tecido muscular de peixe adicionando-se uma solução de $1100 \mathrm{~mL}$ dos metais As, $\mathrm{Cd}$ e $\mathrm{Pb}$ com concentrações menores, respectivamente, $1,0 \mu \mathrm{g} \mathrm{g}^{-1}, 1,5 \mu \mathrm{g} \mathrm{g}^{-1}$, afim de obter recuperação semelhante a anterior.

Após as etapas de limpeza e trituração mecânica em um multiprocessador de alimentos doméstico com lâminas de aço inoxidável, o tecido foi homogeneizado mecânicamente em um misturador de massas (batedeira) doméstico de pás com quatro aros de aço inoxidável tipo "fouet" por 3 minutos. Em seguida, a solução foi adicionada gradualmente ao tecido, o qual foi novamente homogeneizado por mais 3 minutos para completar o processo de homogeneização. FIG. 10a, 10b, 10c, 10d, 10e, 10g. 
O tecido muscular do peixe preparado foi submetido a um estudo de homogeneidade e seus resultados avaliados pela ANOVA, a fim de proceder à etapa de envase, em sachês metalizados.
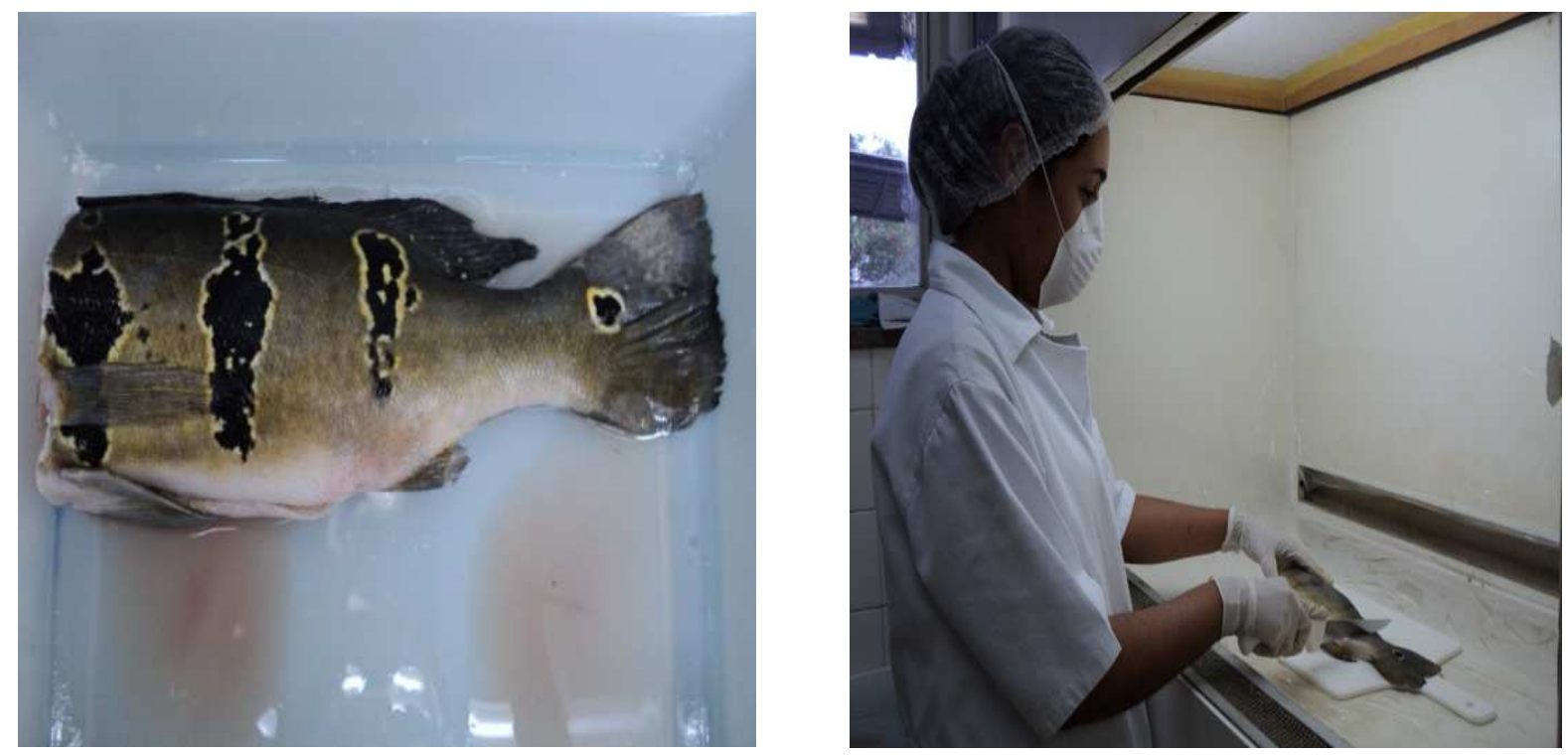

FIGURA 10a- Peixe sem cabeça e eviscerado

FIGURA 10b-Limpeza do Peixe

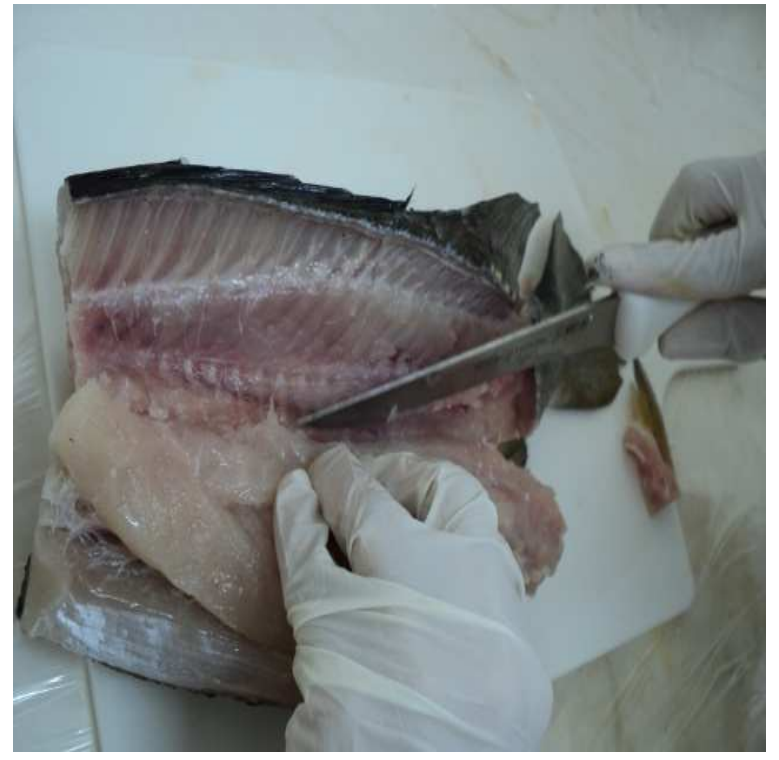

FIGURA 10c-Filetagem do Peixe limpo

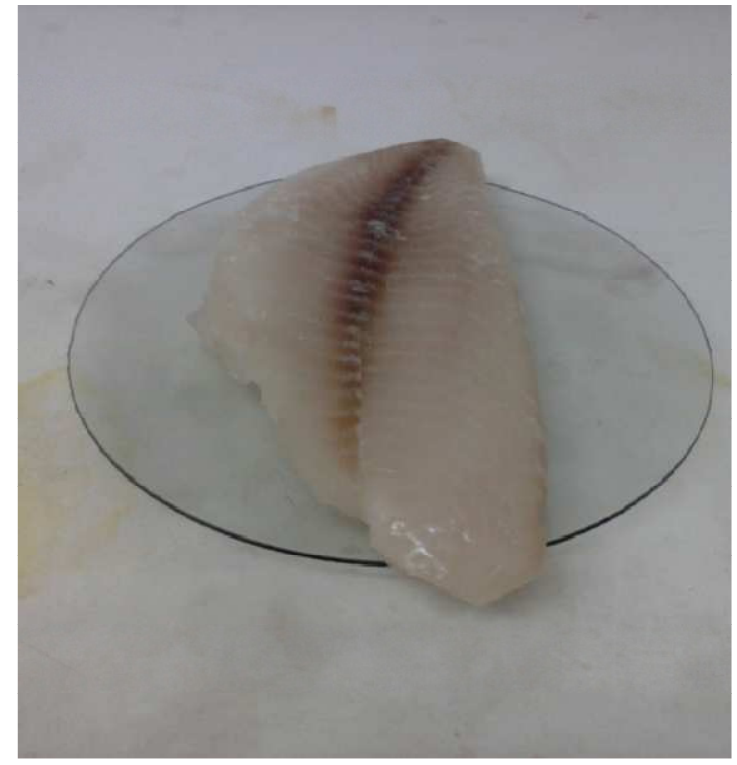

FIGURA 10d-Filé de Tucunaré 


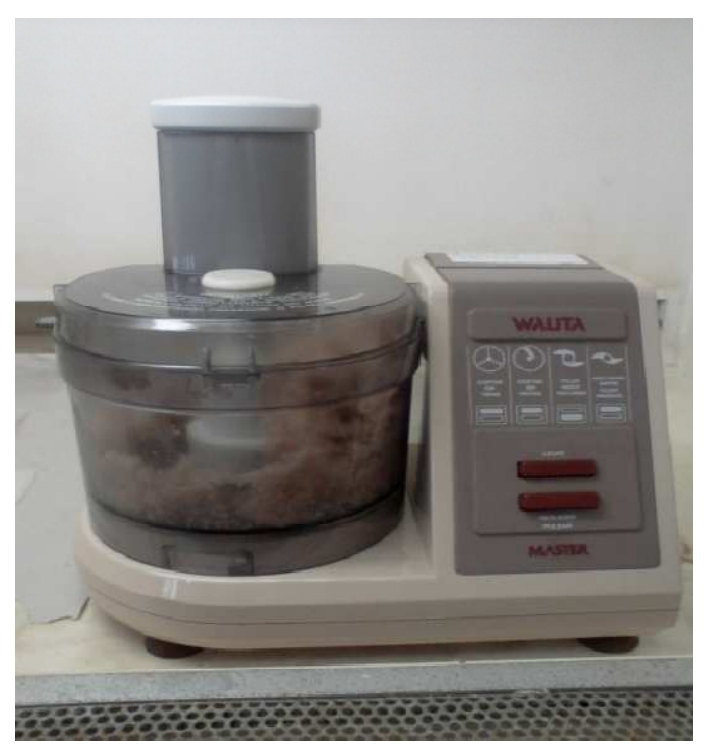

FIGURA 10e-Trituração do Filé

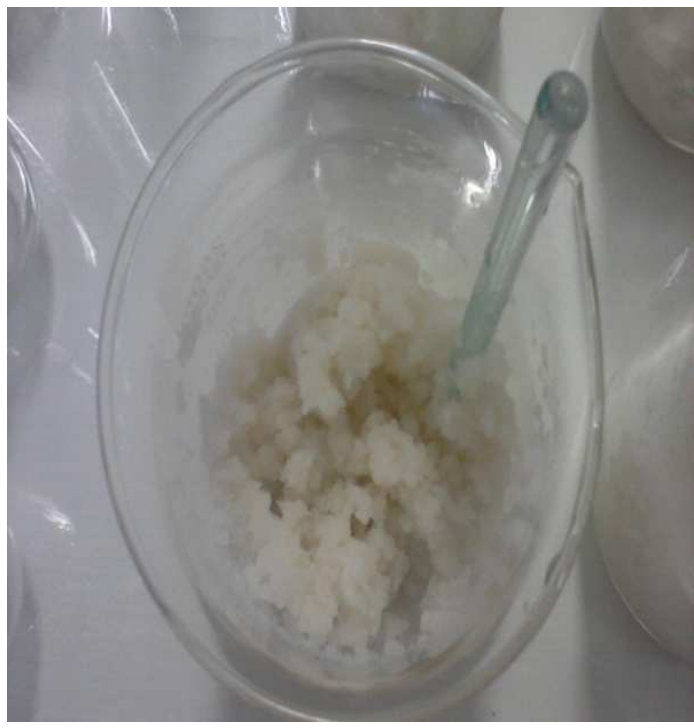

FIGURA 10f-Filé triturado em solução de metais

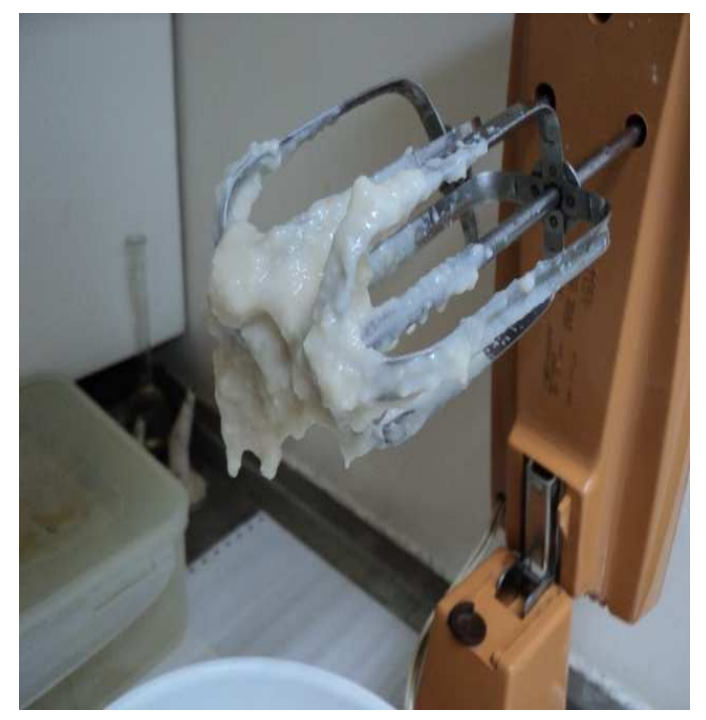

FIGURA 10g- Homogeneização do tecido muscular adicionado de metais

Após avaliar os resultados preliminares, o material foi envasado em um lote de 164 unidades, divididos em maior concentração e menor concentração, 84 unidades de $10 \mathrm{~g}$ foram separadas para os estudos de homogeneidade e estabilidade. O restante foi subdividido em lotes de 40 unidades de $10 \mathrm{~g}$ cada, para o ensaio de proficiência.

Foram selecionados dois tipos de embalagem para este estudo, sachês feitos com plástico (PEBD Polietileno de Baixa Densidade) transparente, devido as suas características como: resistência a temperatura (ponto de fusão a 105$110^{\circ} \mathrm{C}$ ), inerte (ao conteúdo), transparência, impermeabilidade, sendo ideais para 
o uso em alimentos e materiais com alto teor de umidade como leite, água, carne, produtos congelados, etc. (Brunini et al, 2004; Jeronimo et al, 2007). (FIG 11a)

A embalagem metalizada tipo trad-pouch (alumínio revestido com poliéster) é largamente utilizada em diversos segmentos como alimentos, produtos cosméticos, de saúde, pois proporcionam ao produto barreira contra a luz, oxigênio, umidade, e resistência a temperaturas entre $90-100{ }^{\circ} \mathrm{C}$ devido a uma camada dupla de filme plástico com verso metalizado em alumínio (FIG. 11b).

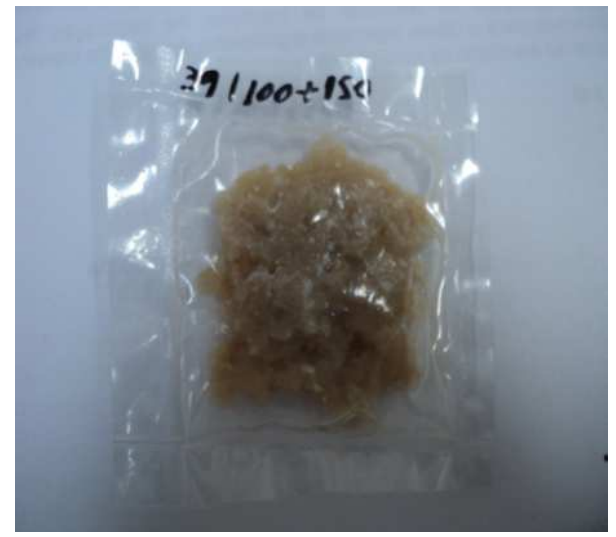

FIGURA 11a- Embalagem plástica de polietileno transparente (PEBD)

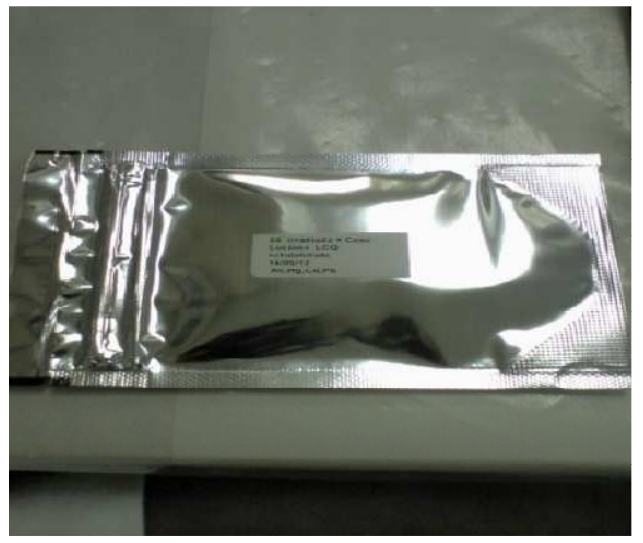

FIGURA 11b- Embalagem Trad-Pouch (metalizada em alumínio revestido internamente com poliéster)

A embalagem tipo trad-pouch de $8,0 \mathrm{~cm}^{2} \times 12,5 \mathrm{~cm}^{2}$ (sachês), apresentou maior resistência a altas temperaturas, assim todo o material foi embalado e devidamente identificado com a mesma (FIG. 12a, 12b, 12c e 12d). 


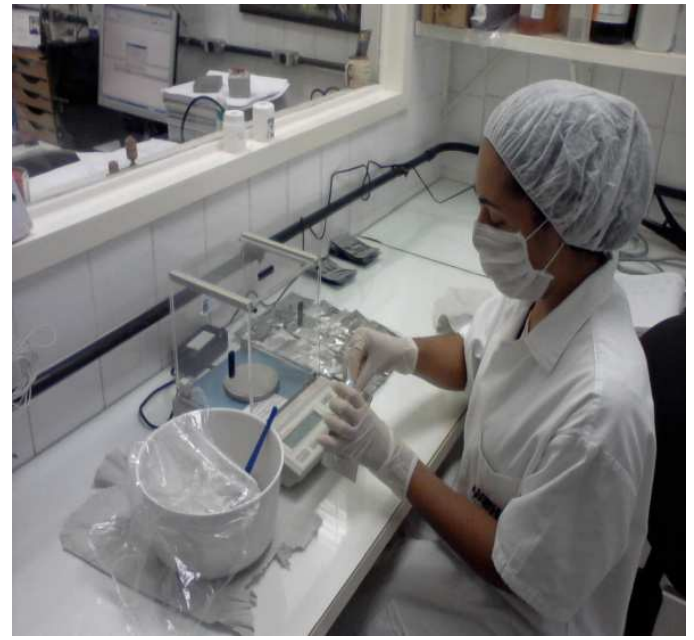

FIGURA 12a- Envase das amostras

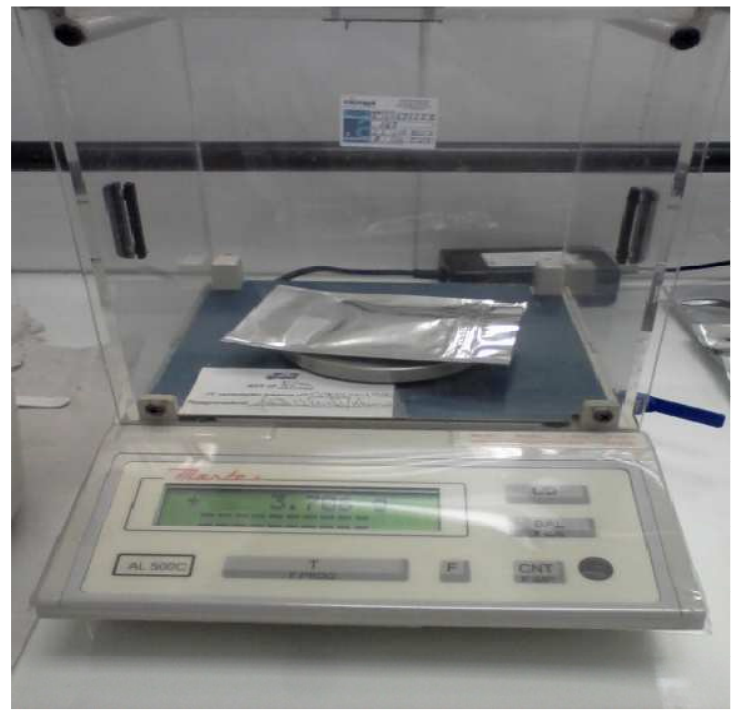

FIGURA 12c-Pesagem das amostras

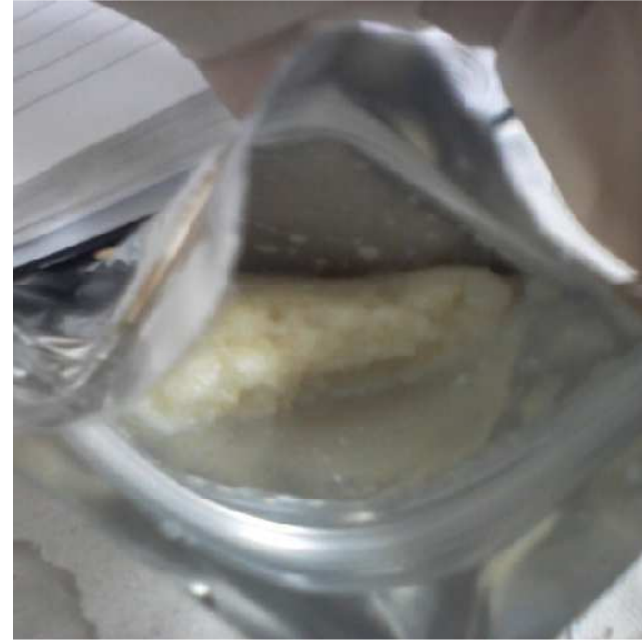

FIGURA 12b-Amostra embalada

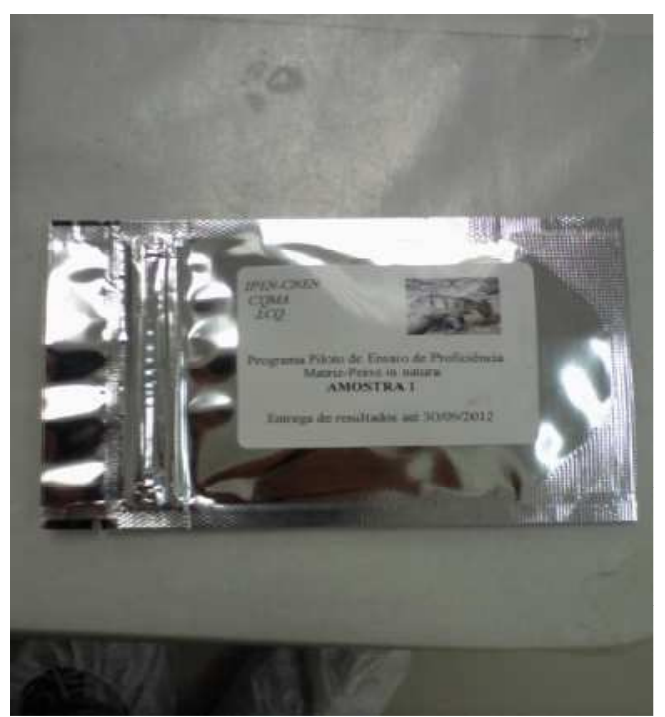

FIGURA 12d-Amostra embalada e etiquetada

As amostras embaladas e identificadas foram separadas em 2 grupos. $\mathrm{O}$ primeiro foi irradiado, enquanto que o segundo seguiu em paralelo como amostras controle, para avaliar a necessidade da etapa de irradiação dentro do prazo de estudo (42 amostras irradiadas e 42 amostras não irradiadas). Todo material correspondente ao ensaio de proficiência foi irradiado. 


\subsubsection{Processo de esterilização com radiação gama}

O Decreto n. 7218/1973 do Ministério da Saúde aprovou a irradiação de alimentos no Brasil e a Comissão Nacional de Energia Nuclear (CNEN) conforme a resolução 05/1980, aprovou as normas de irradiação de alimentos. A legislação sobre irradiação de alimentos existe desde 1985. A resolução RDC № 21 de 2001 da Anvisa é norma em vigor atualmente (Portaria DINAL no. 9 do Ministério da Saúde, 08/03/1985; ANVISA, 2001).

Segundo dados da ANVISA (2003), no Brasil, existem três empresas autorizadas a realizar a irradiação de alimentos. Situadas em Jarinu e Cotia, estão a Companhia Brasileira de Esterilização (CBE) e a Empresa Brasileira de Radiações (EMBRARAD), e com sede em Manaus (AM), a "Tech Ion".

$\mathrm{Na}$ área de pesquisa e desenvolvimento, destacam-se o Centro de Energia Nuclear para Agricultura (CENA), da Universidade de São Paulo, que realiza pesquisas na área e presta consultoria para as indústrias e o Instituto de Pesquisas Nucleares, que além de realizar pesquisas na área, também realiza um trabalho junto aos produtores, mostrando os benefícios e vantagens da irradiação de alimentos (Agência Brasil, 2003).

Neste contexto, em estudos realizados em alimentos cárneos como frango, peixe, carne bovina, ovina, suínos e embutidos verificou-se alterações físicoquímicas e sensoriais quando expostos a doses elevadas de radiação (acima de 10,0 kGy), provocando alteração de cor, sabor, textura, odor, perda de umidade e oxidação lipídica em presença de oxigênio, apresentando também alterações proteicas por radíolise da água. Contudo esses efeitos são minimizados ou erradicados com associação de outros métodos de conservação como embalagens com atmosfera modificada e/ou tratamento térmico dos produtos antes da irradiação (Mantilla, 2010; Leonel, 2008; Alves, 2008; Reis, 2008; Franco, 2005; Siqueira, 2001).

Os benefícios quanto à conservação e destruição de microorganismos são irrefutáveis fazendo com que o uso da irradiação seja uma das melhores 
propostas futuras para conservação e sanitização de alimentos e materiais (Mantilla, 2010; Leonel, 2008; Alves, 2008; Reis, 2008; Siqueira, 2001).

De modo geral a irradiação de alimentos tem como objetivo a inibição do brotamento, desinfestação, radurização (redução de microrganismos formadores de esporos, infestação por insetos) (Fig. 13), radiciação (redução da carga microbiana patogênica não formadora de esporos) e radaperitização, ou seja, a irradiação comercial para conservação (Germano, 2006; Franco \& Landgraf, 2005; Diehl, 2002).

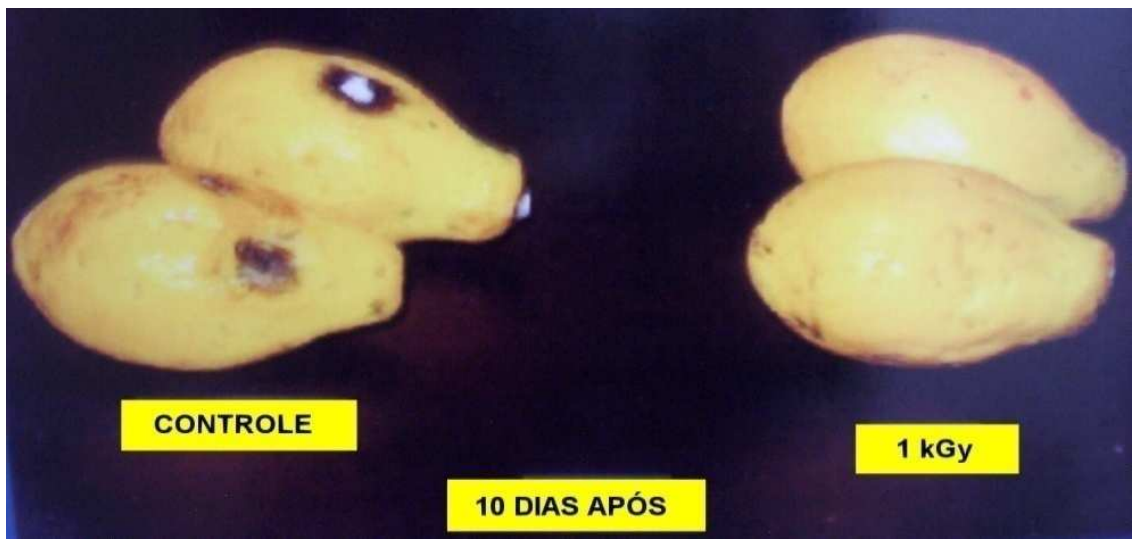

Fonte: IPEN-Instituto de Pesquisas Energéticas e Nucleares, 2004

FIGURA 13- Resultados típicos da irradiação de alimentos

Para alguns alimentos como peixe, carnes e alimentos já preparados é necessário um tratamento prévio antes ou depois da irradiação como, por exemplo, manter o produto sob-refrigeração a temperatura de pelo menos $3{ }^{\circ} \mathrm{C}$, para armazenamento, quando as doses de irradiação forem menores que 1,0 kGy (Lacroix, 2000).

Para produtos de pescado, as doses média recomendadas são 1,0 kGy para filé de peixe e 2,0 kGy para peixe salgado e defumado. A Tabela 3 ilustra doses aceitáveis para um conjunto de alimentos (IAEA, 2001). 
TABELA 3- Doses para Irradiação de Alimentos

\begin{tabular}{|c|c|c|}
\hline TIPO DE ALIMENTO & $\begin{array}{c}\text { DOSE } \\
\text { (kGy) }\end{array}$ & EFEITO \\
\hline $\begin{array}{c}\text { CARNE, FRANGO, PEIXE, MARISCO, } \\
\text { ALGUNS VEGETAIS, ALIMENTOS } \\
\text { PREPARADOS }\end{array}$ & 20 a 70 & $\begin{array}{l}\text { Esterilização. Os produtos tratados } \\
\text { podem ser armazenados. } \\
\text { (temperatura ambiente) }\end{array}$ \\
\hline ESPECIARIAS E OUTROS TEMPEROS & 8 a 30 & $\begin{array}{c}\text { Reduz o número de micro organismos } \\
\text { e destrói insetos. Substitui produtos } \\
\text { químicos. }\end{array}$ \\
\hline CARNE, FRANGO, PEIXE & 1 a 10 & $\begin{array}{c}\text { Retarda a deterioração. Mata alguns } \\
\text { tipos de bactérias patogênicas } \\
\text { (Salmonela). }\end{array}$ \\
\hline MORANGOS E OUTRAS FRUTAS & 1 a 4 & $\begin{array}{l}\text { Aumenta o tempo de prateleira, } \\
\text { retarda o aparecimento de mofo. }\end{array}$ \\
\hline GRÃOS, FRUTAS E VEGETAIS & 0,1 a 1 & $\begin{array}{l}\text { Mata insetos ou evita sua reprodução. } \\
\text { Pode substituir, parcialmente, os } \\
\text { fumigantes. }\end{array}$ \\
\hline $\begin{array}{c}\text { BANANAS, ABACATE, MANGA, } \\
\text { MAMÃO E OUTRAS FRUTAS NÃO } \\
\text { CÍTRICAS }\end{array}$ & 0,25 a 0,35 & Retarda a maturação. \\
\hline CARNE DE PORCO & 0,08 a 0,15 & Inativa a Trinchinela. \\
\hline BATATA, CEBOLA, ALHO & 0,05 a 0,15 & Inibe o brotamento. \\
\hline
\end{tabular}

Fonte: faculdade de ciências farmacêuticas-USP- São Paulo, 2004

Nesse cenário, uma parte do material preparado foi irradiado no Centro de Tecnologia das Radiações no IPEN, em um ciclotron Cyclone 30 da Ion Beam Applications com 10,0 $\pm 1,05 \mathrm{kGy}$ com fonte de cobalto $60\left({ }^{60} \mathrm{Co}\right)$ para esterilização e teve como principal objetivo retardar o processo de deteriorização, para atender as condições de transporte a temperatura ambiente, e para manter o material em condições estáveis por cerca de 45 dias ou mais após a sua produção (De Lara, 2002; IAEA, 2001; Ross, 2000).

O restante seguiu todo o estudo em paralelo de modo a poder-se comparar as amostras após diferentes tratamentos. 


\subsection{Métodos analíticos empregados nos estudos de homogeneidade, estabilidade e caracterização do material}

Tanto o BAM (2010), quanto o ABNT ISO GUIA 35 (2012), sugerem o uso

de métodos analíticos que apresentem boa repetibilidade, seletividade $\mathrm{e}$ reprodutibilidade para a determinação dos mensurandos nos estudos de homogeneidade, estabilidade e caracterização de MRC.

Neste trabalho os métodos analíticos utilizados para a determinação dos elementos de interesse foram, FIA-CV-AAS para determinação de mercúrio, FIAHG-AAS para determinação de As e ICP-MS para determinação de Cd e Pb, a fim de atender as prerrogativas de um ensaio de proficiência.

\subsubsection{Geração de Vapor Frio acoplado ao Espectrometro de Absorção Atômica com injeção em fluxo (FIA-CV-AAS) para análise de mercúrio total}

A técnica de CV-AAS é utilizada para determinação de mercúrio $(\mathrm{Hg})$, pois este é o único elemento metálico cuja forma atômica $\left(\mathrm{Hg}^{0}\right)$ está presente no estado gasoso à temperatura ambiente. Além disso, a técnica é largamente empregada na indústria pela reprodutibilidade, sensibilidade e exatidão (Hortellani, 2003).

O método se baseia na redução do mensurando do estado íonico $\mathrm{Hg}^{+2}$ ao estado fundamental $\mathrm{Hg}^{0}$ através do uso de cloreto estanoso $\left(\mathrm{SnCl}_{2}\right)$ ou borohidreto de sódio $\left(\mathrm{NaBH}_{4}\right)$ como redutor, este é arrastado por um fluxo de gás inerte (argônio por exemplo) para a célula de absorção, um tubo cilíndrico de vidro, com janelas de quartzo, postado longitudinalmente (posição do atomizador) no caminho ótico (lâmpada de catodo oco para mercúrio) do equipamento de absorção atômica. O elemento já chega à célula de absorção na forma atômica, assim não é necessário o aquecimento do mesmo "vapor frio", (Welz \& Sperling, 2008). 
A equação 23 simplifica como ocorre a reação de redução a partir do uso do cloreto estanoso como redutor $\mathrm{Hg}^{+2} \mathrm{a} \mathrm{Hg}^{0}$ :

$\mathrm{Hg}^{+2}+\mathrm{Sn}^{+2} \rightarrow \mathrm{Hg}^{\circ}+\mathrm{Sn}^{+4}$

A redução do mercúrio neste trabalho foi realizada com cloreto estanoso.

\subsubsection{Geração de vapor de hidretos pela técnica de Espectrofotometria de Absorção Atômica com injeção em fluxo (FIA-HG-AAS) para determinação de arsênio}

A técnica de geração de hidretos (HG-AAS) tem sido amplamente utilizada na determinação de TAs (Arsênio total), em função do baixo custo das análises e da sensibilidade adequada à determinação em amostras ambientais (Mustra, 2009).

Está técnica (FIA-HG-AAS) para determinação de arsênio, geralmente utiliza como agente redutor o borohidreto de sódio acrescido de hidróxido de sódio para estabilizar a solução, a transferência do arsênio até o sistema de detecção e sua atomização, ocorre com a conversão dos compostos contendo arsênio até o hidreto volátil correspondente. Este método facilita o transporte do arsênato, o hidreto volátil pela reação com o borohidreto, contudo alguns compostos não apresentam produto volátil com o uso do borohidreto como a maioria dos bioarsênicos: arsenobetaína, arsenocolina, arseno-açúcares e também compostos organo-arsênicos provenientes da indústria: arsenito e arseniato (Barra; Santelli; Abrão; Guardia, 2000).

Assim, o método envolve a determinação da concentração de As total pela pré-redução das espécies de $\mathrm{As}^{+5}$ para $\mathrm{As}^{+3}$. Como o processo de formação da arsina possui cinética diferenciada para as espécies $\mathrm{As}^{+3}$ e $\mathrm{As}^{+5}$ é possível realizar a determinação seletiva da primeira espécie selecionando as condições adequadas. Em casos onde há concentrações consideráveis de arsênio 
inorgânico na amostra, a pré-redução pode ser realizada usando um composto que contenha o grupo tiol, geralmente o iodeto de potássio, associado a Lcisteína, ao Ácido L-Áscorbico e ao tioglicerol, finalizando a redução com borohidreto de sódio. Eq. 24 e 25 (Borba et al., 2009).

$\mathrm{NaBH}_{4}{ }^{-}+\mathrm{HCl}+3 \mathrm{H}_{2} \mathrm{O} \rightarrow \mathrm{H}_{3} \mathrm{BO}_{3}+8 \mathrm{H}^{-}+\mathrm{NaCl}$

$\mathrm{As}_{3}{ }^{+}+8 \mathrm{H}^{-} \rightarrow \mathrm{AsH}_{3}\left(\mathrm{PE}:-62,5^{\circ} \mathrm{C}\right)+\mathrm{H}_{2}$ (excesso)

Isto acaba por permitir, a obtenção de um único sinal para todas as espécies de arsênio em solução nas mesmas condições de acidez.

As determinações de arsênio presentes neste trabalho foram pré-reduzidas com ácido L-ascórbico e realizadas com o agente redutor borohidreto de sódio.

\subsubsection{Espectrometria de Massas com Fonte de Plasma induzidamente acoplada (ICP-MS) para determinação de cádmio e chumbo}

A espectrometria de massas como técnica analítica instrumental permite a separação de espécies iônicas pela razão entre a massa e a carga. É uma técnica de alta sensibilidade capaz de detectar níveis de $\mathrm{pg} \mathrm{g}^{-1}$, além de identificar íons de elementos, compostos simples e moléculas muito complexas, como biopolimeros de alto peso molecular, analisar misturas de substâncias sólidas, líquidas e gasosas, mesmo em presença de matrizes complexas (Giné, 1999; Oliveira 2006; Becker, 2007).

Em moléculas orgânicas podem-se obter informações sobre a constituição estrutural, energias de ligação, informação cinética, físico-química e quântica. Em se tratando de análises inorgânicas, a detecção de isótopos permite a determinação da composição elementar e isotópica, constituindo-se em ferramenta sensível para áreas clínica, geoquímica, paleoambiental, hidrológica, agronômica e de alimentos (Giné, 1999; Oliveira, 2006; Becker, 2007).

Os elementos cádmio e chumbo foram determinados neste trabalho em baixa resolução. 


\subsection{Processo de digestão das amostras}

Neste tabalho foi utilizado o processo de digestão por via úmida em sistema aberto. Assim para a determinação de mercúrio, cádmio e chumbo pesaram-se $0,5 \mathrm{~g}$ de amostra de tecido muscular de peixe em um balão volumétrico de $250 \mathrm{~mL}$. A digestão foi realizada em meio ácido, utilizando-se $1 \mathrm{~mL}$ de ácido nítrico $\left(\mathrm{HNO}_{3}\right)$ concentrado, $2 \mathrm{~mL}$ de ácido sulfúrico $\left(\mathrm{H}_{2} \mathrm{SO}_{4}\right)$ concentrado e $1 \mathrm{~mL}$ de ácido perclórico $\left(\mathrm{HClO}_{4}\right)$ concentrado. Em seguida, 0 material foi mantido em chapa aquecida a $110 \pm 2{ }^{\circ} \mathrm{C}$ durante 30 minutos e após 0 resfriamento, a solução resultante foi diluída até a massa final de $20 \mathrm{~g}$ com água desmineralizada e transferida para frasco plástico com tampa.

A determinação de mercúrio foi realizada por meio da técnica de espectrofotometria de absorção atômica com geração de vapor frio e injeção em fluxo (FIA-CV-AAS), utilizando-se como agente redutor, uma solução de cloreto estanoso a $25 \%$ (v/v). A solução diluída foi inserida manualmente no sistema de introdução de amostra do espectrômetro de absorção atômica.

Para determinação de cádmio e chumbo, uma alíquota de $1 \mathrm{~mL}$ da solução final, foi acrescida de $1 \mathrm{~g}$ de solução de índio $10 \mathrm{ng} \mathrm{g}^{-1}$, utilizada como padrão interno, e diluída até a massa final de $10 \mathrm{~g}$ com água Milli-Q, sendo determinados por meio da técnica de espectrometria de massas com fonte de plasma induzido, HRICP-MS.

A metodologia para determinação de arsênio foi baseada no método descrito por Mustra (2009). Dessa forma, pesou-se 1,0 g de amostra de tecido muscular de peixe em um balão volumétrico de $250 \mathrm{~mL}$. O material foi digerido em meio ácido, utilizando-se $3 \mathrm{~mL}$ de ácido nítrico $\left(\mathrm{HNO}_{3}\right)$ concentrado, onde as amostras permaneceram por 1 hora, após este período foram adicionados 0,5 $\mathrm{mL}$ de ácido sulfúrico $\left(\mathrm{H}_{2} \mathrm{SO}_{4}\right)$ concentrado e $1 \mathrm{~mL}$ de ácido perclórico $\left(\mathrm{HClO}_{4}\right)$ concentrado. (Mustra, 2009; Oygard, 1999).

As amostras foram mantidas em chapa aquecida inicialmente a $100 \pm 2{ }^{\circ} \mathrm{C}$, elevando-se a temperatura gradualmente até atingir $250 \pm 2{ }^{\circ} \mathrm{C}$ durante 4 horas, 
até obter-se um pequeno volume de líquido transparente no fundo do balão volumétrico. A seguir as amostras foram deixadas em geladeira por 24 horas fechadas com filme plástico.

No dia da análise foi adicionado $2 \mathrm{~mL}$ de ácido clorídrico concentrado as amostras e as mesmas foram diluídas até $20 \mathrm{~g}$ de massa final com água Milli-Q. Da solução final, foi retirada uma alíquota de $8 \mathrm{~mL}$ para pré redução com $2 \mathrm{~g}$ de uma solução preparada com iodeto de potássio e Ácido L-áscorbico à $5 \%(\mathrm{v} / \mathrm{v})$, as quais foram completadas até $10 \mathrm{~g}$ de massa com ácido clorídrico diluído a 10 $\%$, após foram colocadas em banho maria à $80^{\circ} \mathrm{C}$ durante 30 minutos.

Após o resfriamento procedeu-se a determinação por meio da técnica de espectrofotometria de absorção atômica com geração de hidretos e injeção em fluxo (FIA-HG-AAS) utilizando uma solução de borohidreto de sódio e hidróxido de sódio a $0,3 \%(\mathrm{v} / \mathrm{v})$ como agente redutor, em espectrofotômetro de absorção atômica.

Para cada lote analisado, foram preparados 2 ensaios em branco e 1 amostra de material de referência certificado (DORM-2 e DOLT-2), submetidos ao mesmo procedimento de digestão a que foram submetidas as amostras. Ambos os ensaios foram medidos em triplicata, durante a determinação de todos os elementos de interesse. A cada 10 leituras de amostras foi lido um branco e um padrão de $0,100 \mu \mathrm{g} \mathrm{mL}^{-1}$.

Solução de $\mathrm{HNO}_{3}$ P. A. $2 \%$ (v/v) (Merck) foi utilizada como diluente para as amostras, construção das curvas de calibração analíticas de $\mathrm{Cd}$ e Pb, e branco da calibração adicionados de solução padrão de índio $1,0 \mu \mathrm{g} \mathrm{mL}^{-1}$ para análise por HRICP-MS.

De modo a verificar o método empregado para determinação de TAs, foram analisadas diferentes alíquotas em triplicata dos materiais de referência designados como Dorm-2 e Dolt-2, ambos provenientes do NRCC - Canadá.

O material de referência Dorm-2, certificado para $\mathrm{Hg}$ total, As total, $\mathrm{Cd}$ total e $\mathrm{Pb}$ total, foi utilizado para comprovar a taxa de recuperação das metodologias utilizadas. 


\subsection{Estudo de homogeneidade}

O material foi submetido ao teste de homogeneidade entre os sachês em duas etapas, antes do envase (sem irradiação), para evitar a reabertura dos sachês, no caso de não se obter um material homogêneo (envase prematuro), e após o envase.

$\mathrm{Na}$ primeira etapa retirou-se uma amostragem de $10 \%$ de cada lote de material preparado por meio de quarteamento. Foram analisados, As, $\mathrm{Hg}, \mathrm{Cd}$ e $\mathrm{Pb}$, a partir de 4 pesagens em triplicata de $1 \mathrm{~g}$ cada, medidas em triplicatas. Após a comprovação estatística da homogeneidade dentro do material, o mesmo foi envasado e enviado para a etapa de irradiação.

Para a segunda etapa do estudo de homogeneidade, após a irradiação, foram selecionados aleatoriamente subconjuntos de 10 sachês de $10 \mathrm{~g}$ cada do material de maior concentração e menor concentração. Os sachês foram subdivididos em 5 unidades irradiadas e 5 unidades não irradiadas, onde foram realizadas as determinações de $\mathrm{Hg}$ e As, em triplicata.

Após a digestão e diluição foram realizadas três leituras em cada uma das triplicatas retiradas de cada um dos 5 sachês selecionados, irradiado e não irradiado, obtendo-se 15 resultados para cada sachê. Os resultados obtidos foram avaliados quanto à normalidade, presença de valores discrepantes (outliers) pelos testes de Dixon e Teste- $Q$, e a homogeneidade foi demonstrada pela análise de variâncias (ANOVA).

O estudo de homogeneidade dentro do sachê foi realizado após envase e irradiação das amostras tomando-se um sachê de ambos os materiais.

Devido a problemas técnicos com o equipamento de ICP-MS, não foi possível a realização do estudo de homogeneidade para os elementos $\mathrm{Cd}$ e $\mathrm{Pb}$, nesta etapa.

Os resultados são descritos nos itens 4.3.1 e 4.3.3, na pg. 111 e 114, respectivamente. 


\subsection{Estudo de estabilidade}

Neste trabalho o estudo de estabilidade foi realizado em curto prazo por meio do planejamento isócrono, uma vez que se procurou simular possíveis condições de temperatura que poderiam ocasionar degradação do material produzido in natura, durante o transporte e recebimento pelos laboratórios participantes do programa piloto de ensaio de proficiência.

Assim, selecionou-se aleatoriamente 32 sachês de cada lote, os quais permaneceram nas temperaturas de $5,23,40$ e $60^{\circ} \mathrm{C}$, pelo período de $0,7,15$, 30 e 45 dias.

Para a avaliação dos resultados obtidos no teste de estabilidade foi utilizada ANOVA para análise de regressão linear e o Teste-t.

A estimativa da incerteza devida à estabilidade em curto prazo (Usts) foi obtida multiplicando-se 0 valor do erro padrão $\left(s\left(b_{1}\right)\right)$ da variável $X$, obtido na ANOVA, dos resultados do teste de estabilidade, testados por um tempo t de 2 meses (os 45 dias foram arredondados para 2 meses, para facilitar os cálculos), conforme a equação 3 (ABNT ISO GUIA 35:2012):

$$
u_{s t s}=\mathrm{s}(\mathrm{b} 1) . t
$$

Onde $\mathbf{u}_{\mathbf{s t s}}=$ incerteza da estabilidade em curto prazo; $\mathbf{s}\left(\boldsymbol{b}_{1}\right)$ é o valor do erro padrão e t é o tempo em dias, meses ou anos.

\subsection{Caracterização dos elementos de interesse}

Os elementos $\mathrm{Hg}$ e As foram caracterizados pela técnica de espectrometria de absorção atômica. Os elementos $\mathrm{Cd}$ e $\mathrm{Pb}$, foram caracterizados pelos 
resultados obtidos a partir de dois laboratórios colaboradores, pela técnica de espectrometria de massas, após passarem por tratamento estatístico adequado.

Desta forma, no caso do material de referência aqui preparado foi conveniente caracterizá-lo para $\mathrm{Hg}$ e As, através dos resultados fornecidos pelas técnicas analíticas empregadas no próprio laboratório. (ABNT ISO GUIDE 35: 2012).

\subsubsection{Cálculo da incerteza para análise pela técnica de AAS}

Neste item do trabalho é demonstrado passo a passo o procedimento de cálculo para determinação de $\mathrm{Hg}$ total via FIA-CV-AAS e As total via FIA-HG-AAS em tecido muscular de peixe.

As etapas envolvidas para estas determinações são: preparação da amostra, preparação da solução padrão, preparação das soluções da curva analítica, calibração e análise das amostras no equipamento.

Deste modo, o diagrama de Ishikawa (espinha de peixe) foi utilizado para identificação dos parâmetros de incerteza acima citados na análise por AAS, como é demonstrado na FIG. 14 (Ulrich, 2011; GUM, 2008; Chui, 2007; EURACHEM, 2002).

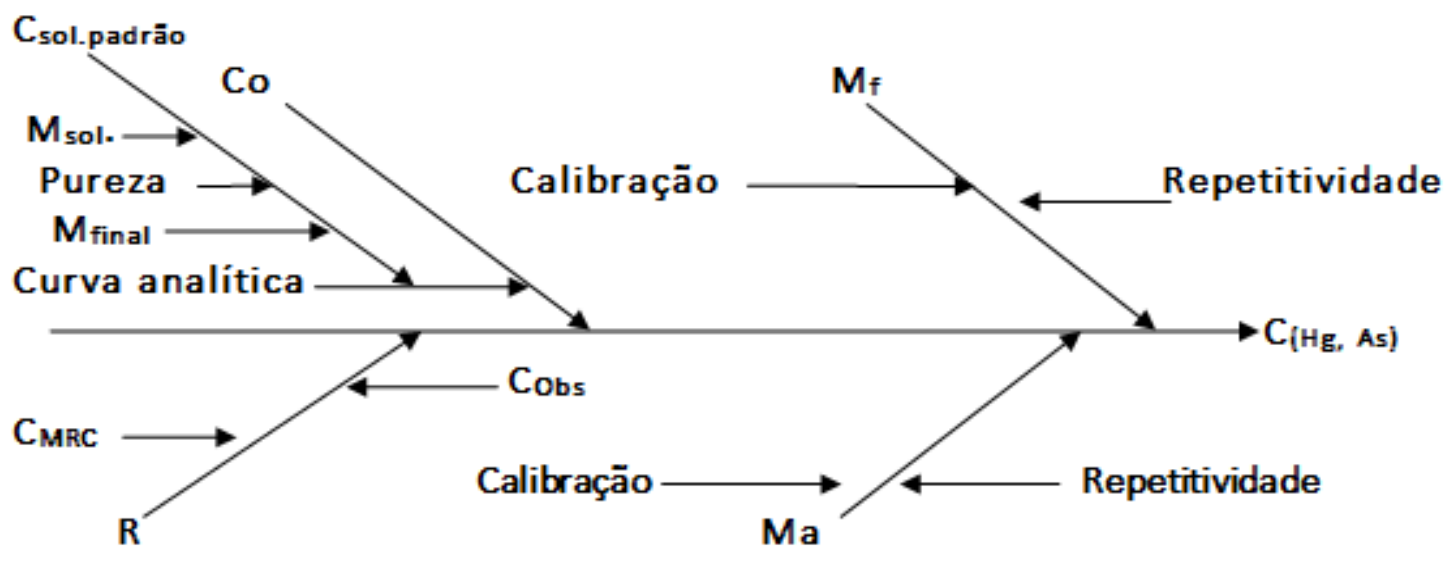

FIGURA 14- Diagrama de causa e efeito para a determinação de THg e TAs por AAS 
Onde: $\mathbf{C}_{\text {solpadrão }}$ - Concentração da solução padrão estoque do elemento; Msol-massa da solução padrão estoque; $\mathbf{M}_{\text {final }}$ - massa da diluição da solução padrão estoque; Pureza - da solução padrão estoque (certificado); Curva analítica - incerteza da curva de calibração; $\mathbf{C}_{\mathbf{M R C}}$ - Concentração do MRC; $\mathbf{C}_{\text {obs }}$ - Concentração do elemento na aliquota do MRC analisado; Co - Concentração do elemento na alíquota analisada; $\mathbf{R}$ - Recuperação de material de referência; mf - Diluição da amostra após digestão; ma - Massa da amostra; Repetibilidade Variabilidade do resultado da medição, obtida por pesagem sucessivas; Calibração - Associada a calibração da balança e/ou micropipetas (preparação da Cdill solução estoque).

A repetibilidade da balança foi determinada pelo desvio padrão obtida na sua verificação diária, utilizando-se padrões calibrados. Além disso, foi empregado para este fim, o gráfico de controle da balança, o qual está inserido como parte do sistema de gestão de qualidade empregado pelo laboratório.

Assim, as incertezas relacionadas a $m_{a}$ e $m_{f}$ são provenientes da pesagem (Ulrich, 2011).

Dessa forma, as etapas de identificação do mensurando $\mathrm{Hg}$ e a relação de cálculo com as variáveis pode ser demonstrada a partir da equação 26 :

$$
C_{H g}=\left(\frac{C_{0} \times m_{f}}{R \times m_{a}}\right) / 1000
$$

Onde $\mathbf{C}_{\mathbf{H g}}=$ Concentração de mercúrio $(\mathrm{Hg})$ na amostra (em ug g ${ }^{-1}$ ), $\mathbf{C o}=$ concentração de $\mathrm{Hg}$ encontrada na alíquota analisada $\left(\mathrm{em} \mathrm{ug} \mathrm{kg}^{-1}\right.$ ), $\mathbf{m}_{\mathbf{f}}=$ massa final, em gramas, (diluição final após digestão da amostra), $\mathbf{R}=$ taxa de recuperação obtida pela análise do material de referência e $\mathbf{m}_{\mathbf{a}}=$ massa de amostra utilizada, em gramas.

Adotando-se o mesmo princípio para o mensurando As total, acrescida de uma segunda etapa de diluição. A relação entre o cálculo e a identificação das variáveis é dada pela equação 27 : 


$$
C_{A s}=\frac{C_{o} \times m_{d i l 1} \times m_{f d i l 2}}{R \times m_{a} \times m_{\text {paradil } 2}}
$$

Onde $\mathbf{C}_{\mathrm{As}}=$ Concentração de arsênio (As) na amostra $\left(\mathrm{em} \mathrm{ug} \mathrm{g}^{-1}\right)$, Co = concentração de As encontrada na alíquota analisada ( $\left.\mathrm{em} \mathrm{ug} \mathrm{kg}^{-1}\right), \mathbf{m}_{\text {dil } 1} \mathbf{l}=$ massa para $1^{\circ}$ diluição em gramas, $\mathbf{m}_{\text {paradil } 2}=$ massa $2^{\circ}$ diluição, em grams, $\mathbf{m}_{\text {fdil }}=$ massa final da $2^{\circ}$ diluição, em gramas, (diluição final), $\mathbf{R}=$ taxa de recuperação obtida pela análise do material de referência e $\mathbf{m}_{\mathbf{a}}=$ massa de amostra utilizada, em gramas.

Em ambos os casos, para cada lote de amostras, é preparada uma curva analítica, com uma série de seis soluções. A análise de cada uma destas soluções foi realizada, no mínimo, por três vezes, para o cálculo da incerteza associada à curva analítica (Ulrich, 2011).

Segundo o Guia Eurachem (2002), a equação utilizada para o cálculo da incerteza na concentração dos mensurandos na alíquota analisada é:

$C_{o}=$ concentração do mensurando determinada na solução de análise $\left(e m \mu g ~ \mathrm{~kg}^{-1}\right)$

$$
u\left(c_{o}\right)=\frac{S}{B_{1}} x \sqrt{\frac{1}{p}+\frac{1}{n}+\frac{\left(c_{o}-\bar{c}\right)^{2}}{Q_{x x}}}
$$

Onde: $\boldsymbol{u}\left(\mathbf{c}_{\boldsymbol{o}}\right)=$ incerteza da concentração elementar estimada do mensurando nas soluções amostra; $\mathbf{S}=$ desvio padrão residual; $\mathbf{B}_{\mathbf{1}}=$ coeficiente angular da função calibração; $\mathbf{p}=$ número de medições realizadas para determinar $\mathrm{C}_{\mathrm{o}} ; \mathbf{n}=$ número total de medições realizadas para a calibração do instrumento; $\mathbf{C}_{\mathbf{o}}=$ concentração do mensurando determinada na solução de 
amostra; $\boldsymbol{c}$ médio = valor médio de concentração das soluções padrão utilizadas na calibração.

Qxx = somatório das concentrações é dado por:

$Q_{x x}=\sum_{j=1}^{n}\left(c_{j}-\bar{c}\right)^{2}$

Onde: $\mathbf{C}_{\mathbf{j}}=$ concentração medida de cada solução utilizada na curva analítica. cjé obtida através da equação da curva analítica $\boldsymbol{c}$ médio = valor médio de concentração das soluções padrão utilizadas na calibração.

$S=$ desvio padrão residual, dado por:

$S=\sqrt{\frac{\sum_{j=1}^{n}\left[A_{j}-\left(B_{0}+B_{1} \cdot c_{i}\right)\right]^{2}}{n-2}}$

Sendo $\boldsymbol{A}_{j}=$ medida de absorbância de cada solução utilizada na curva analítica; $\mathbf{B}_{0}=$ coeficiente linear da função calibração; $\mathbf{B}_{1}=$ coeficiente angular da função calibração; $\mathbf{C}_{\mathbf{i}}=$ concentração real de cada solução utilizada na curva analítica; $\mathbf{n}=$ número total de medições realizadas para a calibração do instrumento; $\mathbf{p}=$ número de medições realizadas para determinar $\mathrm{C}_{\text {o }}$.

C sol padrão: Incerteza para o Preparo da solução padrão

A solução padrão estoque foi preparada a partir da pesagem do Óxido de Mercúrio $(\mathrm{HgO})$ e Óxido de Arsênio (III) $\left(\mathrm{As}_{2} \mathrm{O}_{3}\right)$, sólidos. Os padrões sólidos apresentam pureza informada pelo fabricante. Logo, as contribuições de incerteza 
na preparação da solução padrão estoque são oriundas das atividades de pesagem (balança utilizada) da pureza do padrão (Ulrichl, 2011).

$$
u_{\text {estoque }}=C_{\text {estoque }} \times \sqrt{\left(\frac{u_{P}}{P}\right)^{2}+\left(\frac{u_{m_{p}}}{m_{p}}\right)^{2}+\left(\frac{u_{M_{f}}}{M_{f}}\right)^{2}}
$$

Onde: Cestoque é a concentração calculada da solução padrão estoque, up é a incerteza da pureza (fornecida pelo fabricante), $\mathbf{P}$ é o valor da pureza do padrão, ump e umf é a incerteza da massa utilizada do padrão sólido e incerteza da massa da solução final preparada do padrão, respectivamente. O mesmo procedimento é aplicado para o cálculo das incertezas da massa da amostra e massa final (repetibilidade e calibração da balança utilizada), $\mathbf{m}_{\mathbf{p}}$ é a massa utilizada do padrão e $M_{f}$ é a massa final da solução preparada, como será visto no item $\mathbf{m}_{\mathbf{f}}$ e $\mathbf{m}_{\mathbf{a}}$ :

Foram realizadas duas diluições a partir da solução padrão estoque para o preparo dos pontos da curva de calibração. Estas soluções diluídas tem concentrações iguais a $10 \mu \mathrm{g} \mathrm{g}^{-1}$ e $100 \mu \mathrm{g} \mathrm{kg}^{-1}$.

As incertezas das soluções diluídas são calculadas conforme as equações a seguir:

$$
\begin{aligned}
& u_{C_{\text {dil } \_10}}=C_{\text {dil__ } 10} \times \sqrt{\left(\frac{u_{\text {estoque }}}{C_{\text {estoque }}}\right)^{2}+\left(\frac{u_{m_{p}}}{m_{p}}\right)^{2}+\left(\frac{u_{m_{f}}}{m_{f}}\right)^{2}} \\
& u_{C_{d i l_{-} 100}}=C_{d i l_{-} 100} \times \sqrt{\left(\frac{u_{C_{d i l_{-} 10}}}{C_{\text {dil_ } 10}}\right)^{2}+\left(\frac{u_{m_{t}}}{m_{t}}\right)^{2}+\left(\frac{u_{m_{f}}}{m_{f}}\right)^{2}}
\end{aligned}
$$

Onde: $\mathbf{C}_{\text {dil_10 }}$ e $\mathbf{C}_{\text {dil_100 }}$ são as concentrações calculadas para as soluções de $10 \mu \mathrm{g} \mathrm{g}^{-1}$ e $100 \mu \mathrm{gg}^{-1}, \mathbf{u}_{\mathbf{m t}}$ e $\mathbf{u}_{\mathbf{m f}}$ é a incerteza da massa transferida para 
preparação das soluções e incerteza da massa da solução final preparada, respectivamente. $\mathbf{m}_{\mathbf{t}}$ é a massa transferida de cada solução (no caso da solução de $10 \mu \mathrm{g} \mathrm{g}^{-1}$ é a massa da solução padrão estoque e no caso da solução de 100 $\mu \mathrm{kg}^{-1}$ é a massa da solução de $10 \mu \mathrm{g} \mathrm{g}^{-1}$ ) para obter as diluições e $\mathrm{m}_{\mathrm{f}}$ é a massa final de cada solução preparada.

m $_{\mathbf{f}}$ : diluição da amostra após digestão (massa final) e $\mathbf{m}_{\mathrm{a}}$ : massa da amostra

A massa final da amostra após a digestão é diluída até aproximadamente $20 \mathrm{~g}$ de massa, aqui temos duas fontes de incerteza: $\mathbf{u}_{\mathbf{1}}=$ incerteza da balança fornecida pelo certificado de calibração; $\mathbf{u}_{2}=$ desvio padrão obtido do gráfico de controle (GC) da balança (repetibilidade, ou seja, a variabilidade do resultado da medição através de pesagens sucessivas) (Ulrich, 2011).

A massa da amostra (ma) foi pesada diretamente em balão de vidro com capacidade de $100 \mathrm{~mL}$, sendo influenciada pelas incertezas associadas à repetibilidade e calibração da balança utilizada (Ulrich, 2011).

Neste caso, a incerteza de calibração da balança utilizada é verificada através dos dados do certificado de calibração da mesma. Logo a incerteza padrão combinada $\mathbf{u}_{\mathbf{c}}\left(\mathbf{m}_{\mathrm{f}}\right)$ da massa final e da massa da amostra $\mathbf{u}_{\mathbf{a}}\left(\mathbf{m}_{\mathbf{a}}\right)$ são dadas pela equação 34:

$$
u(m)=\sqrt{\left(u_{1}\right)^{2}+\left(u_{2}\right)^{2}}
$$

Onde $\mathbf{u}_{1}=$ incerteza da repetibilidade, obtida através do desvio padrão informado no gráfico de controle da balança plotado no laboratório, $\mathbf{u}_{\mathbf{2}}=$ incerteza obtida do certificado de calibração da balança. 
R: Incerteza da recuperação obtida pela análise do material de referência certificado

O material de referência certificado (MRC) empregado para todos os mensurandos foi Dorm-2, utilizado para verificar a taxa de recuperação da metodologia. Sua preparação consiste em pesagem de uma massa previamente estabelecida, sendo submetidas à mesma digestão aplicada as amostras de tecido muscular de peixe e diluição até massa final (Ulrich, 2011).

Nesta etapa a incerteza da solução inicial será fornecida pelos dados obtidos do certificado do MRC e das incertezas da massa utilizada do MRC e da massa final da solução preparada.

A incerteza da recuperação do MRC será dada pelas equações 35, 36 e 37:

$u_{\text {sol }}=C_{\text {sol }} \times \sqrt{\left(\frac{u M R C}{C_{M R C}}\right)^{2}+\left(u_{\text {balança }}\right)^{2}}$

Onde: $\boldsymbol{u}_{\text {sol }}=$ incerteza da solução preparada; $\boldsymbol{C}_{\boldsymbol{s o l}}=$ concentração do MRC obtida na análise; $\boldsymbol{u}_{M R C}=$ incerteza do MRC fornecida pelo fabricante do padrão; $\boldsymbol{C}_{M R C}=$ concentração do padrão fornecida pelo fabricante; $\boldsymbol{u}_{\text {balança }}=$ incerteza da balança utilizada como calculado anteriormente.

$$
R_{m}=\frac{C_{o b s}}{C_{M R C}}
$$

Onde: $\boldsymbol{R}_{\boldsymbol{m}}=$ taxa de recuperação; $\boldsymbol{C}_{\boldsymbol{o b s}}=$ Concentração observada na análise do MRC; $\boldsymbol{C}_{\mathbf{M R C}}=$ concentração do MRC fornecida pelo fabricante.

$$
u_{R m}=R_{m} \times \sqrt{\left(\frac{u_{s o l}}{C_{s o l}}\right)^{2}+\frac{S_{o b s}^{2}}{n \times C_{o b s}^{2}}}
$$


Onde: $\boldsymbol{u}_{\boldsymbol{R} \boldsymbol{m}}=$ incerteza na recuperação do $\mathrm{MRC} ; \boldsymbol{R}_{\boldsymbol{m}}=$ taxa de recuperação do MRC; $\boldsymbol{u}_{\text {sol }}=$ incerteza da solução preparada; $\boldsymbol{C}_{\text {sol }}=$ concentração do MRC obtida na análise; $\mathbf{s}_{\mathrm{obs}}=$ Desvio padrão dos resultados das análises replicatas do MRC; $\boldsymbol{C}_{o b s}=$ Concentração observada na análise do MRC; $\mathbf{n}=$ número de replicatas.

Combinando-se as equações anteriores estima-se a incerteza padrão combinada para a análise de $\mathrm{Hg}$ total como é demonstrado nas equações 38 :

$u_{C_{H_{g}}}=C_{H g} \times \sqrt{\left(\frac{u\left(C_{o}\right)}{C_{o}}\right)^{2}+\left(\frac{u\left(\operatorname{Sol}_{100 \mathrm{ppb}}\right)}{\operatorname{Sol}_{100 \mathrm{ppb}}}\right)^{2}+\left(\frac{u\left(m_{f}\right)}{m_{f}}\right)^{2}+\left(\frac{u(R)}{R}\right)^{2}+\left(\frac{u\left(m_{a}\right)}{m_{a}}\right)^{2}}$

Onde: $\boldsymbol{u}\left(\boldsymbol{C}_{\boldsymbol{o}}\right)=$ incerteza na concentração elementar estimada do mensurando na solução amostra; $\mathbf{C}_{\mathbf{o}}=$ concentração elementar estimada do mensurando na solução amostra; $\boldsymbol{u}\left(\right.$ sol $\left._{100 p p b}\right)=$ incerteza da solução diluída de 100 ppb para construção da curva analítica; Sol 100ppb $_{\text {= concentração da solução }}$ de 100 ppb para construção da curva analítica; $\boldsymbol{u}(\boldsymbol{m f})$ = incerteza na diluição da amostra após digestão; $\boldsymbol{m} \boldsymbol{f}=$ massa final da diluição da amostra após digestão, gramas; $\boldsymbol{u}(\boldsymbol{R})=$ incerteza na recuperação do material de referência certificado; $\mathbf{R}$ = recuperação do material de referência certificado; $\mathbf{u}(\mathbf{m a})=$ incerteza na pesagem da amostra; $\mathbf{m a}=$ massa da amostra.

Para TAs, a estimativa é dada pela equação 39 , onde acrescentou-se a incerteza para solução de adição (Spike), u(solad) - incerteza da solução de adição; Csoladiç - Concentração da solução de adição.

$$
u_{C_{A s}}=C_{A s} \times \sqrt{\left.\left(\frac{u\left(C_{o}\right)}{C_{o}}\right)^{2}+\left(\frac{u\left(\text { Sol }_{100 p p b}\right)}{\text { Sol }}\right)_{00 p p b}\right)^{2}+\left(\frac{u\left(m_{f}\right)}{m_{f}}\right)^{2}+\left(\frac{u(R)}{R}\right)^{2}+\left(\frac{u(\text { soladid }}{\text { Csoladic }}\right)^{2}+\left(\frac{u\left(m_{a}\right)}{m_{a}}\right)^{2}}
$$

Desta forma a incerteza expandida (U) é obtida pela multiplicação da incerteza combinada pelo fator de abrangência $k$. $O$ valor do fator utilizado é 
geralmente igual a 2, para um nível de confiança de $95 \%$. Portanto, a incerteza expandida é (GUM, 2008):

$U=u_{c} \times 2$

Então, a concentração de mercúrio ou arsênio com incerteza associada (U) é dada por:

$\mathrm{CHg}_{\mathrm{H}}=\mathrm{x} \pm U \mu \mathrm{gg} \mathrm{g}^{-1}$

$\mathrm{C}_{\mathrm{As}}=\mathrm{x} \pm \mathrm{U} \mu \mathrm{g} \mathrm{g}^{-1}$

\subsubsection{Cálculo da incerteza para análise pela técnica de ICP-MS}

A estimativa da incerteza para a técnica de ICP-MS, apresenta as seguintes etapas: preparação da amostra, diluição das amostras, preparação da solução padrão, preparação das soluções da curva analítica, calibração e análise das amostras no equipamento (GUM, 2008; Chui, 2007; EURACHEM, 2002) (FIG. 15).

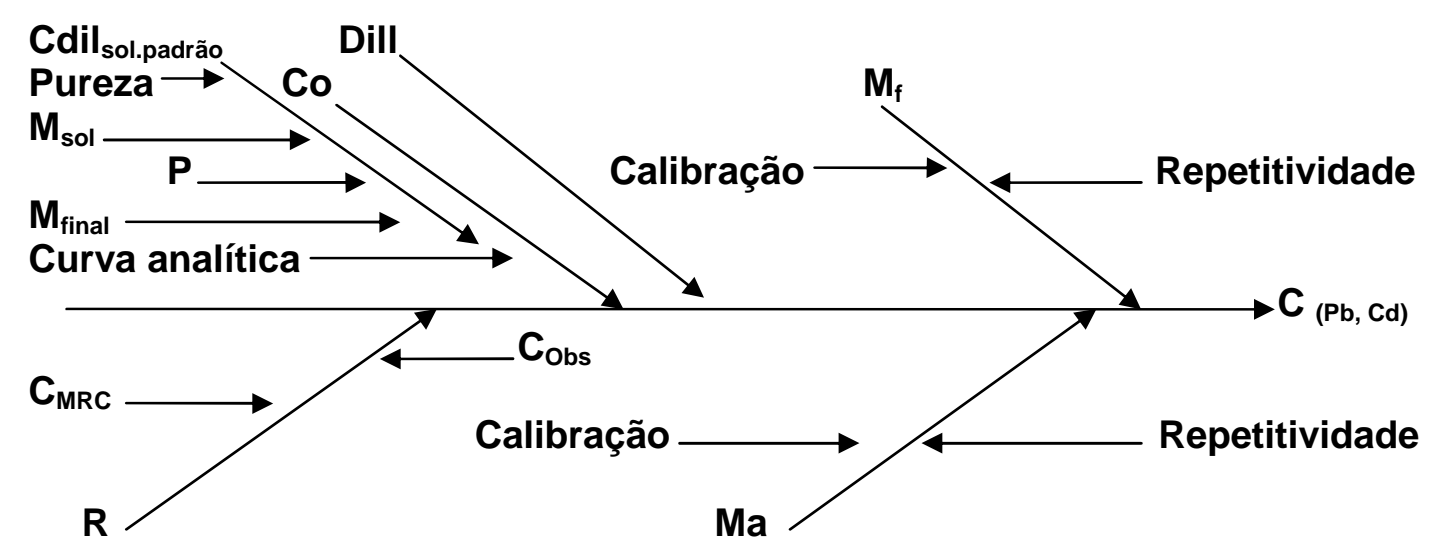

FIGURA 15- Diagrama de causa e efeito para a determinação de TCd e TPb por HRICP-MS

Onde: $\mathbf{C}_{\text {solpadrão }}$ - Concentração da solução padrão estoque do elemento; Msol-massa da solução padrão estoque; Repetibilidade - Variabilidade do 
resultado da medição, obtida por pesagem sucessivas; Calibração - Associada a calibração da balança e/ou micropipeta; $\mathbf{M}_{\text {final }}$ - massa da diluição da solução padrão estoque; Pureza - da solução padrão estoque (certificado); Curva analítica - incerteza da curva de calibração; $\mathbf{C}_{\text {MRC }}$ - Concentração do MRC; $\mathbf{C}_{\text {obs }}$ - Concentração do elemento na aliquota do MRC analisado $\mathbf{C}_{o}$ - Concentração elementar estimada do mensurando nas soluções amostra; $\mathbf{R}$ - Recuperação de material de referência; $\mathbf{m}_{\mathbf{f}}$ - A massa de diluição final; $m_{a}$ - Massa da amostra; $\mathbf{P}$ Precisão associada à diluição das soluções de calibração (Cdill solução estoque); Dill - Diluição da amostra.

A equação 43 é utilizada para o cálculo da incerteza na concentração do mensurando na alíquota analisada:

$\mathbf{C}_{\mathrm{o}}=$ concentração elementar estimada do mensurando nas soluções amostra (em $\mu \mathrm{g} \mathrm{kg}{ }^{-1}$ )

$$
u\left(c_{o}\right)=\frac{S}{B_{1}} x \sqrt{\frac{1}{p}+\frac{1}{n}+\frac{\left(c_{o}-\bar{c}\right)^{2}}{Q_{x x}}}
$$

Onde: $\boldsymbol{u}\left(\boldsymbol{c}_{0}\right)=$ incerteza da concentração elementar estimada do mensurando nas soluções amostra; $\mathbf{S}=$ desvio padrão residual; $\mathbf{B}_{\mathbf{1}}=$ coeficiente angular da função calibração; $\mathbf{p}=$ número total de medições realizadas para a calibração do instrumento; $\mathbf{n}=$ número total de medições realizadas para a calibração do instrumento; $\mathbf{c}_{0}=$ concentração medida; $\boldsymbol{c}$ médio $=$ valor médio de concentração das soluções padrão utilizadas na calibração.

$$
\begin{gathered}
\mathbf{Q} \mathbf{x x}=\text { somatório das concentrações é dado por: } \\
Q_{x x}=\sum_{j=1}^{n}\left(c_{j}-\bar{c}\right)^{2}
\end{gathered}
$$


Onde: $\mathbf{c}_{\mathbf{j}}=$ concentração medida de cada solução utilizada na curva analítica. cjé obtida através da equação da curva analítica $\boldsymbol{c}$ médio $=$ valor médio de concentração das soluções padrão utilizadas na calibração.

$S=\sqrt{\frac{\sum_{j=1}^{n}\left[A_{j}-\left(B_{0}+B_{1} \cdot c_{i}\right)\right]^{2}}{n-2}}$

Onde: $\mathbf{S}=$ desvio padrão residual; $\boldsymbol{A}_{\boldsymbol{j}}=$ medida de absorbância de cada solução utilizada na curva analítica; $\mathbf{B}_{0}=$ coeficiente linear da função calibração; $\mathbf{B}_{1}=$ coeficiente angular da função calibração; $\mathbf{C}_{\mathbf{i}}=$ concentração real de cada solução utilizada na curva analítica; $\mathbf{p}=$ número total de medições realizadas para a calibração do instrumento; $\mathbf{n}=$ número de medições realizadas para determinar Co.

Cdil: Incerteza associada ao preparo da solução padrão

A solução padrão estoque foi preparada a partir da pesagem dos óxidos de Cádmio (CdO) e Chumbo (II) (PbO), sólidos. As contribuições de incerteza na preparação da solução padrão estoque são oriundas das atividades de pesagem (balança utilizada) e da pureza do padrão (informada pelo fabricante) (Ulrich, 2011).

$$
u_{C_{d i l}}=C_{\text {dil }} \times \sqrt{\left(\frac{u_{C_{e s t}}}{C_{\text {est }}}\right)^{2}+\left(u_{\text {equip }}\right)^{2}}
$$

Onde: $\boldsymbol{u}_{\text {cdil }}=$ incerteza da solução padrão diluída; $\boldsymbol{C}_{\text {dil }}=$ concentração da solução padrão diluída; $\boldsymbol{u}_{\text {cest }}=$ incerteza da solução estoque; $\boldsymbol{C}_{\text {est }}=$ concentração da solução estoque; $\boldsymbol{u}_{\text {equip }}$ = incerteza da balança ou pipeta . 
u(solad): incerteza da solução de adição

A incerteza da solução de adição foi calculada do mesmo modo que as soluções estoque padrão de Cádmio, Chumbo e Arsênio, pela equação 31. Assim a principal contribuinte de incerteza na preparação foi à pesagem da solução de adição (balança utilizada) e a pureza dos padrões.

P: Incerteza associada à precisão de uma medida

A partir das soluções padrão das curvas analisadas e os desvios obtidos na leitura dessas soluções (normalmente o desvio utilizado é o de maior valor que esteja na faixa de concentração das amostras analisadas), obtém-se a incerteza de precisão do equipamento (GUM, 2008; Chui, 2007; EURACHEM, 2002).

$$
\mu_{\text {precisão }}=\frac{P}{\sqrt{3}}
$$

Onde: $\boldsymbol{u}_{\text {precisão }}=$ incerteza de precisão; $\mathbf{P}=$ é o desvio padrão de maior valor, para valores extremos assume-se distribuição retangular $(\sqrt{3})$.

Dil: Incerteza na diluição da amostra

A Incerteza na diluição da amostra é fornecida pela equação:

$$
u_{D}=\sqrt{\left(\frac{u_{m f}}{m i}\right)^{2}+\left(\frac{m_{f} \times u_{m i}}{m_{f}^{2}}\right)^{2}}
$$


Onde: $\mathbf{u}_{\mathbf{D}}=$ incerteza da diluição; $\mathbf{u}_{\mathrm{mf}}=$ incerteza da massa final; $\mathbf{M}_{\mathbf{i}}=$ massa inicial; $u_{m i}=$ incerteza da massa inicial; $\mathbf{M}_{\mathbf{f}}=$ massa final da amostra. Incerteza das massas $u_{m i}$ e $u_{m f}$ é dada pela incerteza da balança.,

$\mathbf{m}_{\mathrm{f}}$ : diluição da amostra após a digestão (massa final ) e $\mathrm{m}_{\mathrm{s}}$ : massa da amostra

A amostra é diluída após o processo de digestão para aproximadamente 20 g em massa. Assim, consideraram-se duas fontes de incerteza: u1 = incerteza da balança fornecida pelo certificado de calibração; $\mathbf{u} 2$ = desvio padrão obtido do gráfico de controle (GC) da balança (repetibilidade, ou seja, a variabilidade do resultado da medição através de pesagens sucessivas) (Ulrich, 2011).

Neste caso, massa da amostra também foi pesada diretamente em balão de vidro com capacidade de $100 \mathrm{~mL}$. Sendo influenciada pelas incertezas associadas à repetibilidade e calibração da balança utilizada (Ulrich, 2011).

Logo, a incerteza padrão combinada $\mathbf{u}_{\mathbf{c}}\left(\mathbf{m}_{\mathbf{f}}\right)$ da massa final e da massa da amostra $\mathbf{u a}_{\mathbf{a}}(\mathrm{ma})$ através da equação 49 :

$u(m)=\sqrt{\left(u_{1}\right)^{2}+\left(u_{2}\right)^{2}}$

Onde $\mathbf{u} 1$ = incerteza da repetitividade, obtida através do desvio padrão informado no gráfico de controle da balança plotado no laboratório, $\mathbf{u} 2$ = incerteza obtida do certificado de calibração da balança. 
R: Incerteza da recuperação obtida pela análise do material de referência certificado

O material de referência certificado (MRC) empregado para todos os mensurandos foi o Dorm-2, utilizado para verificar a taxa de recuperação da metodologia. Sua preparação seguiu as mesmas etapas de cálculo da pg. 100.

A incerteza da recuperação do MRC será dada pelas equações 50,51 e 52:

$u_{\text {sol }}=C_{\text {sol }} \times \sqrt{\left(\frac{u_{M R C}}{C_{M R C}}\right)^{2}+\left(u_{\text {balangsa }}\right)^{2}}$

Onde: $\boldsymbol{u}_{\text {sol }}=$ incerteza da solução preparada; $\boldsymbol{C}_{\boldsymbol{s o l}}=$ concentração do MRC obtida na análise; $\boldsymbol{u}_{M R C}=$ incerteza do MRC fornecida pelo fabricante do padrão; $\boldsymbol{C}_{\text {padrão }}=$ concentração do MRC fornecida pelo fabricante; $\boldsymbol{u}_{\text {balança }}=$ incerteza da balança utilizada como calculado anteriormente.

$$
R_{m}=\frac{C_{o b s}}{C_{M R C}}
$$

Onde: $\boldsymbol{R}_{\boldsymbol{m}}=$ taxa de recuperação; $\boldsymbol{C}_{\boldsymbol{o b s}}=$ Concentração observada na análise do MRC; $\boldsymbol{C}_{M R C}=$ concentração do MRC fornecida pelo fabricante.

$u_{R m}=R_{m} \times \sqrt{\left(\frac{u_{s o l}}{C_{s o l}}\right)^{2}+\frac{S_{o b s}^{2}}{n \times C_{o b s}^{2}}}$

Onde: $\boldsymbol{u}_{\boldsymbol{R} \boldsymbol{m}}=$ incerteza na recuperação do $\mathrm{MRC} ; \boldsymbol{R}_{\boldsymbol{m}}=$ taxa de recuperação do MRC; $\boldsymbol{u}_{\text {sol }}=$ incerteza da solução preparada; $\boldsymbol{C}_{\text {sol }}=$ concentração do MRC obtida na análise; $\mathbf{S}_{\text {obs }}=$ Desvio padrão dos resultados das análises replicatas do 
MRC; $\boldsymbol{C}_{\text {obs }}=$ Concentração observada na análise do $\mathrm{MRC} ; \mathbf{n}=$ número de replicatas.

Combinando-se as equações anteriores estima-se a incerteza combinada para a análise de $\mathrm{Pb}$ e Cd por ICP-MS como é demonstrado na equação a seguir:

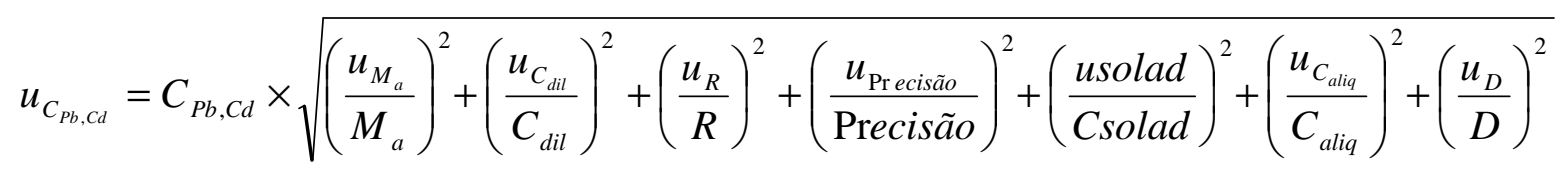

Desta forma a incerteza expandida (U) é obtida pela multiplicação da incerteza padrão combinada pelo fator de abrangência $k$, como descrito anteriormente na pg. 102.

O valor do fator utilizado é geralmente igual a 2, para um nível de confiança de $95 \%$. Portanto, a incerteza expandida é:

$U=u_{c} \times 2$

Então, a concentração de cádmio e chumbo com incerteza associada é:

$$
\begin{aligned}
& \mathrm{CPb}_{\mathrm{Pb}}=\mathrm{x} \pm U \mathrm{Ug} \mathrm{g}^{-1} \\
& \mathrm{C}_{\mathrm{Cd}}=\mathrm{x} \pm U \mathrm{Ug} \mathrm{g}^{-1}
\end{aligned}
$$




\section{RESULTADOS E DISCUSSÕES}

\subsection{Resultados do Teste para Fortificação do material de referência}

O estudo preliminar das concentrações dos metais de interesse no tecido muscular do tucunaré evidenciou concentrações iniciais de mercúrio de $0,243 \mu \mathrm{g}$ $\mathrm{g}^{-1}$ e $0,532 \mu \mathrm{g} \mathrm{g}^{-1}$, (Apêndice $C, \mathrm{TAB}$. 167) demonstrando que não era necessário adicionar este metal ao tecido, enquanto que para as amostras de menor concentração, as concentração de As, $\mathrm{Cd}$ e Pb foram 0,0092 $\mu \mathrm{g} \mathrm{g}{ }^{-1}, 0,0084 \mu \mathrm{g} \mathrm{g}$ ${ }^{1}$ e $0,072 \mu g^{-1}$, respectivamente. Para as amostras de maior concentração foram $0,0096 \mu \mathrm{g} \mathrm{g}^{-1}, 0,0088 \mu \mathrm{g} \mathrm{g}{ }^{-1}, 0,082 \mu \mathrm{g} \mathrm{g}^{-1}$, respectivamente. Devido às baixas concentrações naturais observadas optou-se por adicionar duas concentrações de $\mathrm{As}, \mathrm{Cd}$ e $\mathrm{Pb}$ ao tecido muscular do peixe (TAB. 4 e 5 ).

TABELA 4- Resultados médios da Recuperação do analito adicionado as amostras de tecido muscular de peixe em menor concentração

\begin{tabular}{ccccc}
\hline Analito & $\begin{array}{c}\text { Concentração } \\
\text { Natural } \\
\mu g^{-1}\end{array}$ & $\begin{array}{c}\text { Concentração } \\
\text { Adicionada } \\
\mu g^{-1}\end{array}$ & $\begin{array}{c}\text { Concentração } \\
\text { Obtida } \\
\mu g^{-1}\end{array}$ & Recuperação \\
\hline $\mathrm{As}$ & 0,092 & 0,909 & 0,597 & $\%$ \\
$\mathrm{Cd}$ & 0,0084 & 0,909 & 0,710 & 79 \\
$\mathrm{~Pb}$ & 0,072 & 1,364 & 0,670 & 49 \\
\hline
\end{tabular}

TABELA 5- Resultados médios da Recuperação do analito adicionado as amostras de tecido muscular de peixe em maior concentração

\begin{tabular}{ccccc}
\hline Analito & $\begin{array}{c}\text { Concentração } \\
\text { Natural } \\
\mu \mathrm{g} \mathrm{g}^{-1}\end{array}$ & $\begin{array}{c}\text { Concentração } \\
\text { Adicionada } \\
\mu \mathrm{g} \mathrm{g}^{-1}\end{array}$ & $\begin{array}{c}\text { Concentração } \\
\text { Obtida } \\
\mu \mathrm{g} \mathrm{g}^{-1}\end{array}$ & $\begin{array}{c}\text { Recuperação } \\
\%\end{array}$ \\
\hline $\mathrm{As}$ & 0,096 & 1,154 & 0,894 & 77 \\
$\mathrm{Cd}$ & 0,0088 & 1,154 & 1,100 & 95 \\
$\mathrm{~Pb}$ & 0,082 & 1,923 & 1,151 & 60 \\
\hline
\end{tabular}

As recuperações nas amostras não foram próximas de $100 \%$ e situaramse nos seguintes intervalos: 66-77 \% (As); 79-95 \% (Cd), 49-60\% (Pb). Contudo a presença de compostos voláteis desses elementos não afetou a homogeneidade do material preparado como será observado no item 4.2 e 4.3.2. 


\subsection{Resultados de homogeneidade obtidos na etapa de pré envase}

Foram selecionadas quatro replicatas e realizada três pesagens de $0,5 \mathrm{~g}$ de cada para determinar os teores dos metais de interesse. Os resultados obtidos foram utilizados para análise estatística (ANOVA-fator único) a fim de indicar que o material estava adequado para o envase ou se seria necessária uma nova etapa de homogeneização.

Nas Tabelas 6 e 7 são apresentados os resultados das 4 replicatas analisadas para os elementos de nos estudos de adição de $1,0 \mu \mathrm{g} \mathrm{g}^{-1}$ para As e $\mathrm{Cd}$, para as amostras de concentração baixa e 1,5 $\mathrm{g} \mathrm{g}^{-1}$ para As e Cd para maior concentração, $1,5 \mu \mathrm{g} \mathrm{g}^{-1}$ para $\mathrm{Pb}$ em concentração baixa e 2,5 $\mu \mathrm{g} \mathrm{g}^{-1}$ para maior concentração de $\mathrm{Pb}$.

Aplicou-se a estatística ANOVA fator único para verificar a homogeneidade das amostras obtidas para estes estudos, a fim de encaminha-las para etapa de envase e irradiação. (TAB. 6 e 7).

TABELA 6- Concentração média, variância, desvio padrão, DPR e resultados da ANOVA, calculados na determinação de $\mathrm{Hg}$, As, $\mathrm{Cd}$ e $\mathrm{Pb}$, em $\mu \mathrm{g} \mathrm{g} \mathrm{g}^{-1}$, nas amostras de menor concentração, pré-envase (base úmida)

\begin{tabular}{|c|c|c|c|c|c|}
\hline $\begin{array}{c}\text { Temperatura } \\
23^{\circ} \mathrm{C}\end{array}$ & & $\begin{array}{c}\mathrm{Hg} \\
\left(\mu \mathrm{g} \mathrm{g}^{-1}\right)\end{array}$ & $\begin{array}{c}\text { As } \\
\left(\mu g^{-1}\right)\end{array}$ & $\begin{array}{c}C d \\
\left(\mu g^{-1}\right)\end{array}$ & $\begin{array}{c}\mathrm{Pb} \\
\left(\mu \mathrm{g} \mathrm{g}^{-1}\right)\end{array}$ \\
\hline Média \pm DP & & $0,242 \pm 0,06$ & $0,597 \pm 0,02$ & $0,639 \pm 0,01$ & $0,670 \pm 0,01$ \\
\hline Variância & & 0,00003 & 0,0005 & 0,0002 & 0,0001 \\
\hline DPR \% & & 2,3 & 3,7 & 1,9 & 1,4 \\
\hline$F_{\text {calculado }}$ & & 0,27 & 1,96 & 0,22 & 0,05 \\
\hline$F_{\text {tabelado }}$ & $g l($ total $)=11$ & 4,26 & 4,07 & 4,26 & 4,26 \\
\hline valor-P & & 0,77 & 0,20 & 0,80 & 0,95 \\
\hline
\end{tabular}

DPR \%-desvio padrão relativo percentual, F-valor obtido para teste de Fisher, valor-P para $95 \%$ de confiança, gl-grau de liberdade. 
TABELA 7- Concentração média, variância, desvio padrão, DPR e resultados da ANOVA, calculados na determinação de $\mathrm{Hg}, \mathrm{As}, \mathrm{Cd}$ e $\mathrm{Pb}$, em $\mu \mathrm{g} \mathrm{g}^{-1}$, nas amostras de maior concentração, pré-envase (base úmida)

\begin{tabular}{|c|c|c|c|c|c|}
\hline $\begin{array}{c}\text { Temperature } \\
23^{\circ} \mathrm{C}\end{array}$ & & $\begin{array}{c}\mathrm{Hg} \\
\left(\mu \mathrm{g} \mathrm{g}^{-1}\right)\end{array}$ & $\begin{array}{c}\text { As } \\
\left(\mu g g^{-1}\right)\end{array}$ & $\begin{array}{c}C d \\
\left(\mu g g^{-1}\right)\end{array}$ & $\begin{array}{c}P b \\
\left(\mu g g^{-1}\right)\end{array}$ \\
\hline Média \pm DP & & $0,532 \pm 0,01$ & $0,895 \pm 0,01$ & $1,030 \pm 0,05$ & $1,151 \pm 0,04$ \\
\hline Variância & & 0,0001 & 0,0001 & 0,0033 & 0,0015 \\
\hline DPR\% & & 2,1 & 0,8 & 5,1 & 3,3 \\
\hline$F_{\text {calculado }}$ & $g l($ total $)=11$ & 0,94 & 0,57 & 1,55 & 0,17 \\
\hline$F_{\text {tabelado }}$ & & 4,07 & 4,07 & 4,26 & 4,26 \\
\hline valor- $P$ & & 0,47 & 0,65 & 0,26 & 0,84 \\
\hline
\end{tabular}

Para os elementos analisados, o teste da ANOVA confirmou não haver diferenças significativas entre os resultados, pois o valor de $F_{\text {calculado }}<F_{\text {crítico, }}$, e, portanto, as amostras podem ser consideradas homogêneas para os elementos adicionados podendo prosseguir para as etapas de envase e irradiação (Vieira, 2006; Linsinger, 2004).

\subsection{Resultados obtidos para o estudo de homogeneidade para o elemento Mercúrio após a irradiação}

Para o segundo estudo de homogeneidade selecionou-se 10 sachês, separados em cinco sachês irradiados e cinco sachês não irradiados, de cada material. Após o retorno da irradiação, cerca de dois dias, ambos permaneceram a temperatura de $23 \pm 0,5{ }^{\circ} \mathrm{C}$ até o inicio do estudo. Foi retirado $0,5 \mathrm{~g}$ de amostra de cada sachê em triplicata para realização dos ensaios de determinação como foi descrito no item 3.7. 
Neste item a proposta era verificar se ocorreriam alterações nas concentrações, medidas inicialmente antes do envase, após o envase e irradiação, já que o propósito da irradiação era apenas prolongar a conservação do material até a etapa de análise por parte dos laboratórios participantes do ensaio de proficiência.

Observando a Tabela 8 e 9, verificamos que para o elemento mercúrio determinado na amostra de menor e maior concentração irradiadas ocorreu um aumento de 18,3 \% na concentração, quando comparadas as medidas iniciais (Tabelas 6 e 7) e após a irradiação.

TABELA 8- Média \pm DP, variância, DPR e resultados da ANOVA, obtidos na determinação de mercúrio total em $\mu \mathrm{g} \mathrm{g}^{-1}$ por FIA-CV-AAS, na amostra de menor concentração (base úmida) para o estudo de homogeneidade

\begin{tabular}{|c|c|c|}
\hline \multicolumn{3}{|c|}{ Concentração média de $\mathrm{THg}\left(\mu \mathrm{g} \mathrm{g}^{-1}\right)$} \\
\hline Temperatura & Menor & Menor não \\
\hline $23^{\circ} \mathrm{C}$ & irradiada & irradiada \\
\hline Média $\pm D P$ & $0,294 \pm 0.01$ & $0,284 \pm 0,01$ \\
\hline Variância & 0,0001 & 0,0002 \\
\hline$D P R \%$ & 3,0 & 4,6 \\
\hline$F_{\text {calculado }}$ & 1,85 & 0,21 \\
\hline \multirow[t]{2}{*}{$F_{\text {tabelado }}$} & 3,88 & 3,88 \\
\hline & $g l(M Q d e n t r o)=12$ & \\
\hline valor-P & 0,97 & 0,26 \\
\hline
\end{tabular}


TABELA 9 - Média \pm DP, variância, DPR e resultados da ANOVA, obtidos na determinação de mercúrio total em $\mu \mathrm{g} \mathrm{g}^{-1}$ por FIA-CV-AAS, na amostra de maior concentração (base úmida) para o estudo de homogeneidade

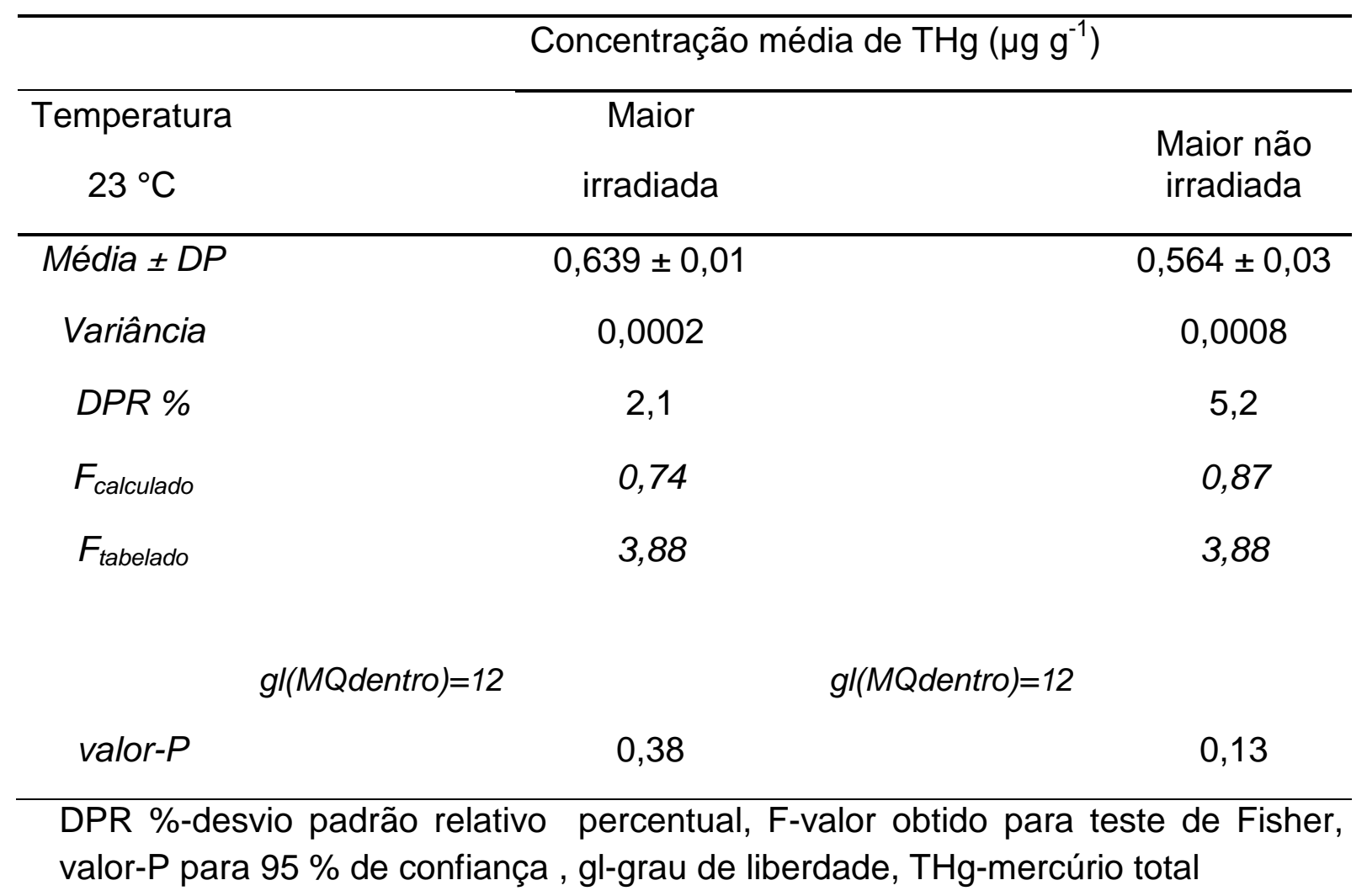

As possíveis causas para o aumento na concentração ocorrem em função da dose de irradiação, pois doses elevadas (acima de 10,0 \pm 1,05 KGy) podem levar a produção de radicais livres presentes na água não ligada (radiólise da água) (Martins, 2011; Silva e Roza, 2010; Ornellas, 2006; Villavicencio, 1998).

A radiação interage com a molécula de água, alterando sua composição nos níveis de energia. As substâncias formadas ficam em um estado excitado $\left(\mathrm{H}_{2} \mathrm{O}^{*}\right)$ ou levam a formação de radicais livres, como: $\mathrm{H}_{3} \mathrm{O}^{+}, \mathrm{H}_{2} \mathrm{O}^{+}$, e $\mathrm{H}_{2} \mathrm{O}^{-}$, que por serem instáveis produzem outros radicais livres do tipo $\mathrm{H}^{+}$e $\mathrm{OH}^{-}$(Martins, 2011; Silva e Roza, 2010; Ornellas, 2006; Villavicencio, 1998).

Esses radicais possuem alta reatividade e interferem na quebra de ligações químicas de proteínas, lipídios gerando carbonetos, mercaptanas, sulfetos e dissulfetos, levando a alteração de sabor, odor, cor, consistência, aumento do pH, liberação de amônia, gás carbônico, compostos de enxofre (Martins, 2011; Silva e Roza, 2010; Ornellas, 2006; Villavicencio, 1998). 
A temperatura atingida durante o processo de irradiação é da ordem de 24 $\pm 4^{\circ} \mathrm{C}$.

Em virtude de problemas técnicos que impossibilitaram a determinação dos metais $\mathrm{Cd} \mathrm{e} \mathrm{Pb}$ durante a segunda etapa do estudo de homogeneidade, o material permaneceu congelado a $-20^{\circ} \mathrm{C}$ durante 3 meses, antes da etapa de irradiação. Desse modo, a exposição de um material com alto teor de umidade, a longos períodos de congelamento, pode ocasionar a formação de microcristais de gelo que podem diluir a concentração do elemento de interesse ou pode acarretar a perda de umidade pela sublimação dos microcristais de gelo, levando ao aumento daconcentração do elemento de interesse (Damodaran, 2010; Dellamodesta, 1994).

Neste caso as amostras de maior concentração apresentaram uma variação de 2,5 \% e a de menor concentração 18,3 \% em relação ao valor medido antes do envase do material.

No entanto, todos os resultados encontram-se dentro da incerteza de expandiada do material aproximadamente $22 \%$.

Os resultados obtidos através da ANOVA para o mercúrio apresentados nas (TAB. 8 e 9) confirmaram não haver diferenças significativas entre eles avaliando-se $o$ valor de $F$, com $F_{\text {calculado }}<F_{\text {crítico, }}$ as amostras podem ser consideradas homogêneas para o elemento estudado.

A análise de tendência foi realizada através da regressão linear via excel®, demonstrando não haver tendência nos resultados obtidos nas Tabelas 8 e 9 , avaliando-se 0 valor- $P$ (probabilidade do valor do teste $t$ tabelado ser $\geq$ ao teste $t$ calculado), ou seja, valor-p adotado ao nível de significância (igual a 0,05) dever ser maior que 0,05 , para indicar que não há tendência. 


\subsubsection{Estudo da massa mínima para mercúrio total}

Foi realizado o estudo da massa mínima para o elemento mercúrio total, assim tomaram-se 6 porções de 0,100 a $1,0 \mathrm{~g}$ do material de maior concentração, realizando determinações de mercurio total por meio da técnica de FIA-CV-AAS. Este estudo também possibilitou avaliar a homogeneidade dentro dos sachês. $\mathrm{Na}$ FIG.16 são apresentados os desvios padrões relativos as porções analisadas, cuja média foi de $9,2 \pm 0,5 \%$ (variação de 1,0 a 2,8\%).

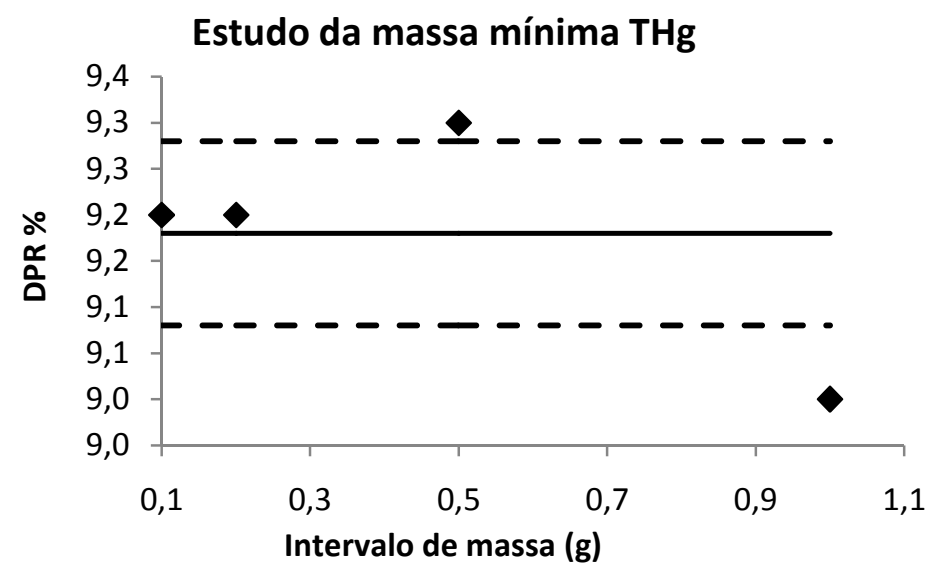

FIGURA- 16 Desvio padrão relativo obtido na determinação de THg no intervalo de massa estudado

Os resultados obtidos são satisfatórios para o intervalo de massa de 0,100 a $1,0 \mathrm{~g}$, optando-se por $0,5 \mathrm{~g}$ como a massa ideal para determinação das amostras de maior concentração, evitando assim a diluição da amostra. 


\subsubsection{Resultados obtidos para o estudo de homogeneidade para o elemento Arsênio}

As amostras utilizadas para os ensaios de arsênio foram selecionadas como descrito no item 3.8, sendo retirado $0,5 \mathrm{~g}$ de amostra em triplicata dos mesmos sachês anteriores utilizados para os ensaios de mercúrio.

Os resultados observados nas Tabelas 10 e 11 são referentes aos valores obtidos para as amostras de maior concentração e menor concentração irradiadas e não irradiadas.

TABELA 10- Média \pm DP, variância, DPR e resultados da ANOVA, obtidos na determinação de arsênio total em $\mu \mathrm{g} \mathrm{g}^{-1}$ por FIA-HG-AAS, na amostra de menor concentração (base úmida) para o estudo de homogeneidade

\section{Concentração média de TAs $\left(\mu \mathrm{g} \mathrm{g}^{-1}\right)$}

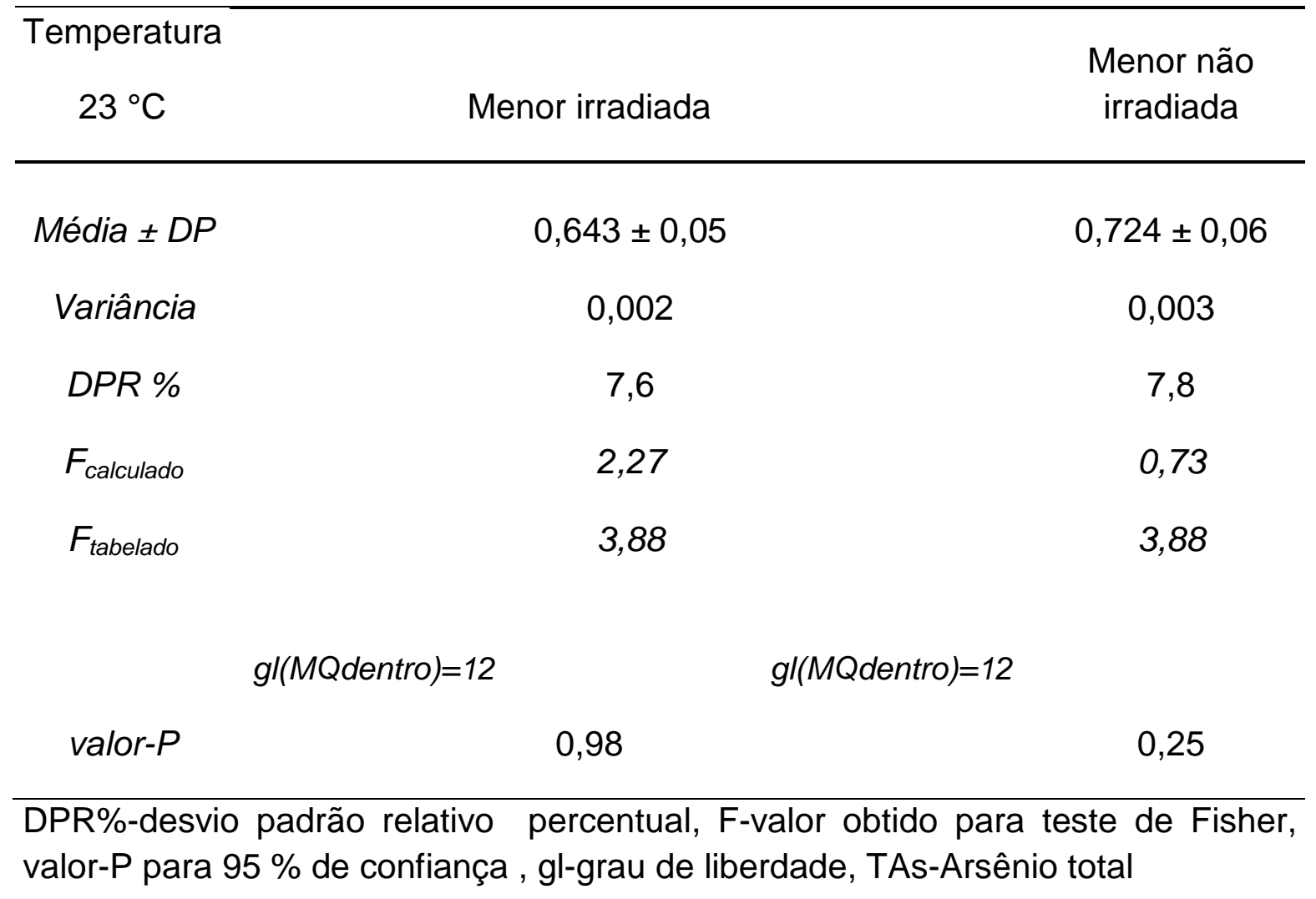


TABELA 11 - Média \pm DP, variância, DPR e resultados da ANOVA, obtidos na determinação de arsênio total em $\mu \mathrm{g} \mathrm{g}^{-1}$ por FIA-HG-AAS, na amostra de maior concentração (base úmida) para o estudo de homogeneidade

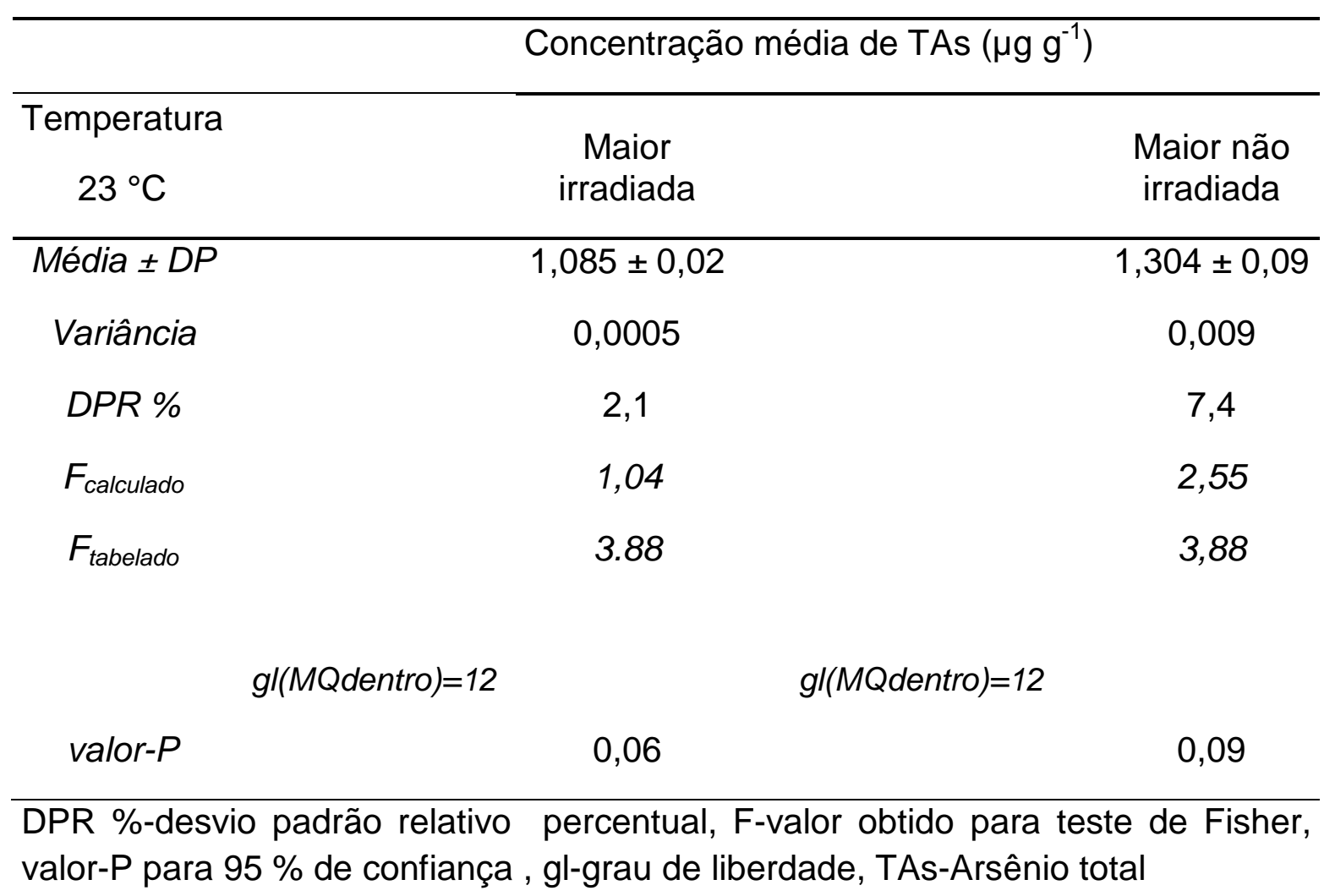

Comparando-se os resultados obtidos na etapa pré-envase e após irradiação, notou-se uma variação de 17 \% e 31 \% para as amostras irradiadas e não irradiadas de maior concentração respectivamente. Para as amostras de menor concentração a variação foi da ordem de $15 \%$ para as irradiadas e $17 \%$ para as não irradiadas.

O elemento arsênio apresentou a mesma variação observada para o mercúrio, como descrito no item 4.3. Neste contexto, o material também apresentou variações dentro da incerteza expandida calculada de $43 \%$.

Para o elemento arsênio o material é suficientemente homogêneo como se pode verificar com os resultados obtidos pela ANOVA. Tanto para as amostras de maior concentração como as de menor concentração, irradiadas e não irradiadas, o valor de $\mathrm{F}$ tabelado foi menor que o valor de Fcrítico (calculado), comprovando a homogeneidade do material (TAB. 10 e 11). 
Os resultados obtidos na análise de regressão demonstraram que não ocorreu tendência nos valores médios para amostras de maior e menor concentração irradiadas e não irradiadas, já que todos os valores de $\mathrm{P}$ foram maiores que 0,05 (TAB. 10 e 11).

Não foi realizado o estudo de homogeneidade para os elementos cádmio e chumbo.

\subsubsection{Estudo da massa mínima para arsênio total}

Para o elemento arsênio o estudo da massa mínima foi realizado com 6 porções da amostra de maior concentração, utilizando o intervalo de massa de 0,100 a 1,0 g, realizando determinações de arsênio total por meio da técnica de FIA-HG-AAS. A média dos desvios padrão relativo a análise das 6 porções do material, o valor médio obtido foi $1,2 \pm 0.5 \%$ (FIG. 17).

Estudo de massa mínima TAs

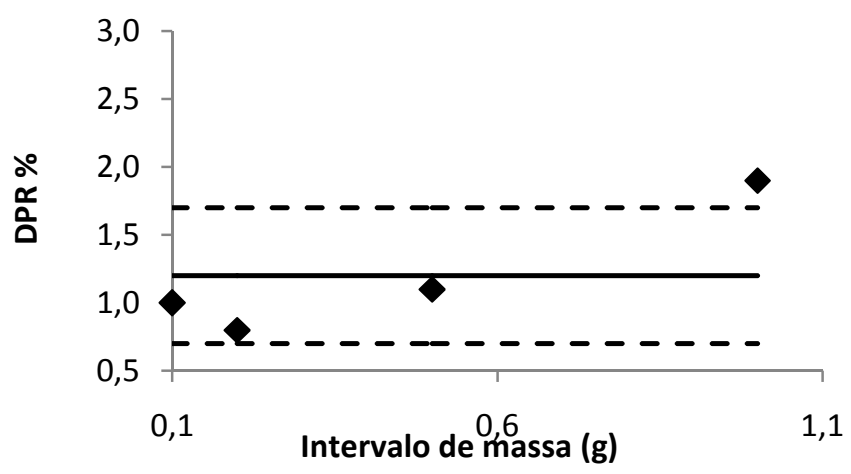

FIGURA- 17 Desvio padrão relativo obtido na determinação de TAs no intervalo de massa estudado

O DPR\% foi maior que o $\mathrm{s}_{\mathrm{r}}$, para todas as massas utilizadas, optando-se por $0,5 \mathrm{~g}$ como a massa ideal já que o procedimento analítico inclui uma etapa de diluição. 


\subsection{Resultados obtidos para o estudo de estabilidade em curto prazo}

O estudo de estabilidade em curto prazo teve como objetivo avaliar as condições extremas de transporte às quais o material poderia ser submetido, até sua chegada aos laboratórios onde seria realizado o ensaio de proficiência. Assim foi adotado o modelo isócrono com temperaturas críticas de $40 \pm 1,3^{\circ} \mathrm{C}$ e $60 \pm 1,2$ ${ }^{\circ} \mathrm{C}$, de referência à temperatura de trabalho $23 \pm 0,5{ }^{\circ} \mathrm{C}$ e de conservação por curto período de tempo (até 45 dias) $5 \pm 0,2^{\circ} \mathrm{C}$.

Foi empregado o Teste t para determinar se houve tendência nos dados avaliando o resultado dos coeficientes de regressão para estimar a intersecção e a significância da inclinação da reta. E também se avaliou a resultante (X1) da tabela da Análise da Variância, para regressão linear para os valores dos resíduos das concentrações no intervalo de tempo de 0, 7, 15, 30 e 45 dias para cada uma das faixas de temperatura acima.

Este item foi dividido em dois subitens para melhor compreensão das tabelas que apresentam os resultados das medições de THg e TAs nos sachês de maior e menor concentração para amostras irradiadas e não irradiadas durante o estudo de estabilidade.

\subsubsection{Estudo de estabilidade em curto prazo para o elemento Mercúrio}

Retirou-se $0,5 \mathrm{~g}$ em replicata de cada um dos sachês irradiados e não irradiado para cada ponto de temperatura e dia de estudo, procedendo-se da maneira descrita no item 3.7.

As Tabelas 12 a 15, apresentam os resultados obtidos por faixa de temperatura em cada ponto do tempo estudado. 
TABELA 12- Valores médios obtidos na determinação de mercúrio total em $\mu \mathrm{g} \mathrm{g}^{-1}$ por FIA-CV-AAS, na amostra de menor concentração irradiada (base úmida), por 0-45 dias

\begin{tabular}{|c|c|c|c|c|}
\hline & $\begin{array}{c}\text { Geladeira } \\
\left(5^{\circ} \mathrm{C}\right)\end{array}$ & $\begin{array}{c}\text { Ambiente } \\
\left(23^{\circ} \mathrm{C}\right)\end{array}$ & $\begin{array}{l}\text { Estufa } \\
\left(40^{\circ} \mathrm{C}\right)\end{array}$ & $\begin{array}{l}\text { Estufa } \\
\left(60^{\circ} \mathrm{C}\right)\end{array}$ \\
\hline Média $\pm D P$ & $0,313 \pm 0,008$ & $0,323 \pm 0,023$ & $0,366 \pm 0,041$ & $0,375 \pm 0,029$ \\
\hline DPR \% & 2,6 & 7,1 & 11,2 & 7,7 \\
\hline Valor-P (95\%) & 0,92 & 0,64 & 0,01 & 0,82 \\
\hline Inclinação $\left(b_{1}\right)$ & 0,0006 & $-0,0073$ & 0,0024 & $-0,0003$ \\
\hline $\begin{array}{c}\text { Erro padrão } \\
\text { Inclinação } \\
\left(s\left(b_{1}\right)\right)\end{array}$ & 0,0052 & 0,0133 & 0,0002 & 0,0013 \\
\hline$\left|b_{1}\right|<t(0,95, n-2)^{*} s\left(b_{1}\right)$ & 0,02 & 0,02 & 0,03 & 0,03 \\
\hline
\end{tabular}

TABELA 13- Valores médios obtidos na determinação de mercúrio total em $\mu \mathrm{g} \mathrm{g}^{-1}$ por FIA-CV-AAS, na amostra de menor concentração não irradiada (base úmida), por 0-45 dias

\begin{tabular}{|c|c|c|c|c|}
\hline & $\begin{array}{l}\text { Geladeira } \\
\left(5^{\circ} \mathrm{C}\right)\end{array}$ & $\begin{array}{l}\text { Ambiente } \\
\left(23^{\circ} \mathrm{C}\right)\end{array}$ & $\begin{array}{l}\text { Estufa } \\
\left(40^{\circ} \mathrm{C}\right)\end{array}$ & $\begin{array}{l}\text { Estufa } \\
\left(60^{\circ} \mathrm{C}\right)\end{array}$ \\
\hline Média $\pm D P$ & $316 \pm 0,006$ & $0,322 \pm 0,021$ & $0,353 \pm 0,037$ & $0,374 \pm 0,022$ \\
\hline DPR \% & 1,9 & 6,5 & 10,5 & 5,9 \\
\hline Valor-P (95\%) & 0,22 & 0,18 & 0,07 & 0,79 \\
\hline Inclinação $\left(b_{1}\right)$ & 0,0031 & $-0,0152$ & 0,0019 & 0,0003 \\
\hline $\begin{array}{l}\text { Erro padrão } \\
\text { Inclinação } \\
\qquad\left(s\left(b_{1}\right)\right)\end{array}$ & 0,002 & 0,0074 & 0,00062 & 0,001 \\
\hline$\left|b_{1}\right|<t(0,95, n-2)^{*} s\left(b_{1}\right)$ & 0,02 & 0,02 & 0,03 & 0,03 \\
\hline
\end{tabular}


TABELA 14- Valores médios obtidos na determinação de mercúrio total em $\mu \mathrm{g} \mathrm{g}{ }^{-1}$ por FIA-CV-AAS, na amostra de maior concentração irradiada (base úmida), por $0-45$ dias

\begin{tabular}{ccccc}
\hline & $\begin{array}{c}\text { Geladeira } \\
\left(5^{\circ} \mathrm{C}\right)\end{array}$ & $\begin{array}{c}\text { Ambiente } \\
\left(23^{\circ} \mathrm{C}\right)\end{array}$ & $\begin{array}{c}\text { Estufa } \\
\left(40^{\circ} \mathrm{C}\right)\end{array}$ & $\begin{array}{c}\text { Estufa } \\
\left(60^{\circ} \mathrm{C}\right)\end{array}$ \\
\hline Média $\pm D P$ & $0,668 \pm 0,024$ & $0,684 \pm 0,064$ & $0,814 \pm 0,052$ & $0,690 \pm 0,075$ \\
DPR \% & 3,6 & 9,4 & 6,4 & 10,9 \\
Valor-P $(95 \%)$ & 0,22 & 0,17 & 0,01 & 0,01 \\
Inclinação $\left(b_{1}\right)$ & $-0,0165$ & 0,0029 & 0,0027 & 0,0043 \\
$\begin{array}{l}\text { Erro padrão } \\
\text { Inclinação }\end{array}$ & 0,0095 & 0,0014 & 0,0002 & 0,0004 \\
$\left(s\left(b_{1}\right)\right)$ & & & & \\
|b & 0,18 & 0,20 & 0,30 & 0,21 \\
DPR \%-desvio padrão relativo percentual. & & &
\end{tabular}

TABELA 15- Valores médios obtidos na determinação de mercúrio total em $\mu \mathrm{g} \mathrm{g}{ }^{-1}$ por FIA-CV-AAS, na amostra de maior concentração não irradiada (base úmida), por 0-45 dias

\begin{tabular}{ccccc}
\hline & $\begin{array}{l}\text { Geladeira } \\
\left(5^{\circ} \mathrm{C}\right)\end{array}$ & $\begin{array}{l}\text { Ambiente } \\
\left(23^{\circ} \mathrm{C}\right)\end{array}$ & $\begin{array}{c}\text { Estufa } \\
\left(40^{\circ} \mathrm{C}\right)\end{array}$ & $\begin{array}{c}\text { Estufa } \\
\left(60^{\circ} \mathrm{C}\right)\end{array}$ \\
\hline Média $\pm D P$ & $0,693 \pm 0,022$ & $0,702 \pm 0,056$ & $0,811 \pm 0,035$ & $0,676 \pm 0,066$ \\
DPR \% & 3,2 & 8,0 & 4,3 & 9,8 \\
Valor-P (95\%) & 0,11 & 0,08 & 0,12 & 0,02 \\
Inclinação $\left(b_{1}\right)$ & $-0,0173$ & 0,0252 & 0,0017 & 0,0037 \\
$\begin{array}{c}\text { Erro padrão } \\
\text { Inclinação }\end{array}$ & 0,0063 & 0,0008 & 0,0006 & 0,0005 \\
$\begin{array}{c}\left(s\left(b_{1}\right)\right) \\
\left|b_{1}\right|<t(0,95, n-2)^{*} s\left(b_{1}\right)\end{array}$ & 0,19 & 0,21 & 0,30 & 0,19 \\
\hline
\end{tabular}

DPR \%-desvio padrão relativo percentual. 
Os resultados obtidos pelas estatísticas aplicadas (ANOVA e Teste t) para os valores médios dos sachês armazenados a cada temperatura de teste $\left(5^{\circ} \mathrm{C}\right.$, $23{ }^{\circ} \mathrm{C}, 40^{\circ} \mathrm{C}$ e $60^{\circ} \mathrm{C}$ ) para as amostras de maior e menor concentração, irradiadas e não irradiadas, demonstram que o material é estável nas temperaturas de $5{ }^{\circ} \mathrm{C}$ a $23^{\circ} \mathrm{C}$ durante 45 dias. Apresentando uma variação de concentração já esperada nas temperaturas de 40 e $60^{\circ} \mathrm{C}$.

A partir dos dados das Tabelas 12 a 15, $\mathrm{X}$ foi considerado como (tempo) e $Y$ (concentração média do elemento), assim os estimadores $\beta 0$ (estimador da intersecção da reta) e $\beta 1$ (estimador da inclinação da reta), ambos os coeficientes de regressão foram obtidos levando-se em consideração $X$ e $Y$ e calculados pelas equações abaixo.

Para $b_{1}$ :

$$
b_{1}=\frac{\sum_{i=1}^{n}\left(X_{i}-\bar{X}\right)\left(Y_{i}-\bar{Y}\right)}{\sum_{i=1}^{n}\left(X_{i}-\bar{X}\right)^{2}}
$$
0,00626 .

Neste caso o valor obtido para $b_{1}$, ou seja, a inclinação da reta foi igual a equação 6:

A estimativa para intersecção da reta é dada por $b_{0}$ e calculada pela $b_{0}=\bar{Y}-b_{1} \bar{X}$

Assim a estimativa para intersecção foi igual a 0,1615 e a incerteza associada à inclinação se dá por:

$$
s\left(b_{1}\right)=\frac{s}{\sqrt{\sum_{i=1}^{n}\left(X_{i}-\bar{X}\right)^{2}}} \quad s\left(b_{1}\right)=0,00403
$$

Logo, baseando-se no desvio padrão de $b_{1}$ e pelo estudo da equação 45 , utilizando-se $\mathrm{o}$ fator $\mathrm{t}$ correspondente ao $\mathrm{n}$ amostral (número de graus de liberdade ideal para $n-2), b_{1}$ foi testado com o Teste t quanto à significância, atendendo-se a condição $\left|b_{1}\right|<t 0,95, n-2 \times s\left(b_{1}\right)$, comprovou-se que a inclinação é 
insignificante e nenhuma instabilidade é confirmada, para um nível de confiança de $95 \%$.

Assim temos: $\left|b_{1}\right|=0,0063<t_{0,95, ~}-2 \times s\left(b_{1}\right)=0,0174$. Portanto para o analito $\mathrm{THg}$ em menor concentração, para amostras irradiadas mantidas a $5{ }^{\circ} \mathrm{C}$, foi confirmada sua estabilidade.

Para corroborar o resultado obtido pelo Teste t para inclinação da reta foi utilizada o teste ANOVA para regressão linear, neste caso avalia-se o resultado do valor-p (probabilidade $P$ ( $t_{\text {calc }} \geq t_{\text {crit }}$ ) observado) o qual indica que a regressão não é estatisticamente significativa quando o valor-P for maior que 0,05 (ela se torna significativa para um nível de confiança de $95 \%$ quando for menor que $0,05)$.

$O$ valor-P foi maior que 0,05 , comprovando que não há tendência nos resultados para estabilidade das amostras irradiadas armazenadas a $5 \pm 0,2^{\circ} \mathrm{C}$ e $23 \pm 0,5^{\circ} \mathrm{C}$ por até 45 dias. A regressão foi considerada insignificante.

Nas Tabelas 12 a 15 observou-se que os resultados para as temperaturas de $40 \pm 1,3^{\circ} \mathrm{C}$ e $60 \pm 1,2^{\circ} \mathrm{C}$ apresentaram uma ligeira tendência, tanto para as amostras irradiadas, quanto para as não irradiadas a partir do $30^{\circ}$ dia de estudo, podendo ser mais bem visualizado nos gráficos do item 4.4.2. A provável causa dessa variação se deve a alteração da umidade frente ao aumento do binômio tempo temperatura.

Contudo todas as medidas enontram-se dentro range de incertezas como será visto no item 4.5 . 


\subsubsection{Representação gráfica dos resultados para o elemento mercúrio}

Os resultados para o teste de ANOVA para regressão demonstraram não haver tendência para as amostras que permaneceram a temperatura de $5 \pm 0,2$ ${ }^{\circ} \mathrm{C}$ a $23 \pm 0,5{ }^{\circ} \mathrm{C}$, como pode ser observado nos gráficos das Figuras 18 e 19, contudo para as temperaturas de $40 \pm 1,3{ }^{\circ} \mathrm{C}$ e $60 \pm 1,2{ }^{\circ} \mathrm{C}$ nota-se uma ligeira tendência nos resultados.

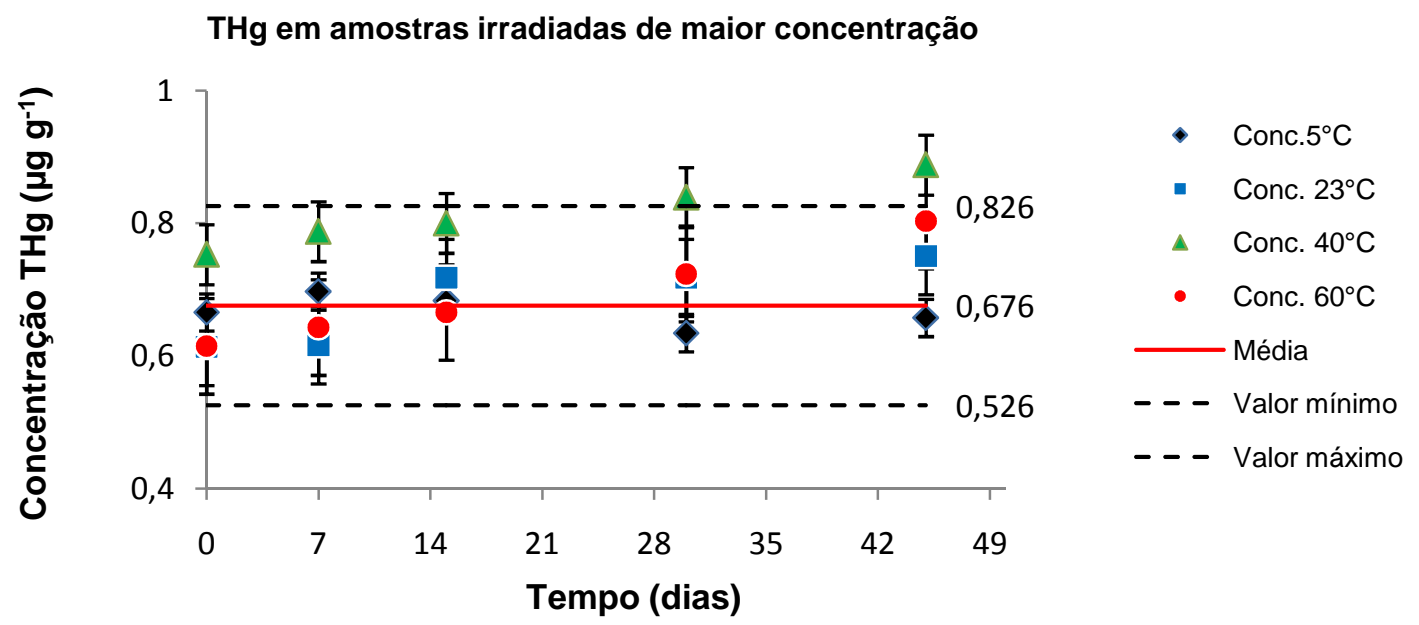

THg em amostras não irradiadas de maior concentração

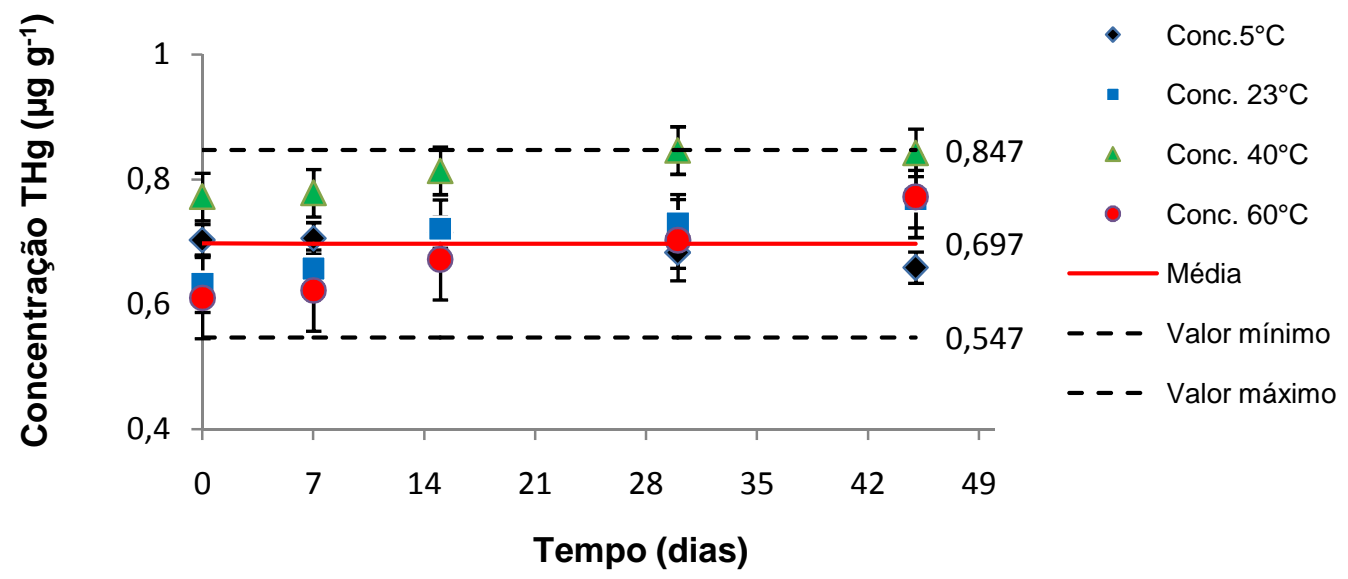

FIGURA 18- Resultados da análise de regressão para o estudo de estabilidade para THg $\left(\mu \mathrm{g} \mathrm{g}^{-1}\right)$ em diferentes temperaturas e períodos de tempo, barra de erro com Desvio Padrão 
THg em amostras não irradiadas de menor concentração

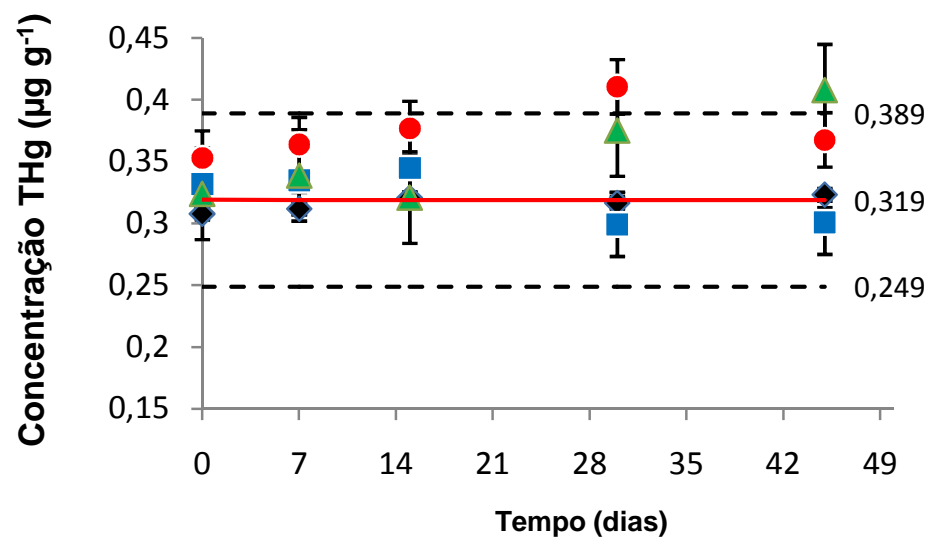

- Conc. $5^{\circ} \mathrm{C}$

- Conc. $23^{\circ} \mathrm{C}$

4 Conc. $40^{\circ} \mathrm{C}$

- Conc. $60^{\circ} \mathrm{C}$

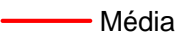

- - - Valor mínimo

THg em amostras irradiadas de menor concentração

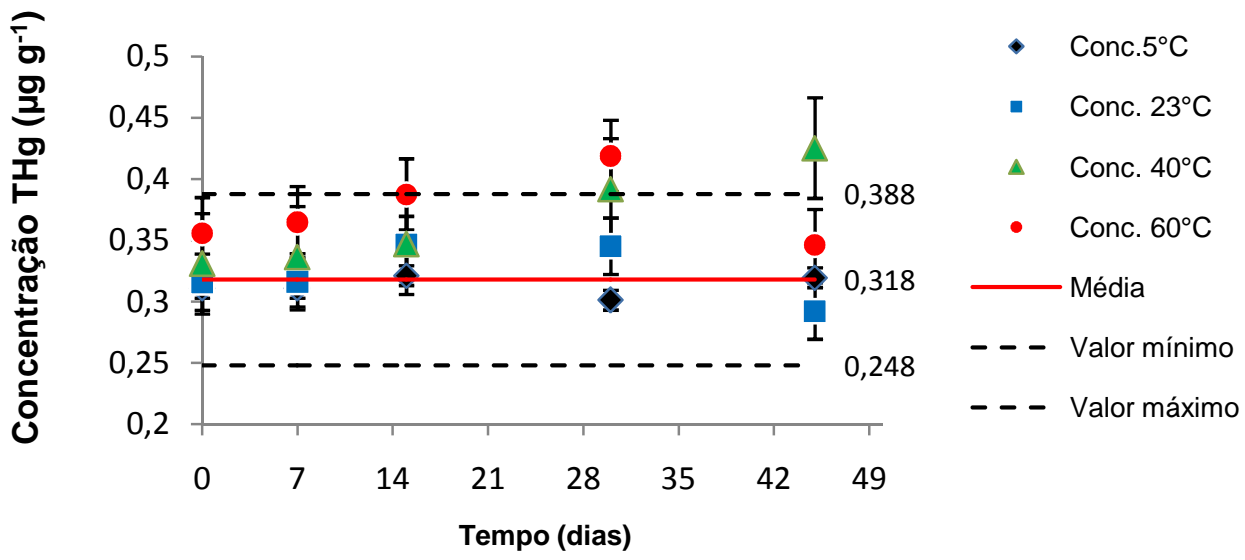

FIGURA 19- Resultados da análise de regressão para o estudo de estabilidade para THg $\left(\mu \mathrm{g} \mathrm{g}^{-1}\right)$ em diferentes temperaturas e períodos de tempo, barra de erro com Desvio Padrão

São apresentados nas Figuras 20 (amostras de maior concentração) e 21 (amostras de menor concnetração), os gráficos das concentrações de THg para as amostras irradiadas e não irradiadas, respectivamente. Verifica-se uma ligeira tendência para amostras que permaneceram nas temperaturas de $40 \pm 1,3{ }^{\circ} \mathrm{C}$ a $60 \pm 1,2{ }^{\circ} \mathrm{C}$ com o passar dos dias. Contudo todos os resultados encontram dentro do limite de incerteza expandida de aproximadamente $23 \%$ para as amostras de menor concentração, irradiadas e não irradiadas e $26 \%$ para as amostras de maior concentração, irradiadas e não irradiadas. 
Concentração $\mathrm{THg} \times \mathrm{Temperatura} 5^{\circ} \mathrm{C}$ Amostras Irradiadas

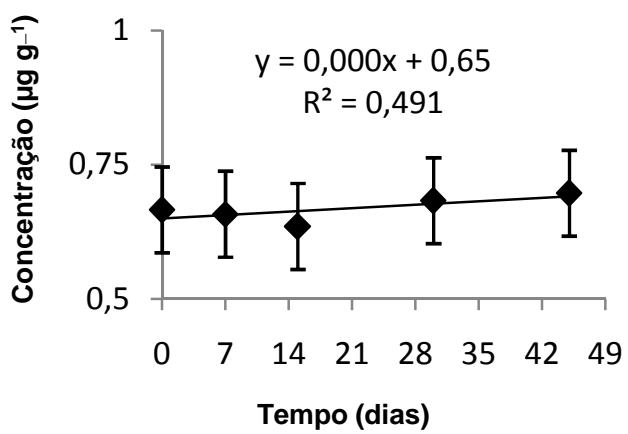

THg $\times$ Temperatura $23^{\circ} \mathrm{C}$ Amostras Irradiadas de maior concentração

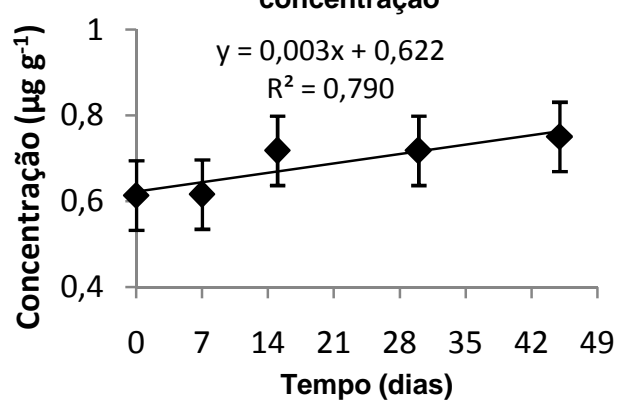

THg x Temperatura $40^{\circ} \mathrm{C}$ Amostras irradiadas de maior concentração

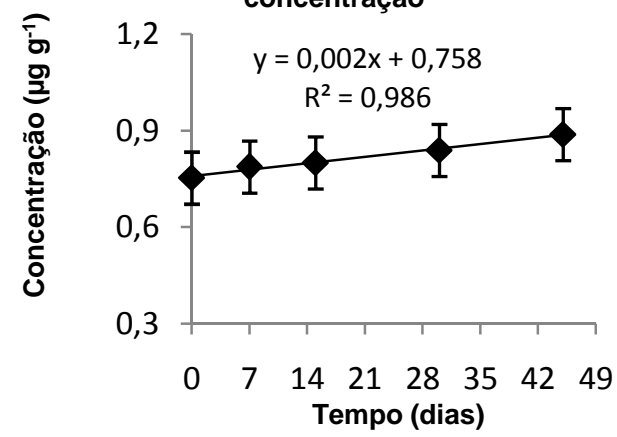

THg x Temperatura $60^{\circ} \mathrm{C}$ Amostras irradiadas de maior concentração

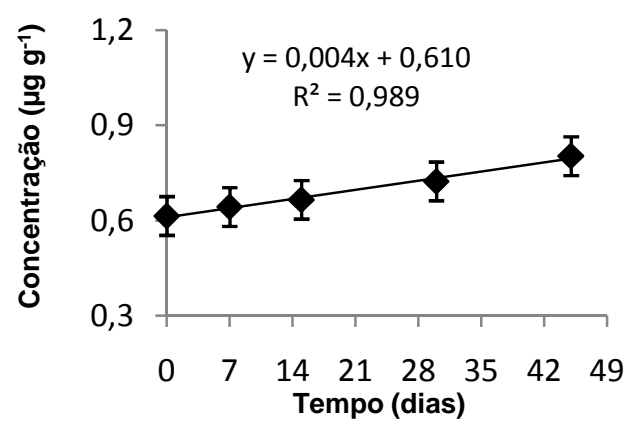

Concentração $\mathrm{THg} \times$ Temperatura $5^{\circ} \mathrm{C}$ Amostras não irradiadas

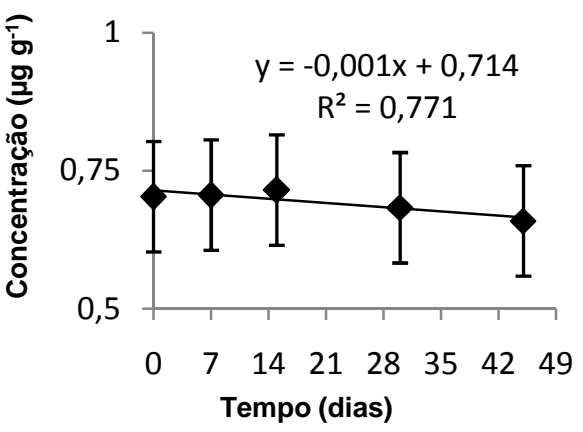

$\mathrm{THg} \times$ Temperatura $23^{\circ} \mathrm{C}$ Amostras não irradiadas de maior concentração

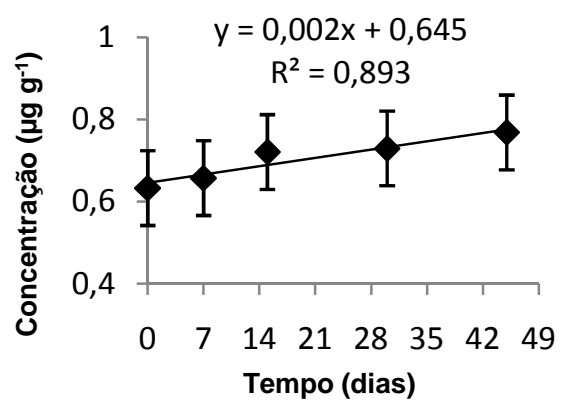

THg x Temperatura $40^{\circ} \mathrm{C}$ Amostras não irradiadas de maior concentração

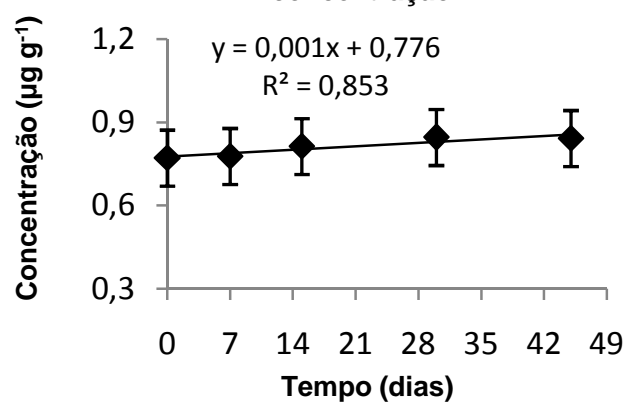

THg x Temperatura $60^{\circ} \mathrm{C}$ Amostras não irradiadas de maior concentração

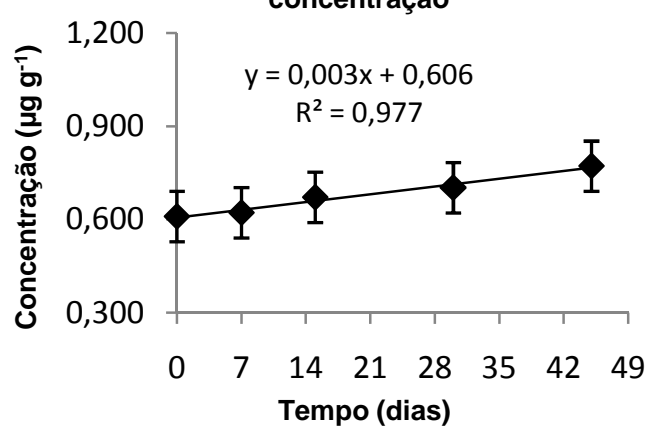

FIGURA 20- Gráficos da Concentração de THg nas amostras de maior concentração x Tempo para cada faixa de temperatura estudada 
THg $\times$ Temperatura $5^{\circ} \mathrm{C}$ Amostras irradiadas de menor concentração

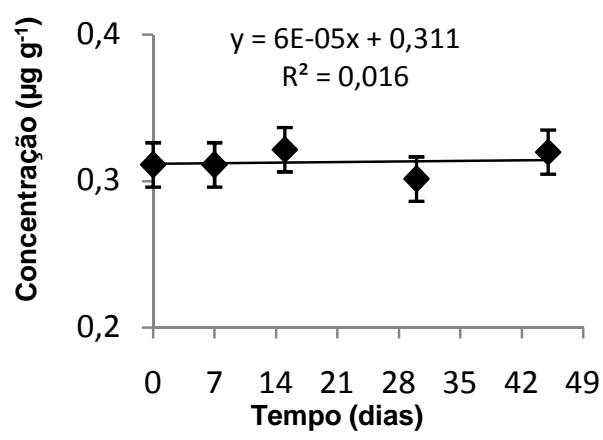

$\mathrm{THg} \times \mathrm{Temperatura} 23^{\circ} \mathrm{C}$ Amostras irradiadas de menor concentração

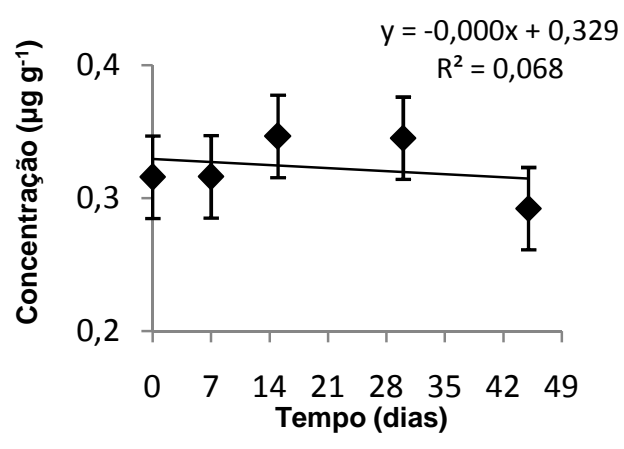

THg x Temperatura $40^{\circ} \mathrm{C}$ irradiadas de menor concentração

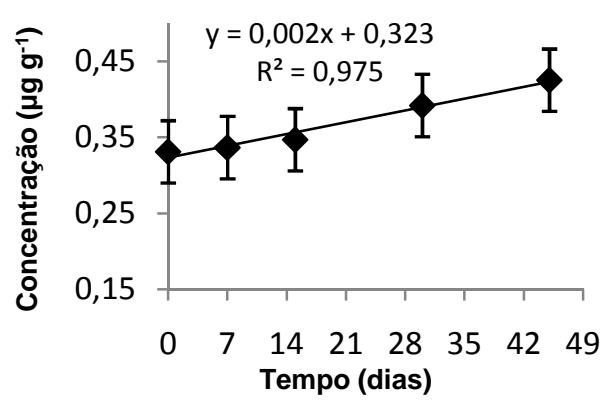

$\mathrm{THg} \times$ Temperatura $60^{\circ} \mathrm{C}$ irradiadas de

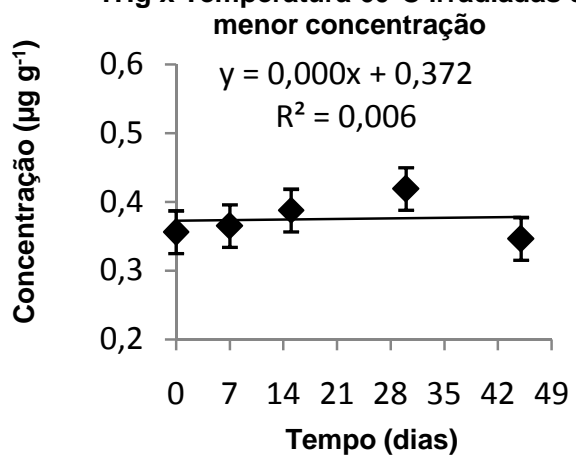

THg $\times$ Temperatura $5^{\circ} \mathrm{C}$ Amostras não irradiadas de menor concentração

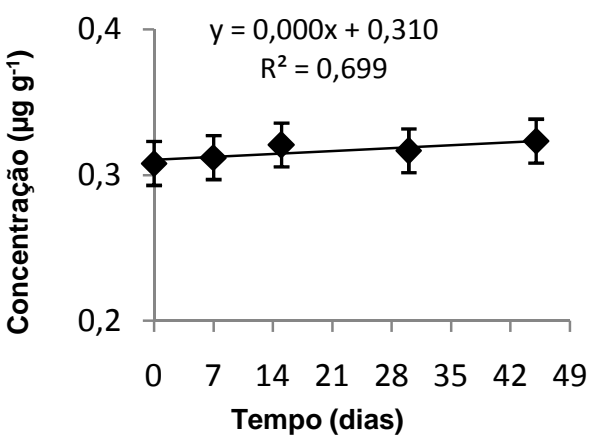

THg x Temperatura $23^{\circ} \mathrm{C}$ Amostras não irradiadas de menor concentração

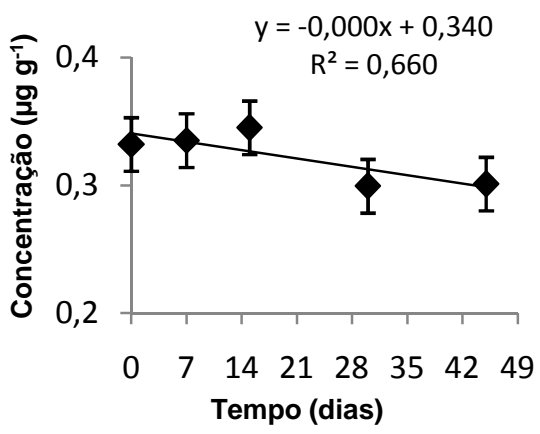

THg x Temperatura $40^{\circ} \mathrm{C}$ não irradiadas de menor concentração

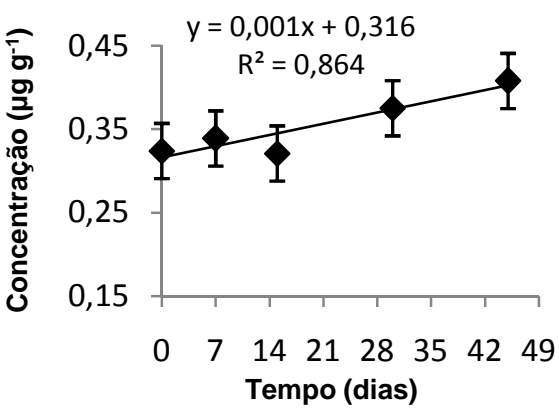

THg x Temperatura $60^{\circ} \mathrm{C}$ não irradiadas

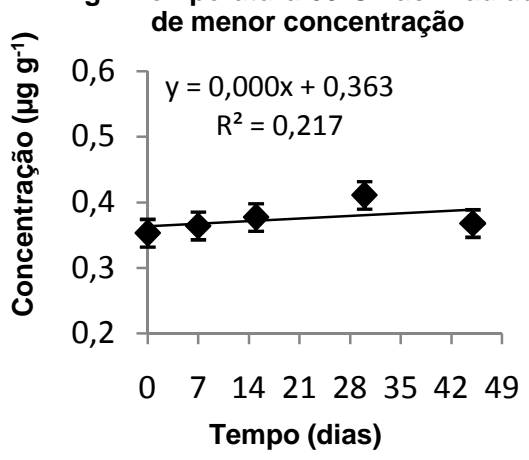

FIGURA 21- Gráficos da Concentração de THg nas amostras de menor concentração x Tempo para cada faixa de temperatura estudada 


\subsubsection{Estudo de estabilidade em curto prazo para o elemento Arsênio}

O elemento arsênio foi adicionado ao tecido muscular de peixe devido a sua baixa concentração natural e passou pelos mesmos testes aplicados anteriormente para o elemento mercúrio, sendo utilizadas amostras dos mesmos sachês estudados nas mesmas condições descritas no item 4.4.1.

Os resultados do experimento podem ser observados nas Tabelas 16 a 19, onde são mostrados os valores médios e desvio padrão para cada sachê de ambos os materiais, irradiados e não irradiados, em função do tempo $x$ temperatura.

TABELA 16- Valores médios obtidos na determinação de arsênio total em $\mu \mathrm{g} \mathrm{g}^{-1}$ por FIA-HG-AAS, na amostra de menor concentração irradiada (base úmida), por 0-45 dias

\begin{tabular}{ccccc}
\hline & $\begin{array}{c}\text { Geladeira } \\
\left(5^{\circ} \mathrm{C}\right)\end{array}$ & $\begin{array}{c}\text { Ambiente } \\
\left(23^{\circ} \mathrm{C}\right)\end{array}$ & $\begin{array}{c}\text { Estufa } \\
\left(40^{\circ} \mathrm{C}\right)\end{array}$ & $\begin{array}{c}\text { Estufa } \\
\left(60^{\circ} \mathrm{C}\right)\end{array}$ \\
\hline Média $\pm D P$ & $0,682 \pm 0,019$ & $0,685 \pm 0,049$ & $0,675 \pm 0,044$ & $0,791 \pm 0,097$ \\
$D P R \%$ & 2,8 & 7,2 & 6,5 & 12,3 \\
Valor-P (95\%) & 0,12 & 0,08 & 0,07 & 0,04 \\
$\begin{array}{c}\text { Inclinação }\left(b_{1}\right) \\
\text { Erro padrão } \\
\text { inclinação } \\
\left(s\left(b_{1}\right)\right)\end{array}$ & 0,00093 & 0,0023 & 0,0023 & 0,0058 \\
& 0,0004 & 0,0007 & 0,0006 & 0,0012 \\
$\left|b_{1}\right|<t(0,95, n-2)^{*} s\left(b_{1}\right)$ & 0,19 & 0,20 & 0,20 & 0,29 \\
& & & & \\
\hline
\end{tabular}

DPR \%-desvio padrão relativo percentual. 
TABELA 17- Valores médios obtidos na determinação de arsênio total em $\mu \mathrm{g} \mathrm{g}{ }^{-1}$ por FIA-HG-AAS, na amostra de menor concentração não irradiada (base úmida) , 0-45 dias

\begin{tabular}{ccccc}
\hline & $\begin{array}{c}\text { Geladeira } \\
\left(5^{\circ} \mathrm{C}\right)\end{array}$ & $\begin{array}{c}\text { Ambiente } \\
\left(23^{\circ} \mathrm{C}\right)\end{array}$ & $\begin{array}{c}\text { Estufa } \\
\left(40^{\circ} \mathrm{C}\right)\end{array}$ & $\begin{array}{c}\text { Estufa } \\
\left(60^{\circ} \mathrm{C}\right)\end{array}$ \\
\hline Média $\pm D P$ & $0,684 \pm 0,039$ & $0,699 \pm 0,020$ & $0,691 \pm 0,055$ & $0,786 \pm 0,115$ \\
$D P R \%$ & 5,7 & 2,9 & 7,9 & 14,6 \\
Valor-P (95\%) & 0,16 & 0,06 & 0,10 & 0,06 \\
Inclinação $\left(b_{1}\right)$ & 0,0021 & $-0,0013$ & 0,0027 & 0,0066 \\
$\begin{array}{c}\text { Erro padrão } \\
\text { inclinação } \\
\left(s\left(b_{1}\right)\right)\end{array}$ & 0,0009 & 0,0003 & 0,00091 & 0,0017 \\
$\mid b_{1} /<t(0,95, n-2){ }^{*} s\left(b_{1}\right)$ & 0,20 & 0,20 & 0,20 & 0,29 \\
\hline
\end{tabular}

DPR \%-desvio padrão relativo percentual.

TABELA 18- Valores médios obtidos na determinação de arsênio total em $\mu \mathrm{g} \mathrm{g}{ }^{-1}$ por FIA-HG-AAS, na amostra de maior concentração irradiada (base úmida) , 0-45 dias

\begin{tabular}{ccccc}
\hline & $\begin{array}{c}\text { Geladeira } \\
\left(5^{\circ} \mathrm{C}\right)\end{array}$ & $\begin{array}{c}\text { Ambiente } \\
\left(23^{\circ} \mathrm{C}\right)\end{array}$ & $\begin{array}{c}\text { Estufa } \\
\left(40^{\circ} \mathrm{C}\right)\end{array}$ & $\begin{array}{c}\text { Estufa } \\
\left(60^{\circ} \mathrm{C}\right)\end{array}$ \\
\hline Média $\pm D P$ & $0,919 \pm 0,039$ & $1,019 \pm 0,054$ & $1,131 \pm 0,051$ & $1,250 \pm 0,148$ \\
DPR \% & 4,2 & 5,3 & 4,5 & 11,8 \\
Valor-P (95\%) & 0,46 & 0,92 & 0,94 & 0,02 \\
$\begin{array}{c}\text { Inclinação }\left(b_{1}\right) \\
\text { Erro padrão } \\
\text { inclinação } \\
\left(s\left(b_{1}\right)\right)\end{array}$ & $-0,0003$ & $-0,00032$ & $-0,0002$ & 0,0081 \\
& 0,0013 & 0,0023 & 0,0023 & 0,0013 \\
$\left|b_{1}\right|<t(0,95, n-2){ }^{*} s\left(b_{1}\right)$ & 0,42 & 0,55 & 0,61 & 0,83 \\
\hline DPR \%-desvio padrão relativo percentual. & & & \\
\hline
\end{tabular}


TABELA 19- Valores médios obtidos na determinação de arsênio total em $\mu \mathrm{g} \mathrm{g} \mathrm{g}^{-1}$ por FIA-HG-AAS, na amostra de maior concentração não irradiada (base úmida), $0-45$ dias

\begin{tabular}{ccccc}
\hline & $\begin{array}{c}\text { Geladeira } \\
\left(5^{\circ} \mathrm{C}\right)\end{array}$ & $\begin{array}{c}\text { Ambiente } \\
\left(23^{\circ} \mathrm{C}\right)\end{array}$ & $\begin{array}{c}\text { Estufa } \\
\left(40^{\circ} \mathrm{C}\right)\end{array}$ & $\begin{array}{c}\text { Estufa } \\
\left(60^{\circ} \mathrm{C}\right)\end{array}$ \\
\hline Média $\pm D P$ & $0,930 \pm 0,056$ & $1,039 \pm 0,045$ & $1,109 \pm 0,046$ & $1,229 \pm 0,148$ \\
$D P R \%$ & 6,0 & 4,3 & 4,1 & 12,0 \\
Valor-P (95\%) & 0,41 & 0,24 & 0,17 & 0,02 \\
$\begin{array}{c}\text { Inclinação }\left(b_{1}\right) \\
\text { Erro padrão } \\
\text { inclinação } \\
\left(s\left(b_{1}\right)\right)\end{array}$ & $-0,0014$ & $-0,0025$ & 0,0018 & 0,0085 \\
& 0,0013 & 0,0015 & 0,0009 & 0,0013 \\
$\left|b_{1}\right|<t(0,95, n-2){ }^{*} s\left(b_{1}\right)$ & 0,40 & 0,51 & 0,66 & 0,85 \\
\hline
\end{tabular}

Como foi descrito no item 4.4.1, também foi calculado para o elemento arsênio a inclinação da reta de regressão $b_{1}$, assim, os resultados obtidos foram: $\left|b_{1}\right|=0,0063<t_{0,95}, n-2 \times s\left(b_{1}\right)=0,042$, para 0 analito TAs em maior concentração irradiadas, $\left|b_{1}\right|=0,0063<t_{0,95}, n-2 \times s\left(b_{1}\right)=0,040$ para maior concentração não irradiada.

Para as amostras de menor concentração $\left|b_{1}\right|=0,0063<t_{0,95}, \mathrm{n}-2 \mathrm{x}$ $s\left(b_{1}\right)=0,019$ e 0,020 respectivamente para amostras irradiadas e não irradiadas a $5{ }^{\circ} \mathrm{C}$; para as amostras de maior concentração irradiadas e não irradiadas a $23^{\circ} \mathrm{C}$ $\left|b_{1}\right|=0,0063<t_{0,95}, \mathrm{n}-2 \times \mathrm{s}\left(b_{1}\right)=0,055$ e 0,51 ; para as amostras de menor concentração $\left|b_{1}\right|=0,0063<t_{0,95}, \mathrm{n}-2 \times \mathrm{s}\left(b_{1}\right)=0,020$, tanto para as amostras irradiadas como não irradiadas.

Portanto para amostras mantidas a $5 \pm 0,2{ }^{\circ} \mathrm{C}$ e $23 \pm 0,5{ }^{\circ} \mathrm{C}$ foi confirmada sua estabilidade. 
A análise de regressão linear foi utilizada para corroborar os resultados de estabilidade e identificar possível tendência nos resultados obtidos, como pode ser observado nas Tabelas 16 a 19 , nas temperaturas de $40 \pm{ }^{\circ} \mathrm{C}$ e $60 \pm{ }^{\circ} \mathrm{C}$ as amostras apresentaram ligeira tendência nos resultados à medida que os dias de estudo aumentam (30 a 45 dias), já que o valor de $P$ foi menor que 0,05.

Avaliando-se o valor de $\mathrm{P}$ para os resultados na faixa de $5^{\circ} \mathrm{C}$ e $23^{\circ} \mathrm{C}$ a estabilidade é comprovada, pois o Valor de $\mathrm{P}$ é maior do que o valor tabelado para o nível de significância adotado de 0,05.

As Figuras 22, 23, 24 e 25 apresentadas a seguir no item 4.4.4, ressaltam gráficamente o que foi descrito aqui. 


\subsubsection{Representação gráfica dos resultados para o elemento arsênio}

TAs em amostras não irradiadas de maior concentração

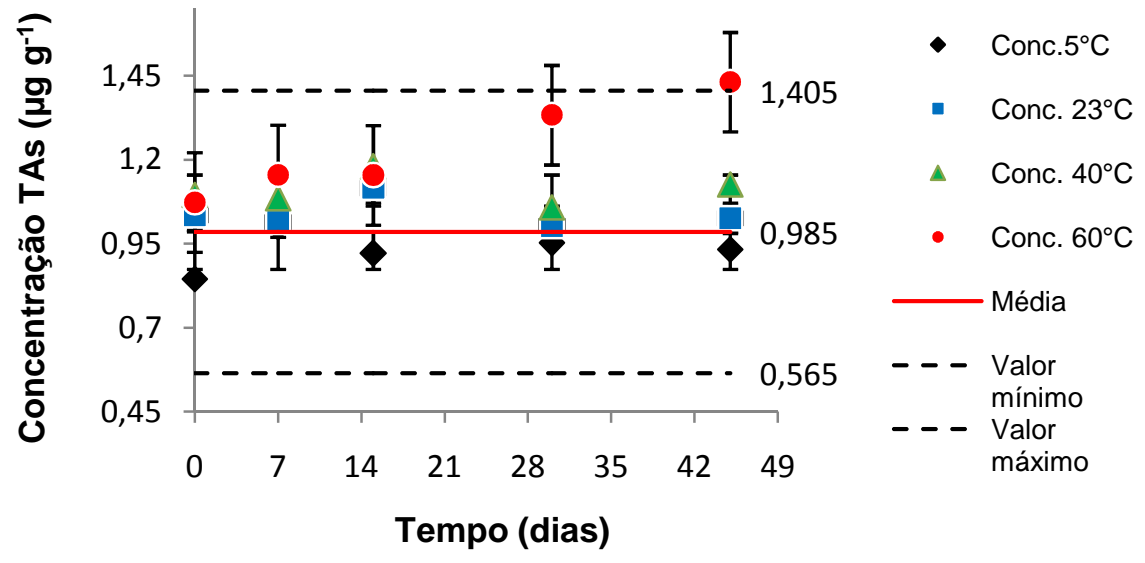

TAs em amostras irradiadas de maior concentração

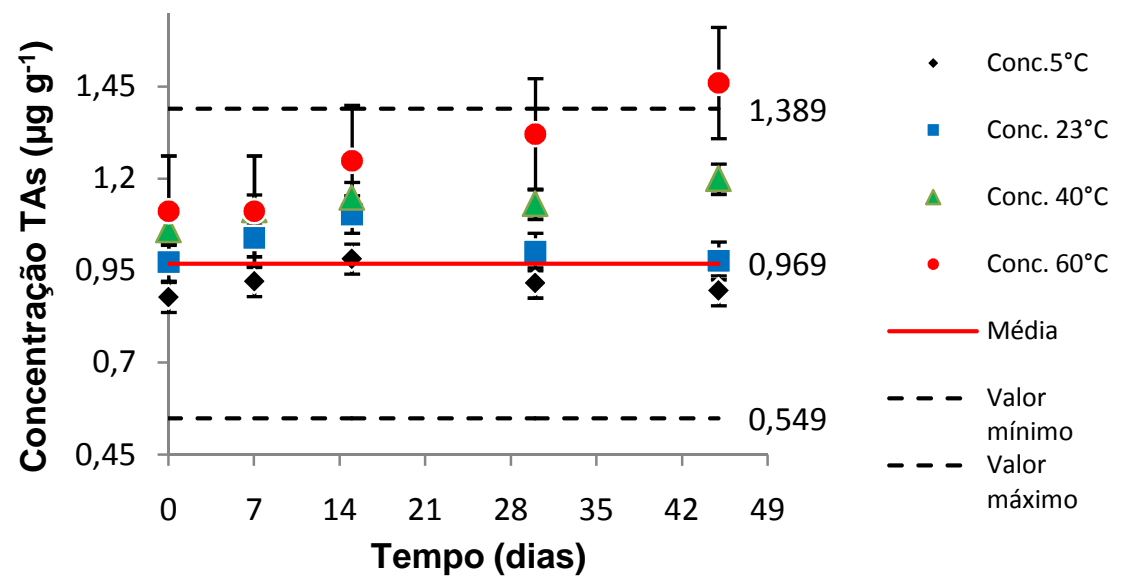

FIGURA 22- Resultados da análise de regressão para o estudo de estabilidade para TAs em diferentes temperaturas e períodos de tempo, barra de erro com Desvio Padrão em $\mu g g^{-1}$ 
TAs em amostras irradiadas de menor concentração

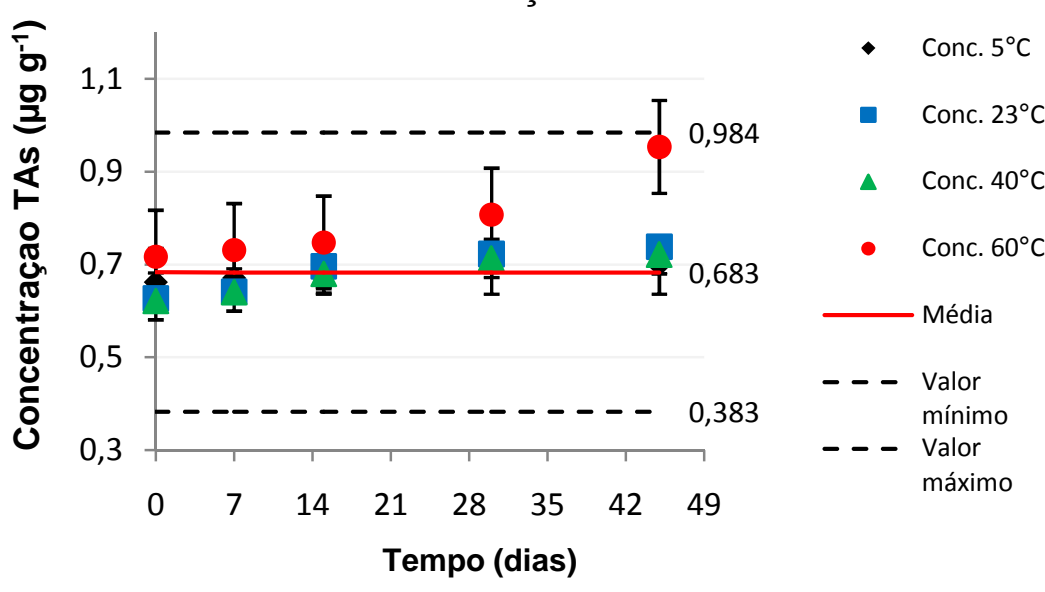

TAs em amostras não irradiadas de menor concentração

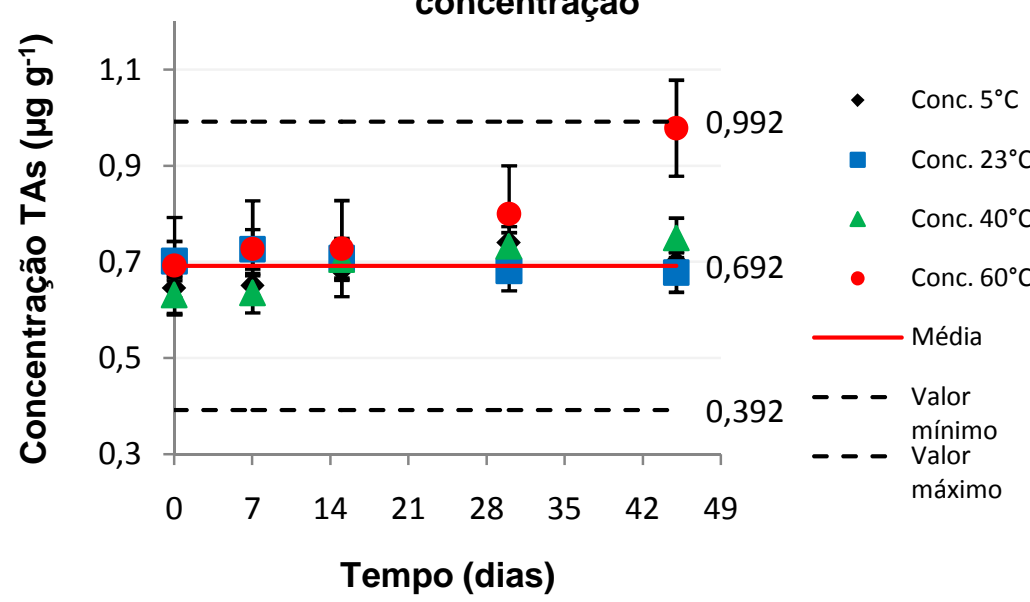

FIGURA 23- Resultados da análise de regressão para o estudo de estabilidade para TAs em diferentes temperaturas e períodos de tempo, barra de erro com Desvio Padrão em $\mu g g^{-1}$

Observando os resultados de concentração pelos gráficos, a variação existente nas amostras é esperada para a faixa de temperatura crítica $\left(40^{\circ} \mathrm{C}\right.$ e 60 $\left.{ }^{\circ} \mathrm{C}\right)$. No entanto, os valores apresentados estão dentro do limite de incerteza expandida de aproximadamente $43 \%$ para as amostras de menor concentração não irradiadas e irradiadas e $45 \%$ para as amostras de maior concentração irradiadas e não irradiadas, para o elemento As. 
Concentração TAs $x$ Temperatura $5^{\circ} \mathrm{C}$ Amostras Irradiadas

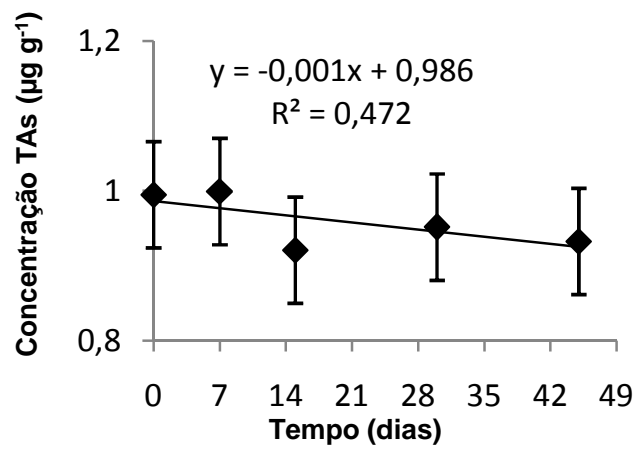

Concentração TAs x Temperatura $23^{\circ} \mathrm{C}$

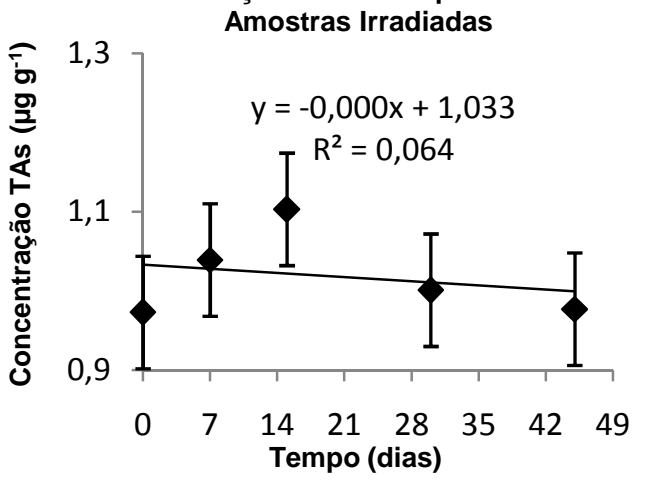

Concentração TAs $x$ Temperatura $40^{\circ} \mathrm{C}$

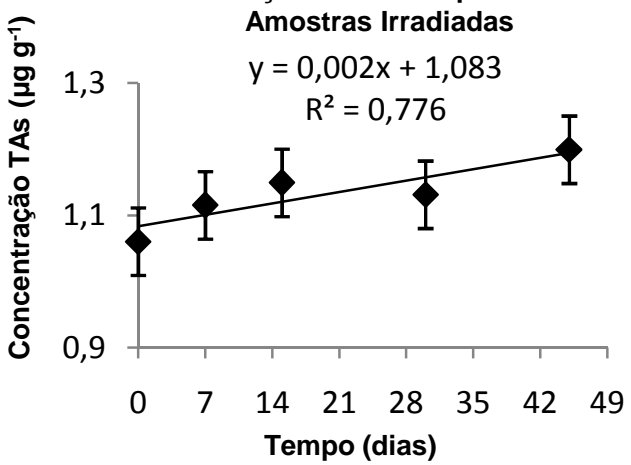

Concentração TAs x Temperatura $60^{\circ} \mathrm{C}$

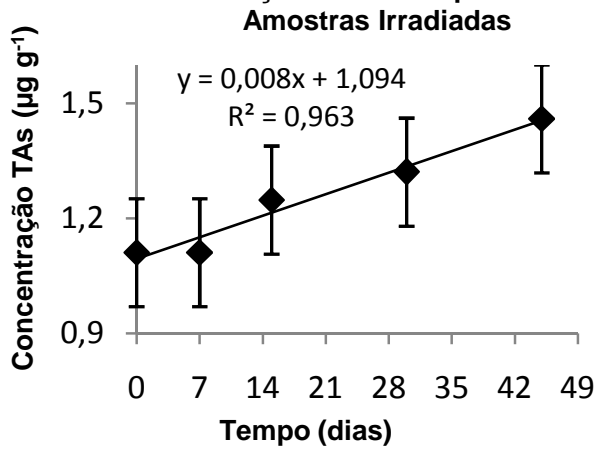

Concentração TAs $\mathrm{x}$ Temperatura $5^{\circ} \mathrm{C}$ Amostras não Irradiadas

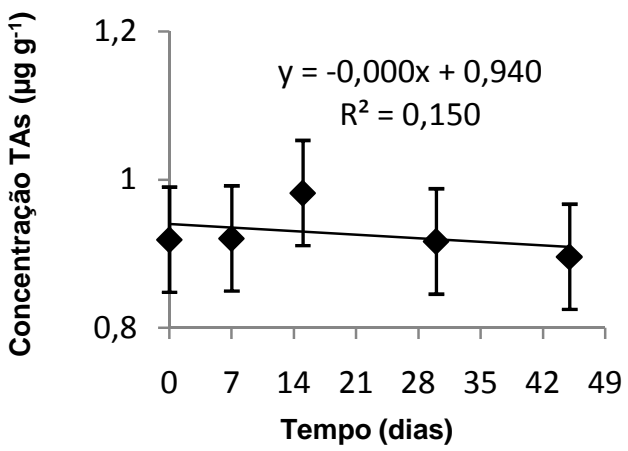

Concentração TAs x Temperatura $23^{\circ} \mathrm{C}$ Amostras não Irradiadas
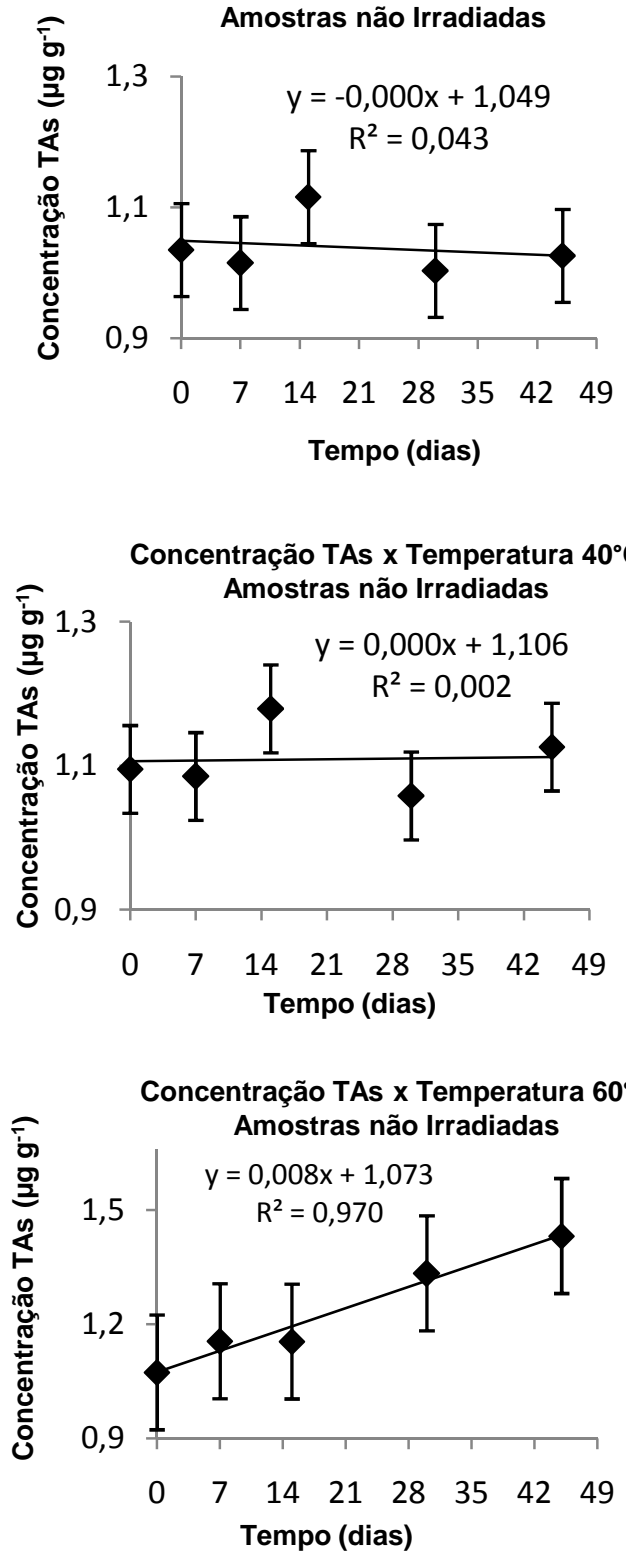

FIGURA 24- Gráficos da Concentração de Tas nas amostras de maior concentração x

Tempo para cada faixa de temperatura estudada 
Concentração TAs x Temperatura $5^{\circ} \mathrm{C}$ Amostras Irradiadas
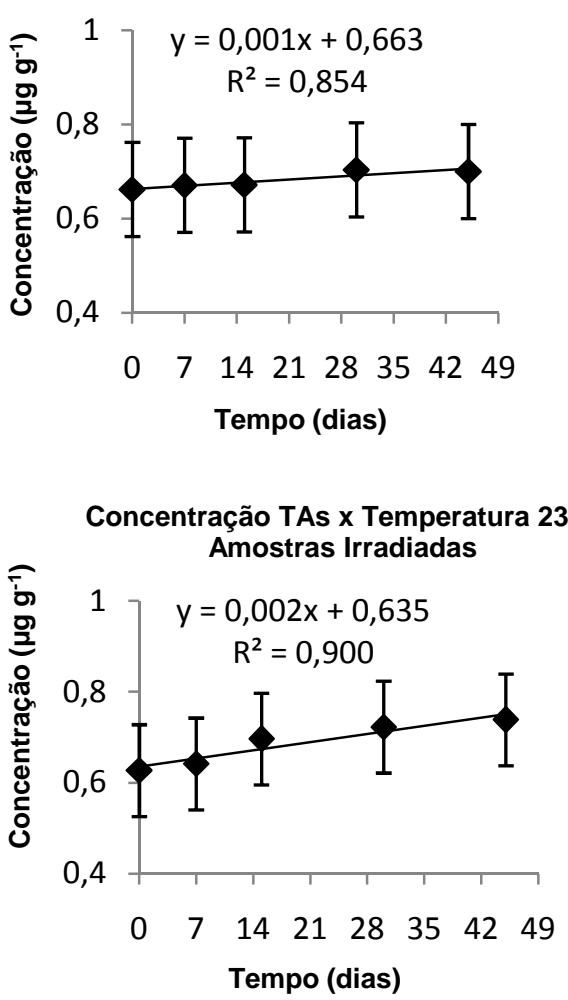

Concentração TAs x Temperatura $40^{\circ} \mathrm{C}$ Amostras Irradiadas
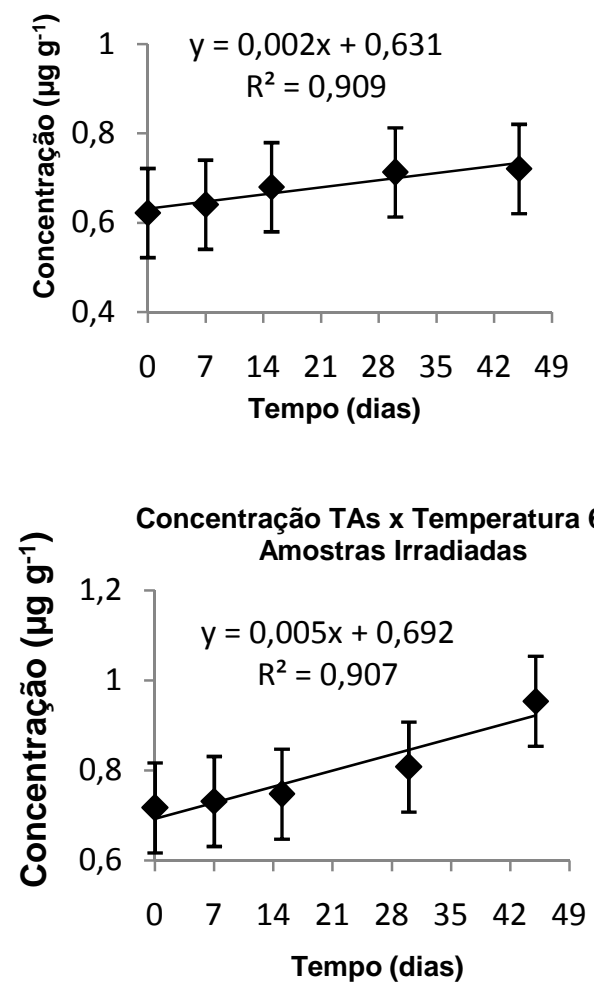

Concentração TAs $\mathrm{x}$ Temperatura $5^{\circ} \mathrm{C}$ Amostras não Irradiadas

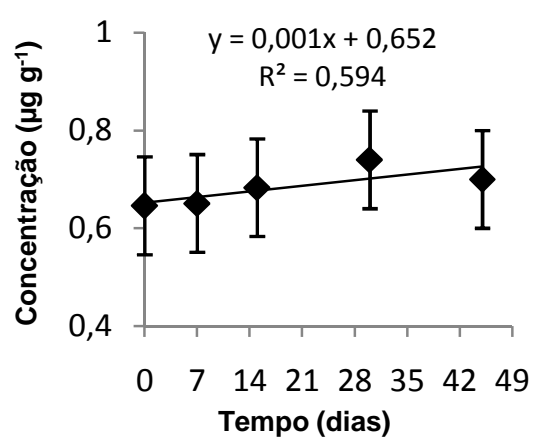

Concentração TAs $x$ Temperatura $23^{\circ} \mathrm{C}$ Amostras não Irradiadas
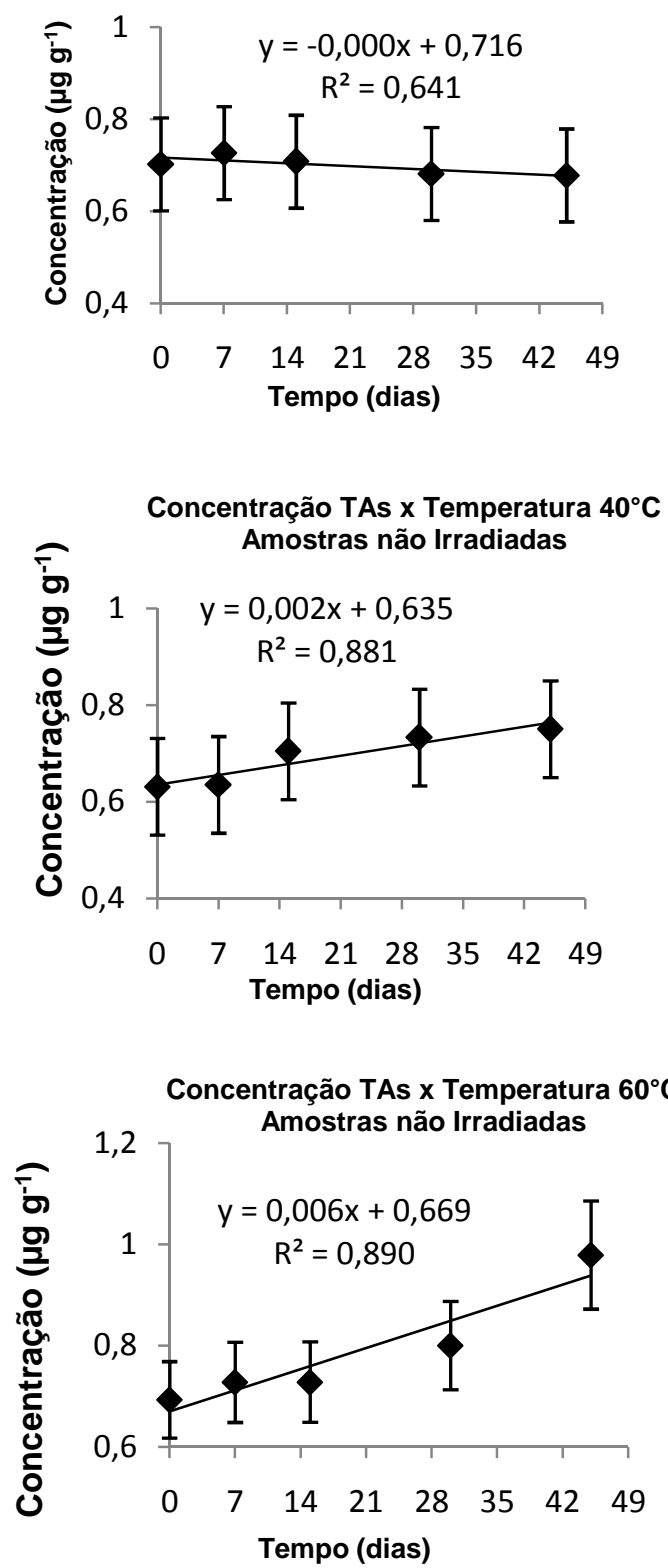

FIGURA 25- Gráficos da Concentração de Tas nas amostras de menor concentração x Tempo para cada faixa de temperatura estudada 


\subsection{Estimativa das incertezas}

\subsubsection{Incerteza de caracterização}

A incerteza para caracterização foi estimada usando-se o cálculo da incerteza expandida para determinação de THg, desenvolvido em planilha Excel ® pelo laboratório como parte de seu programa de qualidade (ensaio acreditado para THg em tecido de peixe, na CGCRE/INMETRO segundo ABNT NBR ISO / IEC 17025: 2005).

Assim, seguindo os passos descritos no item 3.10.1 e utilizando as equações 28 a 56, foi calculada a propagação da incerteza combinada, e multiplicando-se este resultado por 2 obteve-se a incerteza expandida para análise de THg e TAs por AAS.

Os cálculos foram realizados com o valor das concentrações médias das amostras não irradiadas e irradiadas de maior e menor concentração para THg e TAs, para verificar se ocorreriam diferenças significativas entre os resultados da incerteza.

Os resultados da incerteza de medição obtidos podem ser observado nas Tabelas 20 e 21 . O cálculo da incerteza de cada variável encontra-se no Apêndice B, página 179. 
TABELA 20- Estimativa da incerteza expandida e incerteza de caracterização para THg e TAs nas amostras irradiadas, para ambas as concentração

\begin{tabular}{|c|c|c|}
\hline Amostras & $\begin{array}{l}\text { Média } \pm \text { Incerteza } \\
\text { expandida }\left(\mu \mathrm{g} \mathrm{g}{ }^{-1}\right)\end{array}$ & $\begin{array}{c}\text { Incerteza } \\
\text { expandida } \\
(\%)\end{array}$ \\
\hline $\begin{array}{l}\text { THg maior } \\
\text { concentração }\end{array}$ & $0,693 \pm 0,074$ & 12 \\
\hline $\begin{array}{l}\text { THg menor } \\
\text { concentração }\end{array}$ & $0,294 \pm 0,034$ & 12 \\
\hline $\begin{array}{l}\text { TAs maior } \\
\text { concentração }\end{array}$ & $1,085 \pm 0,212$ & 14 \\
\hline $\begin{array}{l}\text { TAs menor } \\
\text { concentração }\end{array}$ & $0,643 \pm 0,145$ & 14 \\
\hline
\end{tabular}

TABELA 21- Estimativa da incerteza expandida e incerteza de caracterização para THg e TAs nas amostras não irradiadas, para ambas as concentração

\begin{tabular}{ccc}
\hline Amostras & $\begin{array}{c}\text { Média } \pm \text { Incerteza } \\
\text { expandida } \\
\left.(\mu \mathrm{g} \mathrm{g})^{-1}\right)\end{array}$ & $\begin{array}{c}\text { Incerteza } \\
\text { expandida } \\
(\%)\end{array}$ \\
\hline $\begin{array}{c}\text { THg maior } \\
\text { concentração }\end{array}$ & $0,564 \pm 0,065$ & 12 \\
$\begin{array}{c}\text { THg menor } \\
\text { concentração } \\
\text { TAs maior }\end{array}$ & $0,284 \pm 0,033$ & 12 \\
concentração & $1,304 \pm 0,226$ & 14 \\
$\begin{array}{c}\text { TAs menor } \\
\text { concentração }\end{array}$ & $0,704 \pm 0,149$ & 14 \\
\hline
\end{tabular}




\subsubsection{Incerteza para homogeneidade}

A incerteza padrão de homogeneidade foi calculada de acordo com a equação (2) como descrito no item 2.2. Sua escolha foi determinada porque $o s_{r}-$ desvio padrão de repetitividade foi maior do que o desvio padrão de homogeneidade $\mathrm{s}_{\mathrm{bb}}$, para algumas amostras (TAB. 22).

$$
u_{b b}=\sqrt{\frac{M Q_{\text {dentro }}}{n}} \sqrt[4]{\frac{2}{v_{M Q_{\text {dentro }}}}}
$$

TABELA 22- Estimativas da incerteza padrão de homogeneidade para os resultados obtidos por FIA-AAS

\begin{tabular}{|c|c|c|c|c|}
\hline Elemento & $\begin{array}{c}\mathrm{S}_{\mathrm{r}} \\
\mu \mathrm{g} \mathrm{g}^{-1}\end{array}$ & $\begin{array}{l}\mathrm{S}_{\mathrm{bb}} \\
\mu \mathrm{g} \mathrm{g}^{-1}\end{array}$ & $\begin{array}{l}u_{b b} \\
\mu g^{-1}\end{array}$ & $\begin{array}{l}\mathrm{u}_{\mathrm{bb}} \\
\%\end{array}$ \\
\hline $\begin{array}{l}\text { THg maior conc. } \\
\text { irrad. }\end{array}$ & 0,019 & 0,015 & 0,0002 & 0,03 \\
\hline $\begin{array}{l}\text { THg maior conc. não } \\
\text { irrad. }\end{array}$ & 0,035 & 0,032 & 0,0004 & 0,07 \\
\hline $\begin{array}{l}\text { THg menor conc. } \\
\text { irrad. }\end{array}$ & 0,012 & 0,015 & 0,0001 & 0,03 \\
\hline $\begin{array}{l}\text { THg menor conc. não } \\
\text { irrad. }\end{array}$ & 0,016 & 0,005 & 0,0002 & 0,07 \\
\hline TAs maior conc. irrad & 0,050 & 0,050 & 0,001 & 0,09 \\
\hline $\begin{array}{l}\text { TAs maior conc. não } \\
\text { irrad. }\end{array}$ & 0,090 & 0,140 & 0,001 & 0,08 \\
\hline TAs menor conc. irrad & 0,045 & 0,066 & 0,0005 & 0,08 \\
\hline $\begin{array}{l}\text { TAs menor conc. não } \\
\text { irrad. }\end{array}$ & 0,061 & 0,061 & 0,001 & 0,14 \\
\hline
\end{tabular}




\subsubsection{Incerteza para estabilidade}

A incerteza padrão de estabilidade foi calculada considerando apenas a incerteza de estabilidade em curto prazo, pois se considerou apenas a incerteza relacionada ao transporte do material. Assim foi utilizada a equaçao (3). Para facilitar os cálculos o tempo de 45 dias foi arredondado para 2 meses, pois a equação utiliza o tempo em meses (TAB. 23 e 24).

$u_{s t s}={ }_{(b 1)} \cdot t_{(\text {meses })}$

TABELA 23- Estimativa da incerteza padrão de estabilidade para os resultados obtidos por FIA-AAS

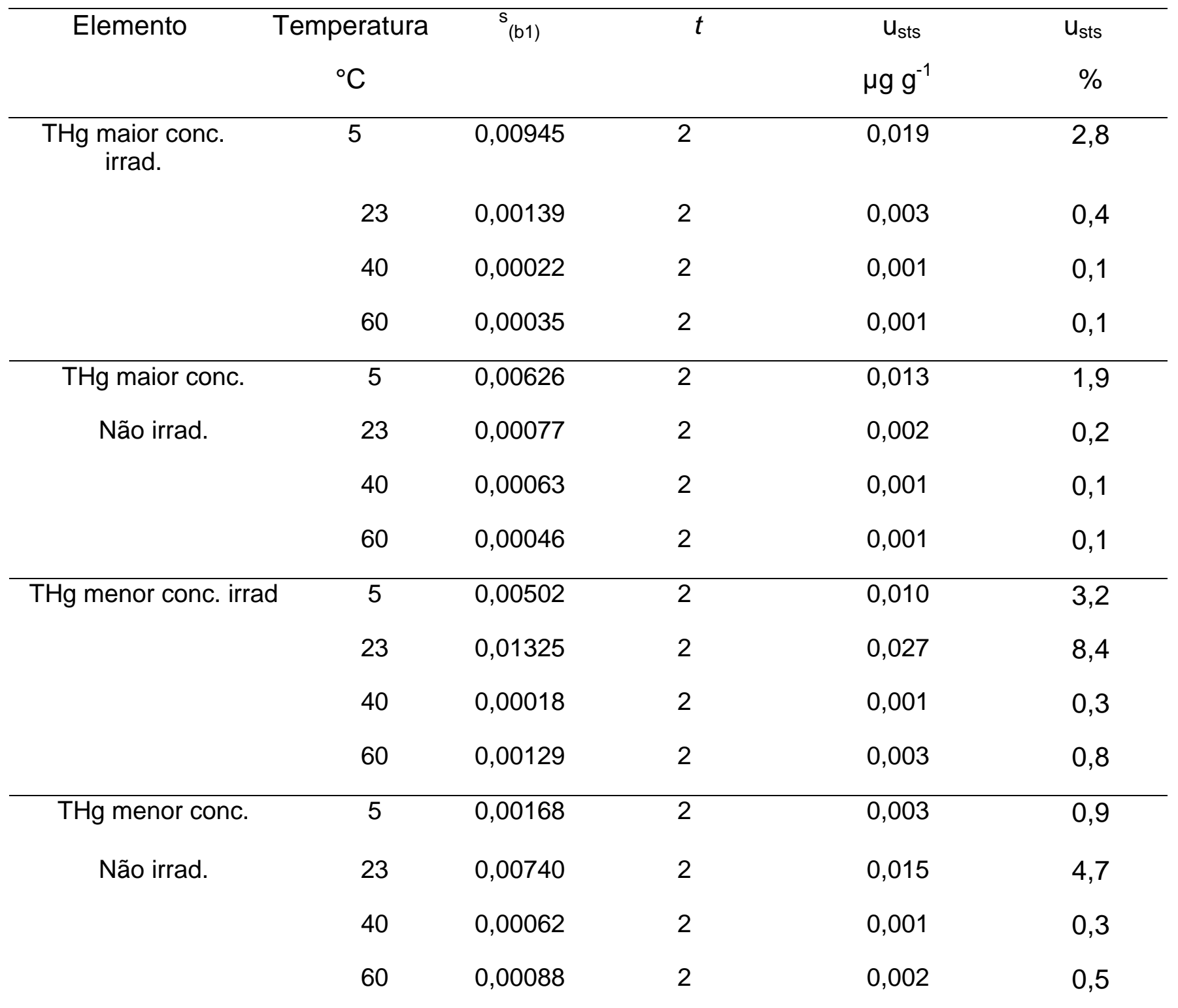

Conc. $=$ concentração; irrad. $=$ irradiação 
TABELA 24- Estimativas da incerteza padrão de estabilidade para os resultados obtidos por FIA-AAS

\begin{tabular}{|c|c|c|c|c|c|}
\hline Elemento & $\begin{array}{c}\text { Temperatura } \\
{ }^{\circ} \mathrm{C}\end{array}$ & ${ }_{(b 1)}^{s_{(b 1)}}$ & $t$ & $\begin{array}{c}\mathrm{u}_{\mathrm{sts}} \\
\mu \mathrm{g} \mathrm{g}^{-1}\end{array}$ & $\begin{array}{l}\mathrm{u}_{\mathrm{sts}} \\
\%\end{array}$ \\
\hline \multirow[t]{4}{*}{ TAs maior conc. irrad. } & 5 & 0,00123 & 2 & 0,002 & 0,2 \\
\hline & 23 & 0,00218 & 2 & 0,004 & 0,4 \\
\hline & 40 & 0,00222 & 2 & 0,004 & 0,4 \\
\hline & 60 & 0,00124 & 2 & 0,002 & 0,2 \\
\hline TAs maior conc. & 5 & 0,00126 & 2 & 0,003 & 0,3 \\
\hline \multirow[t]{3}{*}{ Não irrad. } & 23 & 0,00151 & 2 & 0,003 & 0,3 \\
\hline & 40 & 0,00085 & 2 & 0,002 & 0,2 \\
\hline & 60 & 0,00126 & 2 & 0,003 & 0,2 \\
\hline \multirow[t]{4}{*}{ TAs menor conc. irrad } & 5 & 0,00035 & 2 & 0,001 & 0,1 \\
\hline & 23 & 0,00069 & 2 & 0,001 & 0,1 \\
\hline & 40 & 0,00033 & 2 & 0,001 & 0,1 \\
\hline & 60 & 0,00118 & 2 & 0,002 & 0,3 \\
\hline TAs menor conc. & 5 & 0,00091 & 2 & 0,002 & 0,3 \\
\hline \multirow[t]{3}{*}{ Não irrad. } & 23 & 0,00032 & 2 & 0,001 & 0,1 \\
\hline & 40 & 0,00273 & 2 & 0,005 & 0,7 \\
\hline & 60 & 0,00167 & 2 & 0,003 & 0,4 \\
\hline
\end{tabular}

Conc. $=$ concentração; irrad. $=$ irradiação

De acordo com as características de produção do material e especificidade de seu uso as temperaturas de estabilidade consideradas adequadas foram $5 \pm$ $0,2^{\circ} \mathrm{C}$ e $23 \pm 0,5^{\circ} \mathrm{C}$. Assim adotou-se os valores da incerteza de estabilidade em curto prazo para a temperatura de $23{ }^{\circ} \mathrm{C}$ (temperatura para 0 transporte das amostras), a qual foi usada para o cálculo da incerteza expandida associada ao valor de referência para os elementos THg e TAs. 
A Tabela 25 apresenta os resultados das incertezas combinadas para caracterização $\left(u_{c a r}\right.$, estudo de homogeneidade $\left(u_{b b}\right)$ e estudo de estabilidade em curto prazo $\left(\mathrm{u}_{\mathrm{sts}}\right)$.

TABELA 25- Estimativa das incertezas padrão combinadas para os elementos THg e TAS

\begin{tabular}{|c|c|c|c|}
\hline Elemento & $\begin{array}{c}\mathrm{u}_{\mathrm{car}} \\
\mu \mathrm{g} \mathrm{g}^{-1}\end{array}$ & $\begin{array}{c}\mathrm{u}_{\mathrm{bb}} \\
\mu \mathrm{g} \mathrm{g}^{-1}\end{array}$ & $\begin{array}{l}u_{\text {sts }} \\
\mu g^{-1}\end{array}$ \\
\hline $\begin{array}{l}\text { THg maior conc. } \\
\text { irrad. }\end{array}$ & 0,074 & 0,0002 & 0,003 \\
\hline $\begin{array}{l}\text { THg maior conc. não } \\
\text { irrad. }\end{array}$ & 0,065 & 0,0004 & 0,002 \\
\hline $\begin{array}{l}\text { THg menor conc. } \\
\text { irrad. }\end{array}$ & 0,034 & 0,0001 & 0,027 \\
\hline $\begin{array}{l}\text { THg menor conc. não } \\
\text { irrad. }\end{array}$ & 0,033 & 0,0002 & 0,015 \\
\hline TAs maior conc. irrad & 0,212 & 0,001 & 0,004 \\
\hline $\begin{array}{l}\text { TAs maior conc. não } \\
\text { irrad. }\end{array}$ & 0,226 & 0,001 & 0,003 \\
\hline TAs menor conc. irrad & 0,145 & 0,0005 & 0,001 \\
\hline $\begin{array}{l}\text { TAs menor conc. não } \\
\text { irrad. }\end{array}$ & 0,149 & 0,001 & 0,001 \\
\hline
\end{tabular}

\subsubsection{Incerteza associada ao valor de referência}

Logo a equação 39 expressa como foi calculada a incerteza associada ao valor referência do material produzido neste trabalho. Para este cálculo $k$ é o fator de abrangência, igual a dois, assim observa-se nas Tabelas 26 e 27 os valores referentes à concentração média e incerteza associada ao valor de referência dos materiais produzidos:

$$
U_{M R}=k \sqrt{u_{c a r}^{2}+u_{b b}^{2}+u_{s t s}^{2}}
$$


TABELA 26- Estimativa da incerteza associada ao valor referência das amostras de THg e TAs irradiadas de maior e menor concentração

\begin{tabular}{ccc}
\hline Amostras & $\begin{array}{c}\text { Média } \pm \text { Incerteza } \\
\text { expandida } \\
\left(\mu \mathrm{g} \mathrm{g}^{-1}\right)\end{array}$ & $\begin{array}{c}\text { Incerteza } \\
\text { expandida } \\
\mathrm{U}(\%)\end{array}$ \\
\hline $\begin{array}{c}\text { THg maior } \\
\text { concentração } \\
\text { THg menor }\end{array}$ & $0,693 \pm 0,150$ & 22 \\
concentração \\
$\begin{array}{c}\text { TAs maior } \\
\text { concentração } \\
\text { TAs menor }\end{array}$ & $0,294 \pm 0,077$ & 26 \\
concentração & $0,643 \pm 0,290$ & 39 \\
\hline
\end{tabular}

TABELA 27- Estimativa da incerteza associada ao valor de referência das amostras de THg e TAs não irradiadas de maior e menor concentração

\begin{tabular}{ccc}
\hline Amostras & $\begin{array}{c}\text { Média } \pm \text { Incerteza } \\
\text { associada } \\
\left(\mu \mathrm{g} \mathrm{g}^{-1}\right)\end{array}$ & $\begin{array}{c}\text { Incerteza } \\
\text { associada } \\
\mathrm{U}(\%)\end{array}$ \\
\hline $\begin{array}{c}\text { THg maior } \\
\text { concentração }\end{array}$ & $0,564 \pm 0,131$ & 23 \\
$\begin{array}{c}\text { THg menor } \\
\text { concentração } \\
\text { TAs maior } \\
\text { concentração } \\
\begin{array}{c}\text { TAs menor } \\
\text { concentração }\end{array}\end{array}$ & $0,284 \pm 0,067$ & 23 \\
\hline
\end{tabular}

O valor da concentração dos elementos mercúrio e arsênio foram obtidos na caracterização do material, representando o valor médio de 15 resultados para as amostras irradiadas e 15 para as amostras não irradiadas. 
Nas Tabelas 28 e 29, são apresentados os valores referentes à concentração média e incerteza associada a caracterização dos elementos $\mathrm{Cd}$ e $\mathrm{Pb}$ (valor informativo) de ambos os materiais produzidos.

TABELA 28- Valor informativo \pm incerteza associada das amostras de TCd e TPb irradiadas de maior e menor concentração

\begin{tabular}{|c|c|c|}
\hline Amostras & $\begin{array}{c}\text { Média } \pm \text { Incerteza } \\
\text { associada } \\
\left(\mu \mathrm{g} \mathrm{g}^{-1}\right)\end{array}$ & $\begin{array}{c}\text { Incerteza } \\
\text { associada } \\
U(\%)\end{array}$ \\
\hline $\begin{array}{c}\text { TCd maior } \\
\text { concentração }\end{array}$ & $0,913 \pm 0,229$ & 25 \\
\hline $\begin{array}{l}\text { TCd menor } \\
\text { concentração }\end{array}$ & $0,704 \pm 0,175$ & 25 \\
\hline $\begin{array}{l}\text { TPb maior } \\
\text { concentração }\end{array}$ & $1,769 \pm 0,272$ & 15 \\
\hline $\begin{array}{c}\text { TPb menor } \\
\text { concentração }\end{array}$ & $1,161 \pm 0,168$ & 15 \\
\hline
\end{tabular}

TABELA 29- Valor informativo \pm incerteza associada das amostras de TCd e TPb não irradiadas de maior e menor concentração

\begin{tabular}{ccc}
\hline Amostras & $\begin{array}{c}\text { Média } \pm \text { incerteza } \\
\text { associada } \\
\left(\mu \mathrm{g} \mathrm{g}^{-1}\right)\end{array}$ & $\begin{array}{c}\text { Incerteza } \\
\text { associada } \\
\mathrm{U}(\%)\end{array}$ \\
\hline $\begin{array}{c}\text { TCd maior } \\
\text { concentração }\end{array}$ & $0,910 \pm 0,224$ & 25 \\
$\begin{array}{c}\text { TCd menor } \\
\text { concentração } \\
\text { TPb maior }\end{array}$ & $0,750 \pm 0,189$ & 25 \\
concentração \\
$\begin{array}{c}\text { TPb menor } \\
\text { concentração }\end{array}$ & $2,400 \pm 0,362$ & 15 \\
\hline
\end{tabular}


Para os elementos cádmio e chumbo não foi possível à realização dos ensaios de homogeneidade e estabilidade, assim foram utilizadas as médias e desvio padrão dos valores obtidos por laboratórios colaboradores, e a incerteza associada foi calculada a partir de medições iniciais realizadas no LCQ pela técnica de ICP-MS. Logo seus resultados constam apenas como valor informativo.

\subsection{Resultados do programa piloto de ensaio de proficiência}

Foram utilizadas as recomendações da serie ISO/IEC 13528 (2005), ISO 5725-2 (2005) e ABNT: NBR ISO/IEC 17043 (2011), os critérios da União Internacional de Química Pura e Aplicada IUPAC (2006), na análise dos resultados fornecidos pelos laboratórios participantes do programa piloto de ensaio de proficiência.

Convidaram-se dez laboratórios para participar do programa piloto de ensaio de proficiência, distribuídos em todas as regiões do Brasil, contando com o apoio do MAPA. Todos os laboratórios aceitaram participar. Estes receberam três itens de ensaio, a saber: 1 sachê do material fortificado em menor concentração $(10 \pm 0,2 \mathrm{~g}), 1$ sachê de material fortificado em maior concentração $(10 \pm 0,2 \mathrm{~g}) \mathrm{e}$ 1 sachê com material de referência certificado (2,5 $\pm 0,3 \mathrm{~g})$, DORM-2, proveniente do National Research Council Canada (NRCC).

Os sachês foram enviados para os laboratórios via sedex, em envelopes tipo bolha, com folheto contendo as seguintes instruções: nome do programa; Itens a serem ensaiados; código das amostras e dos laboratórios; prazo para entrega de resultados; planilha para envio de resultados; temperatura de manipulação e armazenamento; formas de abertura e manuseio da embalagem; solicitação para a determinação dos elementos em triplicatas.

Os laboratórios foram orientados a proceder com os itens de ensaio seguindo o mesmo procedimento usado na análise de suas amostras de rotina. Além dos resultados analíticos, expressos em $\mu \mathrm{g} \mathrm{g}^{-1}$, foram solicitadas informações sobre o limite de detecção, limite de quantificação, incerteza analítica, precisão da medida, uso de padrões, recuperação dos padrões 
utilizados, quantidade utilizada dos materiais, realização das determinações em dias diferentes, informações referentes aos métodos empregados e equipamentos utilizados. $O$ tempo para realização dos ensaios e retorno dos resultados foi de 30 dias.

Dos laboratórios participantes: sete possuem ensaios acreditados na CGCRE/INMETRO segundo a norma ABNT NBR ISO/IEC 17025 (2005) na área de alimentos e bebidas; cinco possuem escopo para mercúrio em pescado; um possui escopo para os quatro elementos solicitados no ensaio.

$\mathrm{Na}$ Tabela 30, constam todas as informações que foram solicitadas aos laboratórios e quantos laboratórios atenderam as mesmas.

TABELA 30- Informações solicitadas aos laboratórios participantes do ensaio de proficiência

\begin{tabular}{c|c}
\hline INFORMAÇÕES SOLICITADAS & $\begin{array}{c}\text { QUANTIDADE DE LABORATÓRIOS QUE } \\
\text { ATENDERAM AS SOLICITAÇÕES }\end{array}$ \\
\hline QUANTIDADE DE MASSA UTILIZADA & 10 \\
\hline DESCRIÇÃO DO MÉTODO UTILIZADO & 10 \\
\hline INCERTEZA DE MEDIÇÃO & 8 \\
\hline DESVIO PADRÃO DA MEDIDA & 9 \\
\hline LIMITE DE DETECÇÃO & 10 \\
\hline RESULTADO EM TRIPLICATA & 9 \\
\hline $\begin{array}{c}\text { MRC UTILIZADO PELO LABORATÓRIO } \\
\text { \% DE RECUPERAÇÃO DO MRC } \\
\text { UTILIZADO PELO LABORATÓRIO }\end{array}$ & 4 \\
\hline $\begin{array}{c}\text { ENTREGA DOS RESULTADOS NO } \\
\text { PRAZO ESTIPULADO }\end{array}$ & 4 \\
\hline $\begin{array}{c}\text { TODOS OS ELEMENTOS ANALIZADOS } \\
\text { QUANTIDADE DE AMOSTRAS } \\
\text { SOLICITADA ALÉM DA ENVIADA }\end{array}$ & 4 \\
\hline $\begin{array}{c}\text { ANÁLISE DE TODOS OS ELEMENTOS } \\
\text { SEM MÉTODO VALIDADO }\end{array}$ & 4 \\
\hline $\begin{array}{c}\text { ANÁLISE DA AMOSTRA DE MRC } \\
\text { ENVIADO }\end{array}$ & 3 \\
\hline
\end{tabular}


As técnicas analíticas utilizadas foram espectrometria de absorção atômica- AAS (CV-AAS, HG-AAS, GF-AAS, TDA-AAS), análise de $\mathrm{Hg}$ por decomposição térmica, espectrometria de massas (ICP-MS) e espectrometria ótica (ICPOES).

$\mathrm{Na}$ Tabela 31 observam-se os resultados dos limites de detecção informados pelos laboratórios e as técnicas analíticas utilizadas. Cada laboratório enviou seu resultado na unidade por este utilizada, quando foi solicitado que os resultados fossem enviados em $\mu \mathrm{g} \mathrm{g}^{-1}$.

São apresentados na Tabela 32 os resultados $\mu \mathrm{g} \mathrm{g}^{-1}$, para as amostras enviadas para cada laboratório participante, decidiu-se apresentar os resultados médios e o desvio padrão, pois nem todos os laboratórios reportaram a incerteza expandida associada ao seu resultado de medição. Os valores em negrito e itálico correspondem a resultados considerados outliers. 
TABELA 31- Técnica analítica utilizada, e limite de detecção (LD) para determinação dos elementos pelos laboratórios

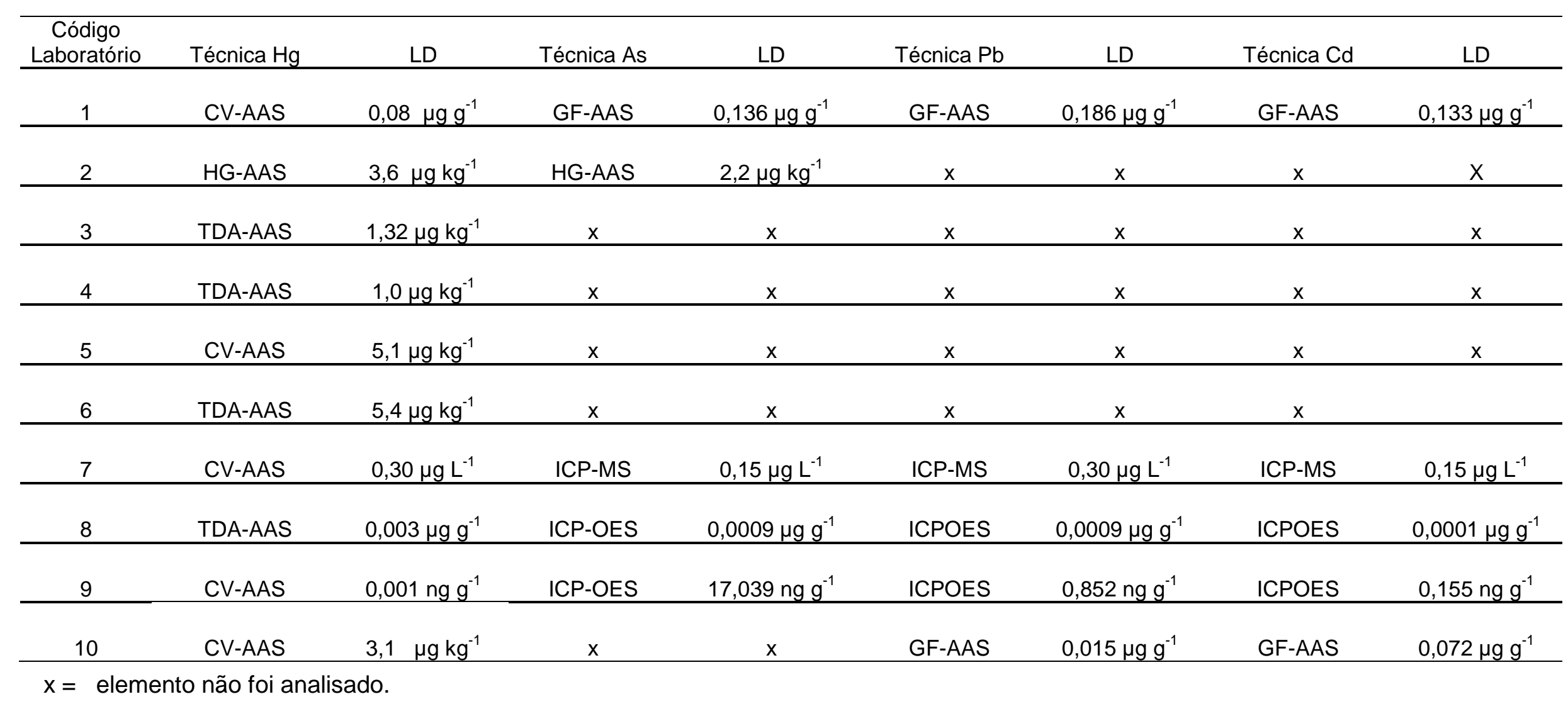


TABELA 32- Resultados reportados, em $\mu \mathrm{g} \mathrm{g}^{-1}$, pelos participantes do programa piloto de ensaio de proficiência (base úmida)

\begin{tabular}{|c|c|c|c|c|c|c|c|c|}
\hline $\begin{array}{c}\text { Código } \\
\text { Laboratório }\end{array}$ & $\begin{array}{c}\mathrm{Hg}+\text { conc. } \\
\left(\mu \mathrm{g} \mathrm{g}^{-1}\right)\end{array}$ & $\begin{array}{c}\mathrm{Hg} \text { - conc. } \\
\left(\mu \mathrm{g} \mathrm{g}^{-1}\right)\end{array}$ & $\begin{array}{c}\text { As + conc. } \\
\left(\mu \mathrm{g} \mathrm{g}^{-1}\right)\end{array}$ & $\begin{array}{c}\text { As - conc. } \\
\left(\mu \mathrm{g} \mathrm{g}^{-1}\right)\end{array}$ & $\begin{array}{c}\mathrm{Pb}+\text { conc. } \\
\left(\mu \mathrm{g} \mathrm{g}^{-1}\right)\end{array}$ & $\begin{array}{c}\mathrm{Pb} \text { - conc. } \\
\left(\mu \mathrm{g} \mathrm{g}^{-1}\right)\end{array}$ & $\begin{array}{c}\text { Cd + conc. } \\
\left(\mu \mathrm{g} \mathrm{g}^{-1}\right)\end{array}$ & $\begin{array}{c}\text { Cd - conc. } \\
\left(\mu \mathrm{g} \mathrm{g}^{-1}\right)\end{array}$ \\
\hline & $0,463 \pm 0,08$ & $0,168 \pm 0,03$ & $1,207 \pm 0,10$ & $0,718 \pm 0,06$ & $1,911 \pm 0,28$ & $1,083 \pm 0,16$ & $0,681 \pm 0,03$ & $0,650 \pm 0,03$ \\
\hline 1 & $0,516 \pm 0,09$ & $0,225 \pm 0,04$ & $1,324 \pm 0,11$ & $0,818 \pm 0,07$ & $2,076 \pm 0,31$ & $1,224 \pm 0,18$ & $0,715 \pm 0,03$ & $0,482 \pm 0,02$ \\
\hline \multirow{3}{*}{2} & \multirow[t]{3}{*}{ 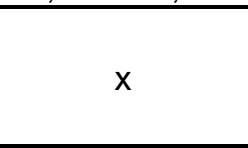 } & $0,290 \pm 0,023$ & $1,000 \pm 0,054$ & \multirow{3}{*}{$x$} & \multirow{3}{*}{$x$} & \multirow{3}{*}{$x$} & \multirow{3}{*}{$x$} & \multirow{3}{*}{$x$} \\
\hline & & $0,300 \pm 0,023$ & $0,950 \pm 0,054$ & & & & & \\
\hline & & $0,280 \pm 0,023$ & $0,980 \pm 0,054$ & & & & & \\
\hline \multirow{3}{*}{3} & $0,637 \pm 0,10$ & $0,264 \pm 0,10$ & \multirow{3}{*}{$x$} & \multirow{3}{*}{$x$} & \multirow{3}{*}{$x$} & \multirow{3}{*}{$x$} & \multirow{3}{*}{$x$} & \multirow{3}{*}{$\mathrm{x}$} \\
\hline & $0,676 \pm 0,10$ & $0,269 \pm 0,10$ & & & & & & \\
\hline & $0,642 \pm 0,10$ & $0,257 \pm 0,10$ & & & & & & \\
\hline \multirow{3}{*}{4} & $0,826 \pm 0,02$ & $0,347 \pm 0,02$ & \multirow{3}{*}{$x$} & \multirow{3}{*}{$x$} & \multirow{3}{*}{$x$} & \multirow{3}{*}{$x$} & \multirow{3}{*}{$x$} & \multirow{3}{*}{$\mathrm{x}$} \\
\hline & $0,844 \pm 0,02$ & $0,380 \pm 0,02$ & & & & & & \\
\hline & $0,798 \pm 0,02$ & $0,355 \pm 0,02$ & & & & & & \\
\hline \multirow{3}{*}{5} & $0,857 \pm 0,04$ & $0,352 \pm 0,01$ & \multirow{3}{*}{$x$} & \multirow{3}{*}{$x$} & \multirow{3}{*}{$x$} & \multirow{3}{*}{$x$} & \multirow{3}{*}{$x$} & \multirow{3}{*}{$\mathrm{x}$} \\
\hline & $0,786 \pm 0,04$ & $0,324 \pm 0,01$ & & & & & & \\
\hline & $0,867 \pm 0,04$ & $0,336 \pm 0,01$ & & & & & & \\
\hline \multirow{3}{*}{6} & $0,680 \pm 0,01$ & $0,311 \pm 0,006$ & \multirow{3}{*}{$x$} & & & & & \\
\hline & $0,700 \pm 0,01$ & $0,322 \pm 0,006$ & & $x$ & $\mathrm{x}$ & $\mathrm{x}$ & $\mathrm{x}$ & $x$ \\
\hline & $0,690 \pm 0,01$ & $0,321 \pm 0,006$ & & & & & & \\
\hline & $0,300 \pm 0,01$ & $0,090 \pm 0,01$ & $0,980 \pm 0,09$ & $0,550 \pm 0,05$ & $1,750 \pm 0,02$ & $1,030 \pm 0,01$ & $0,620 \pm 0,04$ & $0,480 \pm 0,01$ \\
\hline 7 & $0,200 \pm 0,01$ & $0,090 \pm 0,01$ & $1,160 \pm 0,09$ & $0,720 \pm 0,05$ & $1,710 \pm 0,02$ & $1,030 \pm 0,01$ & $0,700 \pm 0,04$ & $0,480 \pm 0,01$ \\
\hline & $0,200 \pm 0,01$ & $0,080 \pm 0,01$ & $1,120 \pm 0,09$ & $0,670 \pm 0,05$ & $1,720 \pm 0,02$ & $1,020 \pm 0,01$ & $0,680 \pm 0,04$ & $0,480 \pm 0,01$ \\
\hline & $4,040 \pm 0,06$ & $2,090 \pm 0,24$ & $0,830 \pm 0,01$ & $0,410 \pm 0,01$ & $1,290 \pm 0,04$ & $0,790 \pm 0,02$ & $0,570 \pm 0,02$ & $0,410 \pm 0,02$ \\
\hline 8 & $4,080 \pm 0,06$ & $2,020 \pm 0,24$ & $0,810 \pm 0,01$ & $0,390 \pm 0,01$ & $1,270 \pm 0,04$ & $0,790 \pm 0,02$ & $0,550 \pm 0,02$ & $0,420 \pm 0,02$ \\
\hline & $3,970 \pm 0,06$ & $2,470 \pm 0,24$ & $0,830 \pm 0,01$ & $0,400 \pm 0,01$ & $1,350 \pm 0,04$ & $0,830 \pm 0,02$ & $0,580 \pm 0,02$ & $0,450 \pm 0,02$ \\
\hline & $0,509 \pm 0,04$ & $0,198 \pm 0,03$ & $1,188 \pm 0,04$ & $0,806 \pm 0,02$ & $1,985 \pm 0,03$ & $1,214 \pm 0,03$ & $0,637 \pm 0,04$ & $0,473 \pm 0,01$ \\
\hline 9 & $0,566 \pm 0,04$ & $0,260 \pm 0,03$ & $1,094 \pm 0,04$ & $0,841 \pm 0,02$ & $2,016 \pm 0,03$ & $1,882 \pm 0,03$ & $0,544 \pm 0,04$ & $0,456 \pm 0,01$ \\
\hline & $0,615 \pm 0,04$ & $0,278 \pm 0,03$ & $1,145 \pm 0,04$ & $0,784 \pm 0,02$ & $1,935 \pm 0,03$ & $1,824 \pm 0,03$ & $0,623 \pm 0,04$ & $0,453 \pm 0,01$ \\
\hline & $0,176 \pm 0,004$ & $0,071 \pm 0,001$ & & & $1,449 \pm 0,03$ & $0,887 \pm 0,05$ & $0,622 \pm 0,001$ & $0,460 \pm 0,01$ \\
\hline 10 & $0,186 \pm 0,006$ & $0,072 \pm 0,001$ & $x$ & $x$ & $1,385 \pm 0,02$ & $0,880 \pm 0,03$ & $0,621 \pm 0,001$ & $0,468 \pm 0,02$ \\
\hline & $0,176 \pm 0,003$ & $0,077 \pm 0,001$ & & & $1,416 \pm 0,01$ & $0,938 \pm 0,02$ & $0,656 \pm 0,001$ & $0,463 \pm 0,01$ \\
\hline
\end{tabular}

Média \pm desvio padrão; $x$ = elemento não foi analisado. 


\subsubsection{Valor designado}

A Tabela 33 apresenta os resultados obtidos para os valores designados de cada elemento. Observá-se a concordância entre os dados da estatística clássica e robusta de Huber para as médias de concentrações, não identificando valores extremos. Avaliandose a dispersão através do desvio padrão, foram observados valores mais baixos para a MAD.

TABELA 33- Estimativa para os valores designados e incerteza de caracterização, em $\mu \mathrm{g}$ $\mathrm{g}^{-1}$, para os resultados do ensaio piloto de proficiência (base úmida)

\begin{tabular}{l|ccc|cc|ccc}
\hline \multicolumn{5}{c|}{$\begin{array}{c}\text { Estatística Clássica } \\
\left(\mu \mathrm{g} \mathrm{g}^{-1}\right)\end{array}$} & \multicolumn{5}{c}{$\begin{array}{c}\text { Estatística Robusta } \\
\left(\mu \mathrm{g} \mathrm{g}^{-1}\right)\end{array}$} \\
\hline \multicolumn{1}{c|}{ Mensurando } & Média & DP & $u_{\text {lab }}$ & Mediana & MAD & H15 Huber & uH15 Huber & $U_{A 15}$ \\
\hline HHg + concentrado & 0,580 & 0,13 & 0,12 & 0,637 & 0,16 & 0,601 & 0,19 & 0,06 \\
THg - concentrado & 0,243 & 0,10 & 0,06 & 0,274 & 0,06 & 0,263 & 0,07 & 0,02 \\
TAs + concentrado & 1,073 & 0,15 & 0,05 & 1,133 & 0,11 & 1,050 & 0,11 & 0,04 \\
TAs - concentrado & 0,646 & 0,18 & 0,04 & 0,718 & 0,15 & 0,717 & 0,01 & 0,01 \\
TPb + concentrado & 1,662 & 0,29 & 0,06 & 1,715 & 0,21 & 1,679 & 0,30 & 0,10 \\
TPb - concentrado & 1,102 & 0,35 & 0,03 & 1,025 & 0,17 & 1,019 & 0,04 & 0,01 \\
TCd + concentrado & 0,629 & 0,05 & 0,12 & 0,623 & 0,05 & 0,627 & 0,06 & 0,02 \\
TCd - concentrado & 0,460 & 0,02 & 0,06 & 0,463 & 0,01 & 0,464 & 0,01 & 0,01 \\
\hline
\end{tabular}

$\mathrm{H} 15 \mathrm{Huber}=$ média robusta, $u \mathrm{H} 15 \mathrm{Huber}=$ desvio padrão robusto, $\mathrm{u}_{\mathrm{A} 15}$ Huber = incerteza de caracterização; MAD = desvio padrão da mediana. + maior concentração; - menor concentração.

Os valores das estimativas de incerteza dos laboratórios não foram concordantes, já que a estimativa pelo método robusto apresentou valores menores.

Os valores certificados para os mensurandos presentes no material de referência certificado (MRC), DORM-2 em $\mu \mathrm{g} \mathrm{g}^{-1}$, com suas incertezas associadas, são: $\mathrm{Hg}(4,64 \pm$ $\left.0,26 \mu \mathrm{g} \mathrm{g}^{-1}\right)$; As $\left(18,0 \pm 1,1 \mu \mathrm{g} \mathrm{g}^{-1}\right)$; $\mathrm{Pb}\left(0,0065 \pm 0,007 \mu \mathrm{g} \mathrm{g}^{-1}\right) ; \mathrm{Cd}\left(0,043 \pm 0,008 \mu \mathrm{g} \mathrm{g}^{-1}\right)$.

Os valores em negrito correspondem à recuperação alcançada pelos laboratórios participantes do ensaio, Tabela 34.

Apenas um laboratório não realizou a análise do MRC. Dentre os laboratórios que analisaram o elemento As apenas um apresentou resultado abaixo do valor certificado. Sete laboratórios que analisaram o elemento $\mathrm{Hg}$, apresentaram boa recuperação. 
TABELA 34- Resultados \pm DP e \% de recuperação, reportados pelos laboratórios participantes para a amostra de MRC em $\mu \mathrm{g} \mathrm{g}^{-1}$.

\begin{tabular}{|c|c|c|c|c|}
\hline $\begin{array}{c}\text { Código } \\
\text { Laboratório }\end{array}$ & $\begin{array}{c}\mathrm{THg} \\
\left(\mu \mathrm{g} \mathrm{g}^{-1}\right) \\
\end{array}$ & $\begin{array}{c}\text { TAs } \\
\left(\mu \mathrm{g} \mathrm{g}^{-1}\right) \\
\end{array}$ & $\begin{array}{c}\mathrm{TPb} \\
\left(\mu \mathrm{g} \mathrm{g}^{-1}\right)\end{array}$ & $\begin{array}{l}\mathrm{TCd} \\
\left(\mu \mathrm{g} \mathrm{g}^{-1}\right)\end{array}$ \\
\hline 1 & $\begin{array}{c}3,08 \pm 0.53 \\
66,4 \%\end{array}$ & $\begin{array}{c}18,26 \pm 1.53 \\
101,4 \%\end{array}$ & 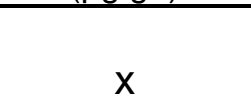 & $x$ \\
\hline $\mathrm{a}_{2}$ & $x$ & $\mathrm{x}$ & $X$ & $x$ \\
\hline 3 & $\begin{array}{c}4,28 \pm 0.10 \\
92,2 \%\end{array}$ & $x$ & $x$ & $x$ \\
\hline 4 & $\begin{array}{c}4,77 \pm 0.14 \\
102,8 \%\end{array}$ & $x$ & $X$ & $X$ \\
\hline 5 & $\begin{array}{c}4,98 \pm 0,03 \\
107,3 \%\end{array}$ & $x$ & $x$ & $X$ \\
\hline 6 & $\begin{array}{c}4,57 \pm 0,04 \\
98,5 \%\end{array}$ & $x$ & $X$ & $x$ \\
\hline 7 & $\begin{array}{c}2,95 \pm 0,31 \\
63,6 \%\end{array}$ & $\begin{array}{c}17,17 \pm 1,4 \\
95,4 \%\end{array}$ & $\begin{array}{c}0,15 \pm 0,002 \\
230,8 \%\end{array}$ & $\begin{array}{c}0,04 \pm 0,01 \\
93,0 \%\end{array}$ \\
\hline 8 & $\begin{array}{c}6,03 \pm 0,53 \\
66,4 \%\end{array}$ & $\begin{array}{c}12,62 \pm 1,53 \\
70,1 \%\end{array}$ & $\begin{array}{c}0,64 \pm 0,02 \\
984,6 \%\end{array}$ & $\begin{array}{c}0,04 \pm 0,01 \\
93,0 \%\end{array}$ \\
\hline 9 & $\begin{array}{c}9,13 \pm 1,38 \\
196,8 \%\end{array}$ & $\begin{array}{c}4,97 \pm 0,05 \\
27,6 \%\end{array}$ & $\begin{array}{c}4,35 \pm 0,10 \\
6692,3 \%\end{array}$ & $\begin{array}{c}0,22 \pm 0,02 \\
511,6 \%\end{array}$ \\
\hline 10 & $\begin{array}{c}2,45 \pm 0,08 \\
52,8 \%\end{array}$ & $x$ & $\begin{array}{c}0,050 \pm 0,01 \\
76,9 \%\end{array}$ & $\begin{array}{c}0,04 \pm 0,001 \\
93,0 \%\end{array}$ \\
\hline
\end{tabular}

Valores em negrito = recuperação do analito em \%; ${ }^{a}$ não realizou a determinação no MRC.

Como pode ser observado nos gráficos de dispersão para a amostra de MRC, 50 $\%$ dos resultados obtidos para o elemento mercúrio estão dentro do valor certificado (Fig. 26).

Para os elementos $\mathrm{Cd}$ e $\mathrm{Pb}$, um laboratório apresentou os resultados dentro do valor certificado. Dois laboratórios apresentaram resultados acima do valor certificado para o elemento $\mathrm{Pb}$ e um laboratório apresentou resultados acima do valor certificado para o elemento $\mathrm{Cd}$.

Importante notar que o MRC apresenta valores de concentração para $\mathrm{Cd}$ e $\mathrm{Pb}$ bem próximos, ou mesmo abaixo, dos limites de detecção declarados por alguns laboratórios. Ainda assim, dos resultados apresentados, três laboratórios obtiveram boa recuperação para o Cd no MRC.

A seguir são apresentados os gráficos de dispersão dos resultados obtidos pelos laboratórios para o MRC e as amostras analisados. (FIG. 26, 27 e 28). 


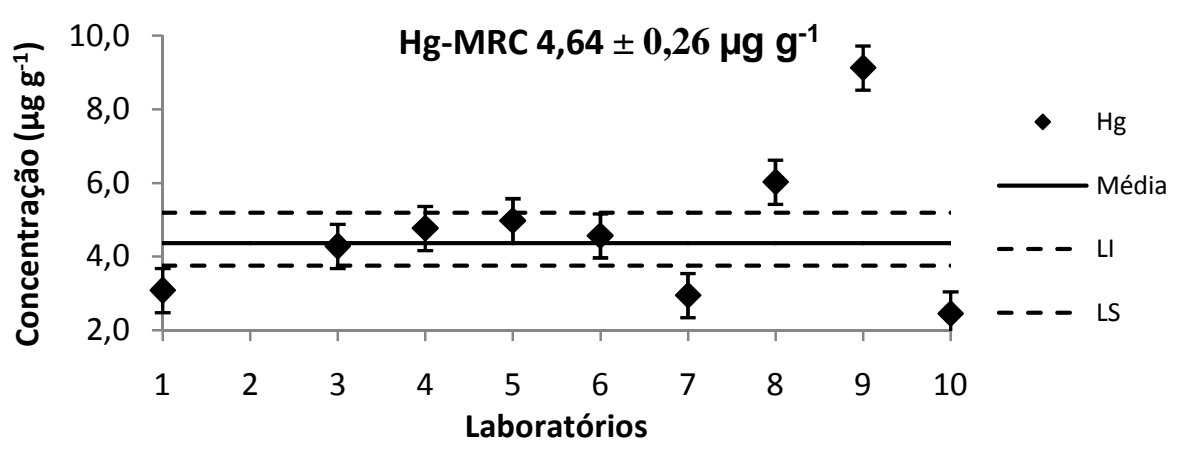

As-MRC $18,0 \pm 1,1 \mu \mathrm{g} \mathrm{g}^{-1}$
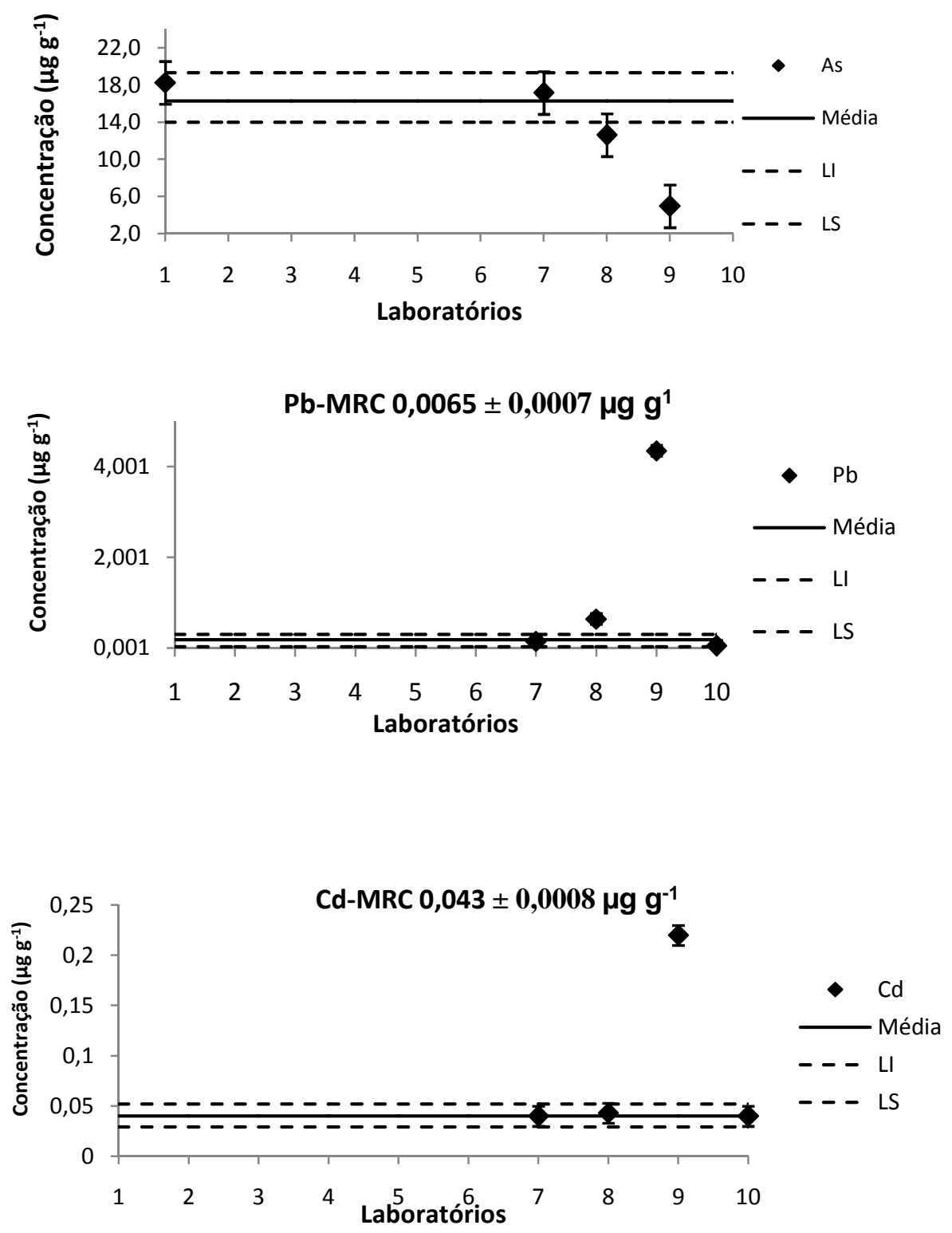

FIGURA 26- Dispersão dos resultados dos laboratórios participantes para o MRC. A linha cheia representa o valor certificado e as linhas tracejadas os limites superior e inferior, LI = limite inferior e LS = limite superior (incerteza fornecida pelo certificado do material de referência). 

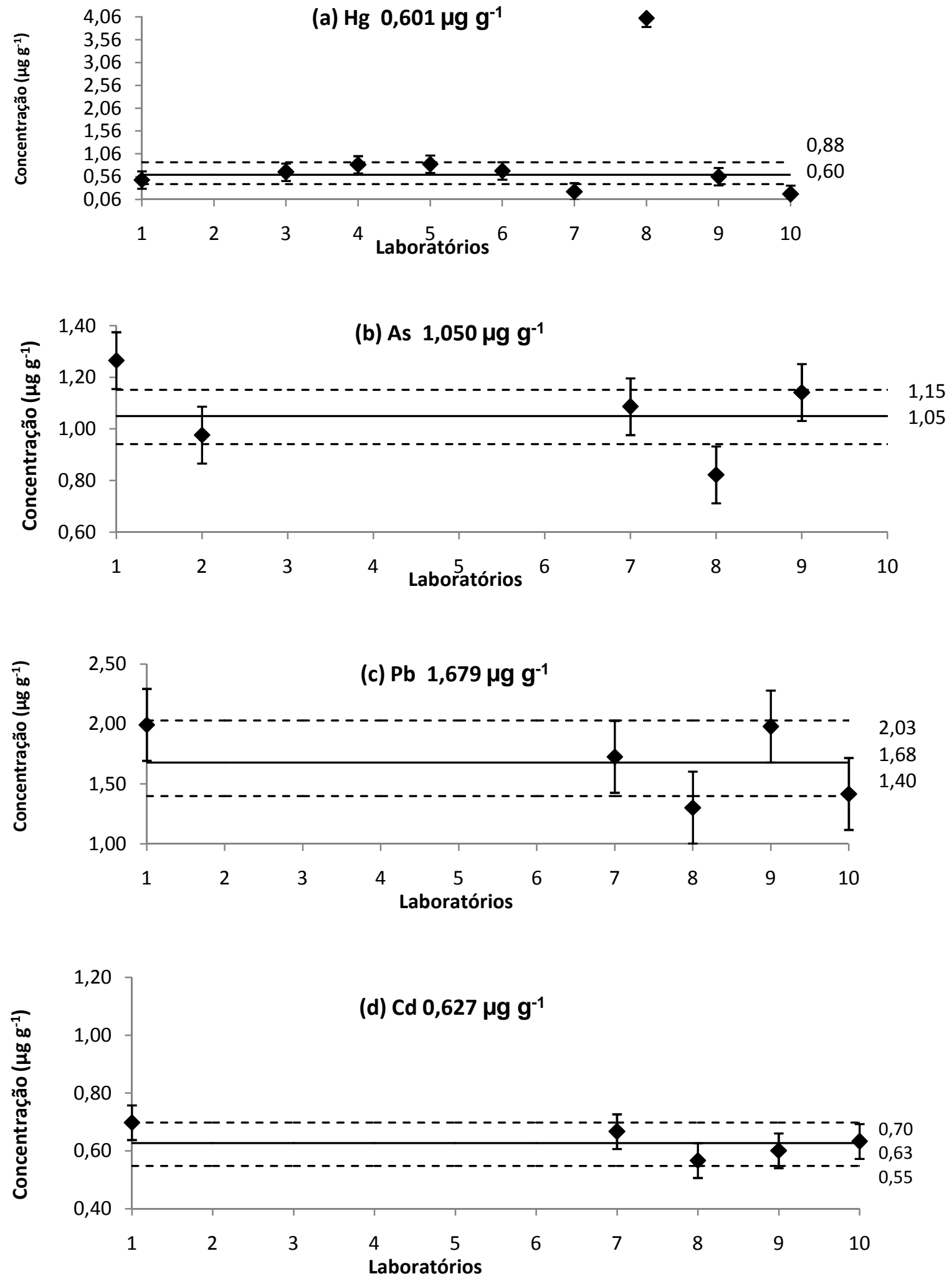

FIGURA 27- Dispersão dos resultados dos laboratórios participantes para os 4 elementos de interesse da amostras (1) a-d maior concentração. A linha cheia representa 0 valor médio designado, linha tracejada limite superior e inferior 

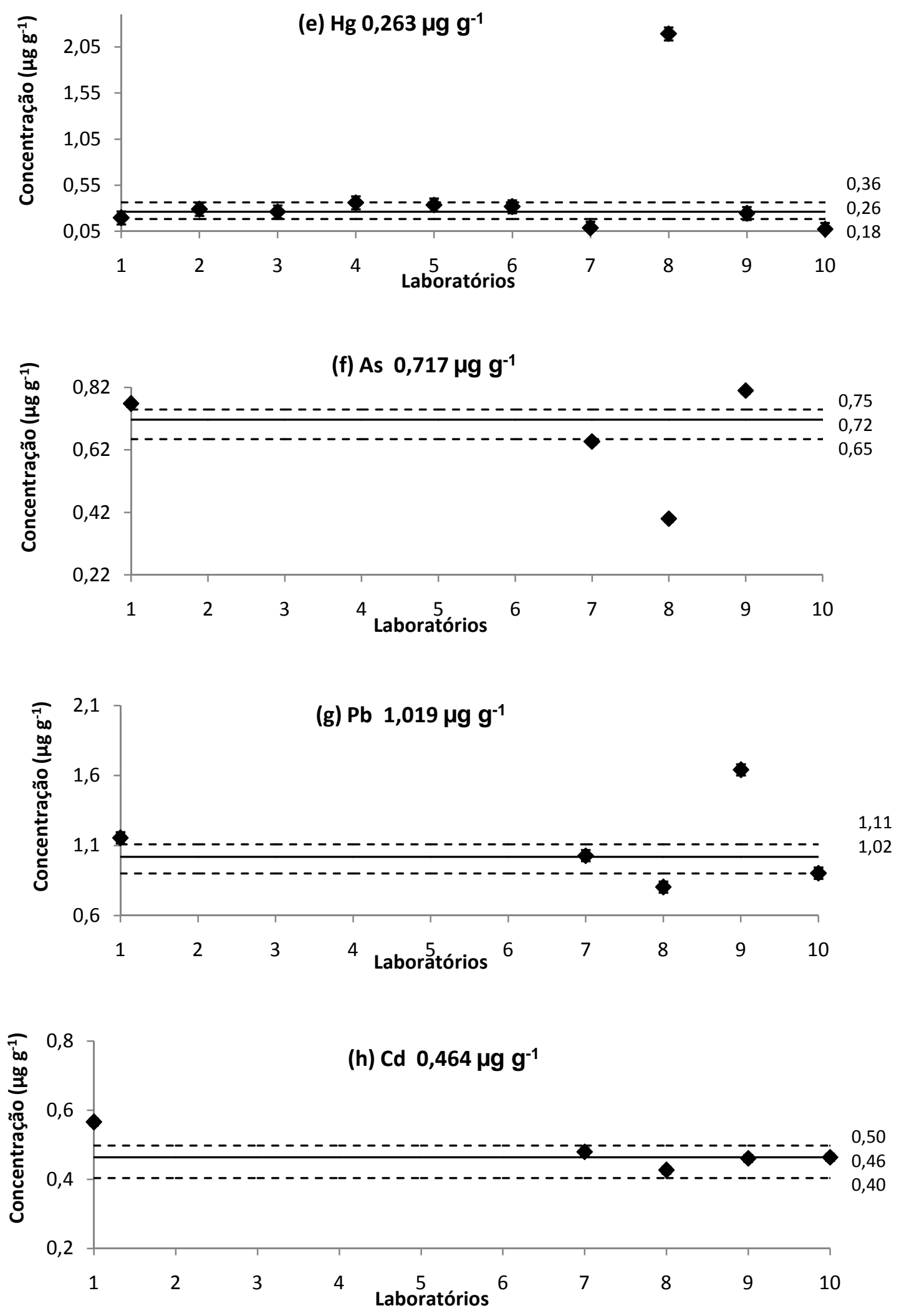

Figura 28- Dispersão dos resultados dos laboratórios participantes para os quatro elementos de interesse. A linha cheia representa o valor médio designado, linha tracejada limites superior e inferior amostra, (2) e-h menor concentração. 


\subsubsection{Resultado dos testes de desempenho}

A partir dos valores obtidos pela estatística robusta, foram calculados os índices de desempenho dos laboratórios. Adotou-se o índice z-score, a elipse de confiança (Gráfico de Youden) e o erro normalizado. Conforme descrito no item 2.8.1 na pag. 56.

\subsubsection{1 Índice z-score}

A avaliação de desempenho dos laboratórios para a análise do MRC, baseado no índice z-score, é apresentada na Tabela 35, (FIG. 29a e 29b).

TABELA 35- Valores de z-score obtidos para o MRC pelos laboratórios participantes

\begin{tabular}{ccccc}
\hline $\begin{array}{c}\text { Código } \\
\text { Laboratório }\end{array}$ & $\mathrm{THg}$ & $\mathrm{TAs}$ & $\mathrm{TPb}$ & $\mathrm{TCd}$ \\
\hline 1 & $-2,2$ & 0,9 & & \\
2 & & & & \\
3 & $-0,1$ & & & \\
4 & 0,7 & & & \\
5 & 1,0 & & & \\
6 & 0,4 & & $-0,3$ & $-0,1$ \\
7 & $-2,4$ & 0,4 & $\mathbf{3 , 8}$ & 0,4 \\
8 & $\mathbf{2 , 8}$ & $-1,6$ & $\mathbf{3 4 , 2}$ & $\mathbf{2 9 , 4}$ \\
9 & $\mathbf{8 , 1}$ & $-4,8$ & $-1,1$ & $-0,1$ \\
10 & $-3,2$ & & -1, & \\
\hline
\end{tabular}

Hg-MRC

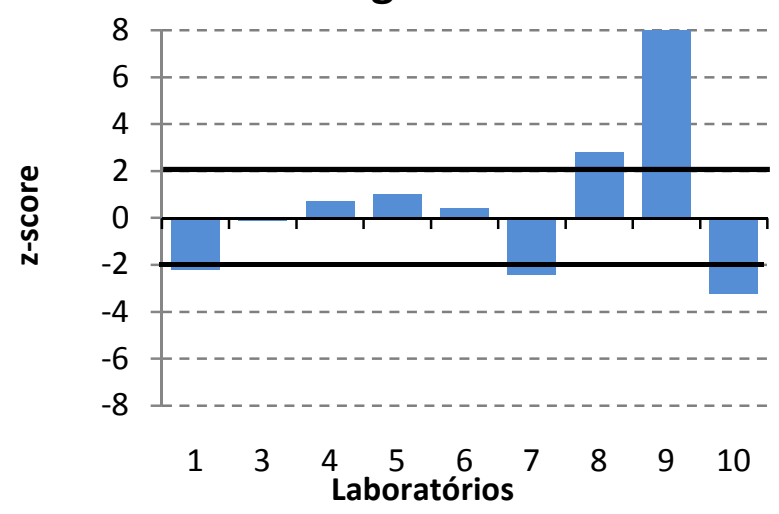

$\mathrm{Pb}-\mathrm{MRC}$

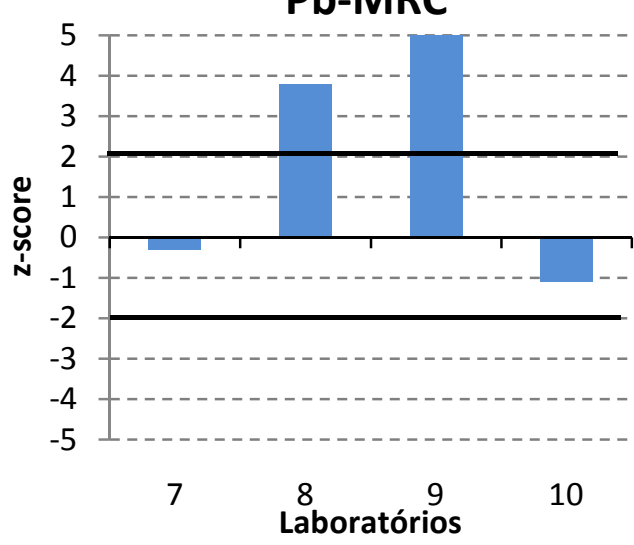

FIGURA 29a - Gráficos de z-score dos laboratórios participantes para o MRC 

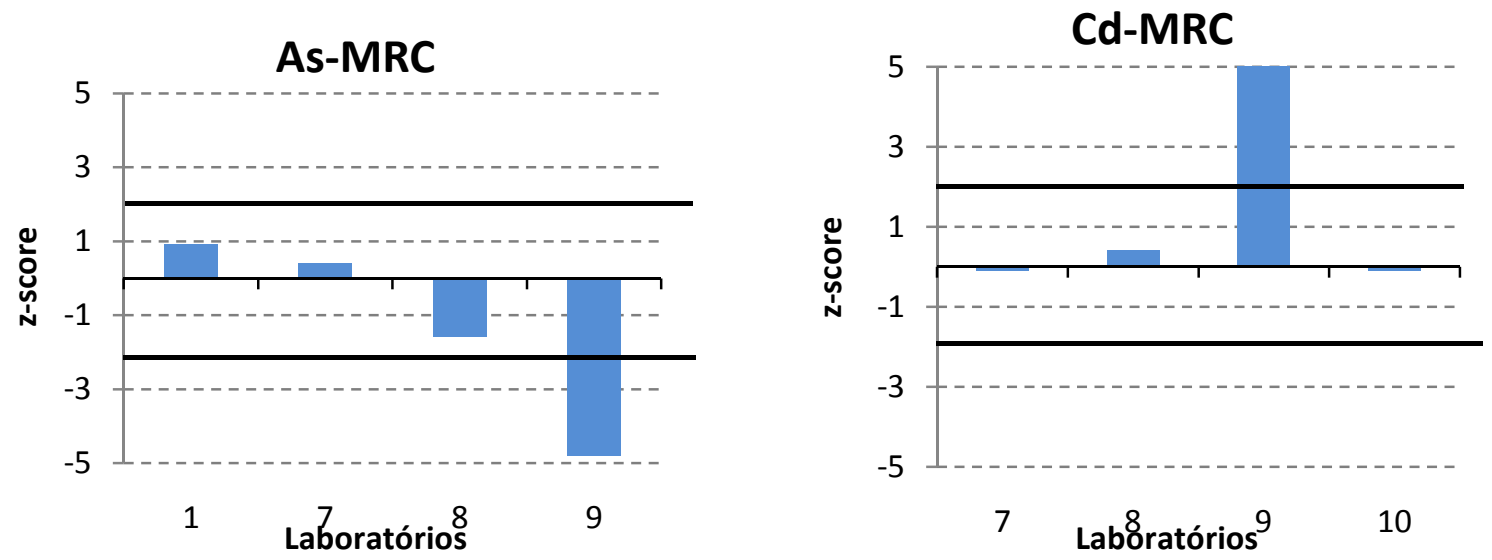

FIGURA 29b- Gráficos de z-score dos laboratórios participantes para o MRC

Observa-se que apenas $30 \%$ dos laboratórios analisaram todos os elementos solicitados e, desses, 80 \% obtiveram índice z-score questionáveis ou insatisfatórios para pelo menos um elemento.

No que diz respeito a avaliação de desempenho dos laboratórios para as amostras 1 e 2, pelo índice z-score apresentado na Tabela 36 e FIG. 33, observa-se que cinco laboratórios ( $50 \%$ ) obtiveram índice z-score satisfatório para pelo menos um elemento. Assim, do total de elementos analisados, dois laboratórios (20\%) apresentaram índice questionável e três laboratórios (30 \%) apresentaram índice insatisfatório.

TABELA 36- Valores de z-score obtidos pelos laboratórios participantes para as amostras 1 e 2

\begin{tabular}{ccccccccc}
\hline $\begin{array}{c}\text { Código } \\
\text { Laboratório }\end{array}$ & $\begin{array}{c}\mathrm{THg}+ \\
\text { conc. }\end{array}$ & $\begin{array}{c}\mathrm{THg}- \\
\text { conc. }\end{array}$ & $\begin{array}{c}\mathrm{TAs}+ \\
\text { conc. }\end{array}$ & $\begin{array}{c}\mathrm{TAs}- \\
\text { conc. }\end{array}$ & $\begin{array}{c}\mathrm{TPb}+ \\
\text { conc. }\end{array}$ & $\begin{array}{c}\mathrm{TPb}- \\
\text { conc. }\end{array}$ & $\begin{array}{c}\mathrm{TCd}+ \\
\text { conc. }\end{array}$ & $\begin{array}{c}\mathrm{TCd}- \\
\text { conc. }\end{array}$ \\
\hline 1 & $-1,6$ & $\mathbf{- 2 , 6}$ & 1,3 & 0,8 & 0,9 & 0,5 & $-0,1$ & 1,0 \\
2 & & $-0,1$ & $-0,4$ & & & & & \\
3 & $-0,3$ & $-0,8$ & & & & & & \\
4 & 1,0 & 1,9 & & & & & & \\
5 & 1,1 & 1,3 & & & & & & \\
6 & $-0,1$ & 0,7 & & & & & \\
7 & $\mathbf{- 3 , 6}$ & $\mathbf{- 5 , 7}$ & 0,2 & $-0,1$ & 0,2 & 0,0 & $-0,3$ & $-0,2$ \\
8 & $\mathbf{2 5 , 7}$ & $\mathbf{5 2 , 7}$ & $-1,3$ & $-1,9$ & $-0,9$ & $-1,1$ & $-1,0$ & $-0,9$ \\
9 & $-1,0$ & $-1,3$ & 0,6 & 1,1 & 0,8 & $\mathbf{2 , 7}$ & $-0,8$ & $-0,5$ \\
10 & $\mathbf{- 4 , 0}$ & $\mathbf{- 6 , 1}$ & & & $-0,6$ & $-0,6$ & $-0,5$ & $-0,4$ \\
\hline
\end{tabular}

Negrito: resultado questionável; negrito e italíco: resultado insatisfatório. 


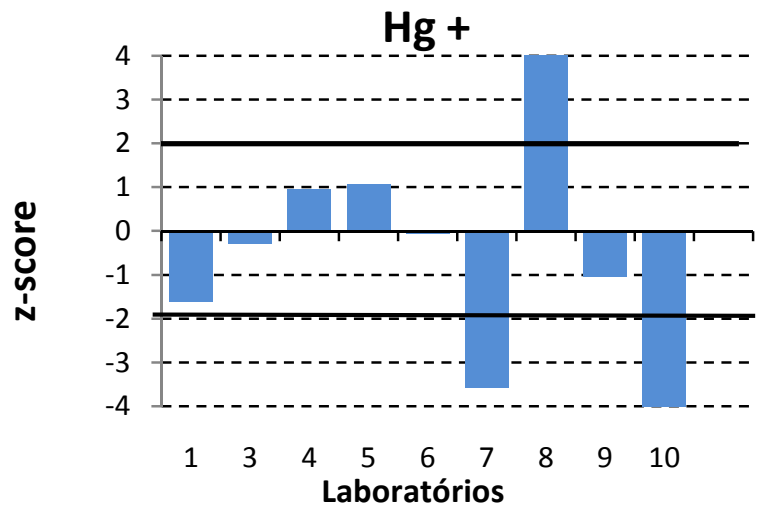

As +
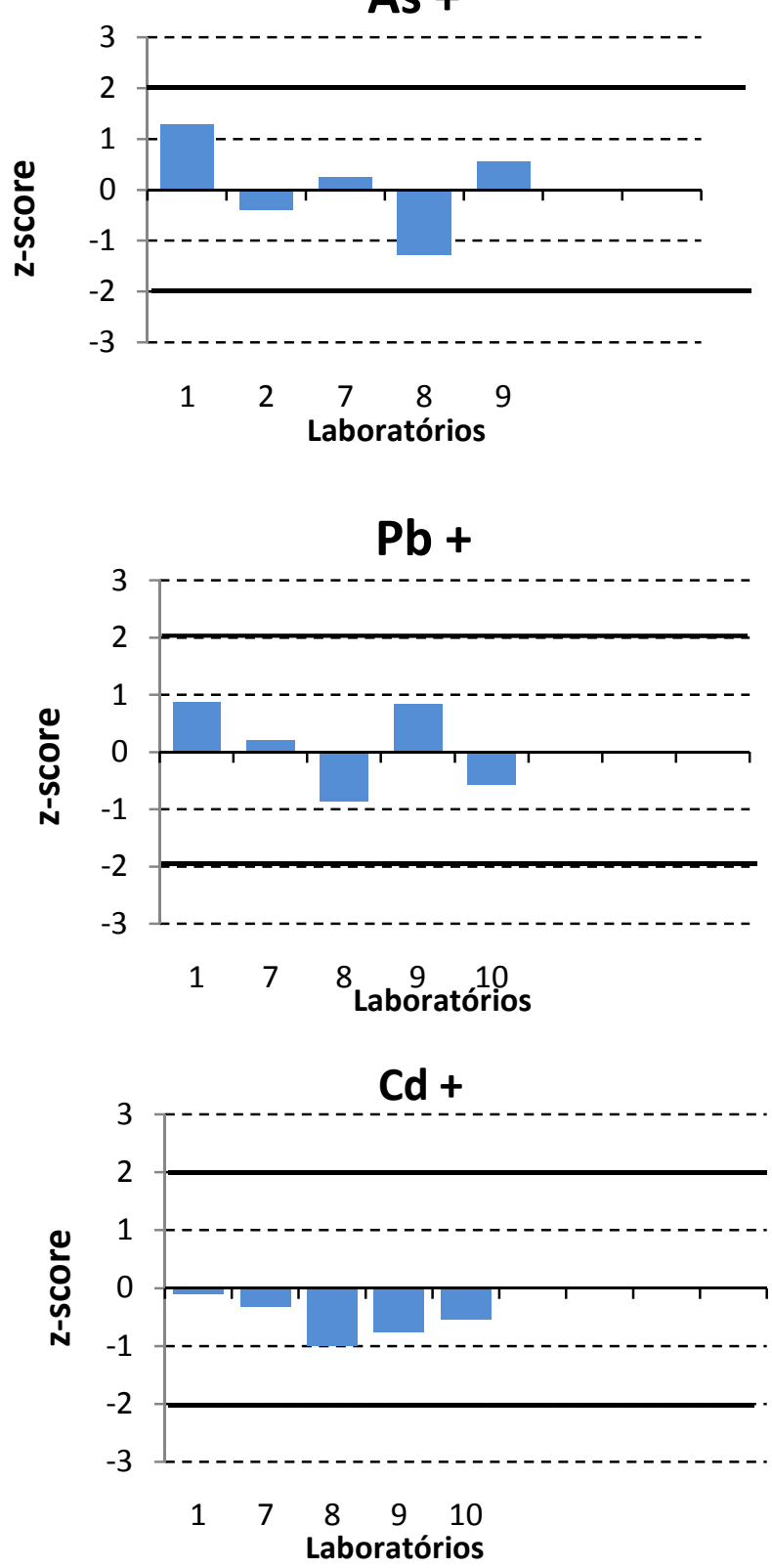
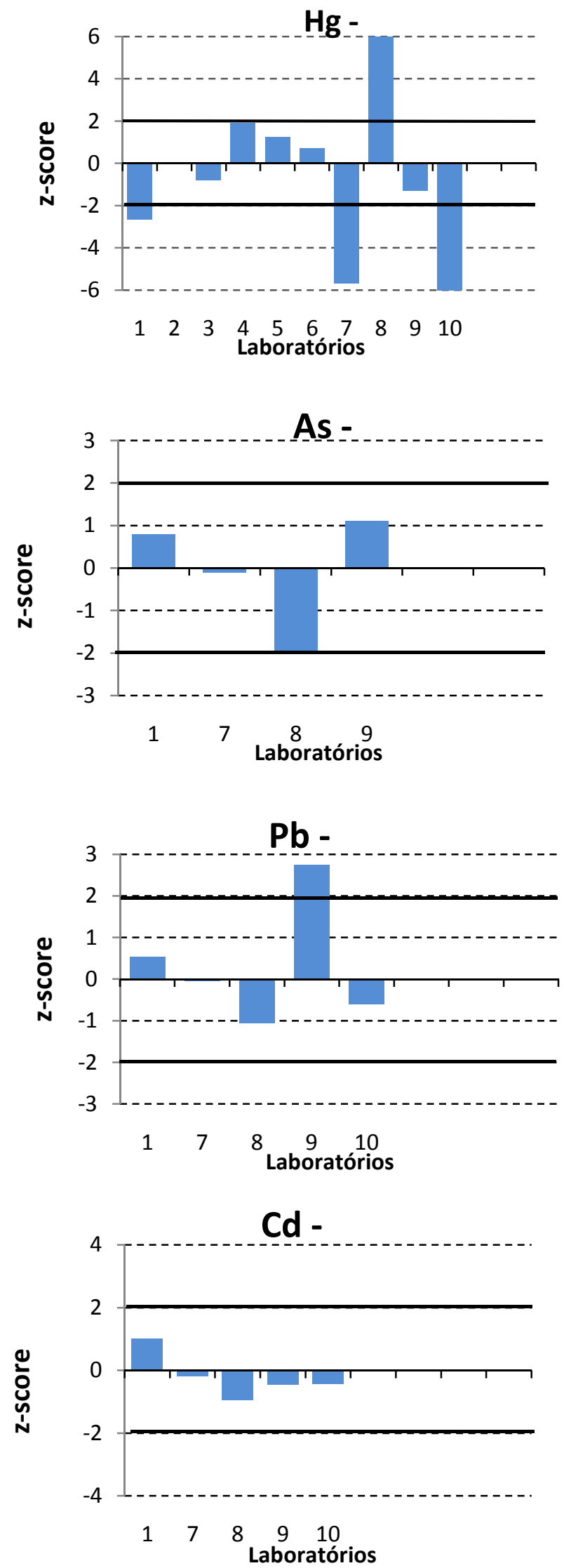

FIGURA 30- Gráficos de z-score dos laboratórios participantes para as amostras 1 e 2. 


\subsubsection{Erro normalizado}

O erro normalizado foi calculado apenas para os laboratórios que enviaram os resultados de incerteza. Neste caso, ele foi calculado conforme a equação 44 no item 2.6 da pag. 52, e foi calculado um valor de referência e incerteza de referência (ambos pela estatística robusta) para analisar estes dados (TAB. 37).

TABELA 37- Valores de referência e incerteza associada para o cálculo do erro normalizado dos laboratórios que enviaram suas incertezas

\begin{tabular}{ccc}
\hline Elemento & $\begin{array}{c}\text { Valor de } \\
\text { referência }\end{array}$ & $\begin{array}{c}\mathrm{U} \\
\mu \mathrm{g} \mathrm{\textrm {g } ^ { - 1 }}\end{array}$ \\
\hline $\mathrm{Hg}+$ & 0,727 & 0,05 \\
$\mathrm{Hg}-$ & 0,297 & 0,01 \\
$\mathrm{As}+$ & 0,997 & 0,07 \\
$\mathrm{As}-$ & 0,627 & 0,06 \\
$\mathrm{~Pb}+$ & 1,540 & 0,15 \\
$\mathrm{~Pb}-$ & 1,003 & 0,08 \\
$\mathrm{Cd}+$ & 0,718 & 0,06 \\
$\mathrm{Cd}-$ & 0,526 & 0,04 \\
\hline
\end{tabular}

Os resultados são mostrados nas Tabelas 38 e 39, destacando-se em negrito os valores de $E n>1$ e $E n<-1$, pertencentes aos laboratórios que obtiveram valores insatisfatórios. Consideram-se adequados valores de $\mathrm{En} \leq 1 \mathrm{e} \leq-1$.

TABELA 38- *Valores dos erros normalizados obtidos pelos participantes para MRC

\begin{tabular}{ccccc}
\hline $\begin{array}{c}\text { Código } \\
\text { Laboratório }\end{array}$ & $\mathrm{THg}$ & $\mathrm{TAs}$ & $\mathrm{TPb}$ & $\mathrm{TCd}$ \\
\hline 1 & $\mathbf{- 5 , 7}$ & $\mathbf{1 , 8}$ & & \\
3 & $-0,3$ & 0,8 & & \\
4 & 1,6 & & & \\
5 & $\mathbf{2 , 3}$ & & & \\
6 & 0,7 & & & \\
7 & $\mathbf{- 4 , 0}$ & 0,8 & $\mathbf{1 2 , 1}$ & 0,0 \\
8 & $\mathbf{6 , 4}$ & $\mathbf{- 3 , 3}$ & $\mathbf{1 1 , 4}$ & $-0,1$ \\
\hline
\end{tabular}

* $O$ erro normalizado foi calculado apenas para os laboratórios que enviaram os resultados de incerteza. 
TABELA 39- *Valores dos erros normalizados obtidos pelos participantes para amostras 1 e 2

\begin{tabular}{|c|c|c|c|c|c|c|c|c|}
\hline $\begin{array}{c}\text { Código } \\
\text { Laboratório }\end{array}$ & $\begin{array}{l}\mathrm{THg}+ \\
\text { conc. }\end{array}$ & $\begin{array}{l}\mathrm{THg}- \\
\text { conc. }\end{array}$ & $\begin{array}{l}\text { TAs + } \\
\text { conc. }\end{array}$ & $\begin{array}{l}\text { TAs - } \\
\text { conc. }\end{array}$ & $\begin{array}{l}\mathrm{TPb}+ \\
\text { conc. }\end{array}$ & $\begin{array}{l}\text { TPb- } \\
\text { conc. }\end{array}$ & $\begin{array}{l}\mathrm{TCd}+ \\
\text { conc. }\end{array}$ & $\begin{array}{l}\text { TCd- } \\
\text { conc. }\end{array}$ \\
\hline 1 & $-2,3$ & $-2,4$ & 3,5 & 2,3 & 2,4 & 1,4 & $-0,1$ & 0,2 \\
\hline 2 & & $-0,3$ & $-0,2$ & & & & & \\
\hline 3 & $-1,4$ & $-0,4$ & & & & & & \\
\hline 4 & 1,3 & 0,8 & & & & & & \\
\hline 5 & 0,8 & 1,2 & & & & & & \\
\hline 6 & 0,4 & 0,4 & & & & & & \\
\hline 7 & $-9,9$ & $-12,7$ & $-3,5$ & $-1,9$ & 1,2 & 0,3 & 5,9 & 2,8 \\
\hline 8 & 12,0 & 12,6 & $-2,0$ & $-3,0$ & $-1,5$ & $-2,6$ & $-2,6$ & $-2,3$ \\
\hline
\end{tabular}

Dos dez laboratórios participantes oito (80 \%) apresentaram o cálculo de incertezas como solicitado. Destes, três $(37,5 \%)$ apresentaram resultados inadequados para os elementos mercúrio $(\mathrm{Hg})$ e arsênio (As) em ambas as amostras e no MRC, enquanto dois laboratórios (33,3 \%) apresentaram resultados inadequados para chumbo $(\mathrm{Pb})$ em maior concentração e para o elemento cádmio nas duas amostras do programa.

\subsubsection{Elipse de confiança}

Os resultados são considerados adequados quando o ponto resultante da intersecção do par de coordenadas (resultados 1 e 2) encontra-se situado dentro da região delineada pela elipse de confiança. (FIG. 31 a 36).

Os laboratórios 7, 8 e 10 apresentaram resultados inadequados para $\mathrm{Hg}+$, laboratório 8 para $\mathrm{Hg}$-, laboratório 8 para As - e laboratório 10 para $\mathrm{Pb}$-.

A avaliação da elipse de confiança para a amostra de material de referência certificado mostrou que os laboratórios $3,6,5$ e 8 apresentaram resultados adequados para $\mathrm{Hg}, 7$ e 1 para $\mathrm{As}, 8$ e 7 para $\mathrm{Pb}$ e 7, 8 e 10 para $\mathrm{Cd}$. 

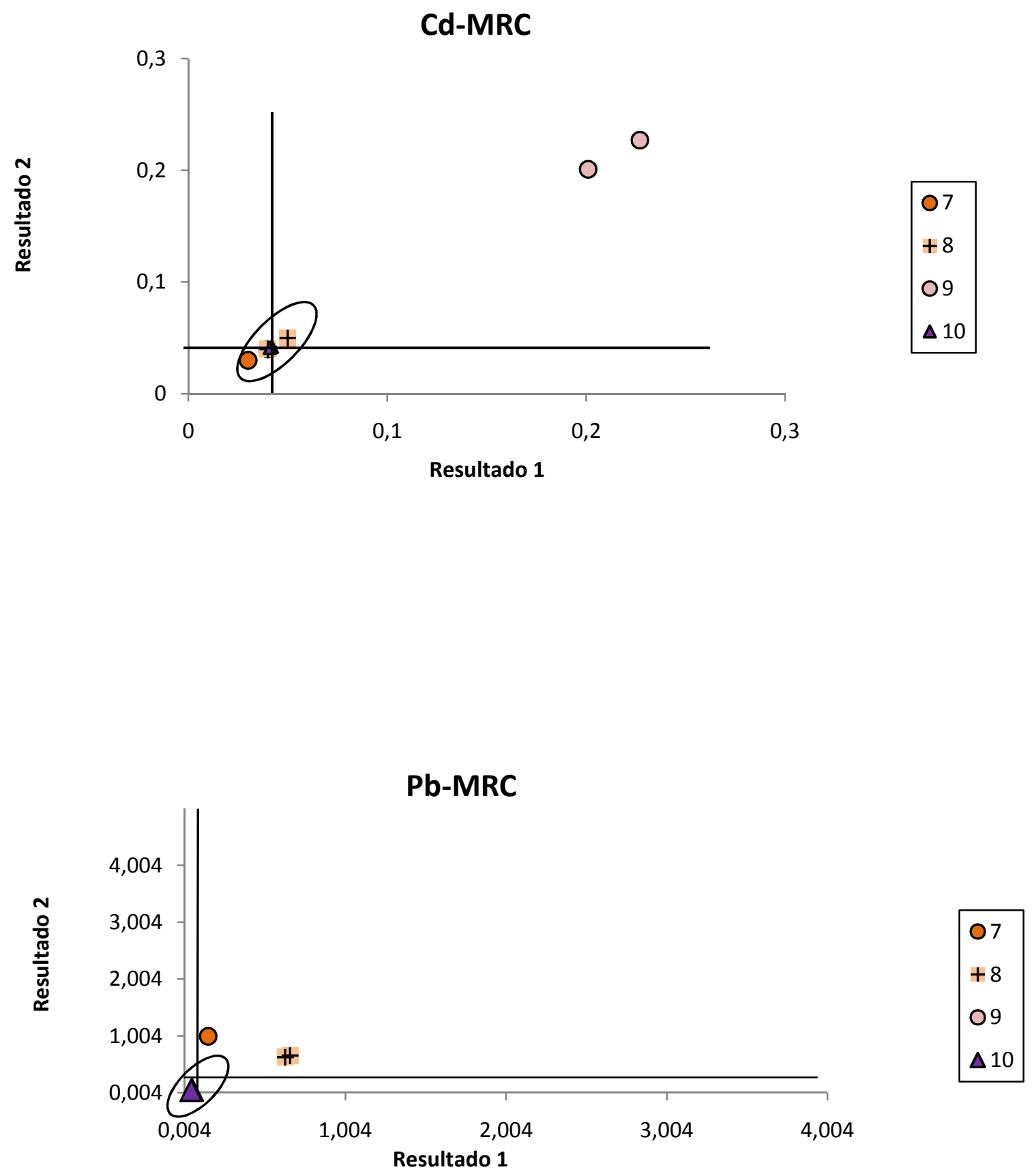

FIGURA 31- Resultados da elipse de confiança para o MRC, elementos TCd e TPb 
Hg-MRC

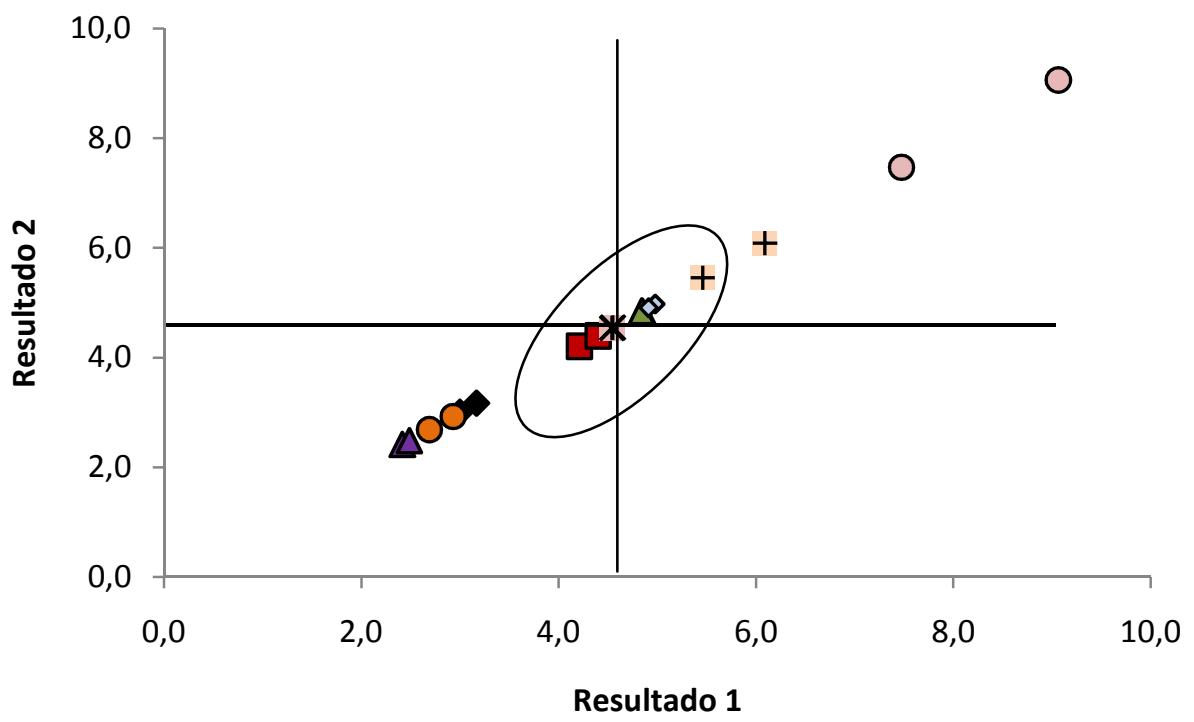

$\diamond 1$
$\square 3$
$\Delta 4$
$\diamond 5$
$* 6$
07
+8
09
$\Delta 10$

Resultado 1

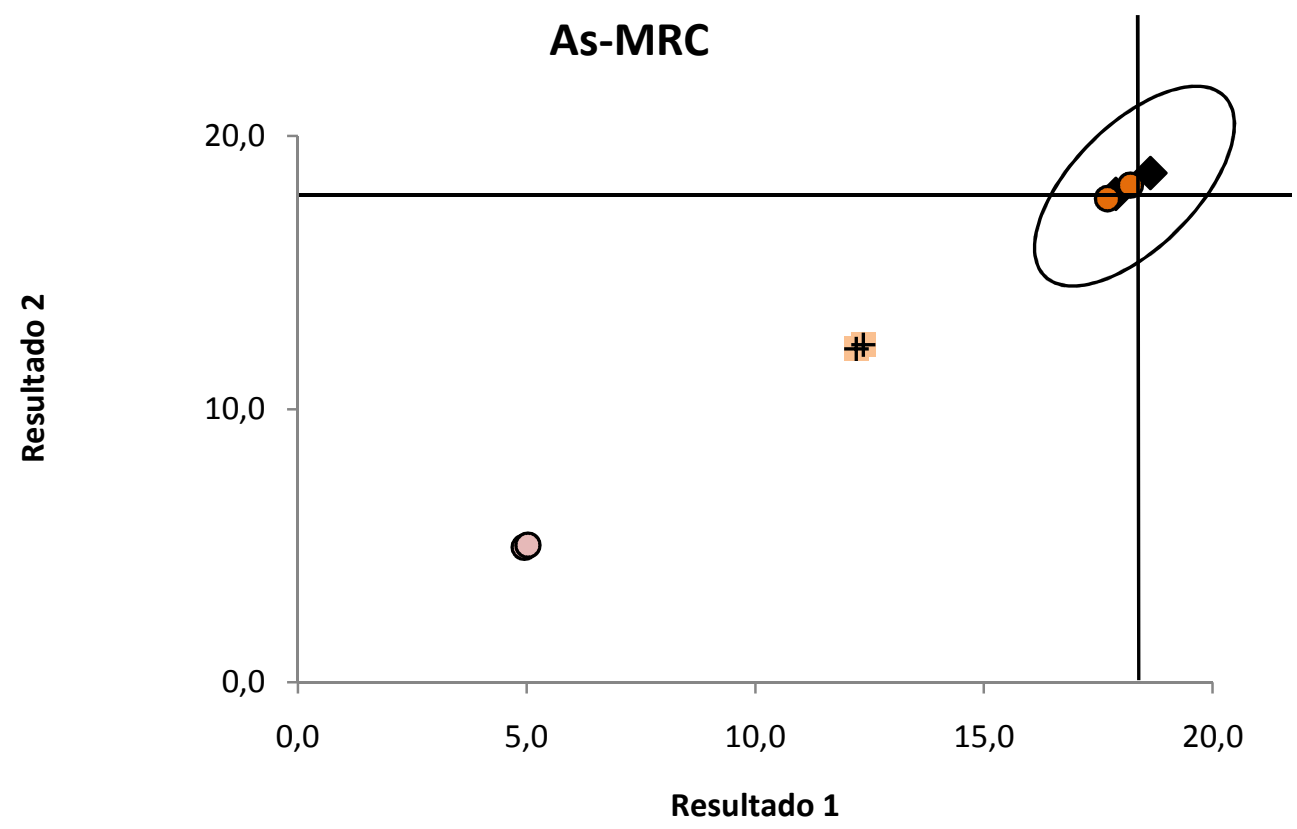

01
07
+8
09

FIGURA 32- Resultados da elipse de confiança para o MRC elementos THg e TAs 

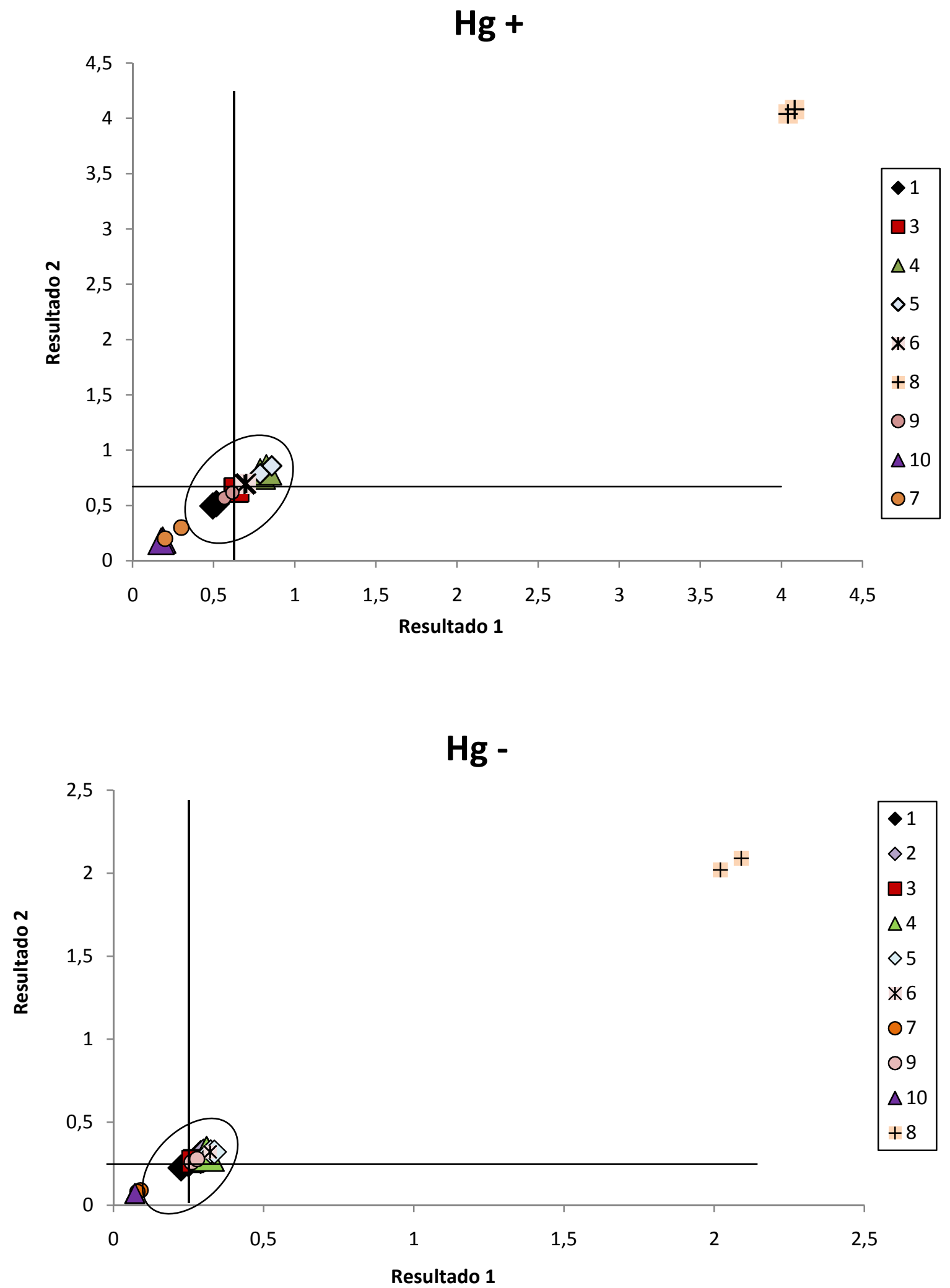

FIGURA 33- Resultados da elipse de confiança para o elemento THg nas amostras 1 e 2 

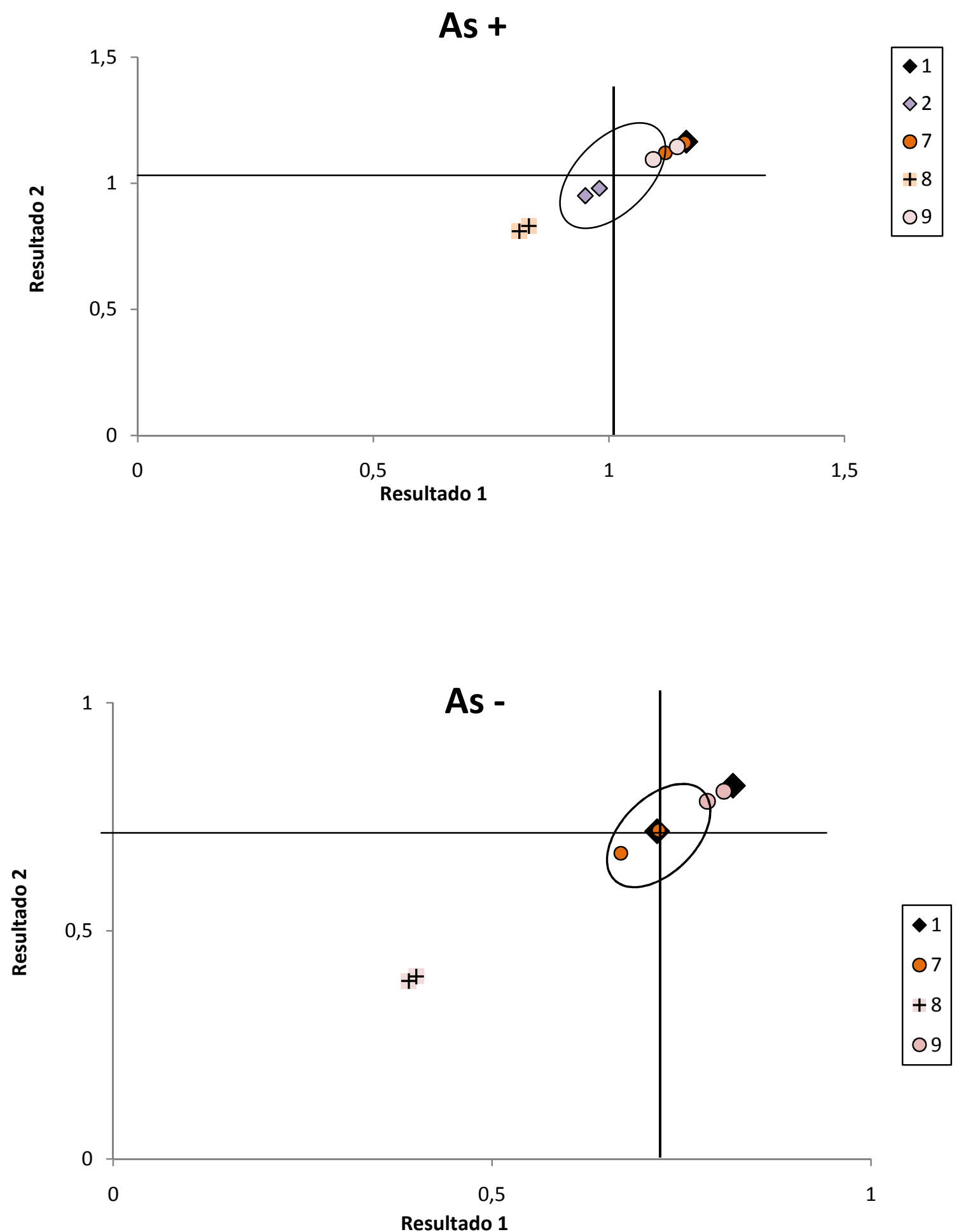

FIGURA 34- Resultados da elipse de confiança para o elemento TAs nas amostras 1 e 2 

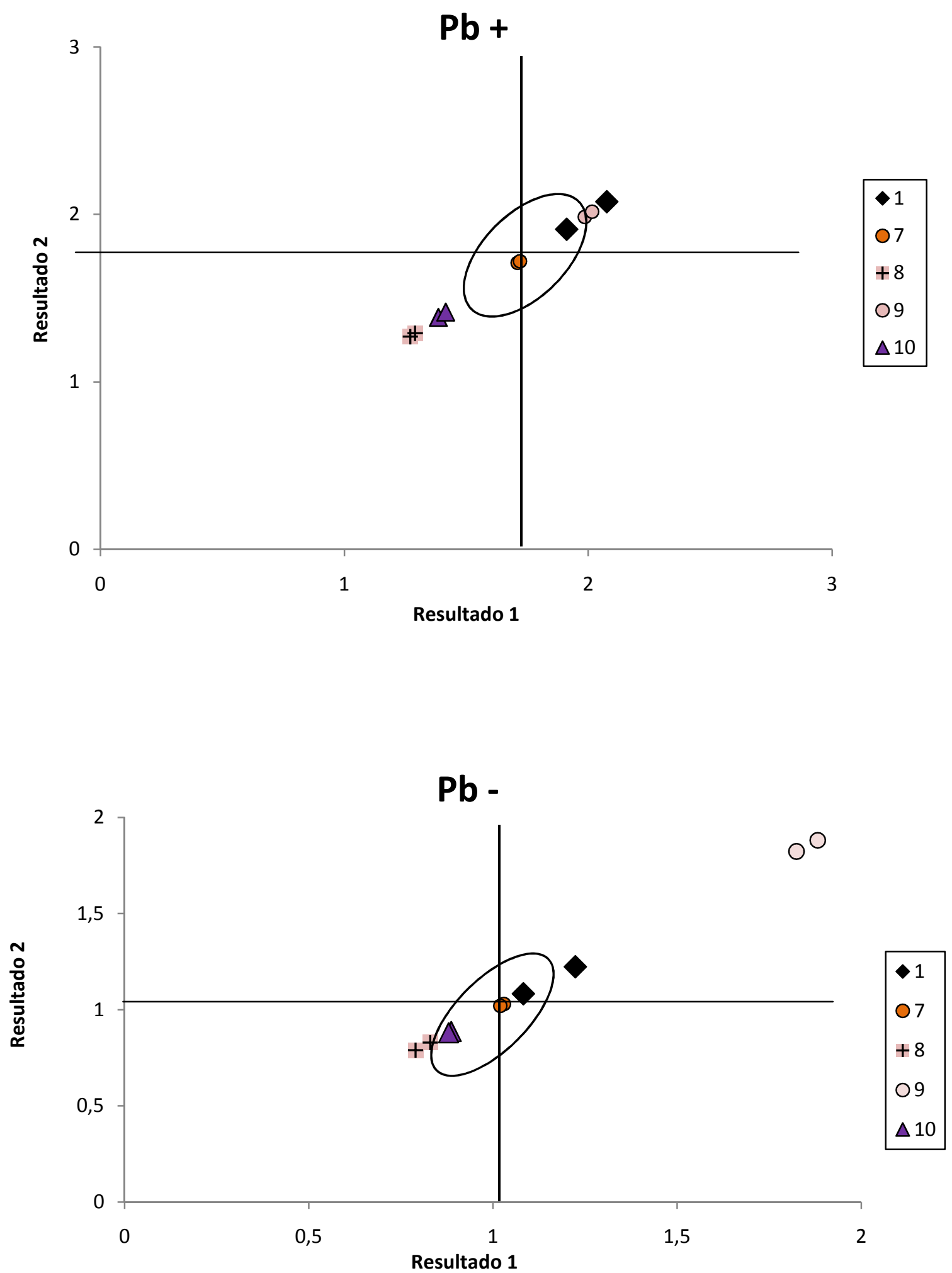

FIGURA 35- Resultados da elipse de confiança para o elemento TPb nas amostras 1 e 2 

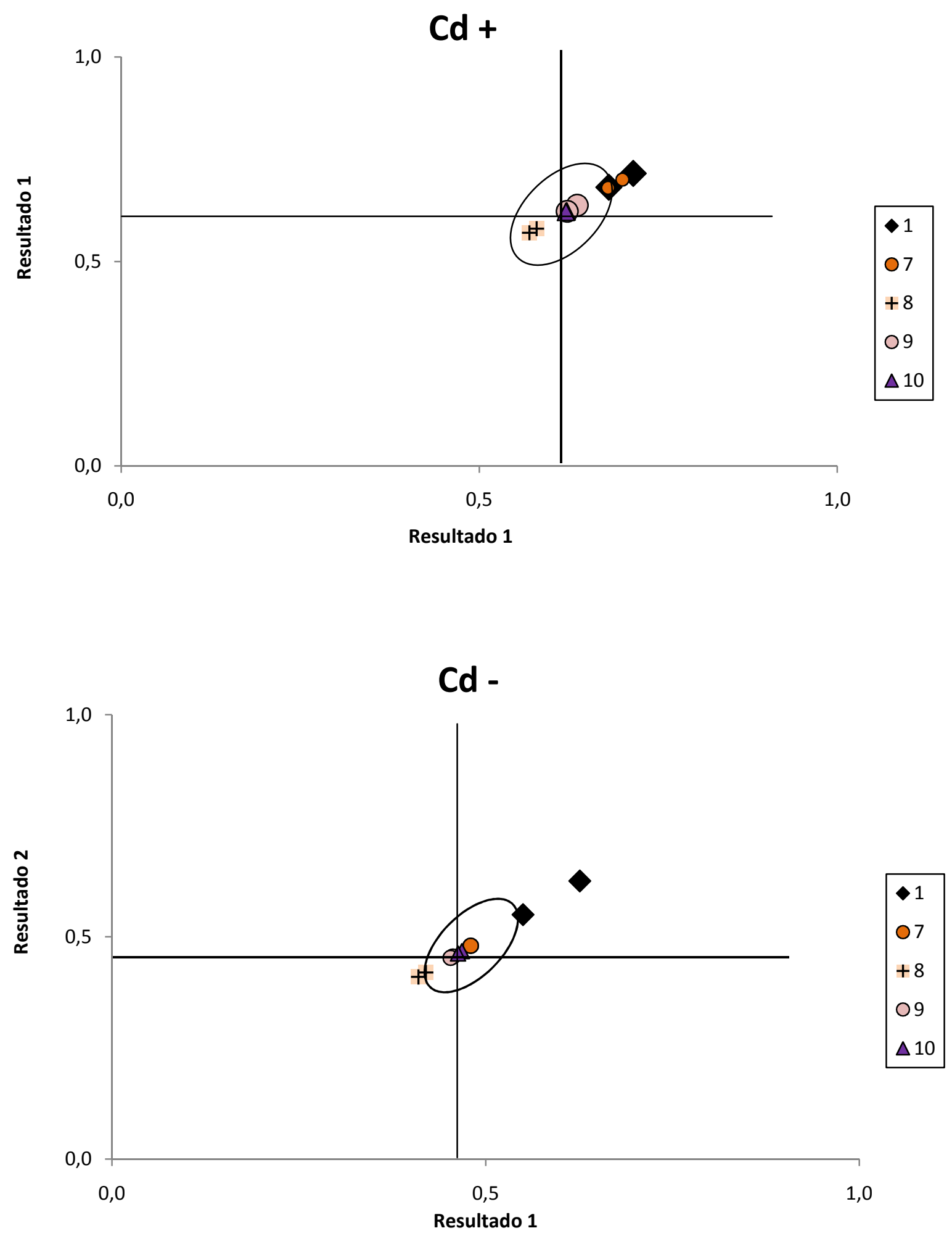

FIGURA 36- Resultados da elipse de confiança para o elemento TCd nas amostras 1 e 2 


\subsubsection{Capacidade analítica (CA) e Viabilidade analítica (VA)}

A capacidade analítica e a viabilidade analítica dos laboratórios participantes foram verificadas para determinação dos quatro elementos de interesse em duas amostras fortificadas com concentrações diferentes e uma amostra de material de referência certificado.

A capacidade do laboratório é considerada satisfatória quando CA igual a 1 . Indicando que o participante se mostrou capacitado para analisar todos os elementos e obteve um índice $z$-score satisfatório. CA igual a 0 significa que 0 participante não se mostrou capacitado para analisar todos os elementos e obteve um índice z-score insatisfatório ou questionável.

Os resultados obtidos são apresentados na Tabela 40.

TABELA 40- Capacidade analítica (CA) dos laboratórios

\begin{tabular}{cccc}
\hline Código & $\begin{array}{c}\text { \% Elementos } \\
\text { Analisados } \\
\text { Laboratório }\end{array}$ & $\begin{array}{c}\text { \%Resultados satisfatórios frente } \\
\text { ao total de elementos analisados } \\
(\mathrm{a})\end{array}$ & CA $=10^{-4}$ axb \\
\hline 1 & 100 & 87,5 & 0,88 \\
2 & 25 & 100 & 0,25 \\
3 & 25 & 100 & 0,25 \\
4 & 25 & 100 & 0,25 \\
5 & 25 & 100 & 0,25 \\
6 & 25 & 100 & 0,25 \\
7 & 100 & 75 & 0,75 \\
8 & 100 & 75 & 0,75 \\
9 & 100 & 85 & 0,85 \\
10 & 75 & 67 & 0,50 \\
\hline
\end{tabular}

De acordo com os resultados obtidos na Tabela 128, dos dez laboratórios participantes, nenhum atingiu $\mathrm{CA}=1$, cinco laboratórios $(50 \%)$ obtiveram $\mathrm{CA}=$ 0,25 , dois laboratórios (20\%) obtiveram CA $>0,80$ e um laboratório $(10 \%), \mathrm{CA}=$ 0,50 . 
A viabilidade analítica também é calculada a partir dos resultados obtidos para 0 índice z-score, contudo ela considera a porcentagem de laboratórios que realizaram a determinação do elemento, a porcentagem de acertos do índice z-score para o elemento fortificado de interesse. Assim foi calculada a viabilidade analítica para a determinação dos quatro elementos, para os 10 laboratórios participantes.

O índice VA = 1 indica que todos os laboratórios se mostraram capacitados para analisar satisfatoriamente os elementos de interesse ao obter um índice z satisfatório.

$\mathrm{VA}=0$ indica que nenhum laboratório se mostrou capacitado para analisar satisfatoriamente os elementos (TAB. 41).

TABELA 41- Viabilidade analítica (VA) na determinação dos elementos fortificados nas amostras enviadas aos laboratórios

\begin{tabular}{cccc}
\hline Elemento & $\%$ LAB. & \%Res. Satisf & $\mathrm{VA}=10-4 \mathrm{axb}$ \\
\hline $\mathrm{THg}+$ & 90 & 60 & 0,54 \\
$\mathrm{THg}-$ & 100 & 40 & 0,40 \\
$\mathrm{TAs}+$ & 50 & 100 & 0,50 \\
$\mathrm{TAs}-$ & 40 & 100 & 0,40 \\
$\mathrm{TCd}+$ & 50 & 100 & 0,50 \\
$\mathrm{TCd}-$ & 50 & 100 & 0,50 \\
$\mathrm{TPb}+$ & 50 & 100 & 0,50 \\
$\mathrm{TPb}-$ & 50 & 100 & 0,50 \\
\hline
\end{tabular}

Os valores calculados para viabilidade analítica demonstraram que dos quatro elementos analisados em diferentes concentrações, o mercúrio e o arsênio em menor concentração apresentaram os menores índices ( $\mathrm{VA}=0,40)$. 


\subsection{Acompanhamento da estabilidade do material de referência durante o ensaio piloto de proficiência}

Como pode ser observado nas Figuras 37 e 38, a estabilidade do material preparado foi acompanhada durante a execução do ensaio de proficiência. $\mathrm{O}$ material selecionado permaneceu na temperatura $23{ }^{\circ} \mathrm{C}$ (transporte), durante $\mathrm{o}$ período de estudo e os resultados obtidos na determinação dos mensurandos $\mathrm{THg}$ e TAs, demonstram que o material ficou estável durante todo o período do ensaio.
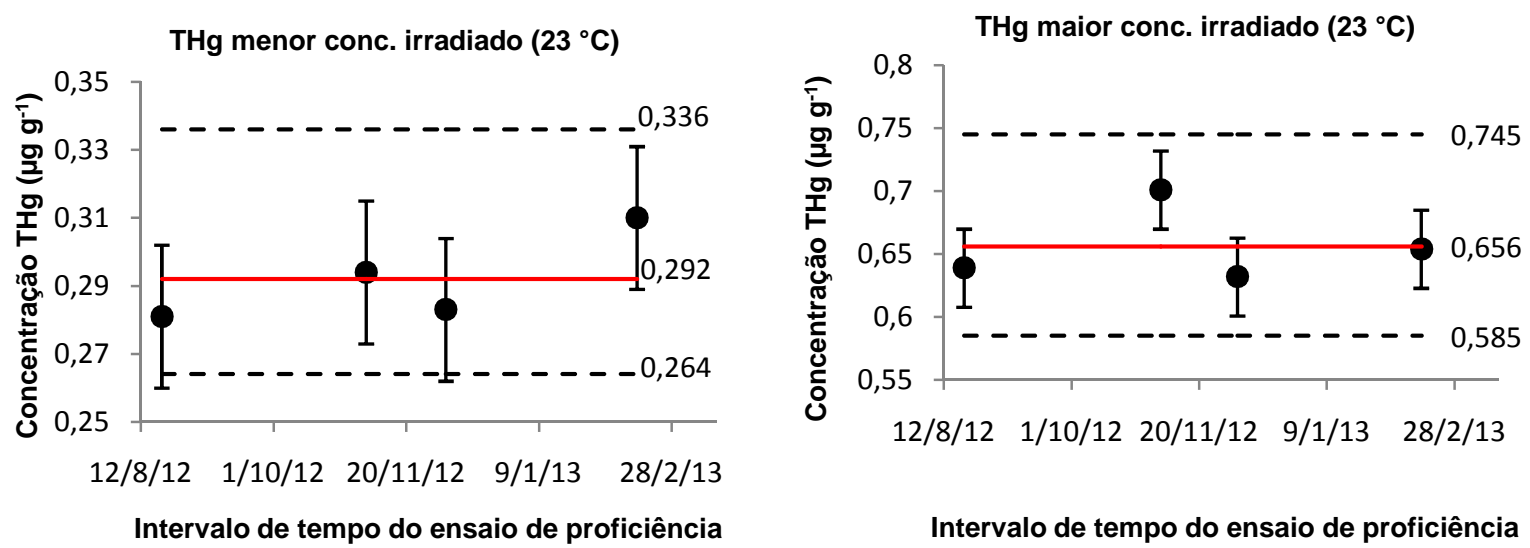

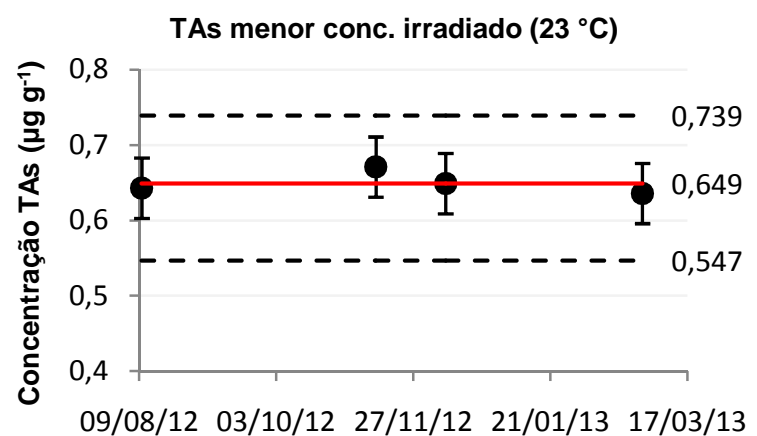

Intervalo de tempo do ensaio de proficiência

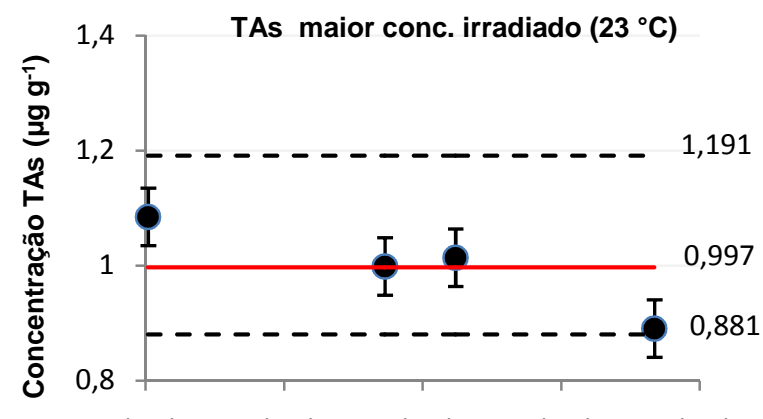

Intervalo de tempo do ensaio de proficiência

FIGURA 37- Gráfico de controle da estabilidade para o ensaio de proficiência, THg e TAs nas amostras 1 e 2, valor da concentração \pm incerteza 
THg no MRC $\left(23^{\circ} \mathrm{C}\right)$

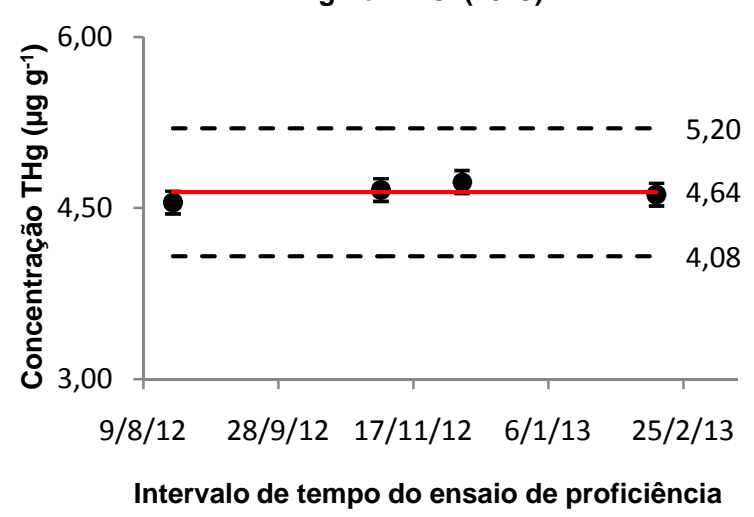

TAs no MRC $\left(23^{\circ} \mathrm{C}\right)$

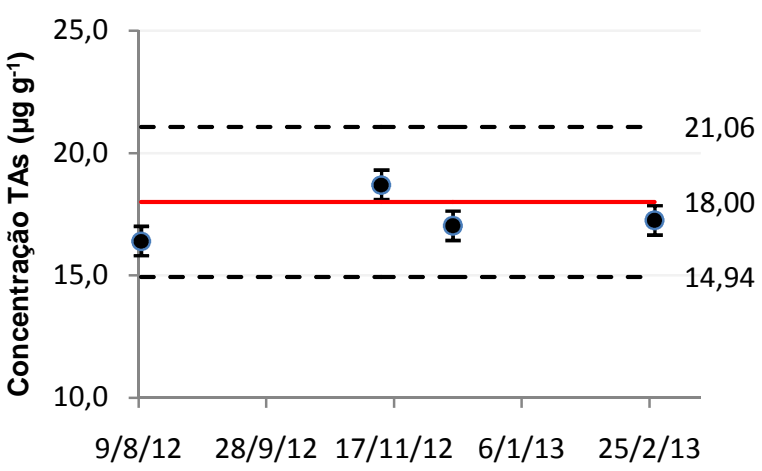

Intervalo de tempo do ensaio de proficiência

FIGURA 38- Gráfico de controle da estabilidade para o ensaio de proficiência, THg e TAs no MRC, valor da concentração \pm incerteza

\subsection{Avaliação do ensaio de proficiência realizado pelos laboratórios participantes}

Os laboratórios participantes do programa receberam junto ao relatório final, um questionário, a fim de avaliar o ensaio de proficiência oferecido. As principais sugestões encaminhadas foram relacionadas à quantidade de amostra formecida, 0 prazo para realização do ensaio e se o programa veio de encontro aos objetivos dos laboratórios participantes.

Nesse sentido, a maioria dos laboratórios (90\%) se mostrou satisfeito com o programa e demonstrou interesse em participar de futuras rodadas (FIG. 39). 


\section{Avaliação do EP/MP 11/12}

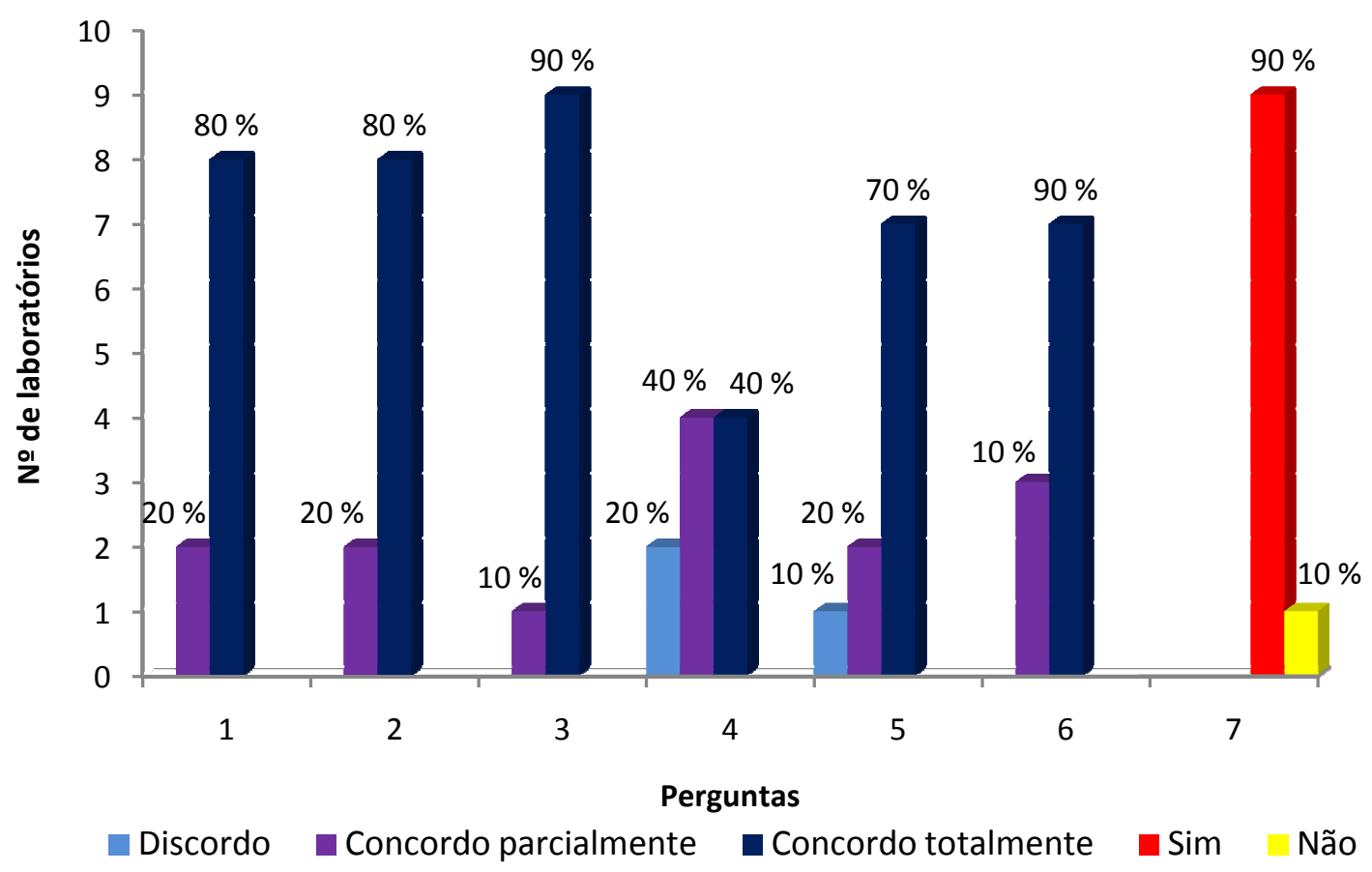

FIGURA 39- Avaliação do Ensaio de Proficiência EP/MP 11/12

\section{Informações solicitadas no questionário de avaliação}

1- Os objetivos foram claramente definidos

( ) Discordo ( ) Concordo parcialmente ( ) Concordo totalmente

Sugestões:

2- O promotor do ensaio contribuiu de forma adequada para orientar possíveis duvidas

( ) Discordo ( ) Concordo parcialmente ( ) Concordo totalmente

Sugestões:

3- As informações fornecidas com o material foram claras e coerentes com o objetivo proposto

( ) Discordo ( ) Concordo parcialmente ( ) Concordo totalmente

Sugestões:

4- A quantidade de material fornecido foi suficiente

( ) Discordo ( ) Concordo parcialmente ( ) Concordo totalmente

Sugestões: 
5- O programa veio de encontro aos objetivos do laboratório

( ) Discordo ( ) Concordo parcialmente ( ) Concordo totalmente

Sugestões:

6- O prazo para a realização do ensaio e envio de resultados foi adequado ( ) Discordo ( ) Concordo parcialmente ( ) Concordo totalmente

Sugestões:

7- Há interesse em participar de novas rodadas do ensaio de proficiência para metais em pescado

( ) $\operatorname{sim}($ ) não 


\section{CONCLUSÕES}

Conforme descrito ao longo deste trabalho, o preparo de um material de referência é uma tarefa complexa que exige um planejamento minucioso e o uso de uma infraestrutura adequada.

Os resultados obtidos demonstraram claramente a adequação dos protocolos, utilizados para a preparação do material. A utilização de um ambiente exclusivo para a etapa de preparação, associado ao sistema de qualidade implantado no LCQ (ensaio para mercúrio acreditado na CGCRE/INMETRO segundo a norma ABNT: NBR ISO / IEC 17025: 2005) e a etapa de irradiação com fonte de cobalto $60\left({ }^{60} \mathrm{Co}\right)$ foram fundamentais para obtenção de um material homogêneo e estável, apropriado para o transporte à temperatura ambiente.

O ensaio de proficiência iniciou-se em novembro de 2012 e foi concluído em abril de 2013, uma vez que alguns laboratórios atrasaram o envio dos resultados. De acordo com questionário de avaliação, os laboratórios participantes se mostraram satisfeitos com o programa e manifestaram o desejo de participar de novas rodadas.

Em linhas gerais, todos os laboratórios apresentaram um bom desempenho, atendendo ao que foi solicitado e suas principais sugestões foram relacionadas ao aumento da quantidade de material enviado e do prazo para entrega dos resultados.

Nesse sentido, foram constatadas algumas dificuldades e a necessidade de alguns aprimoramentos, tais como, uma escolha melhor para o envio das amostras e o aumento da quantidade de material. Assim para as futuras rodadas serão tomadas medidas para corrigir essas questões.

Em se tratando da primeira rodada de um programa inédito e de âmbito nacional, conclui-se, que o laboratório se mostrou apto a produzir materiais de forma continua para futuros programas. Podendo, inclusive, consolidar este programa, com o aumento do número de participantes.

Desse modo, considera-se que os objetivos propostos nesta dissertação foram plenamente alcançados. 


\section{APÊNDICE A}

\section{Resultados obtidos no teste piloto para o preparo do material de referência de pescado in natura}

\section{Testes preliminares para o preparo do candidato a material de referência}

Foi realizado um estudo piloto com $900 \mathrm{~g}$ de Traíra $s p$, adquiridas em mercados, da região oeste de São Paulo, para testar o método de processamento do material (trituração e homogeneização mecânicas) e realizar um ensaio de homogeneidade e estabilidade antes de proceder ao manuseio do material de trabalho.

Os indivíduos foram higienizados, filetados e triturados em um triturador doméstico modelo Walita, com facas de inox. Posteriormente foram homogeneizados com um misturador de massas doméstico, modelo Walita (batedeira) com pás de 4 aros de aço inoxidável tipo "fouet" por aproximadamente 2 minutos.

Para a determinação de mercúrio total pela técnica de FIA-CV-AAS, digeriuse $1,0 \mathrm{~g}$ de amostras de tecido muscular de peixe, em meio ácido, utilizando-se $1 \mathrm{~mL}$ de ácido nítrico $\left(\mathrm{HNO}_{3}\right)$ concentrado, $2 \mathrm{~mL}$ de ácido sulfúrico $\left(\mathrm{H}_{2} \mathrm{SO}_{4}\right)$ concentrado e $1 \mathrm{~mL}$ de ácido perclórico $\left(\mathrm{HClO}_{4}\right)$.

Estas permaneceram em chapa aquecida a $110^{\circ} \mathrm{C}$ durante 30 minutos e após resfriamento, foram avolumadas com $20 \mathrm{~mL}$ de água desmineralizada para posterior leitura.

Foi realizado um teste preliminar de homogeneidade, antes do envase do material. A Tabela 42 apresenta os resultados obtidos para a análise do teor de mercúrio encontrado nas amostras trituradas e a Tabela 43 mostra os resultados do estudo preliminar de homogeneidade do piloto. 
TABELA 42 - Resultados médios, DP ,em $\mu \mathrm{g} \mathrm{g}^{-1}$, DPR \% e incerteza de medição \%, na determinação de Mercúrio total (Traíras $s p$ )

\begin{tabular}{lllllll}
\hline $\begin{array}{l}\text { Código } \\
\text { Amostra } \\
\mathrm{s}\end{array}$ & 80 & 100 & 150 & 180 & $150+100$ & $180+80$ \\
\hline Media & $0,090 \pm 0,0$ & $0,100 \pm 0,0$ & $0,130 \pm 0,0$ & $0,160 \pm 0,0$ & & \\
\%DPR & 12,0 & 1 & 1 & 1 & $0,120 \pm 0,01$ & $0,110 \pm 0,01$ \\
u\% & 14,4 & 13,0 & 8,5 & 6,3 & 8,3 & 9,0 \\
\hline
\end{tabular}

Foram avaliados os resultados de homogeneidade na mistura de amostras de código 80 e 180, 100 e 150, com faixas de concentração de 0,090 a $0,160 \mu \mathrm{g} \mathrm{g}^{-1} \mathrm{e}$ 0,100 a $0,130 \mu \mathrm{g} \mathrm{g}^{-1}$, respectivamente, resultando em 2 grupos de amostras com concentração de $0,110 \mu \mathrm{g} \mathrm{g}^{-1}$ e $0,120 \mu \mathrm{g} \mathrm{g}{ }^{-1}$ (TAB. 42).

Assim, após a determinação do teor de mercúrio, o material foi envasado em embalagens plásticas de polietileno tipo "sachês" e seladas manualmente com uma seladora manual. (FIG. 40 e 41 ).

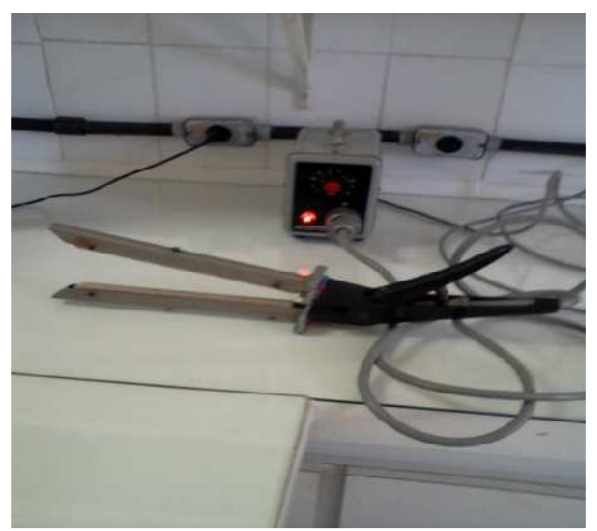

FIGURA -40 Seladora manual

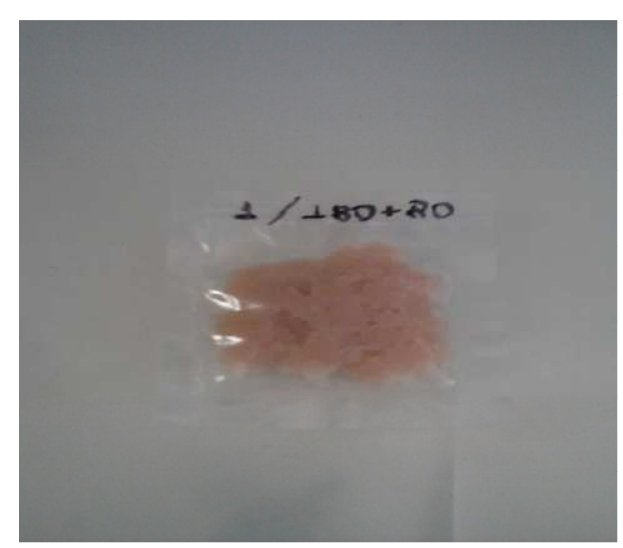

FIGURA 41- Sachê de tecido muscular de peixe

Das 62 amostras preparadas 31 foram submetidas à irradiação gama a 10,0 KGy, a fim de evitar a deteriorização pelo prazo de 45 dias. Para o estudo de 
homogeneidade foram separados aleatóriamente 10 sachês irradiados e 10 sachês não irradiados.

Observando a Tabela 43, comprova-se a homogeneidade, quando se compara o valor de Fcalculado menor do que Ftabelado (crítico).

TABELA 43- Média \pm DP, variância, DPR, resultados da ANOVA, obtidos na determinação de mercúrio total, em $\mu \mathrm{g} \mathrm{g}^{-1}$, por FIA-CV-AAS, para o estudo de homogeneidade (base úmida)

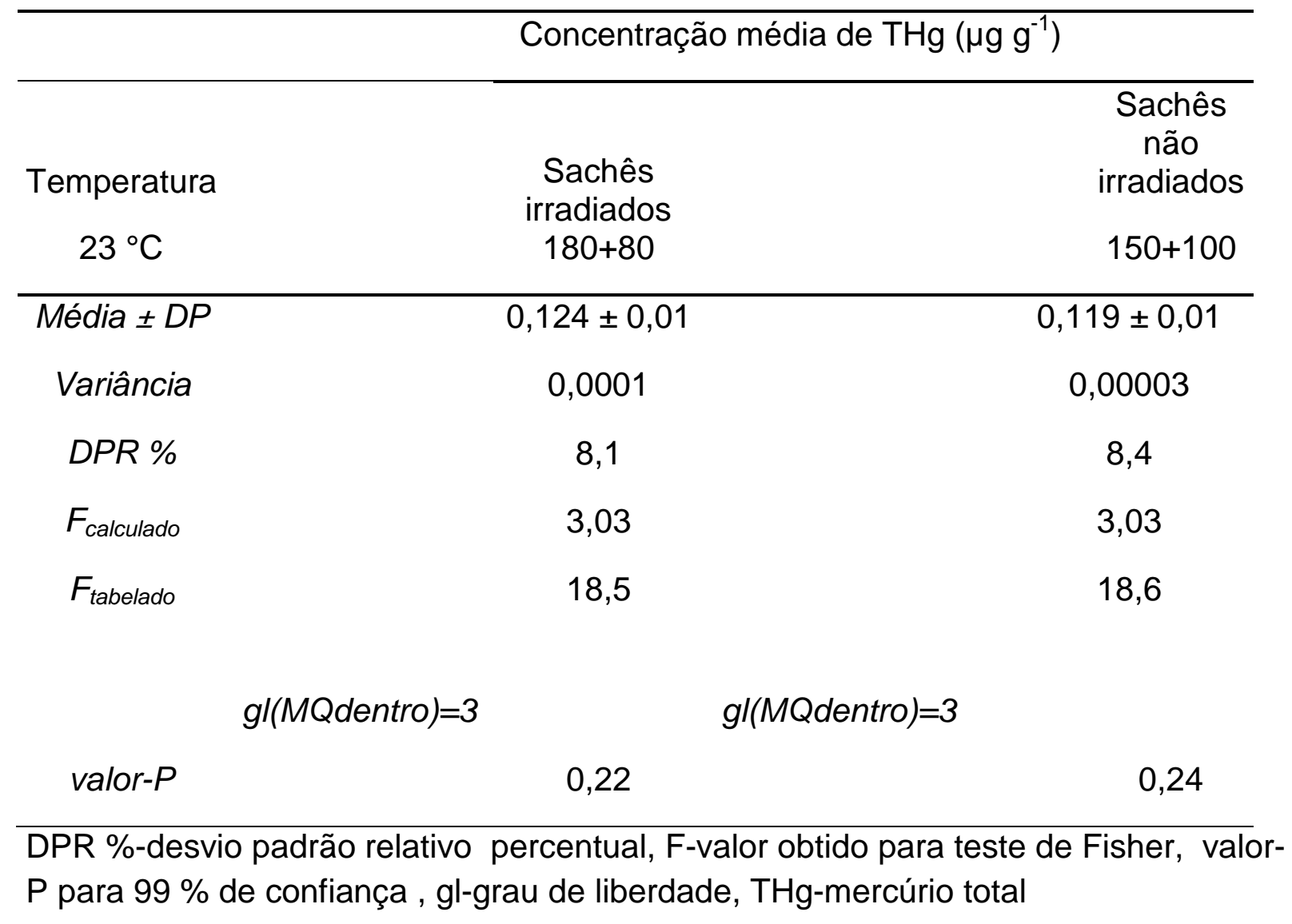

No caso do estudo de estabilidade, 24 amostras foram escolhidas aleatoriamente e separadas em dois grupos, irradiado e não irradiadas, e mantidas em 4 faixas de temperatura diferentes, $5{ }^{\circ} \mathrm{C}, 23^{\circ} \mathrm{C}, 45^{\circ} \mathrm{C}$ e $60^{\circ} \mathrm{C}$, por um período de $0,7,15,30$ e 45 dias, sendo $23^{\circ} \mathrm{C}$ a temperatura determinada para trabalho. (FIG. 42 e 43). 


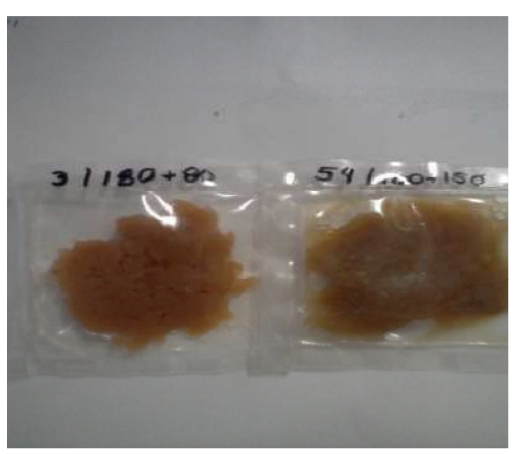

FIGURA 42- Sachê $n^{\circ} 3 \mathrm{I}$ e $54 \mathrm{~N} 23^{\circ} \mathrm{C}$ após 30 dias

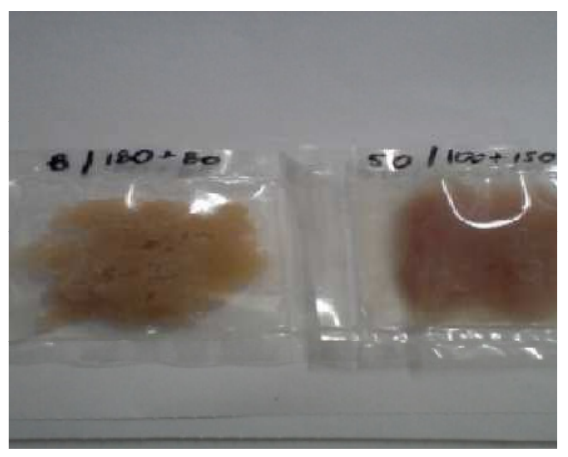

FIGURA 43 - Sachê no 81 e $50 \mathrm{~N} 23^{\circ} \mathrm{C}$, após 45 dias

As amostras foram mantidas em quatro faixas de temperatura $(5,23,40$ e 60 ${ }^{\circ} \mathrm{C}$ ), durante o período que vai de 0 a 45 dias o estudo piloto de estabilidade foi realizado por meio do modelo clássico. Foram determinadas as concentrações de mercúrio total de quatro sachês, por faixa de temperatura.

Os resultados da concentração média de THg dos sachês, no estudo de estabilidade em curto prazo, são apresentados na Tabela 44 para as amostras não irradiadas e na Tabela 45 para as amostras irradiadas. 
TABELA 44- Valores médios obtidos na determinação de mercúrio total em $\mu \mathrm{g} \mathrm{g}^{-1}$ por FIA-CV-AAS, na amostra de não irradiada (base úmida) , por 7-45 dias

\begin{tabular}{ccccc}
\hline & $\begin{array}{c}\text { Geladeira } \\
\left(5^{\circ} \mathrm{C}\right)\end{array}$ & $\begin{array}{c}\text { Ambiente } \\
\left(23^{\circ} \mathrm{C}\right)\end{array}$ & $\begin{array}{c}\text { Estufa } \\
\left(40^{\circ} \mathrm{C}\right)\end{array}$ & $\begin{array}{c}\text { Estufa } \\
\left(60^{\circ} \mathrm{C}\right)\end{array}$ \\
\hline Média $\pm D P$ & $0,134 \pm 0,01$ & $0,115 \pm 0,004$ & $0,380 \pm 0,01$ & $0,440 \pm 0,05$ \\
DPR \% & 7,5 & 3,5 & 2,6 & 11,4 \\
Valor-P $(99 \%)$ & 0,78 & 0,68 & 0,18 & 0,16 \\
Inclinação $\left(b_{1}\right)$ & 0,0062 & 0,0053 & 0,0042 & 0,0063 \\
$\begin{array}{c}\text { Erro padrão } \\
\text { Inclinação }\end{array}$ & 0,00005 & 0,00021 & 0,008 & 0,01 \\
$\left(s\left(b_{1}\right)\right)$ & & & & \\
$\left|b_{1}\right|<t(0,95, n-2)^{*} s\left(b_{1}\right)$ & 0,001 & 0,001 & 0,035 & 0,06 \\
\hline DPR \%-desvio padra & & & &
\end{tabular}

DPR \%-desvio padrão relativo percentual

TABELA 45- Valores médios obtidos na determinação de mercúrio total em $\mu \mathrm{g} \mathrm{g}^{-1}$ por FIA-CV-AAS, na amostra irradiada (base úmida), por 7-45 dias

\begin{tabular}{ccccc}
\hline & $\begin{array}{c}\text { Geladeira } \\
\left(5^{\circ} \mathrm{C}\right)\end{array}$ & $\begin{array}{c}\text { Ambiente } \\
\left(23^{\circ} \mathrm{C}\right)\end{array}$ & $\begin{array}{c}\text { Estufa } \\
\left(40^{\circ} \mathrm{C}\right)\end{array}$ & $\begin{array}{c}\text { Estufa } \\
\left(60^{\circ} \mathrm{C}\right)\end{array}$ \\
\hline Média $\pm D P$ & $0,145 \pm 0,002$ & $0,141 \pm 0,01$ & $0,302 \pm 0,01$ & $0,450 \pm 0,13$ \\
DPR \% & 1,4 & 7,1 & 3,3 & 29 \\
Valor-P (99\%) & 0,77 & 0,32 & 0,20 & 0,31 \\
Inclinação $\left(b_{1}\right)$ & 0,0062 & 0,006 & 0,0063 & 0,0058 \\
$\begin{array}{c}\text { Erro padrão } \\
\text { Inclinação }\end{array}$ & 0,00001 & 0,00002 & 0,035 & 0,038 \\
$\begin{array}{c}\left(s\left(b_{1}\right)\right) \\
\text { | }\end{array}$ & & & & \\
\hline$b_{1} \mid<t(0,95, n-2)^{*} s\left(b_{1}\right)$ & 0,03 & 0,01 & 0,01 & 0,02 \\
\hline DPR \%-desvio padrão relativo percentual & & &
\end{tabular}


Avaliando-se os resultados obtidos no estudo preliminar verificou-se alterações nas concentrações do mensurando para as faixas de temperatura de 40 ${ }^{\circ} \mathrm{C}$ e $60{ }^{\circ} \mathrm{C}$. Neste caso em particular, o motivo deste aumento está relacionado ao rompimento da selagem da embalagem de polietileno transparente nestas faixas de temperatura.

Dos 15 aos 45 dias de estudo ocorreu a concentração do analito pela perda de umidade das amostras em função da temperatura da estufa onde eram mantidas as amostras à $40^{\circ} \mathrm{C}$ e $60^{\circ} \mathrm{C}$. (FIG. 44 e 45 ).

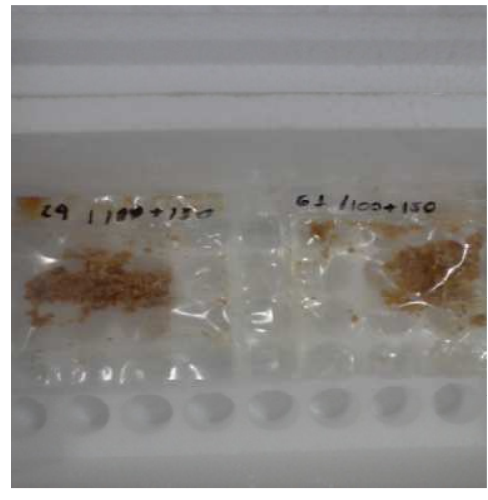

FIGURA 44 - Sachê a $40^{\circ} \mathrm{C}$, por 30 dias

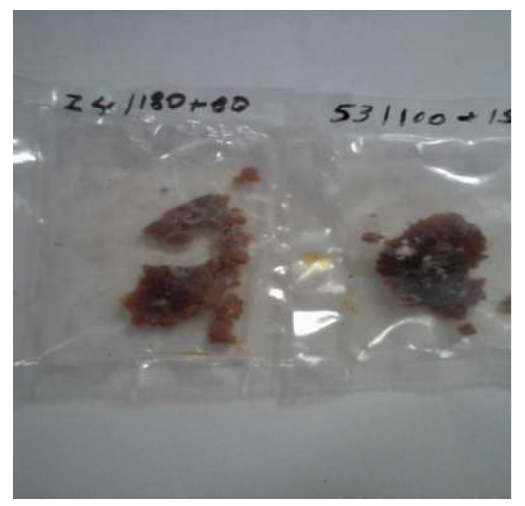

FIGURA 45 - Sachê a $60^{\circ} \mathrm{C}$, por 30 dias

O teste de regressão linear foi aplicado aos resultados de determinação do analito tanto para as amostras irradiadas, quanto para as não irradiadas, o valor-P para a variável $\mathrm{X} 1$ é maior que 0,05 , comprovando que não há tendência nos resultados para homogeneidade das amostras irradiadas e não irradiadas e que portanto a regressão é insignificante.

Para a estabilidade em curto prazo, ao nível de confiança de 99\%, não houve diferença significativa entre as concentrações médias obtidas para cada frasco, independente da temperatura e do tempo de exposição, já que o valor-P apresentouse maior do que o nível de significância de $\alpha=0,01$. (TAB. 44 e 45).

$\mathrm{Na}$ faixa de temperatura de $5{ }^{\circ} \mathrm{C}$ a $23^{\circ} \mathrm{C}$, no prazo de 0 a 45 dias as embalagens plásticas não apresentaram alteração (Figuras 46 e 47 amostras não irradiadas, Figuras 48 e 49 amostras irradiadas). 
Quando a temperatura aumenta para $40^{\circ} \mathrm{C}$ e $60^{\circ} \mathrm{C}$ ocorre alteração da embalagem ocasionando seu rompimento e a perda de umidade do material o que é demonstrado pela variação nos pontos após 30 dias nestas faixas de temperatura (Figuras 50 e 51 amostras não irradiadas, Figuras 52 e 53 amostras irradiadas).

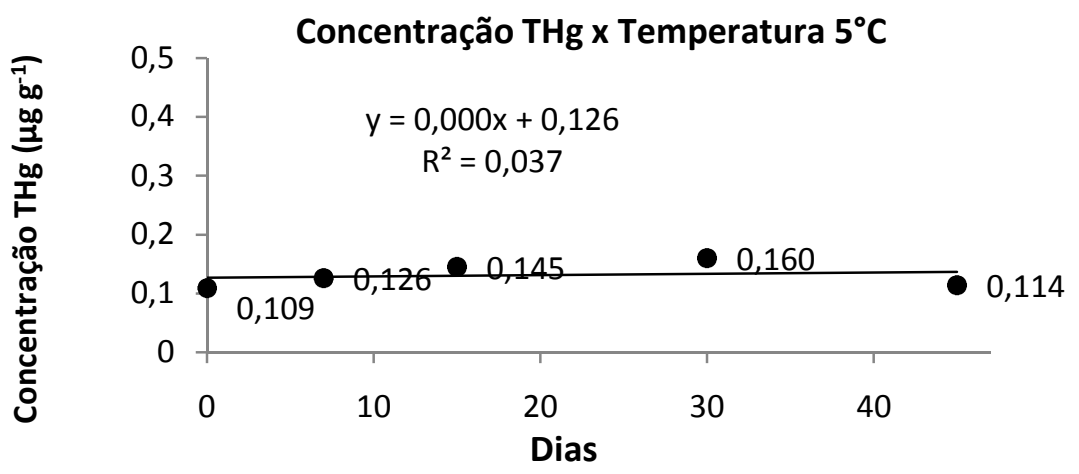

FIGURA 46- Concentração de THg em amostras não irradiadas, temperatura de $5^{\circ} \mathrm{C}$, durante o período de 0 a 45 dias

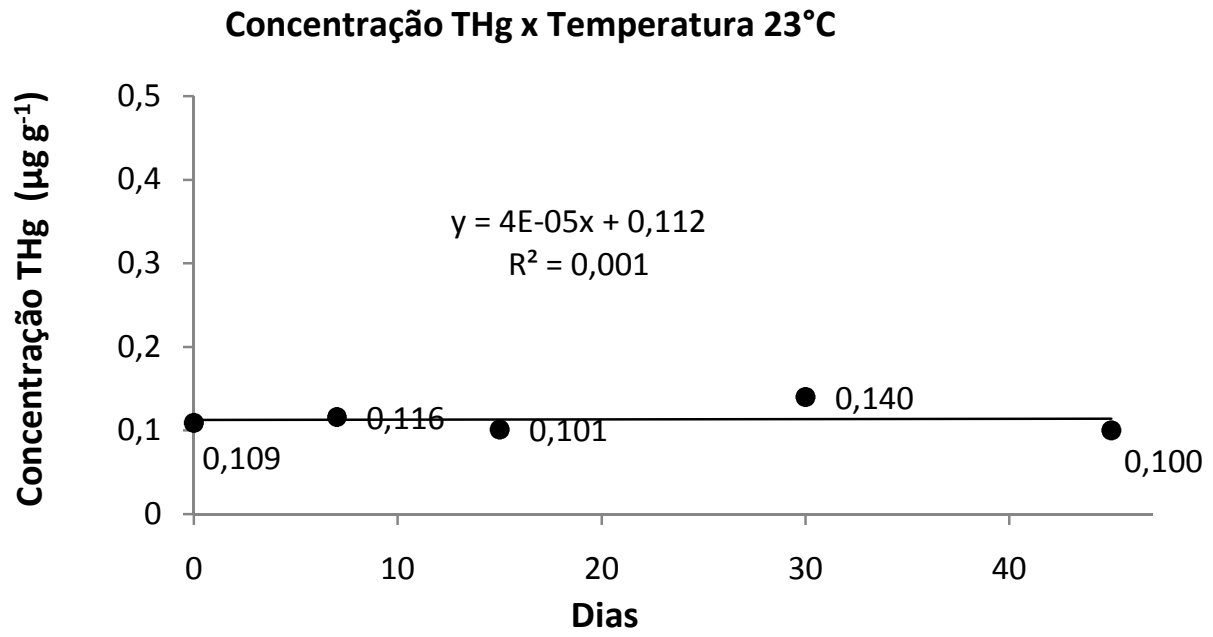

FIGURA 47- Concentração de THg em amostras não irradiadas, temperatura de $23^{\circ} \mathrm{C}$, durante o período de 0 a 45 dias 


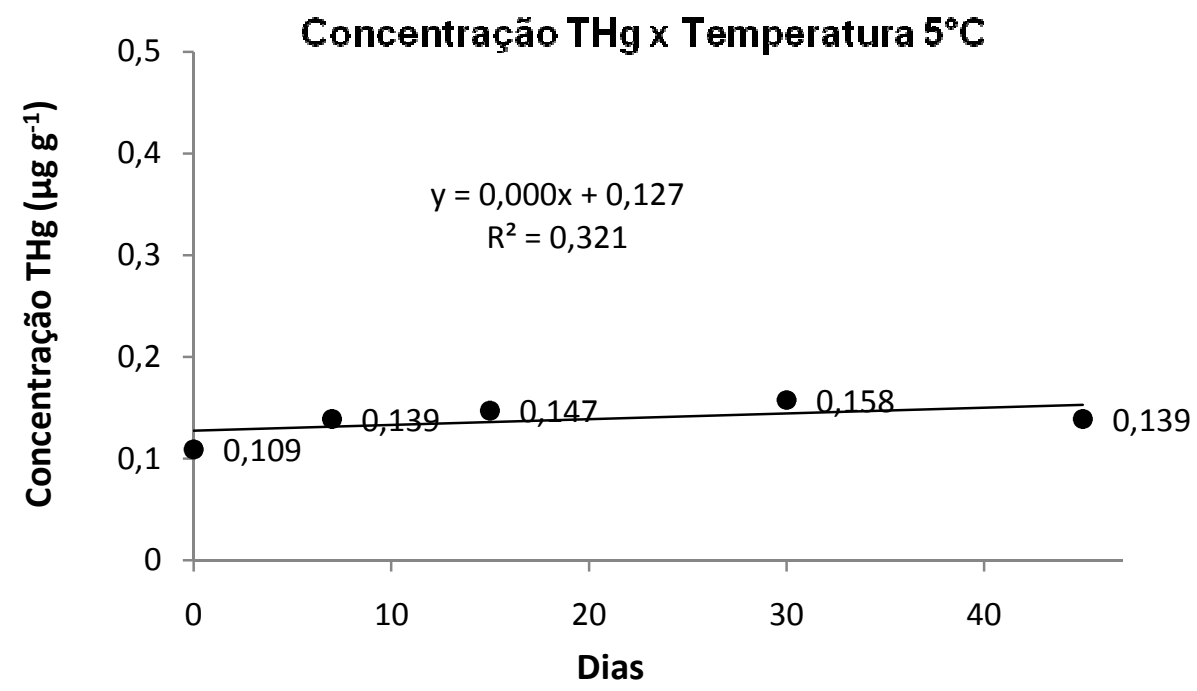

FIGURA 48- Concentração de THg em amostras irradiadas, temperatura de $5^{\circ} \mathrm{C}$, durante o período de 0 a 45 dias

\section{Concentração THg x Temperatura $23^{\circ} \mathrm{C}$}

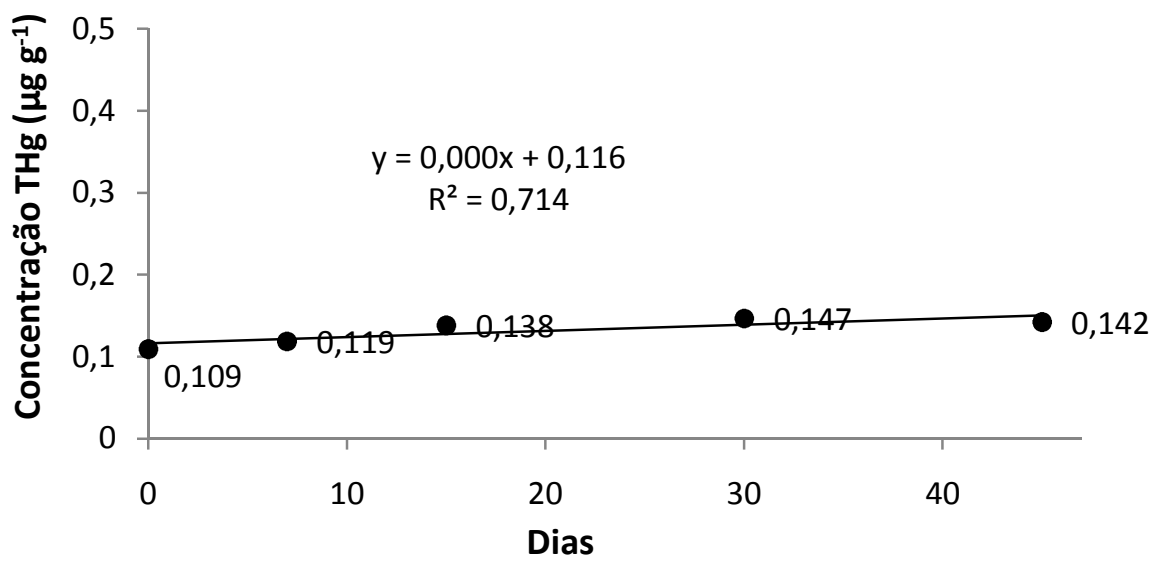

FIGURA 49- Concentração de THg em amostras irradiadas, temperatura de $23^{\circ} \mathrm{C}$, durante o período de 0 a 45 dias 


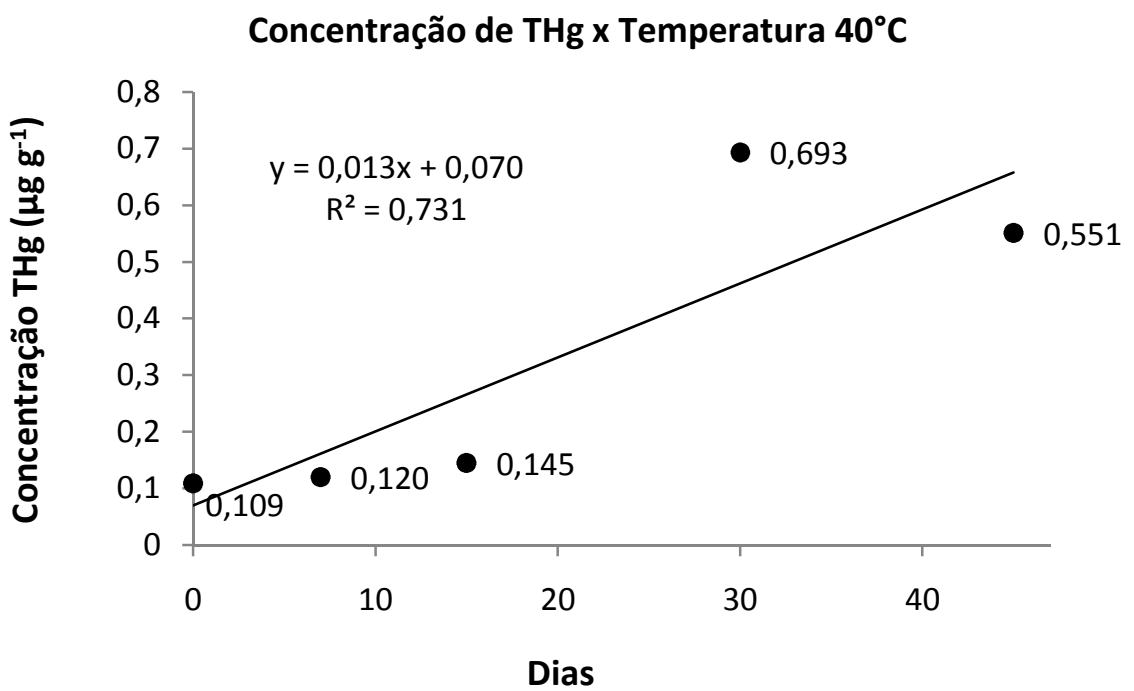

FIGURA 50- Concentração de THg em amostras não irradiadas, temperatura de $45^{\circ} \mathrm{C}$, durante o período de 0 a 45 dias

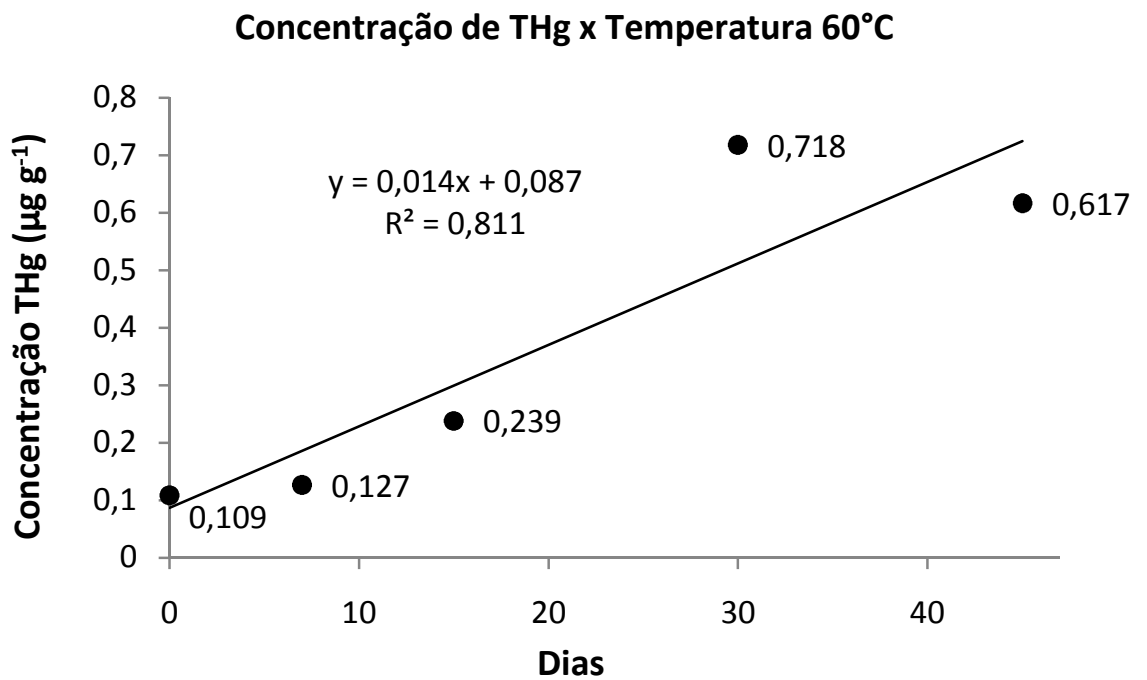

FIGURA 51- Concentração de THg em amostras não irradiadas, temperatura de $60^{\circ} \mathrm{C}$, durante o período de 0 a 45 dias 


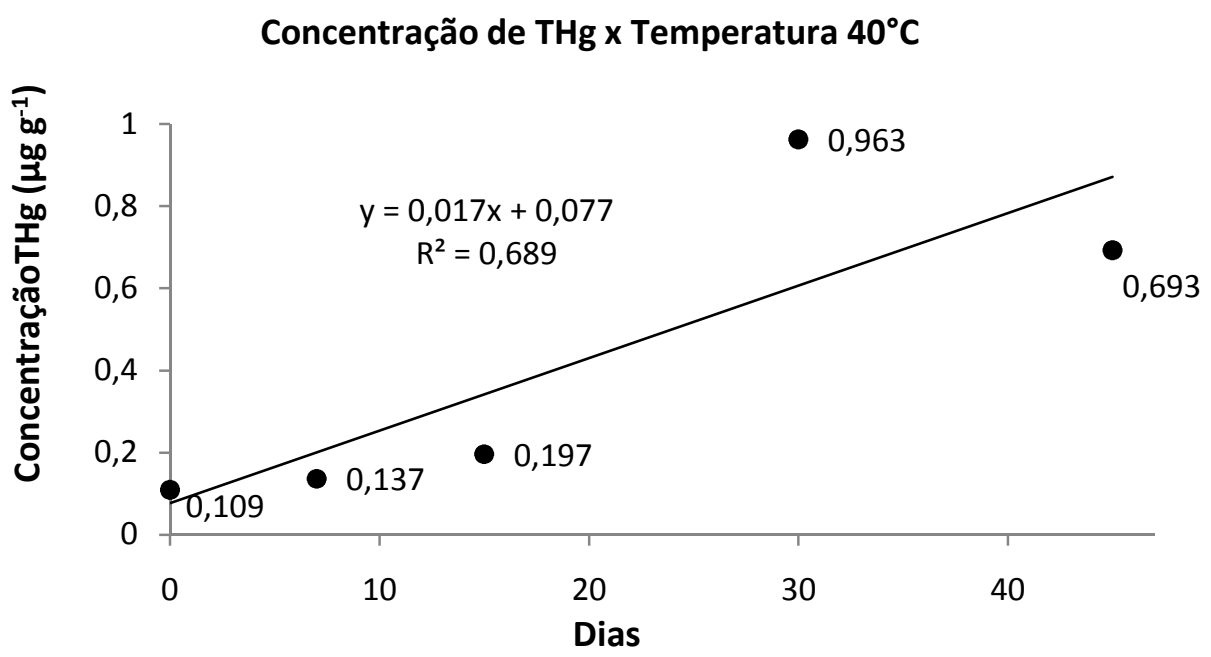

FIGURA 52- Concentração de THg em amostras irradiadas, temperatura de $40^{\circ} \mathrm{C}$, durante o período de 7 a 45 dias

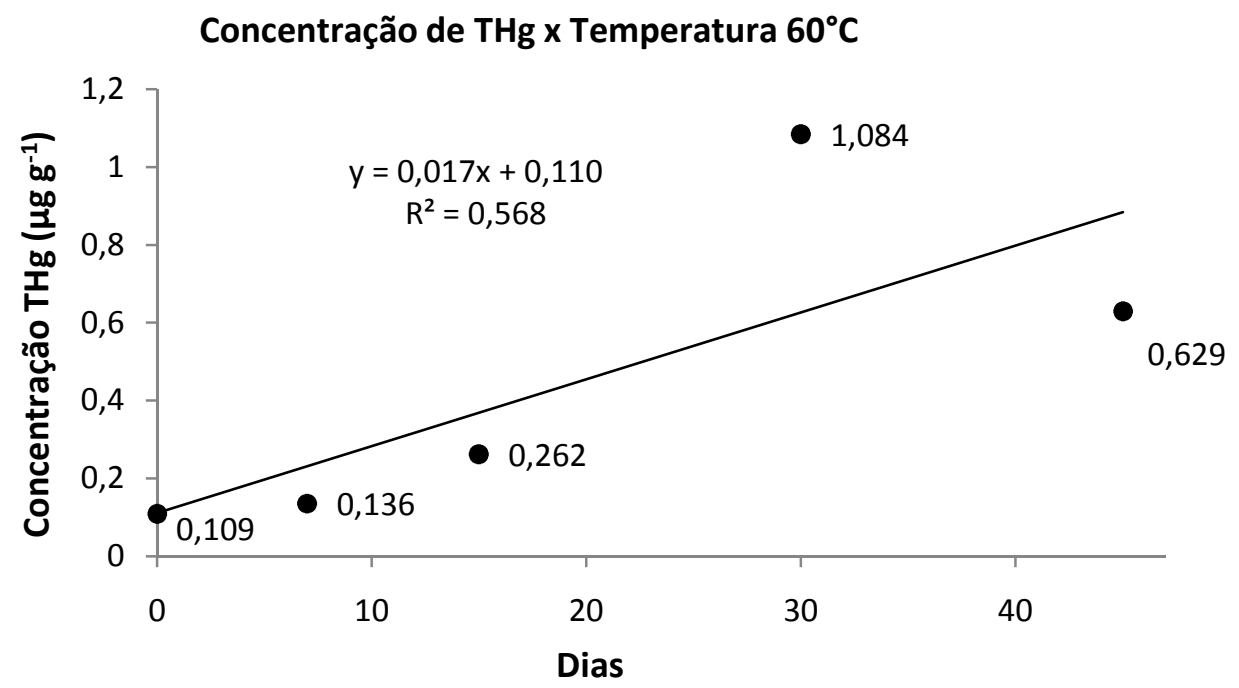

FIGURA 53- Concentração de THg em amostras irradiadas, temperatura de $60^{\circ} \mathrm{C}$, durante o período de 7 a 45 dias

Dessa forma observamos que a estabilidade do material envasado em sachês de polietileno transparente só pode ser garantida na faixa de temperatura de 5 a 23 ${ }^{\circ} \mathrm{C}$ pelo período de 45 dias, pois em temperaturas maiores a embalagem se rompeu. 
Desse modo, o material perde sua umidade característica resultando em aumento da concentração de THg.

Assim, optou-se pela troca de embalagem. A nova embalagem escolhida foi a trand-pouch. Esta embalagem além de apresentar um baixo custo, possui um material mais resistente a altas temperaturas (acima de 90 a $100^{\circ} \mathrm{C}$ ). Temperaturas superiores a $60^{\circ} \mathrm{C}$ podem apresentar uma perda mínima de umidade, sem alteração significativa de massa. A embalagem anterior ocasionou cerca de $20 \%$ de perda de umidade, com uma perda de até $0,01 \%$ de massa na temperatura de $60{ }^{\circ} \mathrm{C}$. 


\section{APÊNDICE B}

\section{Cálculo da incerteza analítica}

O cálculo da incerteza analítica foi realizado através de planilha eletrônica no programa Excel®, para a concentração média de amostras irradiadas e não irradiadas e do material de referência certificado, levando se em conta o diagrama de Ishikawa para análise das fontes de incerteza, de acordo as seguintes etapas:

As equações para o cálculo da incerteza de THg e TAs, são as mesmas, diferenciando-se apenas a etapa de fortificação aplicada ao mensurando TAs.

\section{Exemplo de cálculo de incerteza para mercúrio}

a) Incerteza na concentração do mensurando na alíquota

$$
\begin{aligned}
& u\left(c_{o}\right)=\frac{S}{B_{1}} x \sqrt{\frac{1}{p}+\frac{1}{n}+\frac{\left(c_{o}-\bar{c}\right)^{2}}{Q_{x x}}} \\
& u\left(c_{o}\right)=\frac{0.011599}{0.0288} \times \sqrt{\frac{1}{3}+\frac{1}{18}+\frac{(17.887-\overline{13.9})^{2}}{1655.07}} \\
& u\left(c_{o}\right)=0.2535
\end{aligned}
$$

d) Incerteza no preparo da solução para curva de calibração

$$
\begin{aligned}
& u_{C_{d i i_{-} 100}}=C_{d i l_{-} 100} \times \sqrt{\left(\frac{u_{C_{d i l_{-} 10}}}{C_{d i l_{-} 10}}\right)^{2}+\left(\frac{u_{m_{t}}}{m_{t}}\right)^{2}+\left(\frac{u_{m_{f}}}{m_{f}}\right)^{2}} \\
& u_{C_{d i \_-100}}=100,902 \times \sqrt{\left(\frac{0,0431}{10.053}\right)^{2}+\left(\frac{0,001118}{1,004}\right)^{2}+\left(\frac{0,001118}{100,030}\right)^{2}} \\
& u_{C_{d i L_{-} 100}}=0,447
\end{aligned}
$$


b) Incerteza na solução de Fortificação (Spike), somente para metais As, Cd e Pb. Pureza do elemento no certificado do fabricante Incerteza no preparo de cada solução (As, $\mathrm{Cd}, \mathrm{Pb})$

$$
\begin{aligned}
& u_{P}=\frac{D_{P}}{P} \quad u_{P}=\frac{0,000288675}{0,9999}=0,000288678 \\
& u_{\text {estoque }}=C_{\text {estoque }} \times \sqrt{\left(\frac{u_{P}}{P}\right)^{2}+\left(\frac{u_{m_{p}}}{m_{p}}\right)^{2}+\left(\frac{\left.u_{M_{f}}\right)^{2}}{M_{f}}\right.} \\
& u_{\text {solus } \tilde{a} A s s, c d, P b}=999,98 \times \sqrt{\left(\frac{0,000288678}{0,9999}\right)^{2}+\left(\frac{0,001118}{1,0}\right)^{2}+\left(\frac{0,001118}{200}\right)^{2}} \\
& u_{A s, C d, P b}=3 \times 1,15=3,45
\end{aligned}
$$

d) incerteza na recuperação do material de referencia certificado

$$
\begin{aligned}
& u_{\text {sol }}=C_{\text {sol }} \times \sqrt{\left(\frac{u_{M R C}}{C_{\text {MRC }}}\right)^{2}+\left(u_{\text {balansa }}\right)^{2}} \\
& u_{\text {sol }}=15,621 \times \sqrt{\left(\frac{0,26}{4,64}\right)^{2}+(0,01118)^{2}}=0,876 \\
& R_{m}=\frac{C_{\text {obs }}}{C_{M R C}} \quad R_{m}=\frac{5.46}{4.64}=1,18
\end{aligned}
$$




$$
\begin{aligned}
& u_{R m}=R_{m} \times \sqrt{\left(\frac{u_{s o l}}{C_{s o l}}\right)^{2}+\frac{S_{o b s}^{2}}{n \times C_{o b s}^{2}}} \\
& u_{R m}=1,18 \times \sqrt{\left(\frac{0,876}{15,621}\right)^{2}+\frac{0,04^{2}}{3 \times 18,388^{2}}} \quad u_{R m}=0,066
\end{aligned}
$$

e) Cálculo da propagação da incerteza analítica final

Para a determinação de mercúrio menor concentração não irradiada $\left(0,284 \mu \mathrm{g} \mathrm{g}^{-1}\right)$

$$
\begin{gathered}
u_{C_{H g}}=C_{H g} \times \sqrt{\left(\frac{u\left(C_{o}\right)}{C_{o}}\right)^{2}+\left(\frac{u\left(S o l_{100 p p b}\right)}{S o l_{100 p p b}}\right)^{2}+\left(\frac{u\left(m_{f}\right)}{m_{f}}\right)^{2}+\left(\frac{u(R)}{R}\right)^{2}+\left(\frac{u\left(m_{a}\right)}{m_{a}}\right)^{2}} \\
u_{C_{H g}}=0,284_{(H g)} \times \sqrt{\left(\frac{0,254}{17,337}\right)^{2}+\left(\frac{0,447}{100,902}\right)^{2}+\left(\frac{0,001118}{20,079}\right)^{2}+\left(\frac{0,06599}{1,18}\right)^{2}+\left(\frac{0,001118}{1,049}\right)^{2}}
\end{gathered}
$$

$u_{C_{H g}}=0,01650 \mu \mathrm{g} \mathrm{g}^{-1}$, a incerteza expandida é obtida multiplicando-se este valor pelo fator $k=2$, para um intervalo de confiança de $95 \%$. Assim a incerteza analítica expandida será $U=0,01650 \times 2=0,033 \mu g^{-1}$, equivalente a $U=12 \%$.

Tomando como exemplo a amostra citada acima, a contribuição de cada uma das fontes de incerteza relativas é observada na TAB. 46. 
TABELA 46- Fontes de Incerteza padrão e incerteza relativa para a caracterização do $\mathrm{THg}$

\begin{tabular}{ccccc}
\hline Fonte & Valor & Incerteza padrão & Incerteza relativa & Incerteza relativa \\
& $(\mathrm{x})$ & $(\mathrm{u}(\mathrm{x}))$ & $(\mathrm{u}(\mathrm{x}) / \mathrm{x})$ & $\%$ \\
\hline $\mathrm{u}(\mathrm{Co}) / \mathrm{Co}$ & 17,337 & 0,25439 & 0,01462133 & 1,46 \\
$\mathrm{u}(\mathrm{Cdil1}$ 100)/Cdil100 & 100,902 & 0,4469381 & 0,0044294 & 0,44 \\
$\mathrm{u}(\mathrm{mf}) / \mathrm{mf}$ & 20,079 & 0,001118 & 0,0000557 & 0,01 \\
$\mathrm{u}(\mathrm{Rec}) / \mathrm{Rec}$ & 1,18 & 0,0659883 & 0,05606 & 5,61 \\
$\mathrm{u}(\mathrm{ma}) / \mathrm{ma}$ & 1,049 & 0,001118 & 0,001066 & 0,11 \\
\hline
\end{tabular}

A Figura 54 mostra a porcentagem de incerteza de cada fonte.

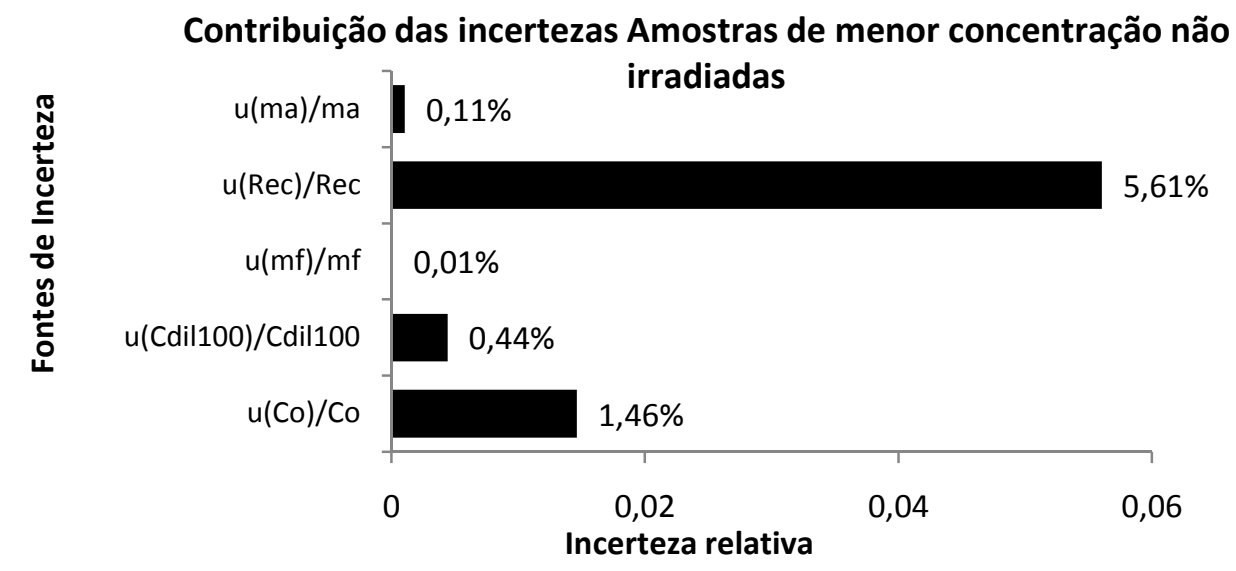

FIGURA 54- Porcentagem de contribuição de incertezas para caracterização do $\mathrm{Hg}$ total

\section{Exemplo de cálculo de incerteza para arsênio}

Para a determinação de arsênio de maior concentração irradiada $\left(1,085 \mu \mathrm{g} \mathrm{g}^{-1}\right)$, seguiram-se as mesmas etapas anteriores até o cálculo da incerteza final (FIG. 55 e TAB. 47). 
$u_{C_{A s}}=C_{A s} \times \sqrt{\left(\frac{u\left(C_{o}\right)}{C_{o}}\right)^{2}+\left(\frac{u\left(\text { Sol }_{000 p p b}\right)}{\text { Sol }_{100 p p b}}\right)^{2}+\left(\frac{u\left(m_{f}\right)}{m_{f}}\right)^{2}+\left(\frac{u(R)}{R}\right)^{2}+\left(\frac{u(\text { soladif }}{\text { Csoladic })}\right)^{2}+\left(\frac{u\left(m_{a}\right)}{m_{a}}\right)^{2}}$

$u_{C_{A s}}=1,085 \times \sqrt{\left(\frac{0,5059}{18,58}\right)^{2}+\left(\frac{0,5148}{100,74}\right)^{2}+\left(\frac{0,001118}{20,077}\right)^{2}+\left(\frac{0,0579}{0,91}\right)^{2}+\left(\frac{3,47}{999,9}\right)^{2}+\left(\frac{0,001118}{1,050}\right)^{2}}$

$u_{C A s}=0,07558 \mathrm{\mu g} \mathrm{g}^{-1}$, a incerteza expandida é obtida multiplicando-se este valor pelo fator $k=2$, para um intervalo de confiança de $95 \%$. Assim a incerteza analítica expandida será $U=0,07558 \times 2=0,15 \mu \mathrm{g} \mathrm{g}{ }^{-1}$, equivalente a $U=14 \%$.

TABELA 47- Fontes de Incerteza padrão e incerteza relativa para a caracterização do TAs

\begin{tabular}{ccccc}
\hline Fonte & Valor & Incerteza padrão & Incerteza relativa & Incerteza relativa \\
& $(\mathrm{x})$ & $(\mathrm{u}(\mathrm{x}))$ & $(\mathrm{u}(\mathrm{x}) / \mathrm{x})$ & $\%$ \\
\hline $\mathrm{u}(\mathrm{Co}) / \mathrm{Co}$ & 18,58 & 0,5059 & 0,02723 & 2,7 \\
$\mathrm{u}(\mathrm{Cdil100}) /$ Cdil100 & 100,74 & 0,5148 & 0,00511 & 0,5 \\
$\mathrm{u}(\mathrm{mf}) / \mathrm{mf}$ & 20,077 & 0,00112 & 0,0001 & 0,1 \\
$\mathrm{u}(\mathrm{Rec}) / \mathrm{Rec}$ & 0,91 & 0,0579 & 0,06391 & 6,4 \\
$\mathrm{u}(\mathrm{ma}) / \mathrm{ma}$ & 1,050 & 0,00112 & 0,0011 & 0,1 \\
$\mathrm{u}$ (soladiç)/Csoladiç & 999,89 & 3,2268 & 0,0032 & 0,3 \\
\hline
\end{tabular}

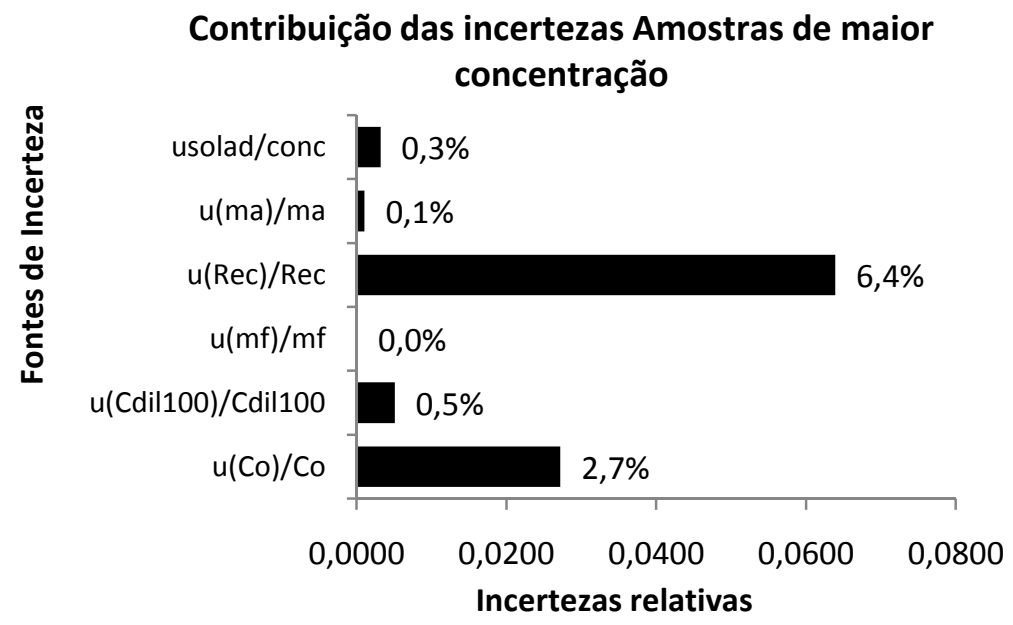

FIGURA 55- Porcentagem de contribuição de incertezas para caracterização do As total 


\section{Exemplo do cálculo de incerteza para cádmio e chumbo}

Os mensurandos cádmio e chumbo foram determinados por ICP-MS, utilizando-se algumas formulas diferenciadas como a incerteza na diluição da amostra e a incerteza na precisão da medida, os demais cálculos são idênticos aos realizados para o mercúrio e arsênio como estão descritas a seguir para o cádmio maior concentração irradiado:

As Tabelas 48 e 49, apresentam a contribuição de cada fonte incerteza relacionada a determinação de $\mathrm{Cd}$ e $\mathrm{Pb}$ totais por ICP-MS.

a) Incerteza no cálculo da precisão da medida

São preparadas e analisadas as soluções padrão da curva analítica e seus respectivos desvios padrões obtidos na leitura, assim normalmente o desvio padrão utilizado é aquele que esteja na faixa de concentração das amostras analisadas.

$$
u_{\text {precisão }}=\frac{P}{\sqrt{3}} \quad u_{\text {precisão }}=\frac{0,015}{\sqrt{3}}=0,009
$$

b) Incerteza para diluição da amostra

A incerteza na diluição é calculada a partir do cálculo do fator $D$, obtido pela média de sucessivas pesagens dos pesos de massa da amostra $\mathrm{mi}=1,008 \mathrm{~g}$ e peso de massa da diluição $\mathrm{mf}=10,002 \mathrm{~g}$, utilizados no preparo das soluções presentes na determinação do mensurando das amostras e da incerteza da balança.

$$
\begin{aligned}
& \mu_{D}=\sqrt{\left(\frac{u_{m f}}{m i}\right)^{2}+\left(\frac{m_{f} \times u_{m i}}{m_{f}^{2}}\right)^{2}} \\
& \mu_{D}=\sqrt{\left(\frac{0,0011}{1,0}\right)^{2}+\left(\frac{20,0 \times 0,0011}{10^{2}}\right)^{2}}=0,0106
\end{aligned}
$$


d) Cálculo da propagação da incerteza analítica final

A incerteza final do método é calculada pela formula 32, para as amostras de $\mathrm{Cd}$ e $\mathrm{Pb}$, incluindo a incerteza para solução de fortificação (Spike) do material.

$$
u_{C_{C d,}}=C_{C d,} \times \sqrt{\left(\frac{u_{M_{a}}}{M_{a}}\right)^{2}+\left(\frac{u_{C_{d i l}}}{C_{\text {dil }}}\right)^{2}+\left(\frac{u_{R}}{R}\right)^{2}+\left(\frac{u_{\text {Precisa } \tilde{o} o}}{\text { Precisão }}\right)^{2}+\left(\frac{u_{C_{\text {aliq }}}}{C_{\text {aliq }}}\right)^{2}+\left(\frac{u_{\text {soladiç }}}{C_{\text {soladic }}}\right)^{2}+\left(\frac{u_{D}}{D}\right)^{2}}
$$

$$
u_{C_{C d}}=0,936 \times \sqrt{\left(\frac{0,00112}{1,005}\right)^{2}+\left(\frac{0,05}{100,687}\right)^{2}+\left(\frac{0,2171}{9,024}\right)^{2}+\left(\frac{0,009}{0,015}\right)^{2}+\left(\frac{105,907}{935,9}\right)^{2}+\left(\frac{3,227}{999,89}\right)^{2}+\left(\frac{0,0106}{10,0}\right)^{2}}
$$

$u_{C d}=0,116 \quad \mu \mathrm{g} \mathrm{g}^{-1}$, a incerteza expandida é obtida multiplicando-se este valor pelo fator $k=2$, para um intervalo de confiança de $95 \%$. Assim a incerteza analítica expandida será $U=0,116 \times 2=0,23 \mu g g^{-1}$, equivalente a $U=24,8 \%$. (TAB. 48 e FIG. 56).

TABELA 48- Fontes de Incerteza padrão e incerteza relativa para a caracterização do TCd

\begin{tabular}{ccccc}
\hline Fonte & Valor & Incerteza padrão & Incerteza relativa & Incerteza relativa \\
& $(\mathrm{x})$ & $(\mathrm{u}(\mathrm{x}))$ & $(\mathrm{u}(\mathrm{x}) / \mathrm{x})$ & $\%$ \\
\hline $\mathrm{u}(\mathrm{Co}) /$ Co & 935,9 & 105,91 & 0,113 & 12,1 \\
$\mathrm{u}(\mathrm{Cdil}) /$ Cdil & 100,687 & 0,05 & 0,001 & 0,1 \\
$\mathrm{u}(\mathrm{P}) / \mathrm{P}$ & 0,015 & 1,732 & 0,009 & 0,9 \\
$\mathrm{u}(\mathrm{Rec}) / \mathrm{Rec}$ & 9,0 & 0,2171 & 0,024 & 2,6 \\
$\mathrm{u}(\mathrm{ma}) / \mathrm{ma}$ & 1,0 & 0,00112 & 0,0011 & 0,01 \\
$\mathrm{u}(\mathrm{D}) / \mathrm{D}$ & 10,0 & 0,0106 & 0,000001 & 0,0001 \\
$\mathrm{u}(\mathrm{soladiç}) /$ Csoladiç & 1000 & 3,45 & 0,003 & 0,4 \\
\hline
\end{tabular}




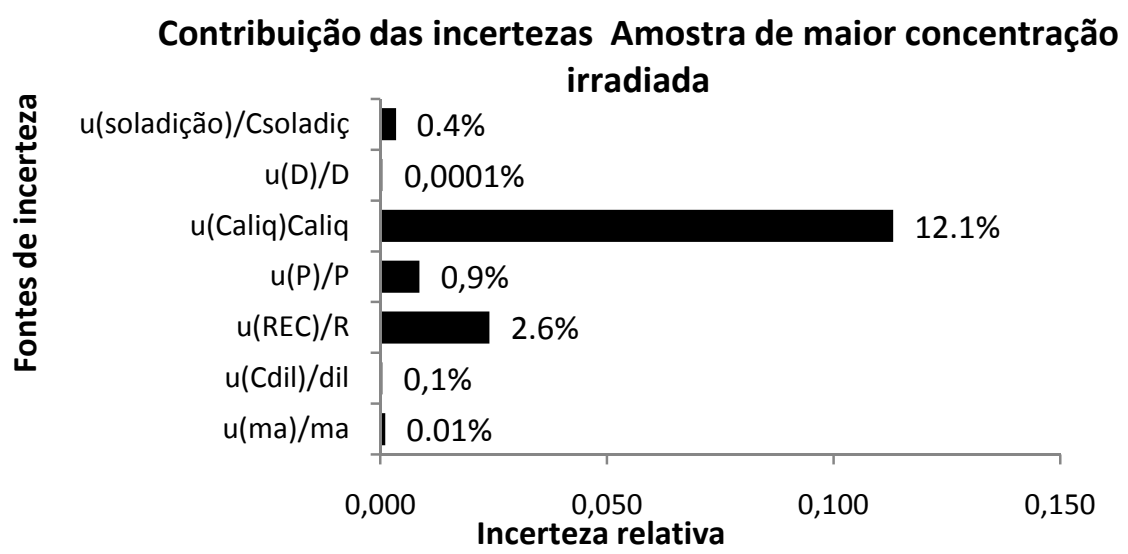

FIGURA 56- Porcentagem de contribuição de incertezas analítica para Cd total

Para a determinação de chumbo de maior concentração irradiada $(2,062 \mu \mathrm{g} \mathrm{g}$ ${ }^{1}$ ), seguiram-se as mesmas etapas anteriores até o cálculo da incerteza final.

$$
u_{C_{P b}}=C_{P b} \times \sqrt{\left(\frac{u_{M_{a}}}{M_{a}}\right)^{2}+\left(\frac{u_{C_{\text {dil }}}}{C_{\text {dil }}}\right)^{2}+\left(\frac{u_{R}}{R}\right)^{2}+\left(\frac{u_{\mathrm{Pr} \text { ecisão }}}{\operatorname{Pr} \text { ecis } \tilde{a} o}\right)^{2}+\left(\frac{u_{C_{\text {aliq }}}}{C_{\text {aliq }}}\right)^{2}+\left(\frac{u_{\text {soladi }}}{C_{\text {solati }}}\right)^{2}+\left(\frac{u_{D}}{D}\right)^{2}}
$$

$$
u_{C_{P b}}=2,062 \times \sqrt{\left(\frac{0,00112}{1,008}\right)^{2}+\left(\frac{0,05}{100,687}\right)^{2}+\left(\frac{1,096}{10,2}\right)^{2}+\left(\frac{0,009}{0,015}\right)^{2}+\left(\frac{234.013}{2062,01}\right)^{2}+\left(\frac{3,227}{999,89}\right)^{2}+\left(\frac{0,0106}{10,0}\right)^{2}}
$$

$u_{C P b}=0,157 \mu \mathrm{g} \mathrm{g}{ }^{-1}$, a incerteza expandida é obtida multiplicando-se este valor pelo fator $k=2$, para um intervalo de confiança de $95 \%$. Assim a incerteza analítica expandida será $U=0,157 \times 2=0,313 \mu \mathrm{g} \mathrm{g}^{-1}$, equivalente a $U=15,2 \%$ (TAB. 49) e (FIG. 57). 
TABELA 49- Fontes de Incerteza padrão e incerteza relativa para a caracterização do $\mathrm{TPb}$

\begin{tabular}{ccccc}
\hline Fonte & Valor & Incerteza padrão & Incerteza relativa & Incerteza relativa \\
& $(\mathrm{x})$ & $(\mathrm{u}(\mathrm{x}))$ & $(\mathrm{u}(\mathrm{x}) / \mathrm{x})$ & $\%$ \\
\hline $\mathrm{u}(\mathrm{Co}) /$ Co & 2062,01 & 234,01 & 0,113 & 11,3 \\
$\mathrm{u}(\mathrm{Cdil}) / \mathrm{Cdil}$ & 100,687 & 0,05 & 0,001 & 0,1 \\
$\mathrm{u}(\mathrm{P}) / \mathrm{P}$ & 0,015 & 1,732 & 0,009 & 0,9 \\
$\mathrm{u}(\mathrm{Rec}) / \operatorname{Rec}$ & 10,18 & 1,0960 & 0,108 & 10,8 \\
$\mathrm{u}(\mathrm{ma}) / \mathrm{ma}$ & 1,0 & 0,00112 & 0,0011 & 0,01 \\
$\mathrm{u}(\mathrm{D}) / \mathrm{D}$ & 10,0 & 0,0106 & 0,000001 & 0,0001 \\
$\mathrm{u}(\mathrm{soladiç}) /$ Csoladiç & 1000 & 3,45 & 0,003 & 0,4 \\
\hline
\end{tabular}

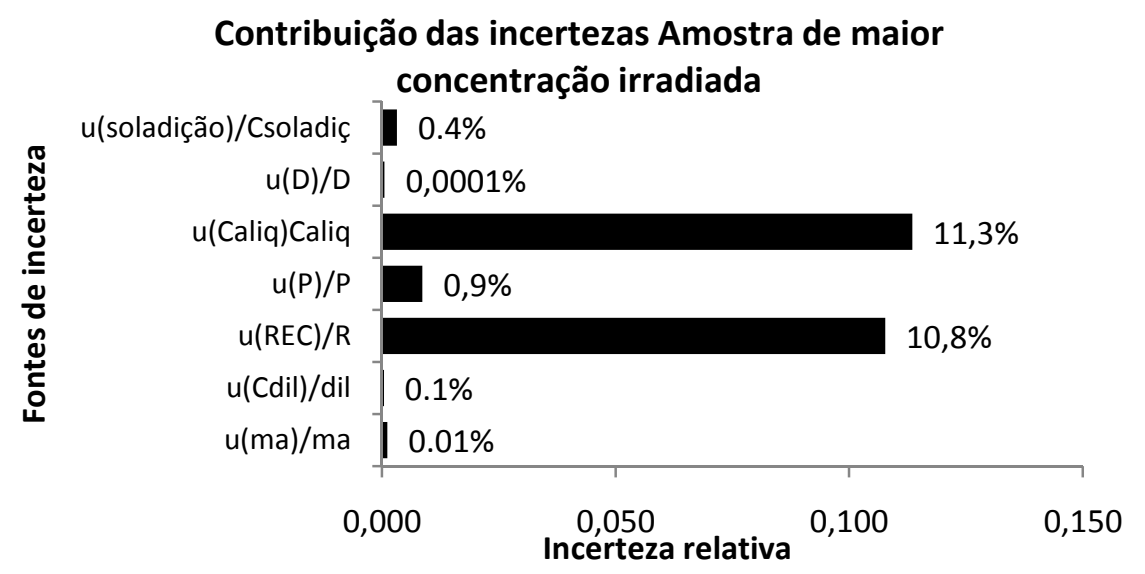

FIGURA 57- Porcentagem de contribuição de incertezas analítica para Pb total 


\section{APÊNDICE C}

\section{Ensaios para validação do método de determinação de arsênio}

Foram realizados alguns ensaios de acordo com os protocolos do INMETRO e ANVISA para a validação da análise de arsênio pela técnica de absorção atômica com geração de hidretos. As Tabelas 50 e 51, apresentam os resultados obtidos. As características de desempenho do método verificadas foram: Limite de detecção; exatidão; precisão; repetitividade; linearidade e incerteza de medição.

TABELA 50- Resultados obtidos para validação do TAs

\begin{tabular}{|c|c|}
\hline Características de Desempenho & Valor Obtido \\
\hline $\begin{array}{l}\text { Limite de detecção e Limite de } \\
\text { Quantificação }\end{array}$ & $\begin{array}{l}\mathrm{LD}=2,7 \mu \mathrm{g} \mathrm{L}^{-1} \\
\mathrm{LQ}=5,7 \mu g \mathrm{~L}^{-1}\end{array}$ \\
\hline Exatidão (Erro normalizado) & $<1$ \\
\hline Precisão & $\begin{array}{l}\text { A precisão das medidas, para o MRC } \\
\text { Dorm-2 variou na faixa de } 2-3 \%(n=6) \text { e } \\
\text { para o MRC Dolt-2 variou na faixa de } \\
3,5-7 \%(n=6) \text {. }\end{array}$ \\
\hline Repetitividade & $\begin{array}{l}\text { Limite de repetitividade (r) calculado foi } \\
\text { igual a } 2,1 \text {. }\end{array}$ \\
\hline Linearidade & $\begin{array}{l}\text { Valor de } r \text { de Pearson }=0,999, \\
\text { correlação fortíssima. }\end{array}$ \\
\hline $\begin{array}{l}\text { Incerteza de medição (k=2 para 95\% } \\
\text { confiança) }\end{array}$ & $\begin{array}{l}\text { O valor médio obtido na incerteza } \\
\text { expandida, com } \mathrm{k}=2 \text { e } 95 \% \text { de } \\
\text { confiança, foi aproximadamente } 14 \% \text { no } \\
\text { resultado da medição, dependendo da } \\
\text { matriz do MRC. }\end{array}$ \\
\hline Temperatura de digestão & $250^{\circ} \mathrm{C}$ \\
\hline Concentração de $\mathrm{NaBH}_{4}$ & $4 \%$ \\
\hline Massa mínima de amostra & $0,200 \mathrm{~g}$ \\
\hline Recuperação do MRC & $>90 \%$ para todos os MRC utilizados \\
\hline
\end{tabular}


TABELA 51- Concentração média de TAs, em $\mu_{\mathrm{g} \mathrm{g}}{ }^{-1}$, obtidas por HG-AAS, para os materiais de referência certificados utilizados neste ensaio

\begin{tabular}{lcccc}
\hline As Total & $\begin{array}{c}\text { Valor } \\
\text { Certificado }^{\text {a }}\end{array}$ & Valor Obtido $^{\mathrm{b}}$ & Recuperação \% $^{\mathrm{U} \%}$ \\
\hline Buffalo River & $24,8 \pm 0,8$ & $23,2 \pm 1,7$ & 99 & 10 \\
San Joaquim & $17,7 \pm 0,8$ & $17,0 \pm 1,12$ & 96 & 12 \\
Dorm-2 & $18,0 \pm 1,1$ & $18,0 \pm 0,5$ & 100 & 14 \\
Dolt-2 & $16,6 \pm 1,1$ & $15,5 \pm 0,3$ & 93 & 15 \\
\hline a'Média \pm 95\% de limite de confiança, ${ }^{\mathrm{b}}$ Média de 3 repetições \pm desvio padrão
\end{tabular}

A Figura 58 apresenta os resultados dos gráficos de controle do arsênio para 2 materiais de referência certificados para a matriz peixe utilizados neste trabalho.
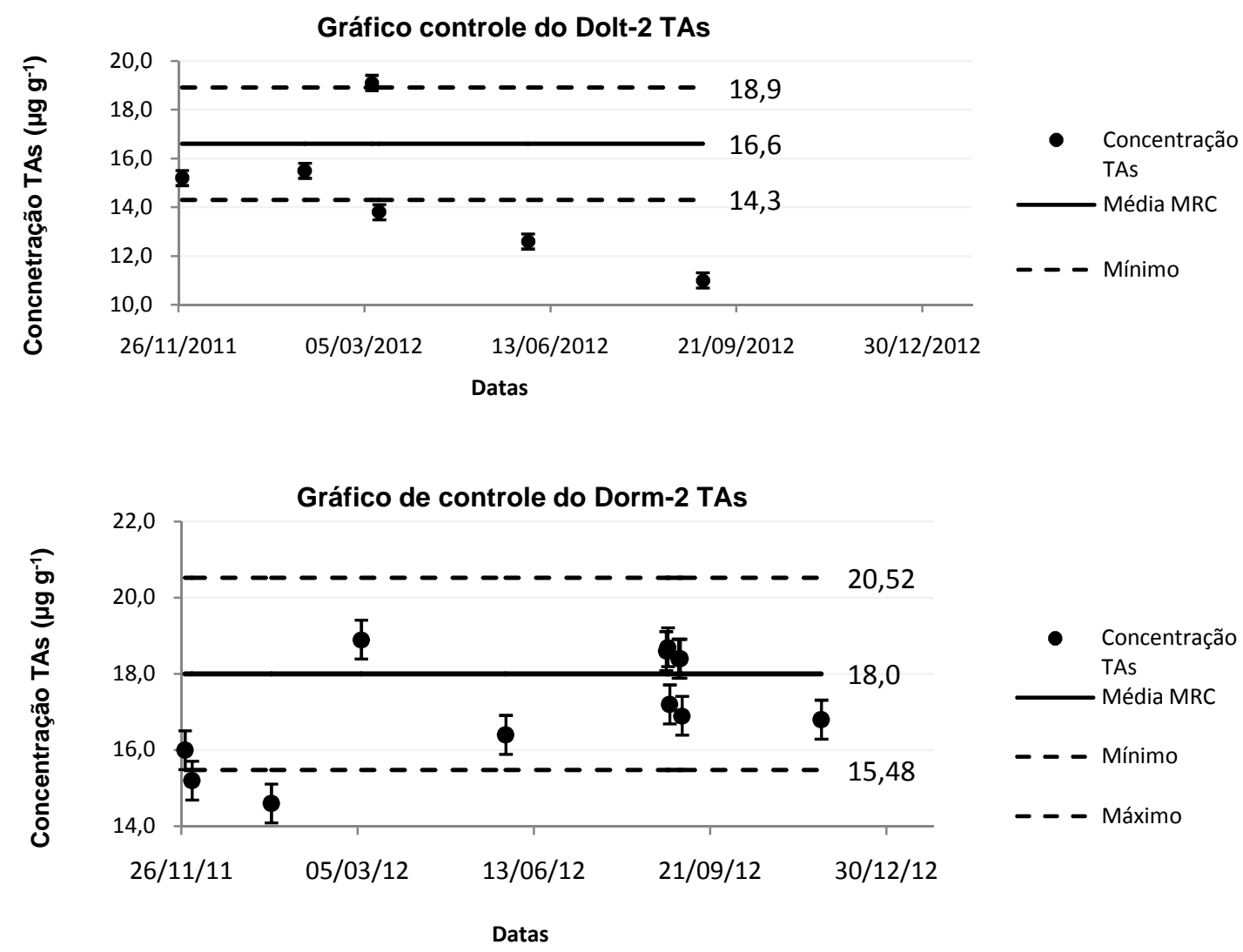

FIGURA 58- Gráfico de controle para ensaio de TAs em MRC para matriz peixe, valor da concentração \pm incerteza

Os gráficos foram plotados a partir dos resultados obtidos durante os ensaios realizados para teste da metodologia aplicada e determinação de TAs no material produzido. 


\section{APÊNDICE D}

\section{Teste para fortificação do tecido de peixe}

Foram preparadas soluções fortificadas a homogeneização de cerca de $600 \mathrm{~g}$ do tecido muscular de peixe, este foi subdividido em porções de $60 \mathrm{~g}$ cada, adicionando-se, padrões em solução de ácido nítrico $2 \%$ para fortificação nas concentrações de $0,200,0,320,0,500,0,512,0,819$, e 1,000, 1,310, 1,500, 2,000, 2,096 $\mathrm{\mu g} \mathrm{g}^{-1}$ para $\mathrm{Hg}$, As, Cd e Pb, na razão de 1/1 Figuras 59 e 60, ou seja, para cerca de $60 \mathrm{~g}$ de tecido foi adicionado $60 \mathrm{~mL}$ de solução aos poucos mexendo sempre até ser novamente homogeneizada em batedeira doméstica com velocidade mínima para não perder as características da fibra muscular do peixe.

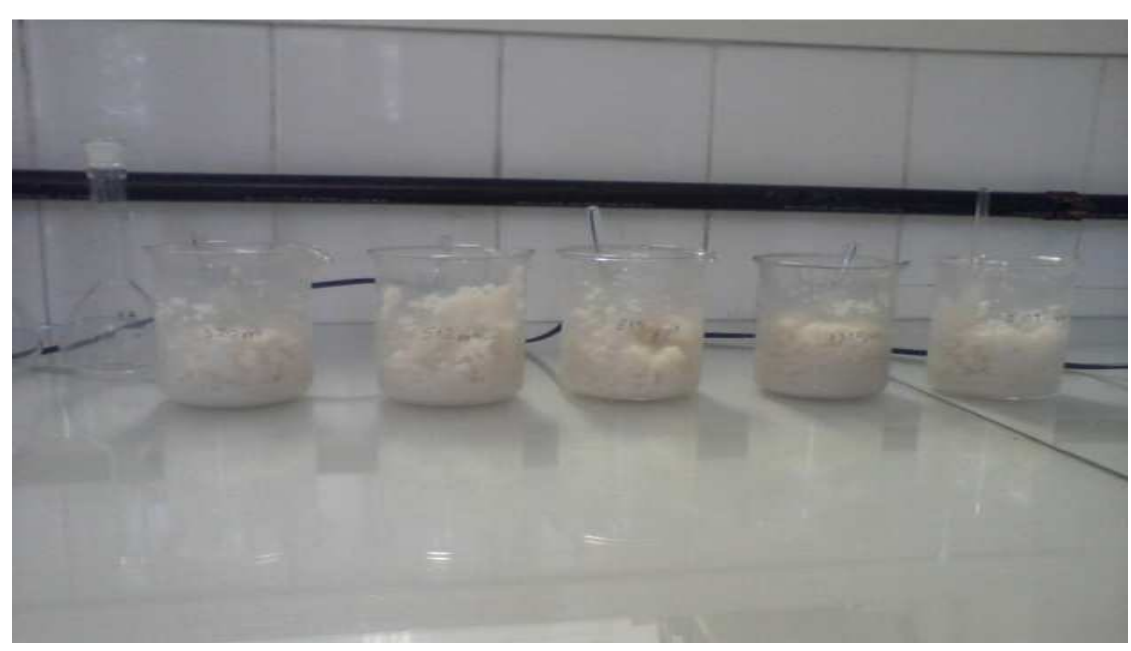

FIGURA 59- Adição de 0,200, 0,320, 0,500, 0,512, 0,819 $\mu \mathrm{g} \mathrm{g}{ }^{-1}$

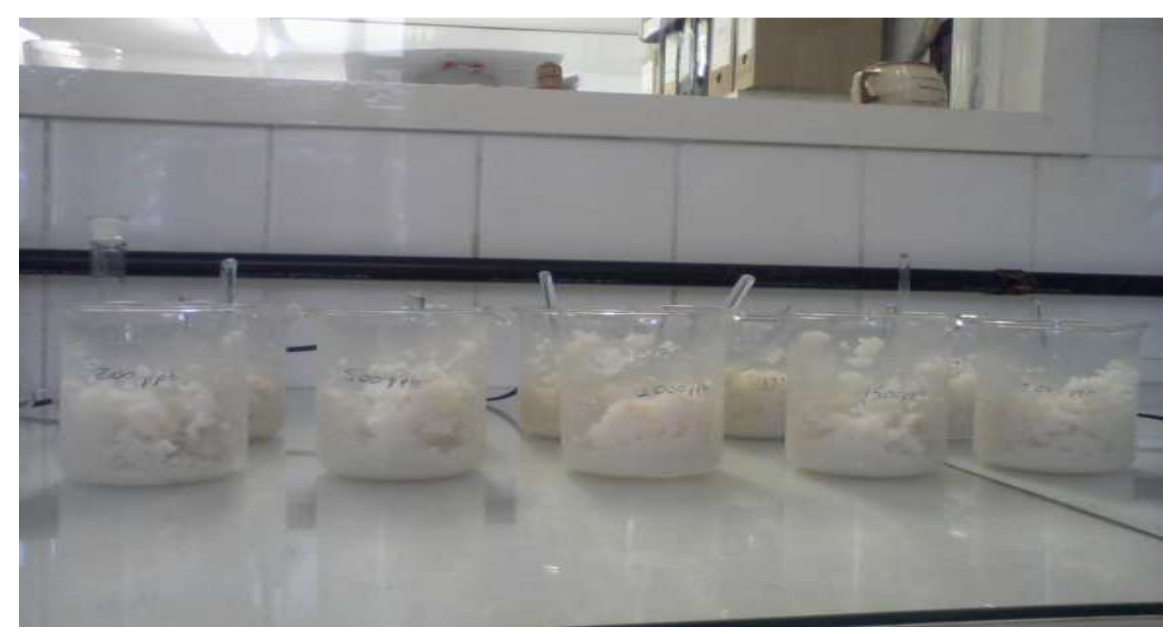

FIGURA 60- Adição de 1,000, 1,310, 1,500, 2,000, 2,096 $\mu \mathrm{g} \mathrm{g}^{-1}$ 
Ao avaliar os resultados as concentrações que se mostraram mais adequadas com menor desvio padrão foram de 1,000, 1,500 e 2,000 $\mathrm{mg} \mathrm{g}^{-1}$, com uma recuperação média de $40 \%$, e resultados robustos e reprodutíveis para as técnicas de preparo e análise empregadas. Não houve adição de $\mathrm{Hg}$, pois o material já possuía concentrações elevadas naturalmente em virtude da região de captura dos mesmos. (TAB. 52 a 55).

TABELA 52- Resultados de TAs adicionado ao tecido muscular do peixe

\begin{tabular}{|c|c|c|c|c|c|c|c|c|c|c|c|c|}
\hline Amostras As & Conc. ( $\mu \mathrm{g} / \mathrm{kg})$ & Conc.-Nat & Conc. $(\mu \mathrm{g} / \mathrm{g})$ & $\operatorname{Rec}$ & Media & DP & med Rec & DPR & Media total & DP total & | DPR total $\mid \mathrm{F}$ & REC \\
\hline & ppb & $(\mu \mathrm{g} / \mathrm{kg})$ & ppm & $\%$ & $(\mu \mathrm{g} / \mathrm{g})$ & $(\mu \mathrm{g} / \mathrm{g})$ & $\%$ & $\%$ & $(\mu \mathrm{g} / \mathrm{g})$ & $(\mu \mathrm{g} / \mathrm{g})$ & $\%$ & $\%$ \\
\hline $1.500-1$ & 874.566 & 865.366 & 0.865 & \begin{tabular}{|c|}
57.7 \\
\end{tabular} & & & & & & & & \\
\hline $1.500-1 \mathrm{~A}$ & 868.529 & 859.329 & 0.859 & 57.3 & & & & & & & & \\
\hline $1.500-1 \mathrm{~B}$ & 974.549 & 965.349 & 0.965 & 64.4 & 0.897 & 0.060 & 59.8 & 6.6 & & & & \\
\hline $1.500-2$ & 933.176 & 923.976 & 0.924 & 61.6 & & & & & & & & \\
\hline $1.500-2 \mathrm{~A}$ & 881.374 & 872.174 & 0.872 & 58.1 & & & & & & & & \\
\hline $1.500-2 B$ & 836.503 & 827.303 & 0.827 & 55.2 & 0.874 & 0.048 & 58.3 & 5.5 & & & & \\
\hline $1.500-3$ & 923.670 & 914.470 & 0.914 & 61.0 & & & & & & & & \\
\hline $1.500-3 \mathrm{~A}$ & 948.903 & 939.703 & 0.940 & 62.6 & & & & & & & & \\
\hline $1.500-3 B$ & 909.810 & 900.610 & 0.901 & 60.0 & 0.918 & 0.020 & 61.2 & 2.2 & & & & \\
\hline $1.500-4$ & 872.504 & 863.304 & 0.863 & 57.6 & & & & & & & & \\
\hline $1.500-4 \mathrm{~A}$ & 892.595 & 883.395 & 0.883 & 58.9 & & & & & & & & \\
\hline $1.500-4 B$ & 927.570 & 918.370 & 0.918 & 61.2 & 0.888 & 0.028 & 59.2 & 3.1 & 0.894 & 0.039 & 4.4 & 60 \\
\hline $1.000-1$ & 563.248 & 554.048 & 0.554 & 36.9 & & & & & & & & \\
\hline $1.000-1 \mathrm{~A}$ & 593.159 & 583.959 & 0.584 & 38.9 & & & & & & & & \\
\hline $1.000-1 B$ & 586.672 & 577.472 & 0.577 & 38.5 & 0.572 & 0.016 & 57.2 & 2.8 & & & & \\
\hline $1.000-2$ & 597.071 & 587.871 & 0.588 & 39.2 & & & & & & & & \\
\hline $1.000-2 \mathrm{~A}$ & 593.304 & 584.104 & 0.584 & 38.9 & & & & & & & & \\
\hline $1.000-2 B$ & 663.747 & 654.547 & 0.655 & 43.6 & 0.609 & 0.040 & 60.9 & 6.5 & & & & \\
\hline $1.000-3$ & 569.330 & 560.130 & 0.560 & 37.3 & & & & & & & & \\
\hline $1.000-3 \mathrm{~A}$ & 530.214 & 521.014 & 0.521 & 34.7 & & & & & & & & \\
\hline $1.000-3 B$ & 646.341 & 637.141 & 0.637 & 42.5 & 0.573 & 0.059 & 57.3 & 10.3 & & & & \\
\hline $1.000-4$ & 662.391 & 653.191 & 0.653 & 43.5 & & & & & & & & \\
\hline $1.000-4 \mathrm{~A}$ & 640.674 & 631.474 & 0.631 & 42.1 & & & & & & & & \\
\hline $1.000-4 B$ & 627.363 & 618.163 & 0.618 & 41.2 & 0.634 & 0.018 & 63.4 & 2.8 & 0.597 & 0.042 & 7.1 & 66 \\
\hline
\end{tabular}


TABELA 53- Resultados de THg presentes no tecido muscular do peixe

\begin{tabular}{|c|c|c|c|c|c|c|c|}
\hline Amostras Hg & Conc. $(\mu \mathrm{g} / \mathrm{g}) \mathrm{ppm}$ & Media & DP & DPR & Media total & DP total & DPR total \\
\hline & & $(\mu \mathrm{g} / \mathrm{g})$ & $(\mu \mathrm{g} / \mathrm{g})$ & $\%$ & $(\mu \mathrm{g} / \mathrm{g})$ & $(\mu \mathrm{g} / \mathrm{g})$ & $\%$ \\
\hline $1051-1$ & 0.553 & & & & & & \\
\hline $1051-1 A$ & 0.548 & & & & & & \\
\hline 1051-1B & 0.508 & 0.536 & 0.024 & 4.6 & & & \\
\hline $1051-2$ & 0.551 & & & & & & \\
\hline $1051-2 A$ & 0.484 & & & & & & \\
\hline $1051-2 B$ & 0.559 & 0.531 & 0.041 & 7.7 & & & \\
\hline $1051-3$ & 0.561 & & & & & & \\
\hline $1051-3 A$ & 0.540 & & & & & & \\
\hline 1051-3B & 0.556 & 0.552 & 0.011 & 2.0 & & & \\
\hline $1051-4$ & 0.514 & & & & & & \\
\hline $1051-4 A$ & 0.546 & & & & & & \\
\hline $1051-4 B$ & 0.469 & 0.510 & 0.039 & 7.6 & 0.532 & 0.031 & 5.8 \\
\hline $480-1$ & 0.234 & & & & & & \\
\hline $480-1 A$ & 0.260 & & & & & & \\
\hline 480-1B & 0.235 & 0.243 & 0.014 & 5.9 & & & \\
\hline $480-2$ & 0.223 & & & & & & \\
\hline $480-2 A$ & 0.202 & & & & & & \\
\hline $480-2 B$ & 0.223 & 0.216 & 0.012 & 5.5 & & & \\
\hline $480-3$ & 0.251 & & & & & & \\
\hline $480-3 A$ & 0.257 & & & & & & \\
\hline 480-3B & 0.241 & 0.250 & 0.008 & 3.3 & & & \\
\hline $480-4$ & 0.270 & & & & & & \\
\hline $480-4 \mathrm{~A}$ & 0.264 & & & & & & \\
\hline $480-4 B$ & 0.243 & 0.259 & 0.014 & 5.4 & 0.242 & 0.020 & 8.1 \\
\hline
\end{tabular}


TABELA 54- Resultados de TCd adicionados ao tecido muscular do peixe

\begin{tabular}{|c|c|c|c|c|c|c|c|c|c|c|}
\hline Amostras Cd & Conc. $(\mu \mathrm{g} / \mathrm{g}) \mathrm{p}$ & Conc. -BC & Conc-Nat & Media & DP & DPR & Media total & DP total & DPR total & REC \\
\hline & & 0.06 & 0.0084 & $(\mu \mathrm{g} / \mathrm{g})$ & $(\mu \mathrm{g} / \mathrm{g})$ & $\%$ & $(\mu \mathrm{g} / \mathrm{g})$ & $(\mu \mathrm{g} / \mathrm{g})$ & $\%$ & $\%$ \\
\hline $1500-1 A$ & 1.01 & 0.95 & 0.945 & & & & & & & \\
\hline 1500-1B & 1.01 & 0.95 & 0.942 & & & & & & & \\
\hline $1500-1 \mathrm{C}$ & 1.17 & 1.11 & 1.097 & 0.995 & 0.09 & 8.9 & & & & \\
\hline $1500-2 A$ & 1.11 & 1.05 & 1.044 & & & & & & & \\
\hline $1500-2 B$ & 0.98 & 0.92 & 0.911 & & & & & & & \\
\hline $1500-2 C$ & 1.00 & 0.94 & 0.936 & 0.963 & 0.07 & 7.3 & & & & \\
\hline $1500-3 A$ & 1.12 & 1.06 & 1.048 & & & & & & & \\
\hline $1500-3 B$ & 1.15 & 1.09 & 1.081 & & & & & & & \\
\hline $1500-3 C$ & 1.27 & 1.21 & 1.201 & 1.110 & 0.08 & 7.3 & & & & \\
\hline $1500-4 A$ & 1.16 & 1.10 & 1.091 & & & & & & & \\
\hline $1500-4 B$ & 1.04 & 0.98 & 0.971 & & & & & & & \\
\hline $1500-4 C$ & 1.16 & 1.10 & 1.089 & 1.051 & 0.07 & 6.6 & 1.10 & 0.09 & 8.0 & 73 \\
\hline $1000-1 A$ & 0.75 & 0.69 & 0.686 & & & & & & & \\
\hline 1000-1B & 0.75 & 0.69 & 0.684 & & & & & & & \\
\hline $1000-1 \mathrm{C}$ & 0.73 & 0.67 & 0.662 & 0.677 & 0.01 & 2.0 & & & & \\
\hline $1000-2 A$ & 0.69 & 0.63 & 0.625 & & & & & & & \\
\hline $1000-2 B$ & 0.70 & 0.64 & 0.629 & & & & & & & \\
\hline $1000-2 C$ & 0.65 & 0.59 & 0.580 & 0.612 & 0.03 & 4.5 & & & & \\
\hline 1000-3A & 0.62 & 0.56 & 0.550 & & & & & & & \\
\hline 1000-3B & 0.67 & 0.61 & 0.599 & & & & & & & \\
\hline $1000-3 C$ & 0.66 & 0.60 & 0.595 & 0.581 & 0.03 & 4.7 & & & & \\
\hline $1000-4 A$ & 0.75 & 0.69 & 0.681 & & & & & & & \\
\hline 1000-4B & 0.77 & 0.71 & 0.701 & & & & & & & \\
\hline $1000-4 \mathrm{C}$ & 0.75 & 0.69 & 0.678 & 0.687 & 0.01 & 1.8 & 0.71 & 0.050 & 7.0 & 71 \\
\hline
\end{tabular}

TABELA 55- Resultados de TPb adicionados ao tecido muscular do peixe

\begin{tabular}{|c|c|c|c|c|c|c|c|c|c|c|}
\hline Amostras $\mathrm{Pb}$ & Conc. $(\mu \mathrm{g} / \mathrm{kg}) \mathrm{ppb}$ & \begin{tabular}{|r|} 
Conc-Nat $(\mu \mathrm{g} / \mathrm{kg}$ \\
72.497 \\
\end{tabular} & Conc. $(\mu \mathrm{g} / \mathrm{g}) \mathrm{ppm}$ & $\begin{array}{l}\text { Media } \\
(\mu \mathrm{g} / \mathrm{g})\end{array}$ & \begin{tabular}{|l|}
$D P$ \\
$(\mu \mathrm{g} / \mathrm{g})$
\end{tabular} & $\begin{array}{l}\text { DPR } \\
\%\end{array}$ & \begin{tabular}{|l|} 
Media total \\
$(\mu \mathrm{g} / \mathrm{g})$
\end{tabular} & \begin{tabular}{|l} 
DP total \\
$(\mu \mathrm{g} / \mathrm{g})$
\end{tabular} & \begin{tabular}{|l|} 
DPR total \\
$\%$
\end{tabular} & $\begin{array}{l}\text { REC } \\
\%\end{array}$ \\
\hline $1500-1 \mathrm{~A}$ & 860.388 & 787.89 & 0.788 & & & & & & & \\
\hline $1500-1 B$ & 790.515 & 718.02 & 0.718 & & & & & & & \\
\hline $1500-1 C$ & 810.456 & 737.96 & 0.738 & 0.748 & 0.036 & 4.8 & & & & \\
\hline $1500-2 A$ & 580.318 & 507.82 & 0.508 & & & & & & & \\
\hline $1500-2 B$ & 701.051 & 628.55 & 0.629 & & & & & & & \\
\hline $1500-2 C$ & 620.464 & 547.97 & 0.548 & 0.561 & 0.061 & 11.0 & & & & \\
\hline $1500-3 A$ & 783.103 & 710.61 & 0.711 & & & & & & & \\
\hline $1500-3 B$ & 777.851 & 705.35 & 0.705 & & & & & & & \\
\hline $1500-3 C$ & 777.272 & 704.78 & 0.705 & 0.707 & 0.003 & 0.5 & & & & \\
\hline $1500-4 A$ & 757.754 & 685.26 & 0.685 & & & & & & & \\
\hline $1500-4 B$ & 733.091 & 660.59 & 0.661 & & & & & & & \\
\hline $1500-4 C$ & 721.071 & 648.57 & 0.649 & 0.665 & 0.019 & 2.8 & 0.670 & 0.080 & 12.0 & 45 \\
\hline $2500-1 A$ & 1362.406 & 1289.91 & 1.290 & & & & & & & \\
\hline $2500-1 B$ & 1265.375 & 1192.88 & 1.193 & & & & & & & \\
\hline $2500-1 C$ & 1353.990 & 1281.49 & 1.281 & 1.255 & 0.054 & 4.3 & & & & \\
\hline $2500-2 A$ & 982.724 & 910.23 & 0.910 & & & & & & & \\
\hline $2500-2 B$ & 925.652 & 853.16 & 0.853 & & & & & & & \\
\hline $2500-2 C$ & 972.946 & 900.45 & 0.900 & 0.888 & 0.031 & 3.4 & & & & \\
\hline $2500-3 A$ & 1387.156 & 1314.66 & 1.315 & & & & & & & \\
\hline $2500-3 B$ & 1403.017 & 1330.52 & 1.331 & & & & & & & \\
\hline $2500-3 C$ & 1186.872 & 1114.38 & 1.114 & 1.253 & 0.120 & 9.6 & & & & \\
\hline $2500-4 A$ & 1302.580 & 1230.08 & 1.230 & & & & & & & \\
\hline $2500-4 B$ & 1326.525 & 1254.03 & 1.254 & & & & & & & \\
\hline $2500-4 C$ & 1215.515 & 1143.02 & 1.143 & 1.209 & 0.058 & 4.8 & 1.151 & 0.177 & 15.4 & 46 \\
\hline
\end{tabular}




\section{APÊNDICE E}

\section{Rastreabilidade do programa piloto de ensaio de proficiência}

Neste apêndice são apresentadas a rastreabilidade dos documentos via email a respeito de informações trocadas com os laboratórios participantes do ensaio piloto de proficiência para metais em pescado in natura, e também o gráfico de controle da estabilidade das amostras enviadas, medida ao longo do ensaio. O material foi encaminhado com a carta de apresentação e instruções de uso via sedex aos laboratórios. Laboratórios do Nordeste, Norte e Sul do Brasil levaram cerca de 3 dias para receber as amostras, o participantes da região Sudeste receberam em 24 horas dentro do Estado de São Paulo e 1 dia para os demais.

A Carta Convite com instruções de uso do material foi encaminhada via email e impressa juntamente com as amostras.

Carta de Apresentação para o Ensaio de Proficiência

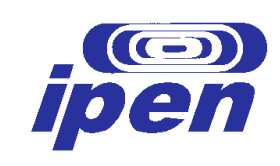

\section{Instruções para o Ensaio de Proficiência de Metais e Tecido de Peixe}

Para:

De: Jorge Eduardo de Souza. Sarkis

Data: 07 de Novembro de 2012

Assunto: Amostras para Programa de Ensaio de Proficiência em Peixe

O Laboratório de Caracterização Química e Isotópica do Instituto de Pesquisas Energéticas e Nucleares agradece sua participação no ensaio de proficiência de metais em tecido de pescado. O objetivo deste projeto é contribuir 
para a Metrologia em Química no Brasil, pela melhoria da qualidade e confiabilidade de resultados de medição em ensaios e controle analítico na cadeia produtiva de pescados no país.

O material utilizado foi coletado na região Amazônica e processado seguindose as recomendações do ISO Guia 35 sobre o preparo de materiais de referência.

Os elementos a serem analisados são: $\mathrm{As}, \mathrm{Cd}, \mathrm{Pb}$ e $\mathrm{Hg}$ em níveis que atendem a legislação brasileira. Havendo interesse podem-se fornecer resultados de quaisquer outros elementos ou mesmo de Metil-Mercúrio.

Neste documento estão as instruções para a utilização do material enviado assim como para o envio dos resultados. Sugere-se aos laboratórios a lidar com as amostras com os mesmos procedimentos usados em sua rotina de trabalho. Dessa forma, cada laboratório decidirá a melhor forma de processamento, amostragem, medida e avaliação dos dados a serem enviados.

\section{INSTRUÇÕES}

Cada participante irá receber duas amostras com 10 gramas de tecido de peixe in natura e um frasco com material de referência certificado. $O$ material certificado será comum a todos os participantes.

Uma vez recebidas, as amostras devem ser armazenadas em geladeira até o momento da análise. Antes da tomada de massa para o início dos ensaios o material deve ser gentilmente homogeneizado segundo procedimentos do próprio laboratório.

Solicita-se aos participantes três determinações independentes a serem realizadas em três dias diferentes assim como a descrição do método utilizado incluindo possíveis pré-tratamentos; a técnica analítica empregada e as principais figuras de mérito do procedimento analítico (limite de detecção, juntamente com a forma que este foi calculado, limite de determinação, precisão da medida, uso de padrões e recuperação). Uma descrição detalhada da avaliação das incertezas envolvidas na determinação dos analitos é muito bem vinda, mas não obrigatória. Neste caso, a incerteza $(U)$ expandida e o fator de abrangência (k) devem ser apresentados de acordo com o Guia para expressão de incertezas (GUM). 
Os laboratórios deverão reportar os resultados em planilhas idênticas ao modelo abaixo email no prazo de até 30 dias do recebimento das amostras.

Resultados obtidos para a amostra número 01:

\begin{tabular}{|c|c|c|c|c|c|c|c|}
\hline Elemento & massa, g & \multicolumn{3}{|c|}{ Resultado, $\mu \mathrm{g}^{-1}$} & U & DP & LD \\
\cline { 3 - 6 } & & 1 & 2 & 3 & & & \\
\hline Hg & & & & & & & \\
\hline Cd & & & & & & & \\
\hline Pb & & & & & & & \\
\hline As & & & & & & & \\
\hline
\end{tabular}

Resultados obtidos para a amostra número 02:

\begin{tabular}{|c|c|c|c|c|c|c|c|}
\hline Elemento & massa, g & \multicolumn{3}{|c|}{ Resultado, $\mu \mathrm{g} \mathrm{g}^{-1}$} & U & DP & LD \\
\cline { 3 - 5 } & & $\mathbf{1}$ & $\mathbf{2}$ & $\mathbf{3}$ & & & \\
\hline Hg & & & & & & & \\
\hline Cd & & & & & & & \\
\hline Pb & & & & & & & \\
\hline As & & & & & & & \\
\hline
\end{tabular}

Resultados obtidos para a amostra MRC: 


\begin{tabular}{|c|c|c|c|c|c|c|c|}
\hline Elemento & massa, g & \multicolumn{3}{|c|}{ Resultado, $\mathrm{\mu g}^{-1}$} & U & DP & LD \\
\cline { 3 - 5 } & & $\mathbf{1}$ & $\mathbf{2}$ & $\mathbf{3}$ & & & \\
\hline Hg & & & & & & & \\
\hline Cd & & & & & & & \\
\hline Pb & & & & & & & \\
\hline As & & & & & & & \\
\hline
\end{tabular}

Resultados obtidos para outros elementos:

\begin{tabular}{|c|c|c|c|c|c|c|c|}
\hline \multirow[t]{2}{*}{ Elemento } & \multirow[t]{2}{*}{ massa, $\mathrm{g}$} & \multicolumn{3}{|c|}{ Resultado, $\mu \mathrm{g} \mathrm{g}^{-1}$} & \multirow[t]{2}{*}{$\mathbf{U}$} & \multirow[t]{2}{*}{ DP } & \multirow[t]{2}{*}{ LD } \\
\hline & & 1 & 2 & 3 & & & \\
\hline & & & & & & & \\
\hline & & & & & & & \\
\hline & & & & & & & \\
\hline & & & & & & & \\
\hline & & & & & & & \\
\hline & & & & & & & \\
\hline & & & & & & & \\
\hline & & & & & & & \\
\hline & & & & & & & \\
\hline
\end{tabular}

DESCRIÇÃO DOS(s) MÉTODO(s) UTILIZADO NA DETERMINAÇÃO DOS ELEMENTOS:

Por favor, reportar os resultados para LCQ /IPEN-SP: jesarkis@ipen.br 
A participação no ensaio não acarretará em custos para os laboratórios participantes.

Quaisquer duvidas remanescentes entrar em contato com Jorge Sarkis, tel : 011-31339377, e-mail : jesarkis@ipen.br

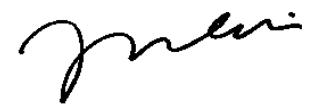

\section{Dr. Jorge Eduardo de Souza Sarkis LCQ/IPEN}

São Paulo, 07 de novembro de 2012

\section{Laboratórios Participantes}

A lista de laboratórios que participaram ensaio de proficiência para metais em pescado é apresentada na Tabela 56.

TABELA 56- Laboratórios participantes da $1^{\circ}$ Rodada do EP MP 11/12

\begin{tabular}{cc}
\hline \multicolumn{1}{c}{ INSTITUIÇÃo } & ESTADO \\
\hline $\begin{array}{c}\text { Ministério da Agricultura Pecuária e Abastecimento } \\
\text { Laboratórios Nacionais Agropecuários }\end{array}$ & GO \\
\hline $\begin{array}{c}\text { Ministério da Agricultura Pecuária e Abastecimento } \\
\text { Laboratórios Nacionais Agropecuários }\end{array}$ & MG \\
\hline $\begin{array}{c}\text { Ministério da Agricultura Pecuária e Abastecimento } \\
\text { Laboratórios Nacionais Agropecuários }\end{array}$ & PA \\
\hline $\begin{array}{c}\text { Ministério da Agricultura Pecuária e Abastecimento } \\
\text { Laboratórios Nacionais Agropecuários }\end{array}$ & PE \\
\hline $\begin{array}{c}\text { Ministério da Agricultura Pecuária e Abastecimento } \\
\text { Laboratórios Nacionais Agropecuários }\end{array}$ & RS \\
\hline $\begin{array}{c}\text { Ministério da Agricultura Pecuária e Abastecimento } \\
\text { Laboratórios Nacionais Agropecuários }\end{array}$ & SP \\
\hline Instituto Adolfo Lutz \\
\hline $\begin{array}{c}\text { Laboratório de Contaminantes Inorgânicos } \\
\text { Instituto Evandro Chagas } \\
\text { Laboratório de Meio Ambiente }\end{array}$ \\
\hline $\begin{array}{c}\text { Instituto de Pesquisas Energética e Nucleares } \\
\text { Laboratório de Análises por Ativação Neutrônica }\end{array}$ \\
\hline $\begin{array}{c}\text { Instituto de Tecnologia de Pernambuco } \\
\text { Laboratório de Química Analítica }\end{array}$ \\
\hline O código de cada participante não está associado à ordem da lista de participantes.
\end{tabular}




\section{Cópia do certificado do material de referência certificado utilizado no preparo} de material e no ensaio de proficiência

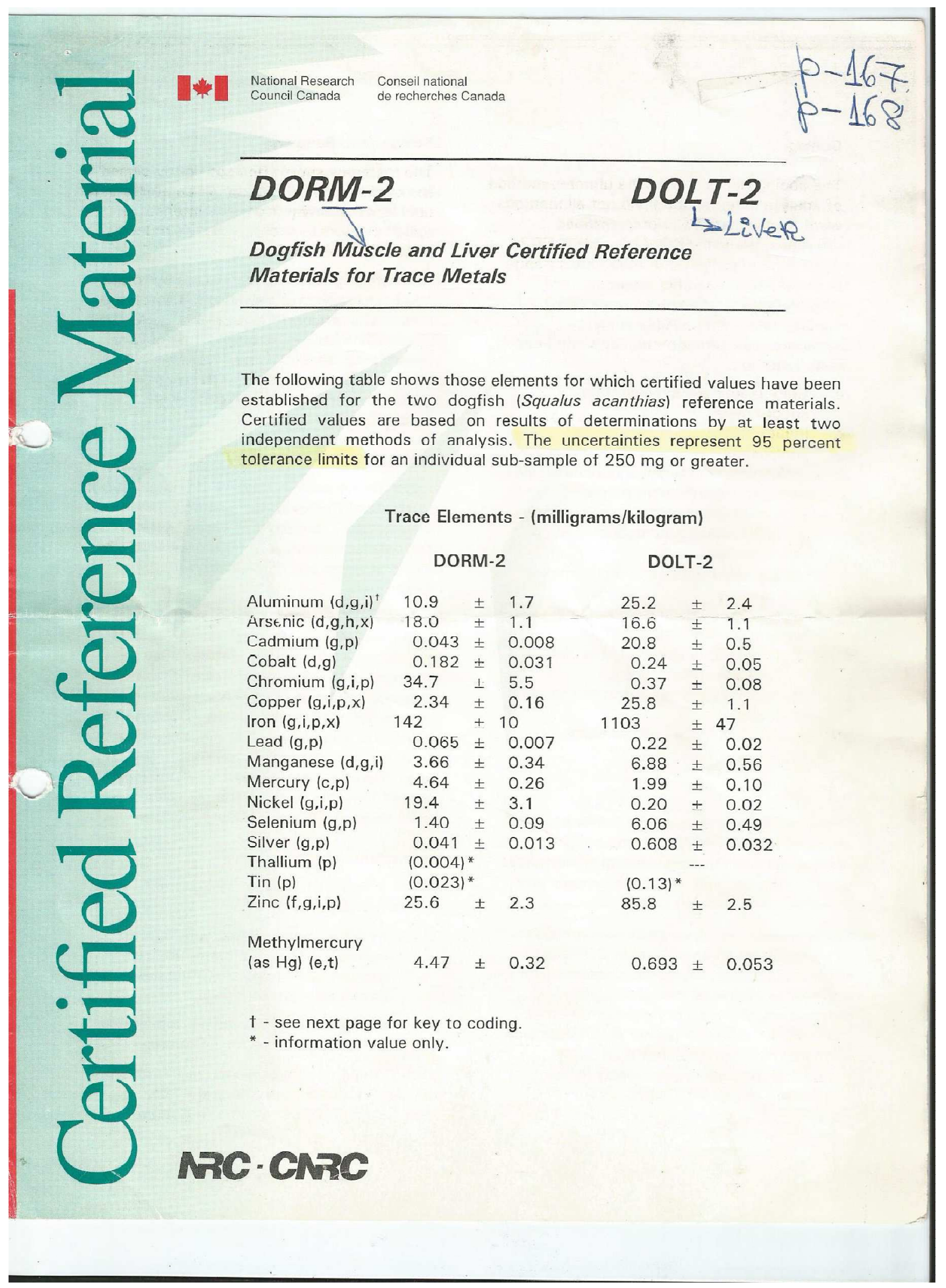




\section{REFERENCIAS BIBLIOGRAFICAS}

AGÊNCIA BRASIL, Rio de Janeiro ganhou a primeira fábrica de irradiação de alimento do País, 22/05/03. Disponível em: www.ecoviagem.com.br Acesso em: 05/04/12.

Alimentos irradiados http:www.fcf.usp.br/Ensino/Graduação/Disciplina/LinkAula/MyFiles/alimentos irradiados.htm. Acesso em 02/09/10.

Analytical Methods Committee. Robust statistics- how not to reject outliers. Part 1. Basic concepts. The Analyst 114, 1693-1697, (1989a)

Analytical Methods Committee. Robust statistics- how not to reject outliers. Part 2. Inter-laboratory trials. The Analyst 114, 1699-1702, (1989b)

Analytical Methods Committee, Robust statistics: a method of coping with outliers. Royal Society of Chemistry $n^{\circ} 6,2001$

Alves F. J. X., Efeito da radiação gama na validade comercial da carne de cordeiros Santa Inês embalada á vácuo e frigorificada, (2008) Dissertação de Doutorado-Universidade Federal Fluminense.

Associação Brasileira de Normas Técnicas. Materiais de referência - Princípios gerais e estatísticos para certificação, ABNT ISO GUIA 34, 2012.

Associação Brasileira de Normas Técnicas. Materiais de referência - Princípios gerais e estatísticos para certificação, ABNT ISO GUIA 35, 2012.

Associação Brasileira de Normas Técnicas. Avaliação de conformidade Requisitos gerais para ensaios de proficiência, ABNT NBR ISO/IEC 17043, 2011.

Associação Brasileira de Normas Técnicas. Requisitos gerais para a competência de laboratórios de ensaio e calibração, ABNT NBR ISO/IEC 17025, 2005.

Associação Brasileira de Normas Técnicas. Avaliação de conformidade Requisitos gerais para os organismos de acreditação que realizam acreditação de organismos de avaliação de conformidade ABNT NBR ISO/IEC 17011, 2005.

Bam Rm Guidelines - Guidelines for the production of BAM reference materials. (2010) Disponível em: <http://www.bam.de/en/fachthemen/referenzmaterialien/referenzmaterialien_medien/ bam_rm_guidelines.pdf >acesso em 23/02/12.

Barra C. M., Santelli R. E., Abrão J. J., Guardia M. Especiação de arsênio - Uma revisão. QUÍMICA NOVA, 23(1) (2000).

Borba P. R. et al. Estudo da especiação de arsênio inorgânico e determinação de arsênio total no monitoramento ambiental da qualidade de águas subterrâneas. Quimica Nova, Vol. 32, No. 4, 970-975, 2009 
BRASIL. Leis, decretos, etc. Anvisa Portaria $n^{\circ}$ 31/98. publicada no Diário Oficial da União, Brasília. seç.1-E, pág.4 mar 1998. Disponível em:< http://www.anvisa.gov.br/legis/portarias/31_98.htm> acesso em 23/02/12.

BRASIL. Leis, decretos, etc. Anvisa Portaria $n^{\circ}$ 685/98. Republicada no Diário Oficial da União, Brasília. seç.1, pt.1, p. 1415-1437, 24 set 1998.

BRASIL, Resolução RDC ํo. 21, de 26 de janeiro de 2001. Aprova o Regulamento Técnico para a Irradiação de Alimentos. Ministério da Saúde. ANVISA, Brasília, DF, 2001.

Brunini M. A. et al., Influência de embalagens e temperaturas no armazenamento de jabuticabas (Myrciaria jabuticaba (Vell) Berg.) cv. Sabará . Ciência e Tecnologia de Alimentos, Campinas, Vol. 24, no 3, p. 378-383, 2004.

Becker J. S., Inorganic mass spectrometry: Principles and spplications, Editora: John Wiley \& Sons Ltda, Inglaterra, 2007, cap. 2, pg. 28.

Cardoso M. H. M. et al., Preparação de um material de referência certificado para controle de agrotóxicos em hortifrutigranjeiros: Estudo da homogeneidade, Ciênc. Tecnol. Aliment., Campinas, 30(2): 429-438, abr-jun. 2010.

Capar S. G. \& Mindak W. R. \& Cheng J. Analysis of food for toxic elements. Anal Bioanal Chem (2007) 389:159-169.

CBE - Companhia Brasileira de Esterilização. Disponível em: http://www.cbesa.com.br/ Acesso em: 30/04/12.

Chui Q. S. H. Uncertainties related to linear calibration curves: A case sudy for flame atomic absorption spectrometry. J. Braz. Chem. Soc., Vol. 18, No. 2, 424430, 2007.

Chui Q. S. H. O papel dos programas interlaboratoriais para a qualidade dos resultados analíticos. Química Nova, Vol.27, nº 6, 993-1003, 2004

Damodaran, S., Parkin, K.L., FENNEMA, O.R. Química de alimentos de Fennema, tradução da 4a . Edição em inglês, ARTMED, 2010, 900p.

De Lara J, et al., Irradiation of spores of Bacillus cereus and Bacillus subtilis with electron beams. Innovative Food Science and Emerging Technologies 3 (2002) 379-384

Dellamodesta, R.C. Manual de análise sensorial de alimentos e bebidas: geral Rio de Janeiro: Embrapa - CT AA, 1994.

Diehl, J. F.; Food irradiation - Past, present and future, Radial. Phys. Chem., 63: 211215, 2002.

Donatti F. C., Importância das embalagens dos alimentos. Disponível em <http://www.itag-es.com.br/itag/?page_id=226> acesso em abril de 2011.

EMBRARAD, Empresa Brasileira de Radiação. Disponível em: www.embrarad.com.br Acesso em 14/04/12. 
EURACHEM/CITAC Guide. Quantifying Uncertainty in Analytical Measurement. 2. Edition, 2002.

FEARN,T.; THOMPSON, M. A new test for "sufficient homogeneity". Analyst, no 126, p. 1414-1417, 2001.

FOOD AND AGRICULTURE ORGANIZATION (FAO) Norma geral do codex para os contaminates e toxinas presentes em alimentos e grãos (CODEX STAN 1931995) .

Disponível

em

http://www.fao.org/fileadmin/user_upload/livestockgov/documents/CXS_193s.pdf> acesso em 17/04/12.

Franco, B. D. G. M.; Landgraf, M. Microbiologia de alimentos. São Paulo: Atheneu, 2005.

Fonseca B. C. et al., Avaliação da concentração de elementos traço e de mercúrio total em pescados comercializados na cidade de Cubatão, Estado de São Paulo. 2009 International Nuclear Atlantic Conference - INAC 2009, Rio de Janeiro, RJ, Brazil, September 27 to October 2, 2009, ASSOCIAÇÃO BRASILEIRA DE ENERGIA NUCLEAR - ABEN.

Giné R. M. F, Espectrometria de massas com fonte de plasma. (ICP-MS). Piracicaba: CENA, 1999.

Germano, M.I.S, Germano, P.M.L. Higiene e vigilancia sanitaria de alimentos. 3 ed. Varela: Sao Paulo, 2008.

HORTELLANI, M.A. Avaliação da contaminação por mercúrio dos sedimentos do estuário Santos - São Vicente, no período de 1996-2000. 2003. Dissertação de Mestrado - Instituto de Pesquisas Energéticas e Nucleares, São Paulo.

IAEA, INTERNATIONAL ATOMIC ENERGY AGENCY, Preparation of reference materials and organization of proficiency test rounds, (IAEA INT 1/054 Interregional project), 2003-2005. Disponível em: < http://www.iaea.org/programmes/aqcs/int1054/index.html >. Acesso em: 02/09/11.

IAEA, INTERNATIONAL ATOMIC ENERGY AGENCY, Irradiation to control Vibrio infection from consumption of raw seafood and fresh produce, (IAEA-YECDOC1213), Austria, 2001. Disponível em: <http://wwwpub.iaea.org/MTCD/Publications/PDF/te_1213_prn.pdf>. Acesso em: 10/11/12.

IBAMA - Balança Comercial do Pescado 2009, Brasil 2009.

IBAMA - Balança Comercial do Pescado 2009, Brasil 2010.

IBAMA - Estatística da Pesca Brasileira 2009, Brasil 2012.

INCQS, INSTITUTO NACIONAL PARA O CONTROLE DE QUALIDADE EM SAÚDE, Ensaio de Proficiência em produtos sujeitos ao regime de vigilância sanitária (EP/INCQS-Rodada 06/11), 2012. 
INMETRO, INSTITUTO NACIONAL DE METROLOGIA, NORMALIZAÇÃO E QUALIDADE INDUSTRIAL Protocolo internacional harmonizado para ensaio de proficiência em laboratórios analíticos (QUÍmICOS). 2006. Disponível em < www.inmetro.gov.br/metcientifica/palestras/ThiagoAraujo2.pdf $>$ Acesso em 02/01/11.

INMETRO, INSTITUTO NACIONAL DE METROLOGIA, NORMALIZAÇÃO E QUALIDADE INDUSTRIAL, Projeto piloto para acreditação de produtores de materiais de referência segundo requisitos do ABNT ISO Guia 34 em combinação com a norma ABNT NBR ISO/IEC 17025. 2004. Disponível em: $<$ http://www.inmetro.gov.br/credenciamento/produtoresMat.asp>. Acesso em: 25/02/12.

INSTITUTO NACIONAL DE METROLOGIA, NORMALIZAÇÃO E QUALIDADE INDUSTRIAL. Avaliação de dados de medição - Guia para a expressão de incerteza de medição. Rio de Janeiro, 2008.

INMETRO, INSTITUTO NACIONAL DE METROLOGIA, NORMALIZAÇÃO E QUALIDADE INDUSTRIAL, Orientação sobre validação de métodos de ensaios químicos, revisão 04, Rio de Janeiro: INMETRO, 2011 (DOQ-CGCRE-008).

INMETRO, INSTITUTO NACIONAL DE METROLOGIA, NORMALIZAÇÃO E QUALIDADE INDUSTRIAL, Vocabulário internacional de metrologia: conceitos fundamentais e gerais e termos associados, (VIM 2012). 1ㄹ Edição LusoBrasileira. Rio de Janeiro, 2012.

Ishikawa N. M. et al. Hematological parameters in Nile Tilápia, Oreochromis niloticus exposed to Sub-letal concentrations of mercury. Brazilian Archives of Biology and Technology, Vol.50, n. 4: pp. 619-626 July 2007.

International Organization for Standardization (ISO); ISO 5725-2: Accuracy (trueness and precision) of measurement methods and results - Practical guidance for the use of ISO 5725-2:1994 in designing, implementing and statistically analyzing interlaboratory repeatability and reproducibility results. Geneva, $2005 \quad$ (ISO/TR 22971).Disponivel em: <http:// http://www.stat.ucl.ac.be/cours/stat3320/Doc_2004_2005/GUIDE_ISO.pdf>. Acesso em 15/06/11.

International Organization for Standardization (ISO); ISO 13528: Statistical methods for use in proficiency testing by interlaboratiry comparisons. Geneva, Switzerland 3ำedition, 2005.

International laboratory accreditation cooperation-ILAC G13. Guidelines for the requirements for the competence of providers of proficiency testing schemes, 2007.

Jeng $\mathrm{H}$. W. On small samples and the use of robust estimators in loss reserving. Casualty Actuarial Society E-Forum, Fall 2010.

Jeronimo E. M. et al., Qualidade de mangas Tommy Atkins armazenadas sob atmosfera modificada. Ciênc. agrotec., Lavras, Vol. 31, no 4, 1122-1130, jul./ago., 2007 
Kalay M., Canli M. Elimination of essential ( $\mathrm{Cu}, \mathrm{Zn})$ and non-essential $(\mathrm{Cd}, \mathrm{Pb})$ metals from tissues of a freshwater fish Tilapia zilli. Turk Journal Zoology, Vol. 24,1999 .

Kehrig H. A. et al., Methyl and total mercury found in two Man-Made Amazonian Reservoirs, J. Braz. Chem. Soc., Vol. 20, No. 6, 1142-1152, 2009.

Lacroix, M., Outarra, B. Combined industrial processed with irradiation to assure innocuity and preservation of food products - a review, 33: 719-724, 2000.

Leonel, F. R. Irradiação e qualidade da carne de frango congelada e embalada a vácuo, (2008) Dissertação de Doutorado - Universidade Estadual Paulista, Faculdade de Ciências Agrárias e Veterinárias de Jaboticabal. São Paulo.

Lima A. P. S. et al., Mercury and Selenium Concentrations in Fish Samples from Cachoeira do Piriá Municipality, Pará State, Brazil. Environmental Research, vol. 97, pages 236-244, 2005.

Lisinger T. P. J.; Pauwels J.; van der Veen A. M. H.; Schimmel H, Lamberty A. Homogeneity and stability of reference materials. Accred Qual Assur 6:20-25, 2001.

Mantilla S. P. S. et al., Atmosfera modificada e irradiação: Métodos combinados de conservação e inocuidade alimentar, Revista Científica Eletrônica de medicina Veterinária - № 15, Ano VIII, Julho de 2010.

Martins F. N., Uma síntese sobre os efeitos biológicos da radiação ionizante e o papel da alanina utilizada para dosagem de radiações. REB Volume 4 (2): 73-79, 2011.

Martiniano L. C. et al ., Novo método espectrofotométrico para determinação de Hg (II) em amostras de peixe. Ciênc. Tecnol. Aliment., Campinas, 28(2): 373-379, abr.-jun. 2008.

Ministério da Agricultura Pecuária E Abastecimento (MAPA)- Estatística e dados básicos de economia agrícola, Brasil. Dezembro de 2012.

Ministério da Agricultura, Pecuária E Abastecimento (MAPA). Instrução Normativa № 1, de 16 de janeiro de 2007. Disponível em:<http://www.agricultuta.gov.br/portal/page/portal//nternet-

MAPA/paginainicial/animal/laboratorios/legislacao MAPA/ >. Acesso em: 01/04/11.

Ministério da Pesca e Aquicultura (MPA)- Estatística da pesca e aquicultura, Brasil. Fevereiro de 2012.

Ministério das Relações Exteriores, Como Exportar - União Européia, Departamento de Promoção Comercial, Divisão de Informação Comercial, Brasília, 2002.

Moura, R. C.; Banzato, J. M. Embalagem, utilização \& conteinerização. São Paulo: IMAN, 1977, 354 p. 
Moreira E. G. Preparo e caracterização de um material de referência de mexilhão Perna. 2010. Tese de Doutorado em Ciências - Instituto de Pesquisas Energeticas e Nucleares, Sao Paulo.

Mustra C. J. G. O. Aplicacão da tecnica de espectrofotometria de absorcão atomica na análise de metais e metalóides em amostras biológicas. 2009. Dissertação de Mestrado - Universidade de Lisboa, Faculdade de Medicina de Lisboa.

NIST/SEMATECH, NATIONAL INSTITUTE OF STANDARDS \& TECHNOLOGY/ SEMICONDUCTOR MANUFACTURING TECHNOLOGY CONSORTIUM, NIST/SEMATECH e-Handbook of Statistical Methods. Disponível em <http://www.itl.nist.gov/div898/handbook/, date>. Acesso em: 02/09/11.

NRCC, NATIONAL RESEARCH COUNCIL OF CANADA, Certificate of analysis, DORM-2, Dogfish muscle certified reference material for trace metals, 1999.

Ornellas, C.B.D., et al. Atitude do consumidor frente à irradiação de alimentos. Cienc. Tecnol. Aliment., 26: 211-213, 2006.

Oliveira Junior O.P., Preparação, caracterização e certificação de materiais de referência isotópicos de urânio. 2006. Tese de Doutorado em Ciências - Instituto de Pesquisas Energeticas e Nucleares, Sao Paulo.

ØYGARD J K; LUNDEBYE A K; JULSHAMN K, Determination of inorganic arsenic in marine food sample by hydrochloric acid distillation and flowinjection hydride-generation atomic absorption spectrometry. Journal of AOAC International Vol. 82, №. 5, 1999.

Poornima S. K.; Harini, P.; Veeraiah, K.. A Study on biochmical changes in the fresh water fish, Catla Catla (HAMILTON) exposed to the heavy metal toxicant cadmium chloride. JOURNAL OF SCIENCE, ENGINEERING AND TECHNOLOGY, KATHMANDU UNIVERSITY, VOL.I, №.IV, AUGUST, 2007.

Provedores de Ensaios de Proficiência. Disponível em < http://www.eptis.bam.de/php/eptis/index.php?task=show_search_scheme> Acesso em 02/02/13.

Regulamento (CE) n.. 1881/2006, de 19 de Dezembro de 2006, que fixa os teores máximos de certos contaminantes presentes nos géneros alimentícios, que fixa os teores máximos de certos contaminantes presentes nos gêneros alimentícios. Disponível em < http://europa.eu/legislation_summaries/food_safety/contamination_environmental_fa ctors/121290_pt.htm> Acesso em 02/09/11.

Reis M. C. C. Qualidade da carne de frango submetida à irradiação ou atmosfera modificada e armazenada por diferentes períodos. 2008. Tese de Doutorado-Universidade Estadual Paulista, Faculdade de Medicina Veterinária e Zootecnia, Botucatu - São Paulo. 
Ribeiro S. C. A. et al. Otimização da desidratação osmótica de filés de mapará (Hypophthalmus edentatus) através da metodologia de superfície de resposta. Ciênc. Tecnol. Aliment., Campinas, 28(2): 485-492, abr.jun. 2008 São Paulo, São Paulo.

Ross, R.T., Engeljohn, D. Food irradiation in the United States: irradiation as a phytosanitary treatment for fresh fruits and vegetables and for the control of microorganisms in meat and poultry. Radial. Phys. Chem., 57: 211-214, 2000.

Secretaria de Comércio Exterior, Ministério do Desenvolvimento. Indústria e Comércio Exterior - Balança comercial brasileira 2010. Brasil, 2010.

Segurança Alimentar: da exploração agrícola até a mesa. Disponível em < http://ec.europa.eu/food/index_pt.htm> Acesso em 02/09/11.

Silva F. L. A., Roza C. R. Uso da irradiação em alimentos: Revisão. B.CEPPA, Curitiba, Vol. 28, no 1, p. 49-56, jan./jun. 2010

Siqueira A. A. Z. C. Efeitos da Irradiação e Refrigeração na Qualidade e no Valor Nutritivo da Tilápia (Oreochromis miloticus). 2001. Dissertação de MestradoUniversidade de São Paulo, Escola superior de Agricultura, Piracicaba, São Paulo.

Shibuya, K. E. Acoplamento laser-espectrômetro de massa de dupla focalização com fonte de plasma induzindo (LA-HR-ICPMS): estudos fundamentais e análises quantitativas em amostras sólidas. (1999) Dissertação de MestradoUniversidade Federal de São Paulo.

Skoog, D. A., Holler, J. F., Nieman, A. T. Princípios de análise instrumental. Artmed, 2002.

Tavares A. D. Determinação de cádmio e chumbo em alimentos e bebidas industrializados por espectrometria de absorção atômica com atomização eletrotérmica. (2010) Dissertação de Mestrado-Universidade Federal da Paraíba.

Thompson, M.; Ellison, S. L. R.; Wood, R. The international harmonized protocol for the proficiency testing of analytical chemistry laboratories. (IUPAC Technical Report). Pure Appl. Chem. v. 78, n. 1, p. 145-196, 2006.

Ulrich, J.C.; Sarkis, J.E.S.; Shihomatsu, H.M.; Hortellani, M.A.; Estimativa da incerteza associada à determinação do teor de mercúrio em amostras de peixes por absorção atômica. METROLOGIA-2003 - Metrologia para a Vida Sociedade Brasileira de Metrologia (SBM), Recife, Pernambuco, Setembro 01-05, 2003.

Ulrich, J. C. Preparo e caracterização de um material de referência de Peixe. 2011. Tese de Doutorado em Ciências - Instituto de Pesquisas Energeticas e Nucleares, Sao Paulo.

van Der Veen A. M. H; Lisinguer T.; Pauwels J. Uncertainty calculations in the Certification of Reference Materials. 2. Homogeneity study, Accred Qual Assur (2001) 6:26-30.

Vieira S. Análise de Variância (ANOVA). Editora Atlas, São Paulo, 2006. 
Villavicencio, A.L.C.H. Avaliação dos efeitos da radiação ionizante de ${ }^{60} \mathrm{Co}$ em propriedades físicas, químicas e nutricionais dos feijões Phaseolus vulgaris $\mathrm{L}$. e Vigna unguiculata (L) Walp. 1998. Tese de Doutorado em Ciência dos Alimentos -F.C.F.-USP, São Paulo.

Vutukuru S. S. Prabhath N. A.; Raghavende M.; Yerramilli A. Effect of arsenic and chromium on the serum amino-transferases activity in indian major carp, Labeo rohita. Int. J. Environ. Res. Public Health, 2007, 4(3), 224-227

Welz B. Sperling M. Atomic absorption spectrometry. Wiley-VCH, 3o ed. 203-218. 2005

Ysrael M. V.; Carvalho R. J.; Castilhos Z. C.; Kurtz M. J. R. Mercury bioaccumulation in the Brazilian Amazonian tucunares (Cichla sp., Cichlidae, Perciformes). Revista Ambiente \& Água - An Interdisciplinary Journal of Applied Science: Vol. 3 ํo. 2, 2008 (doi:10.4136/ambi-agua.49)

Zarbielli $M$. et al. Formulação e caracterização físico-química e sensorial de queijo minas light enriquecido com fonte de ferro. Alim. Nutr., Araraquara, v. 15, n. 3, p. 251-257, 2004. 